\title{
BASALT FEATURES OBSERVED IN OUTCROPS, CORES, BOREHOLE VIDEO IMAGERY AND GEOPHYSICAL LOGS, AND BASALT HYDROGEOLOGIC STUDY AT THE IDAHO NATIONAL ENGINEERING LABORATORY, EASTERN IDAHO
}

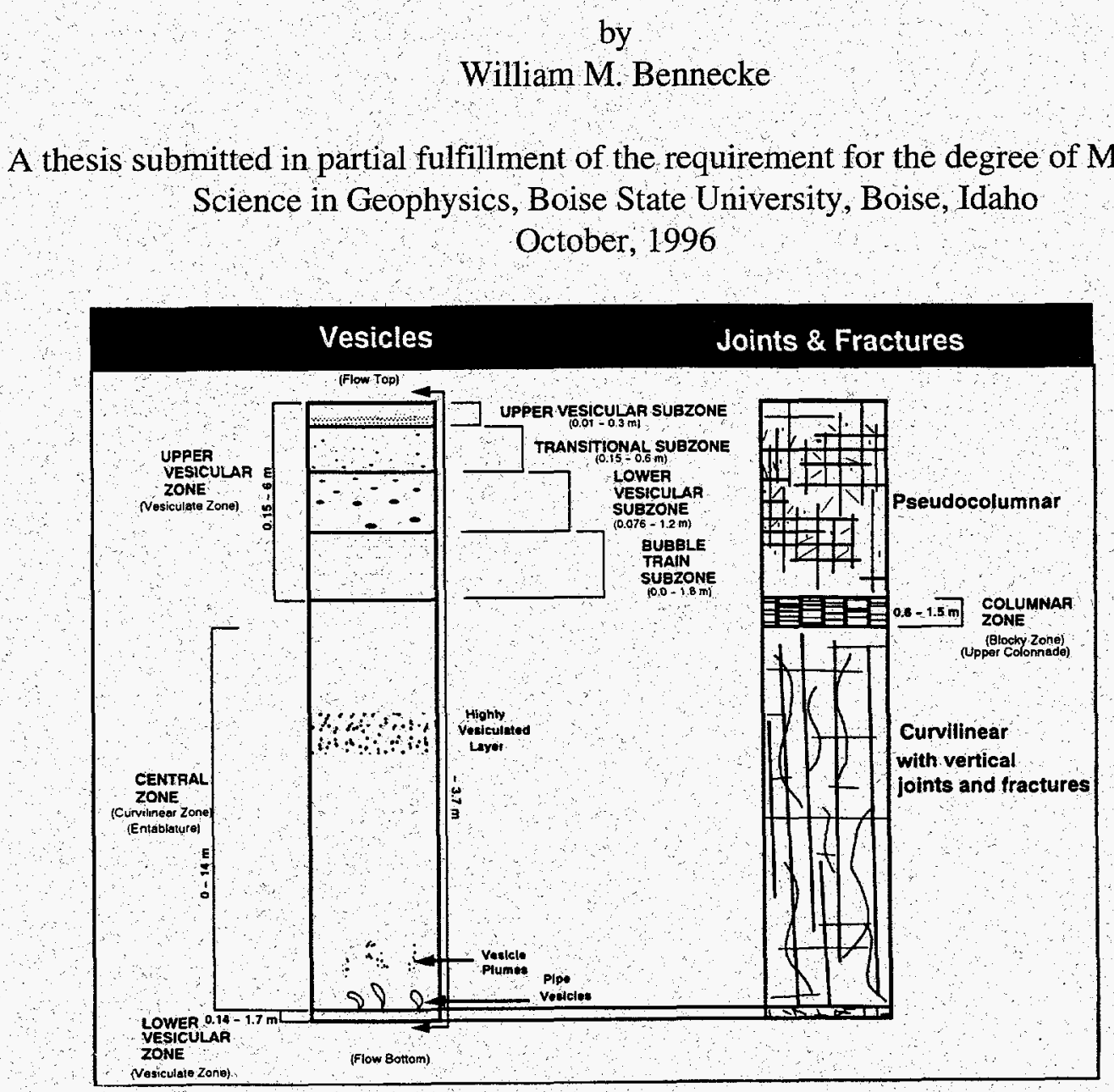

Study supported by the State of Idaho INEL Oversight Program - funded by the U.S. Department of Energy

Should you no longer need this copy, will you please send it to Dr. S.H. Wood, Dept. of Geosciences, Boise State University, Boise, Idaho 83725 , (208)385-1631. Tape enclosed return-mail envelope to parcel. 


\section{$D O E / I D / 13042--53$}

BASALT FEATURES OBSERVED IN OUTCROPS, CORES,

BOREHOLE VIDEO IMAGERY AND GEOPHYSICAL LOGS, AND BASALT

HYDROGEOLOGIC STUDY AT THE

IDAHO NATIONAL ENGINEERING LABORATORY, EASTERN IDAHO

by

William M. Bennecke

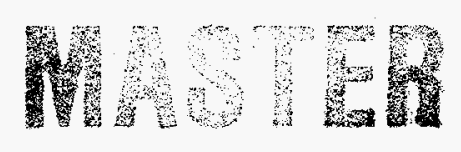

A thesis

submitted in partial fulfillment

of the requirement for the degree of

Master of Science in Geophysics

Boise State University

DISTRIBUTION OF THIS DOCUMENT IS UNLIMITED

October, 1996 


\section{DISCLAMMER}

Portions of this document may be illegible in electronic image products. Images are produced from the best available original document. 
The thesis presented by William M. Bennecke entitled BASALT FEATURES OBSERVED IN OUTCROPS, CORES, BOREHOLE VIDEO IMAGERY AND GEOPHYSICAL LOGS, AND BASALT HYDROGEOLOGIC STUDY AT THE IDAHO NATIONAL ENGINEERING LABORATORY, EASTERN IDAHO is hereby approved:
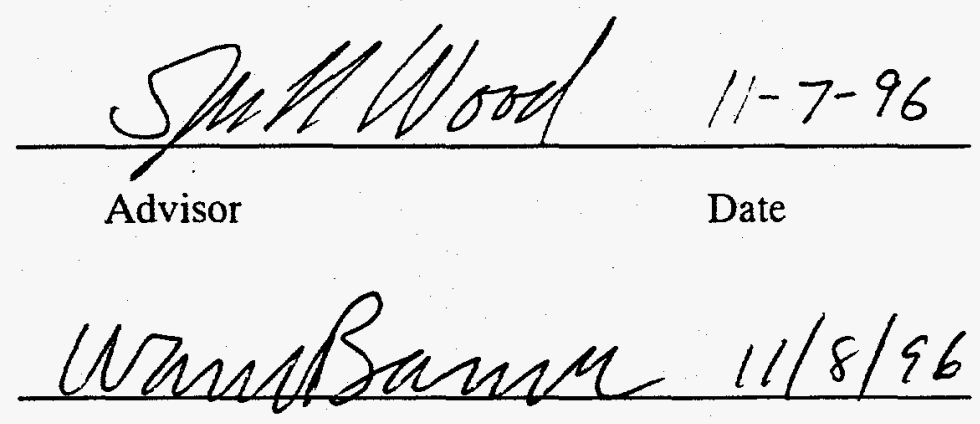

Committee Member

Date

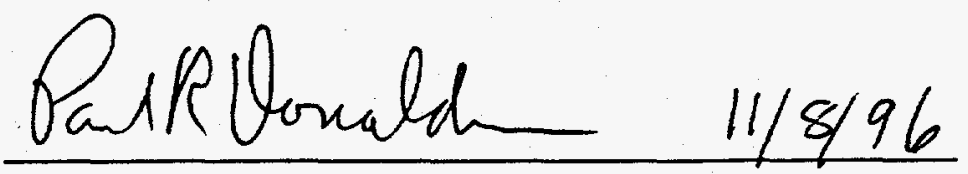

Committee Member

Date

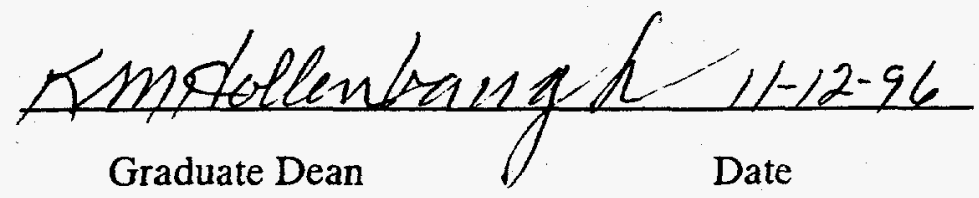

Note: original thesis of 181 pages has been shortened to $178 \mathrm{p}$. to economize on color copies. 


\section{ACKNOWLEDGMENTS}

I greatly appreciate the assistance and support given to me by the faculty and students of the geology and geophysics department. I would also like to thank the State of Idaho INEL Oversight Program for their funding and helpful suggestions. A lot of work went into this project and I would especially like to thank Sandi Bennecke, Carlton Parker, Rob Vincent, Jack Pelton, my thesis committee, R. Jensen and may other friends for their help on this project. 


\begin{abstract}
A study was undertaken to examine permeable zones identified in boreholes open to the underlying basalt and to describe the vertical cross flows present in the boreholes. To understand the permeable zones in the boreholes detailed descriptions and measurements of three outcrops in the Snake River Plain, three cores at the Idaho Chemical Processing Plant (ICPP) at the INEL, and over fifty borehole TV logs from the INEL were carried out. Based on the observations made on the three outcrops an idealized basalt lava flow model was generated that used a set of nomenclature that would be standard for the basalt lava flows studied. An upper vesicular zone, a sometimes absent columnar zone, central zone, and lower vesicular zone make up the basalt lava flow model. The overall distinction between the different zones are based on the vesicle shape size, vesicularity, and fractures present. The results of the studies also indicated that the basalt lava flows at the INEL are distal to medial facies pahoehoe lava flows with close fitting contacts. The most permeable zones identified in these basalts are fractured vesiculated portions of the top of the lava flow, the columnar areas, and basalt-flow contacts in order of importance. This was determined from impeller flowmeter logging at the INEL. Having this information a detailed stratigraphy of individual basalt lava flows and the corresponding permeable units were generated. From this it was concluded that groundwater flow at the ICPP prefers to travel along thin basalt lava flows or flow-units. Flow direction and velocity of intrawell flows detected by flowmeter is controlled by a nearby pumping well.
\end{abstract}




\section{TABLE OF CONTENTS}

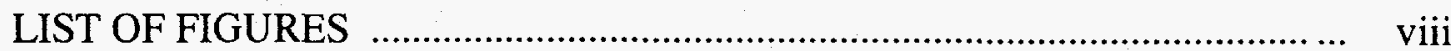

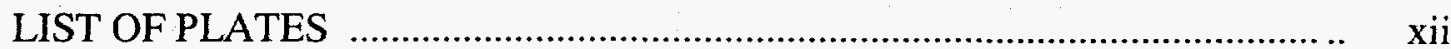

LIST OF TABLES ...............................................................................

LIST OF ABBREVIATIONS .............................................................. xvi

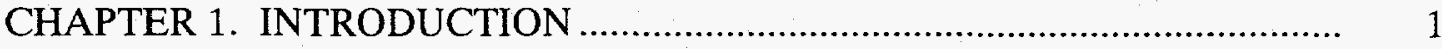

Purpose And Objectives..........................................................................

Geologic Setting ............................................................................. 2

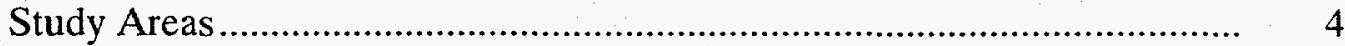

General Geohydrologic Setting At The INEL ........................................ 6

CHAPTER 2. DATA COLLECTION METHODS: OUTCROPS..................... 9

Outcrop Locations.......................................................................... 9

Outcrop Measurements .................................................................... 10

CHAPTER 3. OUTCROP FEATURES …................................................... 22

Size And Shape Of Basalt Lava Flows ..................................................... 22

Interface Between Basalt Lava Flows ..................................................... 24

Internal Features ................................................................................. 27

CHAPTER 4. ANALYSIS OF OUTCROP FEATURES …............................. 55

Type Of Basalt Lava Flows Seen In Outcrop .......................................... 55

Flow-units ...................................................................................... 63

Nomenclature of a Basalt Flow and its Internal Features ........................ 66

Origin of Vesicle Zones................................................................... 73

Columnar Structure ............................................................................ $\quad 77$

Spheroidally Jointed Basalt .............................................................. 80

Jointing: Non-Columnar ................................................................ 80

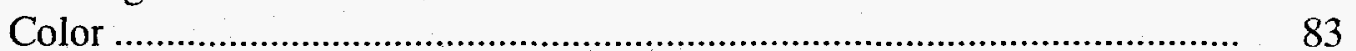


CHAPTER 5. DATA COLLECTION METHODS: BOREHOLE

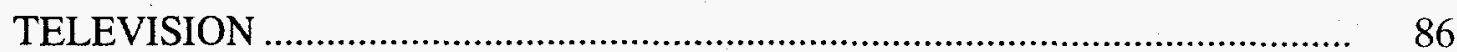

Purpose And Objectives....................................................................... 86

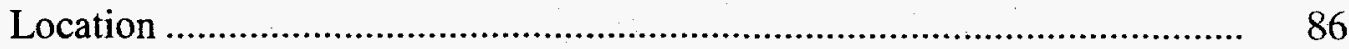

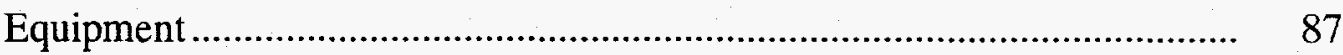

Calibration And Measurements Taken Off Photographs............................ $\quad 90$

CHAPTER 6. BOREHOLE TV FEATURES ……………............................... 99

Basalt Lava Flows............................................................................ 99

Interface Between Basalt Lava Flows ...................................................... 99

Internal Features .......................................................................... 100

Deviations From Normal Borehole Diameter ........................................... 106

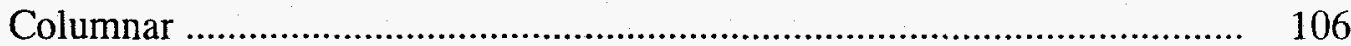

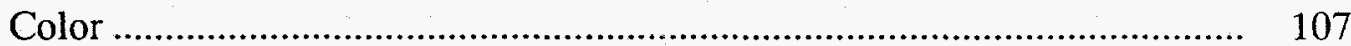

Other Features Observed On Borehole TV Logs....................................... 108

CHAPTER 7. ANALYSIS OF BOREHOLE TV FEATURES ............................. 122

Basalt Lava Flows............................................................................... 122

Interface Between Basalt Lava Flows …………………......................... 123

Basalt Flow Model Applied to Borehole TV Observations........................ 124

Vesicles ..................................................................................... 124

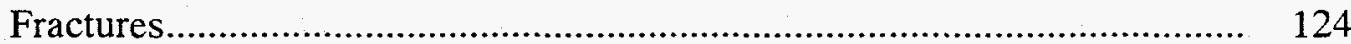

Deviations From Normal Borehole Diameter ............................................ 125

CHAPTER 8. DATA COLLECTION METHODS: IMPELLER

FLOWMETER

Purpose And Objectives....................................................................... 127

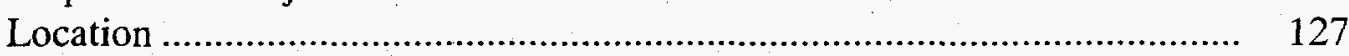

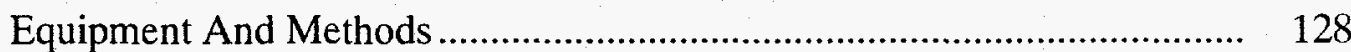

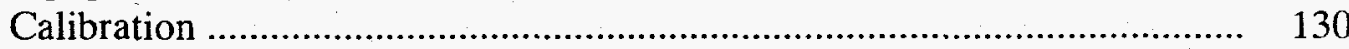

Impeller Flowmeter Measurements .......................................................... 131

CHAPTER 9. IMPELLER FLOWMETER RESULTS …………..................... 134

Fluid Movement In Boreholes Studied .................................................. 134

Analysis Of Impeller Flowmeter Results..................................................... 141 
CHAPTER 10. OTHER GEOPHYSICAL LOGGING OF BOREHOLES IN BASALT.

Purpose And Objectives..................................................................... 151

Borehole Geophysical Results On Basalts.................................................. 151

CHAPTER 11. CONCLUSIONS ................................................................... 157

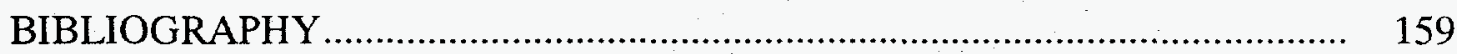

APPENDIX A Cross-section ICPP........................................................ 167

APPENDIX $\quad \mathrm{B} \quad$ Temperature Logs.............................................................. 169

APPENDIX C $\quad$ Geophysical Logs ......................................................... 172 


\section{LIST OF FIGURES}

Figure 1. Map showing the major late Cenozoic geologic units ......................... 3

Figure 2. Geologic setting and facilities at the Idaho National Engineering

Laboratory

Figure 3. Location of wells at the Idaho Chemical Processing Plant .................. 5

Figure 4. Figure difference between vertical and horizontal hydraulic head gradient 7

Figure 5. Map showing direction of groundwater movement at the INEL............ 8

Figure 6. Schematic representation of sampling swath ................................... 10

Figure 7. Figure showing reference axes for the orthogonal coordinates............. 11

Figure 8. Schematic representation true spacing (TS) and apparent spacing (AS) 13

Figure 9. Figure showing how the major and minor axis are defined ............... 14

Figure 10. Quadrangle 7.5 minute showing the location of the Box Canyon outcrop16

Figure 11. Quadrangle 7.5 minute showing the location of the Twin Falls outcrop 17

Figure 12. Quadrangle 7.5 minute showing the location of the Swan Falls outcrop 18

Figure 13. Plot of lava flow length against average effusion rate for lava eruptions 22

Figure 14. Dimensions of lavas of different compositions ................................... 23

Figure 15. A sketch showing the detail of the small openings ........................... 26 
Figure 16. Hypothetical sketch showing the three types of joints.

Figure 17. Longitudinal and transverse cross sections ................................. 56

Figure 18. Figure illustrating lava tube formation in a lava channel.................. 57

Figure 19. An idealized section of a basalt lava flow ....................................... 61

Figure 20. Three diagrammatic sketches showing tongues (flow-units) in plan.. 63

Figure 21. Simple and compound lava flows shown ................................... 65

Figure 22. Nomenclature used in previous studies for a typical intraflow structures 67

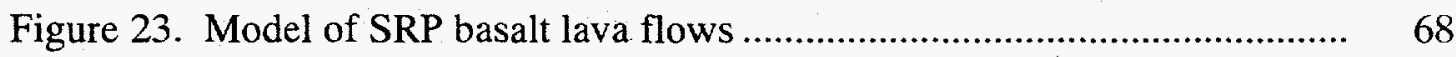

Figure 24. Advancing crystal front movement is shown leaving various layers.. $\quad 75$

Figure 25. Hypothetical method of continual fracture propagation...................... 78

Figure 26. Relationship of the attitude of the columns to the isothermal planes.. 79

Figure 27. Dutch cheese structure ............................................................. 79

Figure 28. Feather-fracture or hackle plume is seen here ........................... 82

Figure 29. Schematic diagram of the borehole TV camera set-up ................... 87

Figure 30. Borehole TV tool shown in two styles of operation........................... 88

Figure 31. Artists sketch of camera-VCR-TV setup to obtain still photographs.. 90

Figure 32. Figure showing the template generated from a photograph ............. 92

Figure 33. Figure showing the nonlinear relationships (arc length) .................... 93

Figure 34. Figure showing the nonlinear relationships (radial distance) .............. 93 
Figure 35. Figure illustrating (template not to scale).

Figure 36. Model of SRP basalt lava flows showing differences.

Figure 37. Figure showing the third type of fractures

Figure 38. Figure showing a part of the template in Figure 32

Figure 39. Figure showing possible cause of borehole planar features

Figure 40. Figure showing Halliburton bi-directional impeller flowmeter

Figure 41. Figure of multiple ( 5 separate) flowmeter runs in the same well........

Figure 42. Figure showing impeller flowmeter log of well USGS 44

Figure 43. Figure showing impeller flowmeter log of well USGS 45

Figure 44. Figure showing impeller flowmeter log of well USGS 46

Figure 45. Figure showing the relations of fracture strike azimuth to depth

Figure A-46. Figure showing cross-section at the ICPP.

Figure B-47. Figure showing a temperature log from borehole 44

Figure B-48. Figure showing a temperature log from borehole 45

170

Figure B-49. Figure showing temperature logs from borehole 46

Figure C-50. Figure showing six geophysical logs from borehole 44

Figure C-51. Figure showing six geophysical logs from borehole $44 \ldots$...(cont.) ...

Figure C-52. Figure showing six geophysical logs from borehole 44 ....(cont.) ...

Figure C-53. Figure showing six geophysical logs from borehole 45 
Figure C-54. Figure showing six geophysical logs from borehole $45 \ldots$...(cont.) ... 176

Figure C-55. Figure showing six geophysical logs from borehole 45....(cont.) ... 176

Figure C-56. Figure showing six geophysical logs from borehole $46 \ldots \ldots \ldots \ldots \ldots \ldots . .177$

Figure C-57. Figure showing six geophysical logs from borehole 46.......(cont.) 178

Figure C-58. Figure showing six geophysical logs from borehole $46 \ldots . . .($ cont.). . 178 


\section{LIST OF PLATES}

Plate 1. Picture showing typical basalt outcrop at the Box Canyon site.............. 20

Plate 2. Picture showing typical basalt lava flows outcropping in section $28 \ldots . . \quad 20$

Plate 3. Picture of the Swan Falls outcrop located by Figure 12. ...................... 21

Plate 4. Picture showing the $15 \mathrm{~cm}^{2}$ zone on the outcrop wall........................... 21

Plate 5. Picture taken at the Twin Falls outcrop of a basalt lava flow................ 41

Plate 6. Picture taken at the Twin Falls outcrop of a basalt lava flow ................ 41

Plate 7. Picture taken at the Twin Falls outcrop of two individual lava flows..... 42

Plate 8. Picture taken at the Swan Falls outcrop showing two individual basalt. 42

Plate 9. Picture taken at the Twin Falls outcrop showing the contact................. 43

Plate 10. Picture taken at the Box Canyon outcrop of the top of a lava flow ...... 43

Plate 11. Picture from the Swan Falls outcrop showing the vesicle pattern ......... 44

Plate 12. Picture taken at the Swan Falls outcrop showing the downward ......... 44

Plate 13. Picture from Swan Falls outcrop showing a large vesicle ................... 45

Plate 14. Picture of core with large vesicles from borehole $123 . \ldots \ldots \ldots \ldots \ldots \ldots \ldots . . . \ldots \ldots$

Plate 15. Picture of core with a close-up of the upper part of the lava flow ........ 46

Plate 16. Picture of core with vesicles forming a bubble train ........................ 46 
Plate 17. Picture of core with a close-up of a bubble train.

Plate 18. Picture from the Twin Falls outcrop showing the central part

Plate 19. Picture from the Swan Falls outcrop showing a vesicle sheet

Plate 20. Picture from Swan Falls outcrop showing a detailed close-up. 48

Plate 21. Picture from Box Canyon outcrop showing a vesicle plume 49

Plate 22. Picture from borehole 80 showing several pieces of core

Plate 23. Picture from borehole 123 showing a piece of core with many hollow.

Plate 24. Picture taken from the Twin Falls outcrop showing vesiculation 50

Plate 25. Picture taken from Swan Falls outcrop showing vesicle rich shelly-like 51

Plate 26. Picture from Swan Falls outcrop showing the underside of a shell......

Plate 27. Picture from Swan Falls outcrop showing unusual round basalt..........

Plate 28. Picture from Swan Falls outcrop showing a detailed close-up............. 52

Plate 29. Picture showing hexagonal columns from the Box canyon outcrop.... 53

Plate 30. Picture of a column showing breaks along its surface

Plate 31. Picture at Swan Falls outcrop showing a curvilinear joint

Plate 32. Picture at the Swan Falls outcrop showing white fine grained 1

Plate 33. Picture of ropy pahoehoe lava flow looking down on its surface 85

Plate 34. Picture of a basalt core at the INEL showing a bubble train. 85

Plate 35. Picture of borehole 55 showing the standard used to help calibrate..... 98 
Plate 36. Picture of borehole 46 (ICPP) at a depth of $553 \mathrm{ft}$ of a basalt contact. 113

Plate 37. Picture from borehole 46 (ICPP) depth $546 \mathrm{ft}$ showing sediment........ 113

Plate 38. Picture from borehole 50 (ICPP) depth $366 \mathrm{ft}$ showing basalt ............. 114

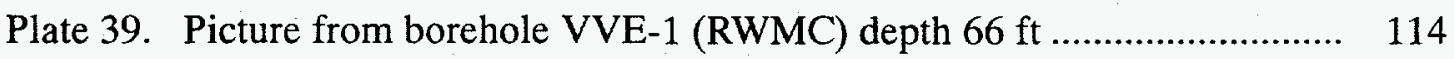

Plate 40. Picture from borehole ID-8 (NPR) depth $46 \mathrm{ft}$................................. 115

Plate 41. Picture from borehole VVE-3 (RWMC) depth $202 \mathrm{ft} \ldots \ldots \ldots \ldots \ldots \ldots \ldots \ldots \ldots . . . . . . . . . . .115$

Plate 42. Picture from borehole VVE-1 (RWMC) depth $72 \mathrm{ft} \ldots \ldots \ldots \ldots \ldots \ldots \ldots \ldots \ldots \ldots . . . . . . . . . . .116$

Plate 43. Picture from borehole VVE-1 (RWMC) depth $20 \mathrm{ft} \ldots \ldots \ldots \ldots \ldots \ldots \ldots \ldots \ldots \ldots . . . . . . . . . . . .116$

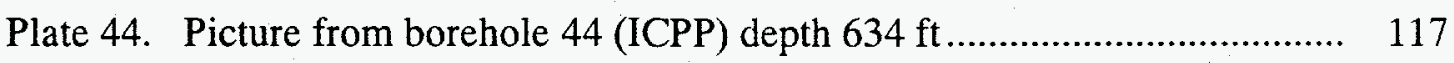

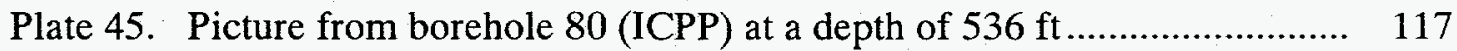

Plate 46. Picture from borehole 46 (ICPP) at a depth of $644 \mathrm{ft} \ldots \ldots \ldots \ldots \ldots \ldots \ldots \ldots \ldots . . . . . . . . . . .118$

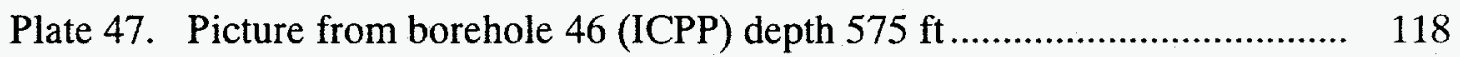

Plate 48. Picture from borehole VVE-3 (RWMC) at a depth of $164 \mathrm{ft} \ldots \ldots \ldots \ldots \ldots . .119$

Plate 49. Picture from borehole 46 (ICPP) at a depth of $476 \mathrm{ft} . \ldots \ldots \ldots \ldots \ldots \ldots \ldots \ldots \ldots . . . . . . . . . . .119$

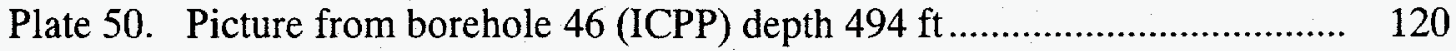

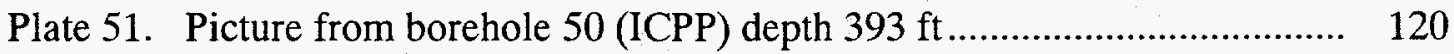

Plate 52. Picture from borehole IC-7 (NPR) at a depth of $68 \mathrm{ft} . \ldots \ldots \ldots \ldots \ldots \ldots \ldots \ldots \ldots . . . . . . . . . .121$

Plate 53. Picture from VVE-10 (RWMC) at a depth of $190 \mathrm{ft} \ldots \ldots \ldots \ldots \ldots \ldots \ldots \ldots \ldots \ldots . . . . . . . . . .121$ 


\section{LIST OF TABLES}

Table 1. Table showing data collected at the three outcrops ............................... 25

Table 2. Table showing location of three wells at the ICPP .............................. 127

Table 3. Showing different wells and authors studying fluid movement in them 141

Table 4. Heat-pulse flowmeter measurements in wells 44,45 , and 46 at the INEL143

Table 5. Table of wells at the ICPP that shows permeable intervals within them 145 


\title{
LIST OF ABBREVIATIONS
}

\section{Conversion Factors - Abbreviated Units And Terms}

\author{
Multiply \\ gallon \\ gallon per minute (gal/min) \\ foot $(\mathrm{ft})$ \\ inch (in) \\ inch (in) \\ mile (mi) \\ square miles $\left(\mathrm{mi}^{2}\right)$
}

$\underline{B y}$

To obtain

3.785

0.06309

0.3048

25.40

2.54

1.609

2.589 liter

liter per second

meter

millimeter

centimeter

kilometer

square kilometers

To convert degrees Fahrenheit $\left({ }^{\circ} \mathrm{F}\right)$ to degrees Celsius $\left({ }^{\circ} \mathrm{C}\right)$, use the following formula:

$$
{ }^{\circ} \mathrm{C}=\left({ }^{\circ} \mathrm{F}-32\right) \frac{5}{9}
$$

\section{Following Terms And Abbreviations Used In This Report}

$\begin{array}{ll}\sim & \text { approximately } \\ \text { BSU } & \text { Boise State University } \\ \mathrm{CFA} & \text { Central Facilities Area } \\ \mathrm{Ci} & \text { Cures } \\ \mathrm{cm} & \text { centimeter } \\ \mathrm{cm} / \mathrm{sec} & \text { centimeter per second } \\ \mathrm{cps} & \text { counts per second } \\ { }^{\mathrm{o}} & \text { degrees } \\ { }^{\circ} \mathrm{C} & \text { degrees Celsius } \\ { }^{\circ} \mathrm{F} & \text { degrees Fahrenheit } \\ \Delta & \text { delta (the difference) } \\ \mathrm{dia} & \text { diameter }\end{array}$




\begin{tabular}{|c|c|}
\hline $\begin{array}{l}\text { ESRP } \\
\mathrm{ft} \text { bls }\end{array}$ & $\begin{array}{l}\text { Eastern Snake River Plain } \\
\text { feet below land surface }\end{array}$ \\
\hline $\mathrm{ft} / \mathrm{d}$ & feet per day \\
\hline $\mathrm{ft}^{2} /$ day & feet squared per day \\
\hline $\mathrm{ft}$ & foot \\
\hline $\mathrm{ft} / \mathrm{min}$ & foot per minute \\
\hline $\mathrm{ft} / \mathrm{s}$ & feet per second \\
\hline $\mathrm{ft}-\mathrm{lbs}$ & foot-pound(s) \\
\hline gal & gallons \\
\hline $\mathrm{g} / \mathrm{cm}^{3}$ & grams per cubic centimeter \\
\hline $\mathrm{gal} / \mathrm{min}$ & gallons per minute \\
\hline$>$ & greater than \\
\hline $\mathrm{Hz}$ & Hertz \\
\hline $\mathrm{H}$ & horizontal \\
\hline ICPP & Idaho Chemical Processing Plant \\
\hline INEL & Idaho National Engineering Laboratory \\
\hline $\mathrm{kJ}$ & kilo-Joules \\
\hline $\mathrm{km}$ & kilometers \\
\hline $\mathrm{km} / \mathrm{s}$ & kilometers per second \\
\hline$<$ & less than \\
\hline $\mathrm{L}$ & liter \\
\hline $\mathrm{L} / \mathrm{min}$ & liter per minute \\
\hline $\mathrm{m}$ & meters \\
\hline $\mathrm{m} / \mathrm{min}$ & meter per minute \\
\hline $\mathrm{m} / \mathrm{s}$ & meters per second \\
\hline $\mathrm{mi}$ & miles \\
\hline $\mathrm{mph}$ & miles per hour \\
\hline $\mathrm{ms}$ & milli-second \\
\hline $\mathrm{md}$ & millidarcy \\
\hline $\mathrm{mm}$ & millimeters \\
\hline $\mathrm{MeV}$ & million electron volts \\
\hline $\mathrm{mr} / \mathrm{hr}$ & milliroentgen per hour \\
\hline NPR & New Production Reactor \\
\hline $\mathrm{N}$ & Newton(s) \\
\hline O.D. & outside diameter \\
\hline
\end{tabular}




$\begin{array}{ll}\mathrm{Pa} & \text { Pascal } \\ \% & \text { percentage } \\ \pi & \text { pi }(3.141592654 \ldots . .) \\ \mathrm{lb} & \text { pound(s) } \\ \mathrm{pcf} & \text { pounds per cubit feet } \\ \text { psi } & \text { pounds per square inch } \\ \text { RWMC } & \text { Radioactive Waste Management Complex } \\ \text { sec. } & \text { second(s) } \\ \text { SRP } & \text { Snake River Plain } \\ \text { SRPA } & \text { Snake River Plain Aquifer } \\ \text { TV } & \text { television } \\ \text { TAN } & \text { Test Area North } \\ \text { TRA } & \text { Test Reactors Area } \\ \theta & \text { theta (an angle) } \\ \text { U. S. } & \text { United States } \\ \text { USGS } & \text { United States Geological Survey } \\ \text { vs. } & \text { versus } \\ \text { V } & \text { vertical } \\ \text { VCR } & \text { video-cassette-recorder }\end{array}$




\section{CHAPTER 1. INTRODUCTION}

\section{Purpose And Objectives}

At the Idaho National Engineering Laboratory (INEL) great concern exists about the potential for migration of radioactive and chemical wastes from the various facilities there to the underlying Snake River Plain Aquifer (SRPA). More than forty wells at the INEL have a significant open intervals in the aquifer. These wells have cemented casing to water level and $30(100 \mathrm{ft})$ to $90(300 \mathrm{ft})$ meters of uncased borehole in the saturated zone. These open intervals in the basalt rocks of the aquifer have numerous fracture zones of varying aperture, overall thickness, and lateral extent. A high likelihood for movement of contaminants across aquitards owing to artificial connection by wells exists. A better understanding of flow in these wells would help to estimate the effects of contaminant movements and their impacts on the SRPA.

Studies and projects have tried to address these issues, but most projects were done twenty five years ago and the overall effects of these well interconnections were never studied in detail. As part of an ongoing effort to study and characterize fluid flow, the present research project was conducted to describe and analyze the hydrogeological parameters that effect fluid flow in Quaternary-aged basalt. This study involves detailed measuring and describing of features from three outcrops, three borehole cores from the INEL, over forty borehole TV logs of wells at INEL, and analysis of borehole geophysical logs. One objective is to understand the types of basalt flows and their variations and the physical properties of rocks (color, vesicle size and shape, fracture orientation, apertures, and traceable lengths) in the subsurface at the INEL. From this I developed a model of a typical basalt lava flow that can be used to identify characteristic zones by their vesicle and 
fracture patterns (Figure 23, p. 68). This model is useful for interpretations of borehole TV logs in basalt lave flows and for "calibrating" the borehole geophysical data. The second objective is to generate a detailed stratigraphy of the saturated zone of an area at the INEL. This stratigraphy is based on identifying characteristic lava-flow zones in addition to using natural gamma logs which were the primary tool for stratigraphic correlations of petrochemical units by Anderson (1991). Another objective is to measure vertical crossflows of water in the wells between permeable zones in open-hole intervals using primarily temperature and flowmeter logs.

The basalt lava flow model and geophysical logs are used to construct a cross-section through the area of the Idaho Chemical Processing Plant (ICPP) for the section below the water table (Figure A-46. p. 168). On this section, the broad petrochemical units identified by Anderson (1991) are further subdivided into zones based upon physical volcanological features. I was, however, unable to confidently correlate zones from well to well. Also shown on the cross-section are intervals across which intrawell flows occur. These intervals have small head differences either natural or induced by pumping. These intrawell flow zones have a permeable unit at the top and at the base, and in some cases in between.

\section{Geologic Setting}

The study area is located in the eastern Snake River Plain (ESRP). The Snake River Plain (SRP) (Figure 1) is a vast lowland, $50(31 \mathrm{mi})$ to $100(62 \mathrm{mi}) \mathrm{km}$ wide, that cuts an arcuate swath across southern Idaho (Kuntz, et al., 1992). The following description of the ESRP is summarized from Kuntz, et al. (1992). The ESRP portion of this lowland is a broad lava plain consisting, at the surface, of mostly Quaternary basaltic lava flows, pyroclastic deposits, and thin, discontinuous deposits of loess, sand dunes, and alluvial sediments. 


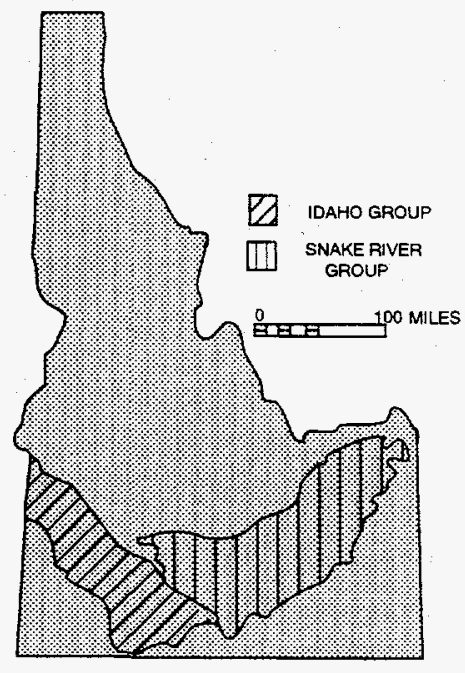

Figure 1. Map showing the major late Cenozoic geologic units of the Snake River Plain. Snake River Group is primarily Pliocene and Quaternary basalt. The Idaho Group is primarily fluvial-lacustrine rocks with minor basalt ranging in age from Late Miocene to Quaternary.

Basalt and sedimentary sequences underlie the plain and are then underlain by rhyolitic lava flows, ignimbrites, and pyroclastic deposits. Available geological and geophysical data suggest that the SRP has been the site of a north-easterly propagating system of rhyolitic volcanic centers and associated basaltic volcanism. Field characteristics of vent areas and lava flows in the ESRP are remarkably similar to those of well studied volcanoes and volcanic rift zones in Hawaii, with coalesced shield volcanoes and lava cones, the flows of which are mainly of the tube-fed type, which constitute more than $95 \%$ of the total volume of basalt in the ESRP. The remainder is made up of eruptive-fissure deposits, tephra cones, and deposits of hydrovolcanic eruptions.

Basalts found in the ESRP are chiefly olivine tholeiite that show little of differentiation or contamination. The basalts consists of normative olivine and hypersthene, a single clinopyroxene, plagioclase, titanomagnetite, ilmenite, accessory apatite, and brown glass 
(Kuntz, et al., 1992 and Lanphere, et al., 1994). Most samples have a coarse, intergranular texture, with others ranging from ophitic and subophitic to intergranular and diktytaxitic (Kuntz, et al., 1992).

\section{Study Areas}

The INEL was established in 1949 by the U.S. Atomic Energy Commission as an area to build, test and operate various nuclear reactors and to have fuel processing plants, and support facilities with maximum safety and isolation. The site is comprised of seven major facilities operated by government contractors. The site covers $2304 \mathrm{~km}^{2}\left(890 \mathrm{mi}^{2}\right)$ of semiarid land in the northeastern part of the eastern Snake River Plain (Figure 2).

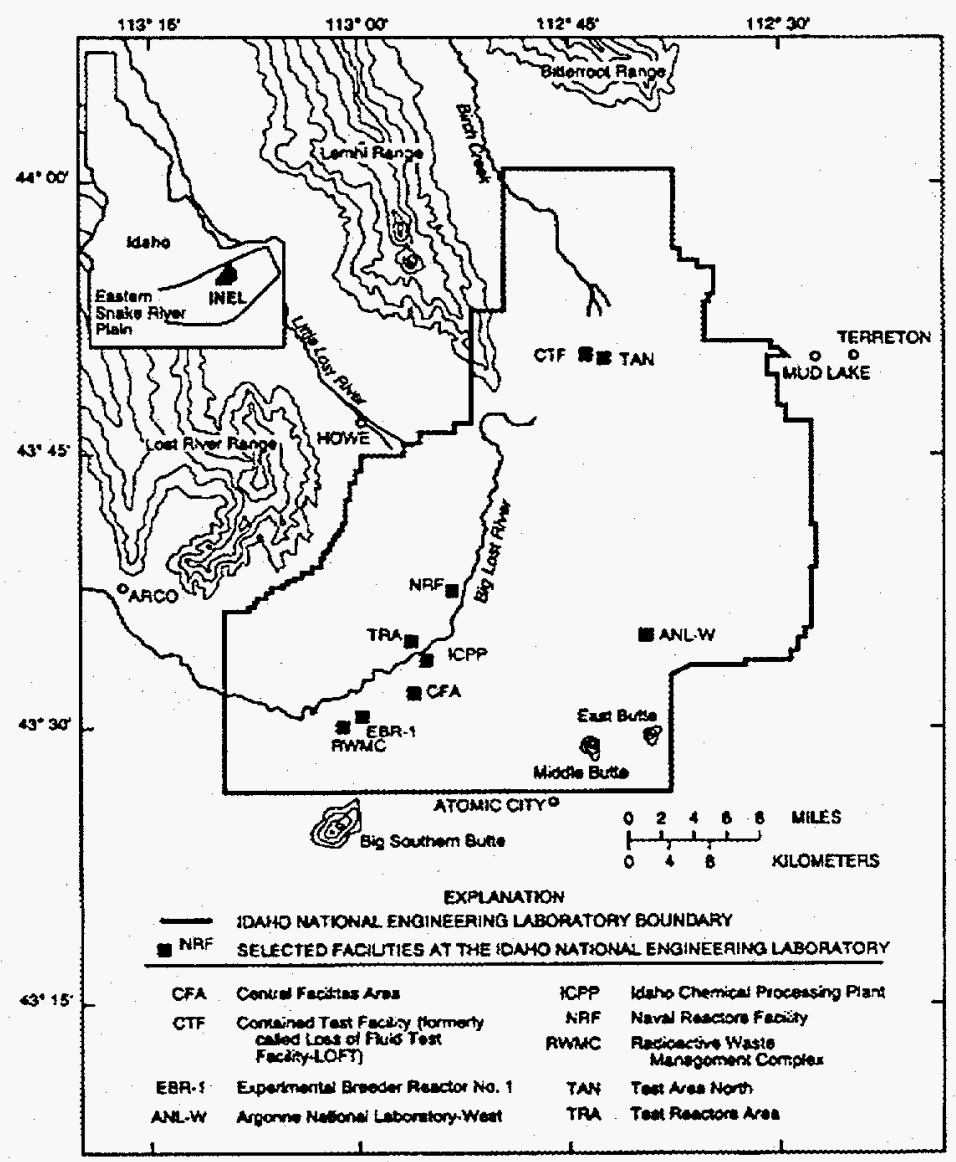

Figure 2. Geologic setting and facilities at the Idaho National Engineering Laboratory. 
The primary focus of this study is the vicinity of the Idaho Chemical Processing Plant (ICPP). The ICPP complex houses reprocessing and research facilities for spent nuclear fuel derived mostly from nuclear-powered navy ships and submarines. Facilities at the ICPP includes: spent fuel storage and reprocessing areas, a waste solidification facility and related waste storage bins, remote analytical laboratories, and a coal-fired steam generating plant. The ICPP is $13 \mathrm{~km}(8 \mathrm{mi})$ north of the southern boundary of the INEL and covers about $0.39 \mathrm{~km}^{2}\left(0.15 \mathrm{mi}^{2}\right)$ (Figure 3).

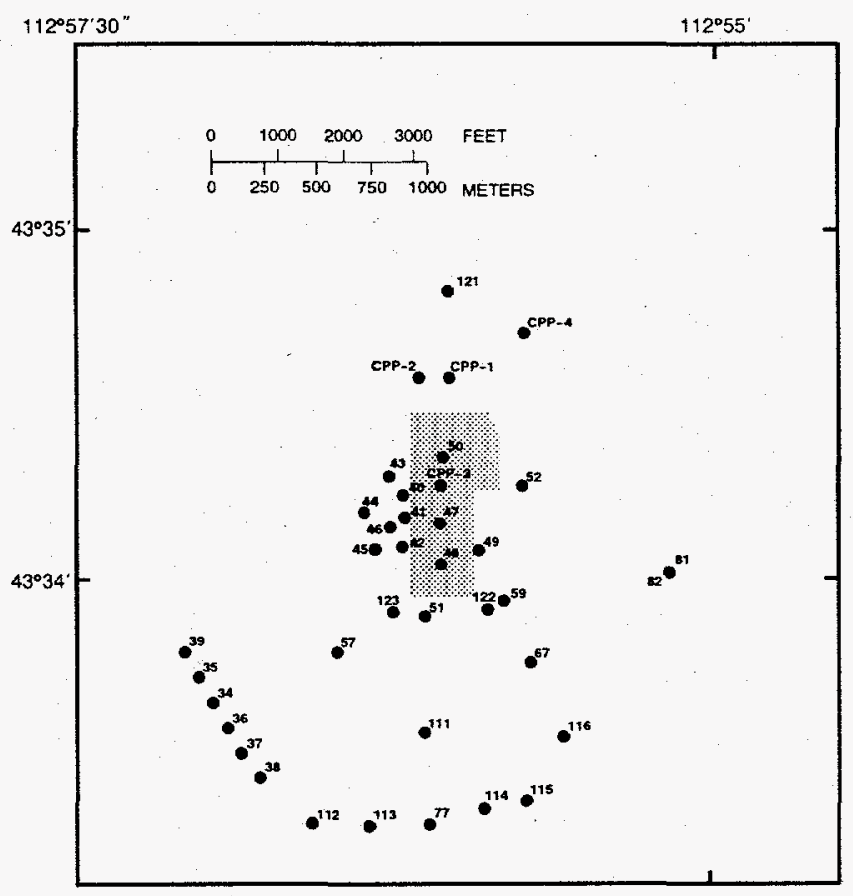

Figure 3. Location of wells at the Idaho Chemical Processing Plant

The ICPP has discharged radioactive and chemical wastes to a disposal well and unlined percolation ponds for several decades. From 1953 to 1984 the ICPP discharged low-level radioactive and chemical wastewater directly into the Snake River Plain aquifer through well CPP \#3 (Figure 3), a 183 m (600 ft) deep disposal well. From 1982-1985, 1684 million liter/year (445 million gal/year) of waste water containing an average of $287 \mathrm{Ci} / \mathrm{year}$ of 
strontium-90 also was discharged to percolation ponds at the ICPP (Pittman, 1988). The ICPP no longer discharges wastes down the disposal well, but percolation ponds are still in operation (Anderson, 1991).

Three sites were picked for their excellent basalt outcrops and in the case of Box Canyon its proximity to the INEL. Each outcrop has an exposure of over $21 \mathrm{~m}(70 \mathrm{ft})$ of basalt and sedimentary interbeds in cross-section. These outcrop study sites are located at Swan Falls, Twin Falls, and Box Canyon, Idaho.

\section{General Geohydrologic Setting At The INEL}

Basaltic rocks, which underlie the INEL to a depth of as much as $610 \mathrm{~m}(2,000 \mathrm{ft})$, are interbedded with fluvial, lacustrine, and eolian deposits of clay, silt sand, and gravel (Anderson, 1991). For a very detailed account of the past geologic events occurring at the INEL site a review of Nace and others (1956) work is suggested. The layered basalt rocks and sediment interbeds are saturated at depth with ground water and these rocks are called the Snake River Plain Aquifer (SRPA). Depth to the water in the aquifer ranges from tens to hundreds of meters across the plain and from 61 to $274 \mathrm{~m}$ (200 to $900 \mathrm{ft}$ ) below land surface at the INEL (Anderson, et al., 1989). Saturated thickness of the basalt aquifer ranges from less than 152 to more than $1,219 \mathrm{~m}$ (500 to more than $4,000 \mathrm{ft}$ ) (Whitehead, 1986). These basaltic rocks rank among the most transmissive aquifers in the world.

Transmissivity values on the order of $8,000 \mathrm{~m}^{2} /$ day $\left(9 \times 10^{4} \mathrm{ft}^{2} /\right.$ day $)$ were reported from well tests by Ackerman (1991) for a 60 to $120 \mathrm{~m}$ (200 to $400 \mathrm{ft}$ ) thick upper sequence of saturated permeable lava. The upper $150 \mathrm{~m}(500 \mathrm{ft})$ of SRPA is thought to be the most permeable with transmissivity ranging from $1 \times 10^{4}$ to $1 \times 10^{6} \mathrm{~m}^{2} /$ day $\left(1 \times 10^{5}\right.$ to $1 \times 10^{7}$ $\mathrm{ft}^{2} /$ day) reported by Robertson (1974). Storage coefficients of the aquifer are highly variable both spatially and temporally, ranging from 0.001 to 0.2 and averaging 0.15 (Robertson, 1974). Vertical-head (Figure 4) gradients (increasing with depth) are usually less than 0.01 over the first 


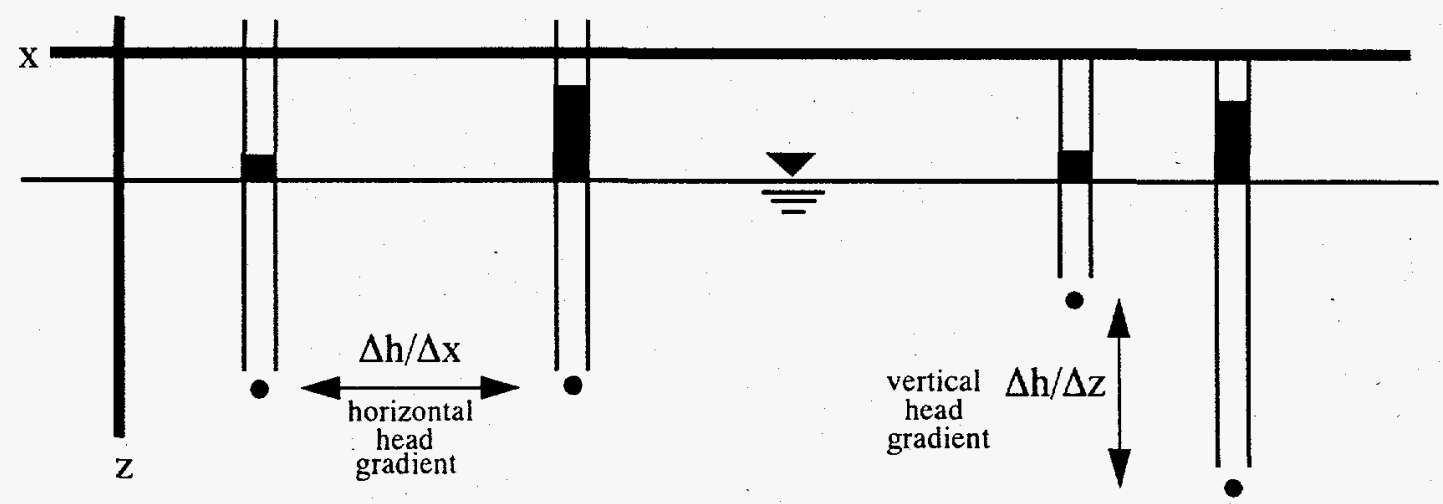

Figure 4. Figure showing the difference between vertical and horizontal hydraulic head gradient in aquifers.

$200 \mathrm{ft}$ and less than 0.02 over the first $550 \mathrm{ft}$ of saturated thickness (Ackerman, 1991). These storage coefficients depend in large part on the "confinedness" of the aquifers tested (Bennecke and Wood, 1992). Groundwater in the SRPA flows from the northeast to southwest (Figure 5) with a horizontal head gradient of approximately $1 \mathrm{~m} / \mathrm{km}(5 \mathrm{ft} / \mathrm{mile}$ $(0.0009 \mathrm{ft} / \mathrm{ft}))$ to the southwest. Horizontal percolation velocities are estimated to be between 2 and $6 \mathrm{~m} /$ day ( 5 and $20 \mathrm{feet} /$ day) (Ackerman, 1991). Recharge into the aquifer is by streams issuing onto the northern margin of the plain. Discharge is by pumping wells and the spectacular spring discharges along the walls of the Snake River Canyon by Hagerman. The total spring discharge of the aquifer is approximately $185 \mathrm{~m}^{3} \mathrm{~s}^{-1}$ and occurs primarily on the western edge of the aquifer at Thousand Springs (Brott et al., 1981 and Whitehead and Covington, 1987). 


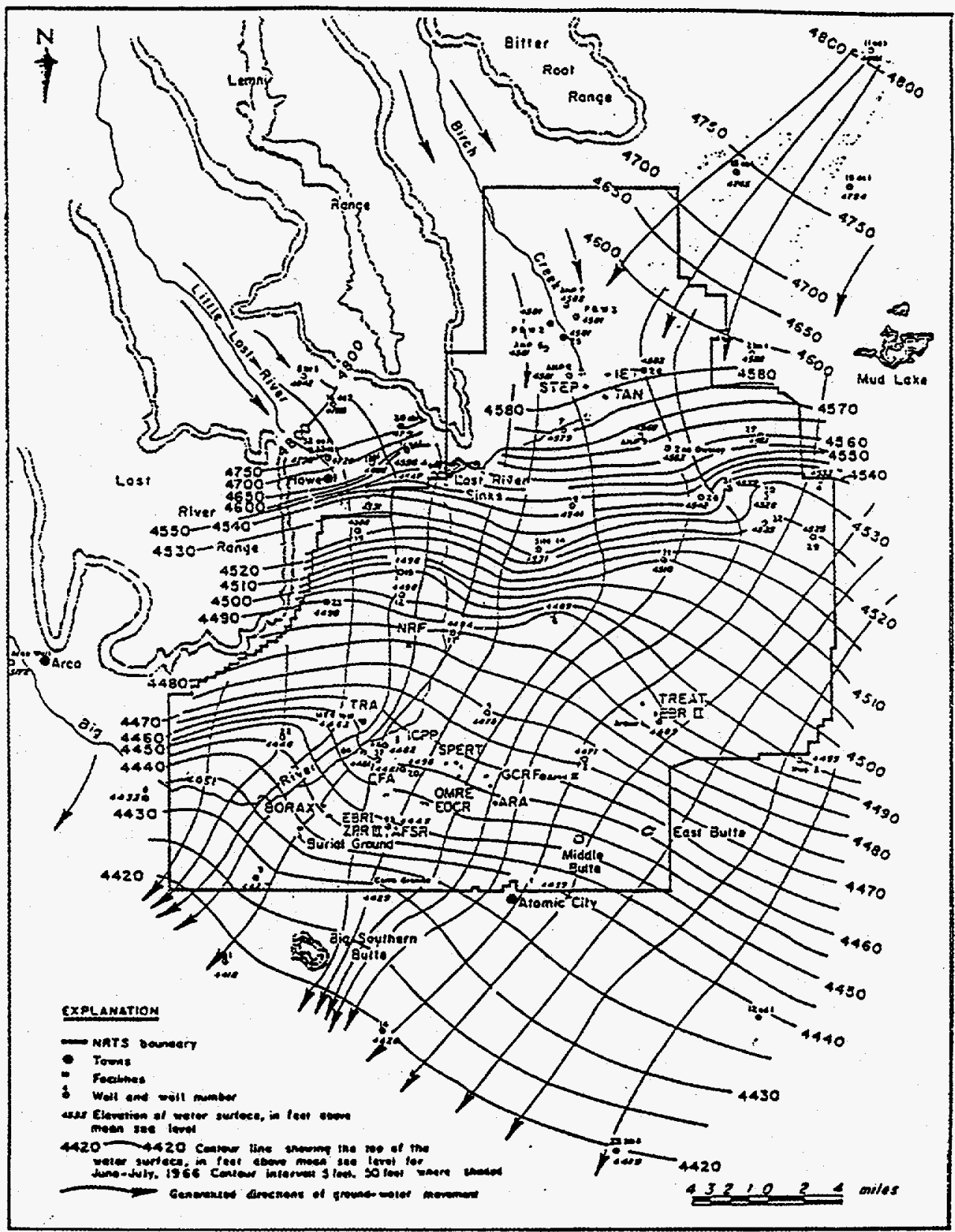

Figure 5. Map showing direction of groundwater movement at the INEL (After Barraclough, 1965). 


\section{CHAPTER 2. DATA COLLECTION METHODS: OUTCROPS}

\section{Outcrop Locations}

Three outcrops were picked purposely for their accessibility and good exposure of unweathered rock. The three outcrops are designated Swan Falls, Twin Falls, and Box Canyon. Box Canyon on the Big Lost River is the closest of the outcrops to the INEL site. The best section is in the south halves of section 35 and 36 Township 3 N, Range $27 \mathrm{E}$ (Figure 10) (Plate 1). Access to the site is by rough gravel and dirt roads that parallel the Big Lost River Southeast of Arco. The locality can be reached by a turnoff from U. S. Highway $20 / 26$ at mileage 265.6 .

The Twin Falls outcrops are exposed along the Snake River north of the city of Twin Falls at Section 33, Range 4, Township 9 South (Figure 11) (Plate 2). The locality can be accessed by Highway US 93, to the golf course access road which travels parallel to the outcrop and to the river allowing year around access to the rock wall. Further outcrops of basalt rock can be seen in the Snake River Canyon, but are not as easily accessible.

The Swan Falls outcrop is the furthest away from the INEL along the Snake River at the Swan Falls Dam 55 km (34 mi) south west of Nampa (Figure 12) (Plate 3). It is located on the Swan Falls Road just south of Kuna and can be accessed from Boise by traveling west on Interstate 84, at Exit 44: Kuna-Meridian Exit, south on Meridian Road (Idaho State Highway 69), then west on Kuna Road, and south on Swan Falls Road to the gorge of the Snake River. Like the Twin Falls outcrop a paved road travels down the outcrop to the river and Swan Falls Dam allowing year-around access. Each outcrop is over $21 \mathrm{~m}(70 \mathrm{ft})$ in thickness with basalt lava flows and sedimentary interbeds. 


\section{Outcrop Measurements}

Certain parameters needed to be measured at the outcrops to better understand the basalt lava flows. The parameters measured at each outcrop are: color, relative amount of vesicles in the different parts of the outcrop (vesicularity), relative fracture orientation (parallel, perpendicular, and oblique to a reference line), density of fractures, fracture apertures, and location of fracture in the sequence.

\section{Fractures and Joints}

Basalt fractures were measured using a modified scan-line technique used in rock engineering investigations (Call et al., 1976). A scan-line method entails recording joints

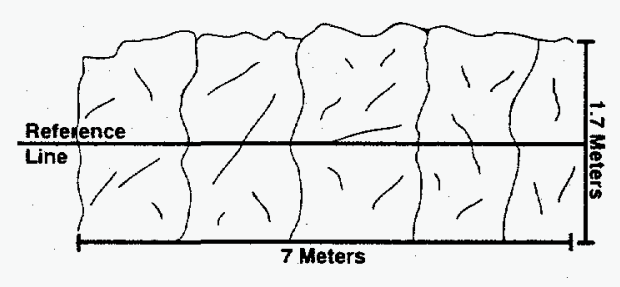

note: vertical exaggeration

Figure 6. Schematic representation of sampling swath in a generalized section of a basalt lava flow.

in a band $1.7 \mathrm{~m}(5.6 \mathrm{ft})$ about a reference line $7 \mathrm{~m}(23 \mathrm{ft})$ along the outcrop (Figure 6). To do this a metric tape is adhered to an outcrop wall parallel to a basalt lava flow boundary seen on the outcrop and intersecting a typical fracture pattern and density. This metric tape then becomes a reference line from which to take further measurements. Fractures with a length of a least $15 \mathrm{~cm}(6 \mathrm{in})$ only were sampled primarily because the accuracy of measuring smaller fractures decreased with the tools used in this research. The $15-\mathrm{cm}-$ minimum-length was also used as a cutoff because some short fractures are suspected of being generated by outcrop weathering and not representative of the subsurface fracture 
distribution. Short fractures generally have thin aperture and are believed to have little hydrogeologic significance. Any fractures that occurred in the band along the reference line were thus recorded. Recorded information for each fracture was in the form of listing the orientation with respect to the scan line (parallel, vertical or oblique), distance along the tape where the fracture intersected the tape, length of the fracture as given by the maximum traceable distance that can be observed. Attitude of fracture plane was estimated. Fractures were noted as to whether they defined columns. An average value of aperture was found by measuring the aperture along a fracture every $10 \mathrm{~cm}$ (4 in). The outcrop color was recorded every $15 \mathrm{~cm}(6 \mathrm{in})$ along the reference line and perpendicular to it for the measurable part of the outcrop wall, and a judgement made whether color was intrinsic or a result of weathering of outcrop.

True fracture spacing is found by first finding the apparent spacing on the outcrop and then making a correction to find the true spacing. The calculations to find the true fracture spacing is taken from Meints (1986) and is given briefly here:

A orthogonal coordinate reference axes (Figure 7) was used for a directional cosine
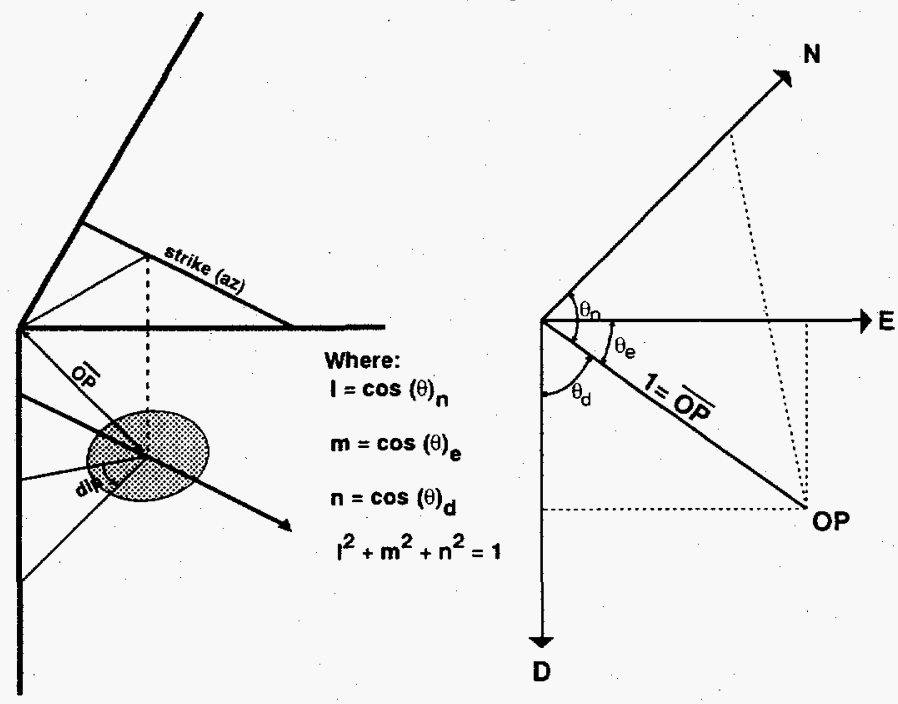

Figure 7. Figure showing reference axes for the orthogonal coordinates used for directional cosine computations. 
computations. The positive ends of the axes point north, east and down. The angles that the unit vector OP (this represents a pole to plane) make with the positive directions of the three coordinate axes define the directional cosines of OP as:

$$
\begin{aligned}
& l=\cos (\Theta)_{n} \\
& m=\cos (\Theta)_{e} \\
& n=\cos (\Theta)_{d}
\end{aligned}
$$

Directional cosines can then be calculated for poles to fractures:

$$
\begin{gathered}
l=\sin (d i p) \times \cos (a z+180) \\
m=\sin (d i p) \times \sin (a z+180) \\
n=\cos (d i p)
\end{gathered}
$$

where: $\operatorname{dip}=\operatorname{dip}$ of fracture, $a z=$ dip direction of fracture.

Secondly, for any given fracture set (a fracture set is a set of two or more fractures with strike and dip within $\pm 3^{\circ}$ ) of $N$ orientations a resultant vector can be calculated. The length of the resultant vector, $R$, is given by:

$$
R=\sqrt{\left(\sum^{N} l\right)^{2}+\left(\sum^{N} m\right)^{2}+\left(\sum^{N} n\right)^{2}}
$$

The directional cosines of the resultant vector direction can then be calculated by dividing the sums of the direction cosines $(1, m, n)$ by the magnitude of the resultant vector.

$$
l_{m v}=(1 / R) \times\left(\sum^{N} l\right) \quad m_{m v}=(1 / R) \times\left(\sum^{N} m\right) \quad n_{m v}=(1 / R) \times\left(\sum^{N} n\right)
$$

$\mathrm{mv}=$ mean vector directional cosine

These estimated resultant vector directional cosines are then used in conjunction with the directional cosines of the reference mapping line, or meter tape, to convert apparent fractures spacings as measured on the tape to true spacings between adjacent fractures in a 


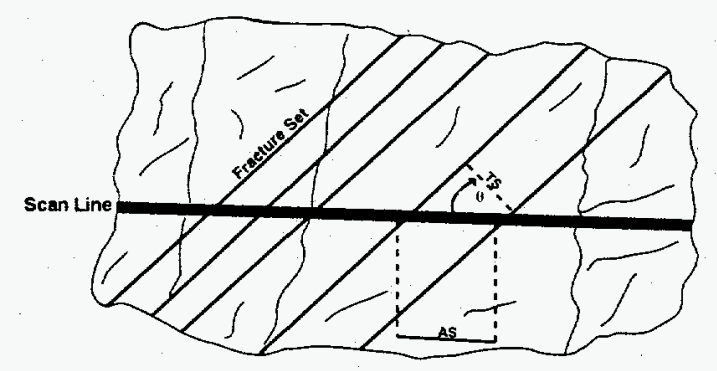

Figure 8. Schematic representation of the difference between true spacing (TS) and apparent spacing (AS) in-between fractures.

given set (Figure 8). The directional cosines for an attitude of tape are given by:

$$
\begin{gathered}
l=\cos (P) \times \sin (T) \\
m=\cos (P) \times \sin (T) \\
n=\sin (P)
\end{gathered}
$$

where: $\mathrm{T}=$ azimuthal trend of tape and $\mathrm{P}=$ plunge of mapping line.

The true spacing or perpendicular distance between adjacent fractures in the set is given by the following equation:

$$
\begin{gathered}
\text { True }=\text { (apparent }) \times|\cos (\Theta)| \\
\cos (\Theta)=\left|\left(l_{T} \times l_{m v}\right)+\left(m_{T} \times m_{m v}\right)+\left(n_{T} \times n_{m v}\right)\right|
\end{gathered}
$$

where: apparent spacing = array of tape distance measurements, in order from left to right, for $\mathrm{N}$ fractures.

$$
\begin{aligned}
& (1, \mathrm{~m}, \mathrm{n})_{\mathrm{T}}=\text { directional cosines of the meter tape. } \\
& (1, \mathrm{~m}, \mathrm{n})_{\mathrm{mv}}=\text { directional cosines of the resultant vector of the fracture }
\end{aligned}
$$

orientations in a given set.

The raw data on fractures is then recalculated and reported as true fracture spacing using the above formulas. 
$\underline{\text { Vesicles }}$

Vesicles are roughly spherical cavities in the basalt that occur throughout a basalt lava flow. The amount of vesicles is qualitatively determined by estimating the general percent of vesicles that occupy a $15 \times 15 \mathrm{~cm}(6 \times 6$ in) area along the reference line and perpendicular to it for the measurable part of the outcrop wall (Plate 4). An approximate percentage is then estimated for other regions of the basalt flow. Vesicularity can be defined by the relative amount of vesicles found in a zone of rock. A rock with a large vesicularity is defined in this study as having more then $50 \%$ of the rock volume made up of vesicles. The overall shape of the vesicles can be described with a major and minor axis measured off an ellipsoidal shape (Figure 9).
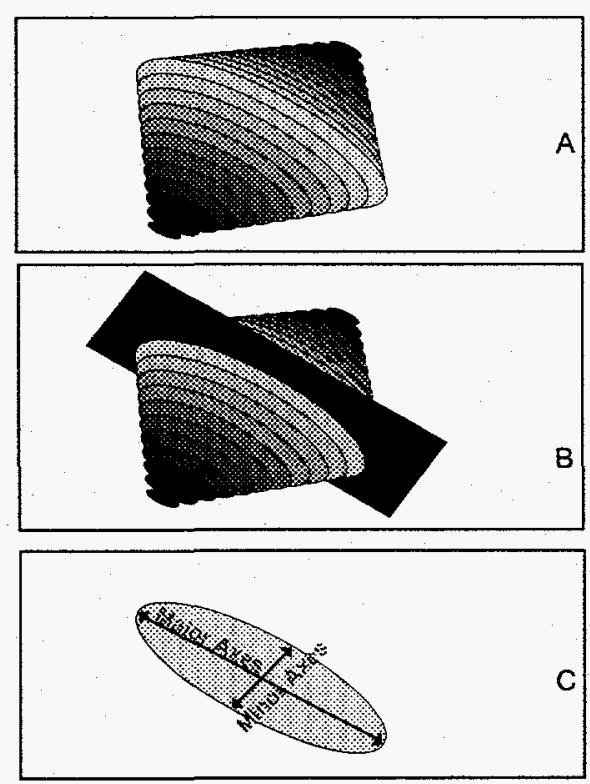

Figure 9. Figure showing how the major and minor axis are defined for a vesicle seen on an outcrop. The top diagram " $\mathrm{A}$ " is showing the side view of a vesicle. In diagram " $\mathrm{B}$ " an imaginary plane that cuts the vesicle. This apparent ellipticity is measured in outcrop. The diagram " $C$ " then shows the plane of intersection from diagram " $B$ " and defines the major and minor axis on it. 
$\underline{\text { Color }}$

Color designations were determined by holding a Munsell soil color chart (Goddard, et al., 1992) next to dry fresh rock, but in some cases rock may have been slightly tarnished by weathering, and the judgement was noted. 


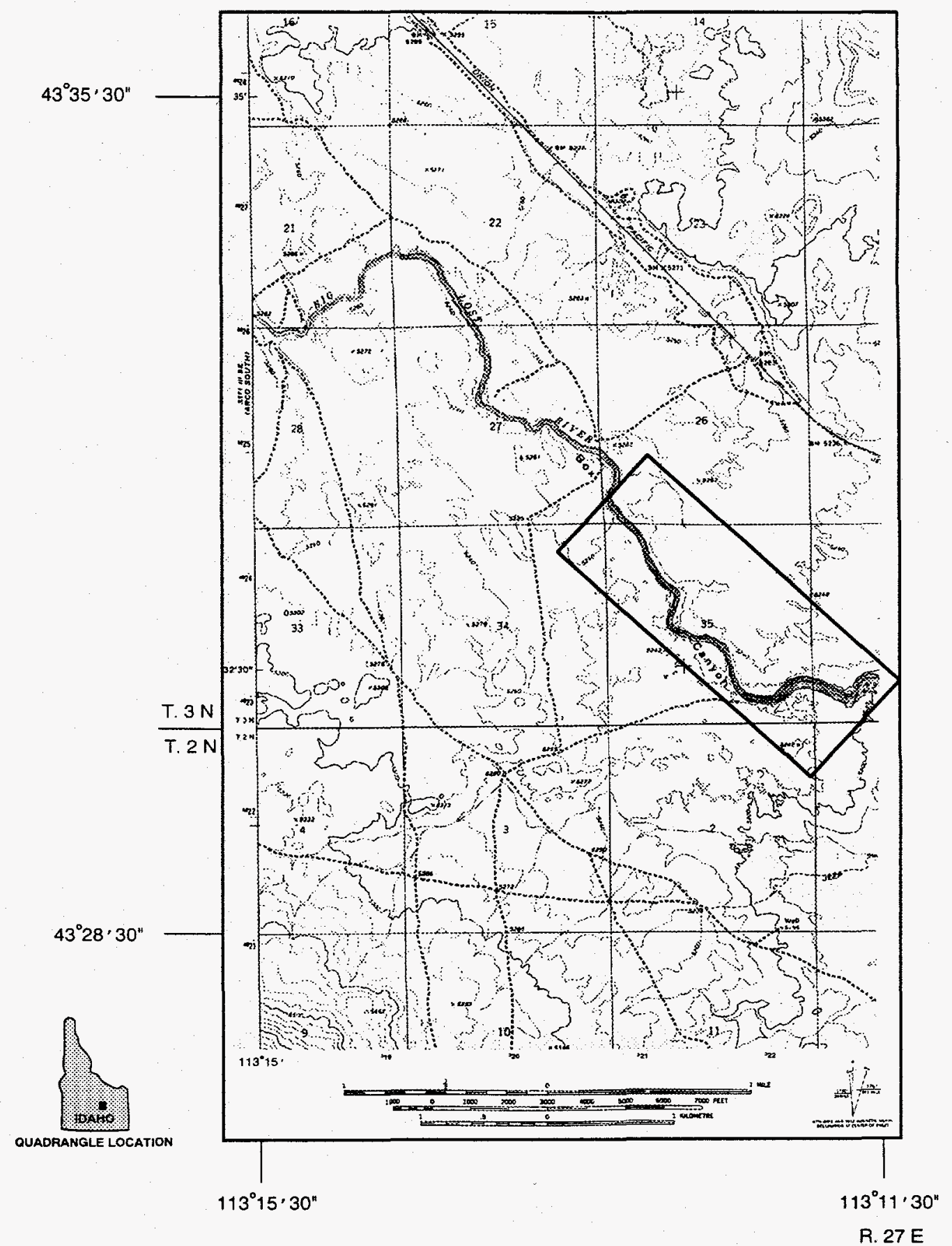

Figure 10. Part of the Butte City, quadrangle 7.5 minute showing the location of the Box Canyon outcrop studied (shown in the black box). 


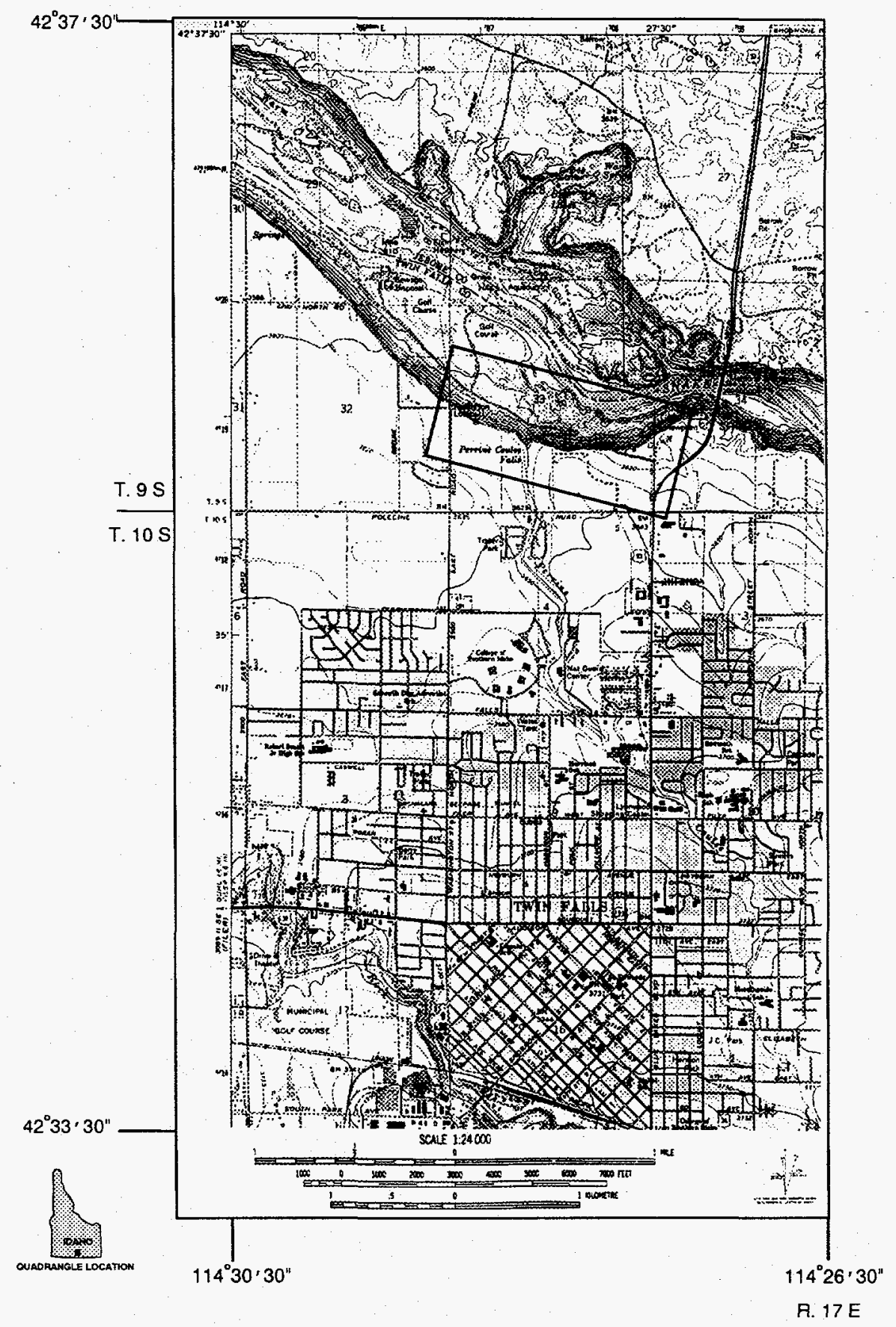

Figure 11. A part of the Twin Falls quadrangle 7.5 minute showing the location of the Twin Falls outcrop shown in the black box. 


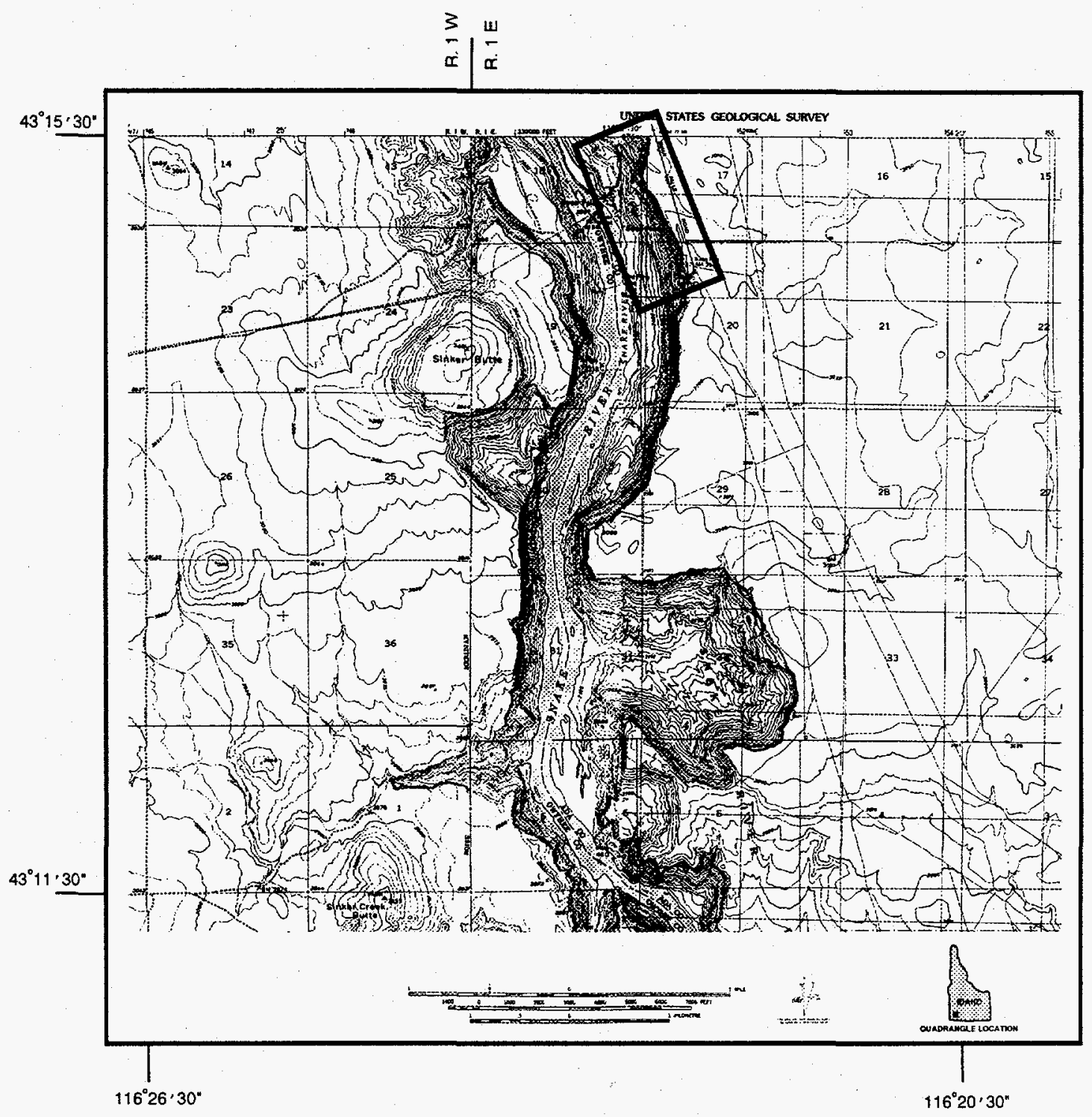

Figure 12. A part of the Sinker Butte and Wild Horse Butte quadrangle 7.5 minute showing the location of the Swan Falls outcrop located in the black box. 
Plate 1. Picture showing typical basalt outcrop at the Box Canyon site. Basalt lava flows and fractures can be seen in the photograph which is about $16 \mathrm{~m}(53 \mathrm{ft})$ across and 20 $\mathrm{m}(67 \mathrm{ft})$ high.

Plate 2. Picture showing typical basalt lava flows outcropping in section 28 along the Snake River. This picture was taken looking directly north across the river from the Twin Falls outcrop study area and is very similar to where the outcrop work was done.

Plate 3. Picture of the Swan Falls outcrop located by Figure 12.

Plate 4. Picture showing the $15 \mathrm{~cm}^{2}$ zone on the outcrop wall outlined by the white box. The lower $1 / 5$ th of the zone is of higher vesicularity, whereas the upper $4 / 5$ th is representative of the bulk of the rock. The metal ruler is $15 \mathrm{~cm}$ (6 in) long. 
Plate 1.

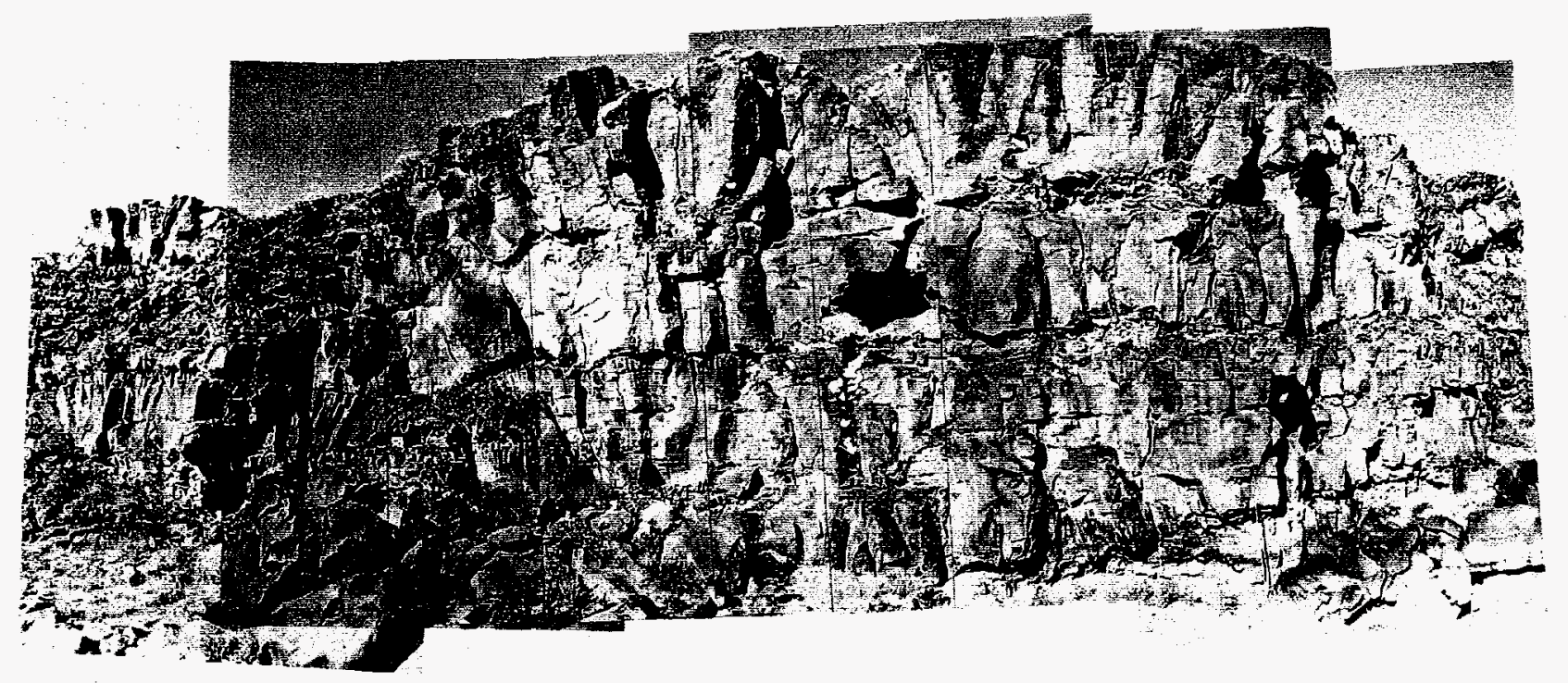

Plate 2.

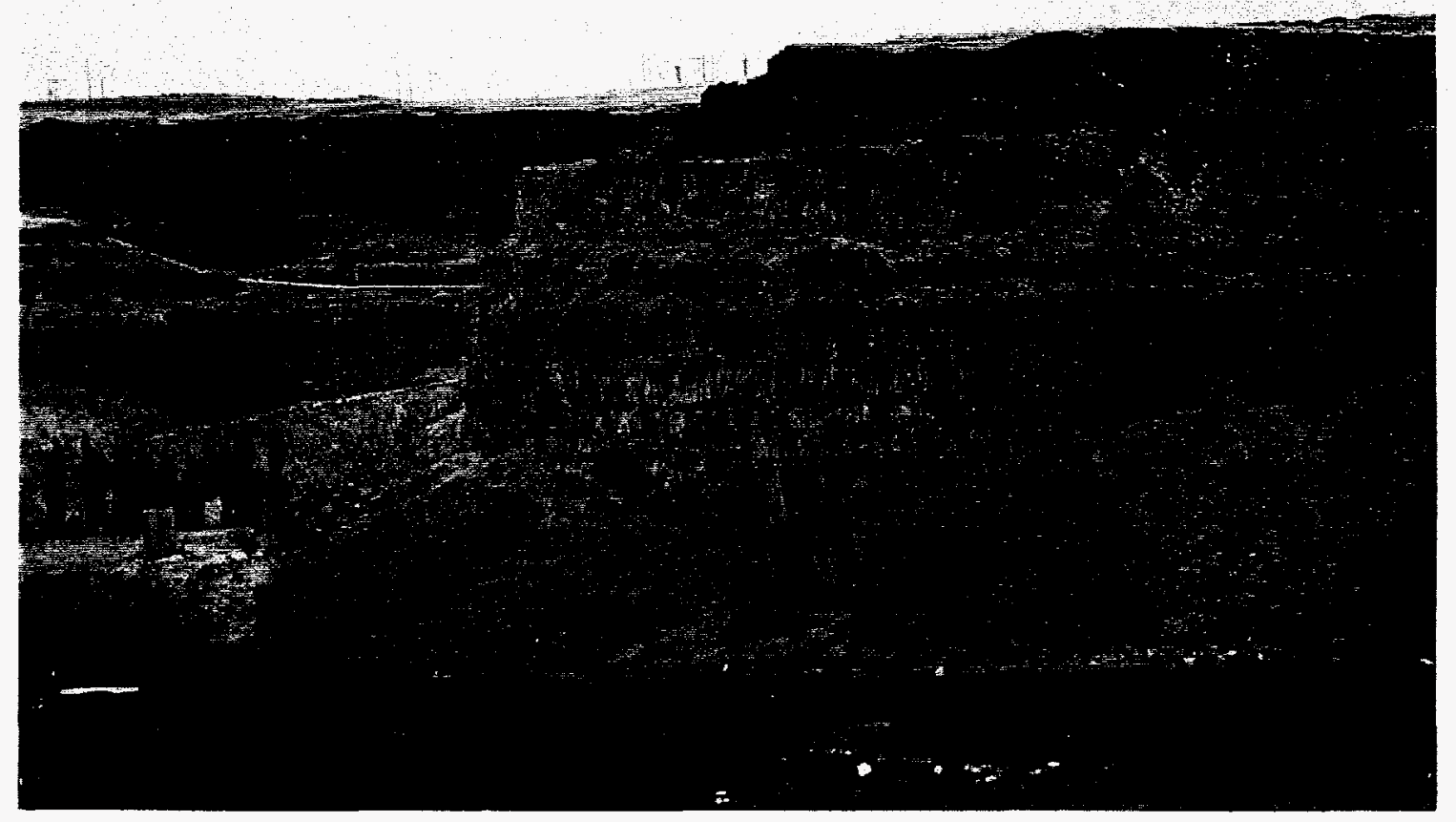


Plate 3.

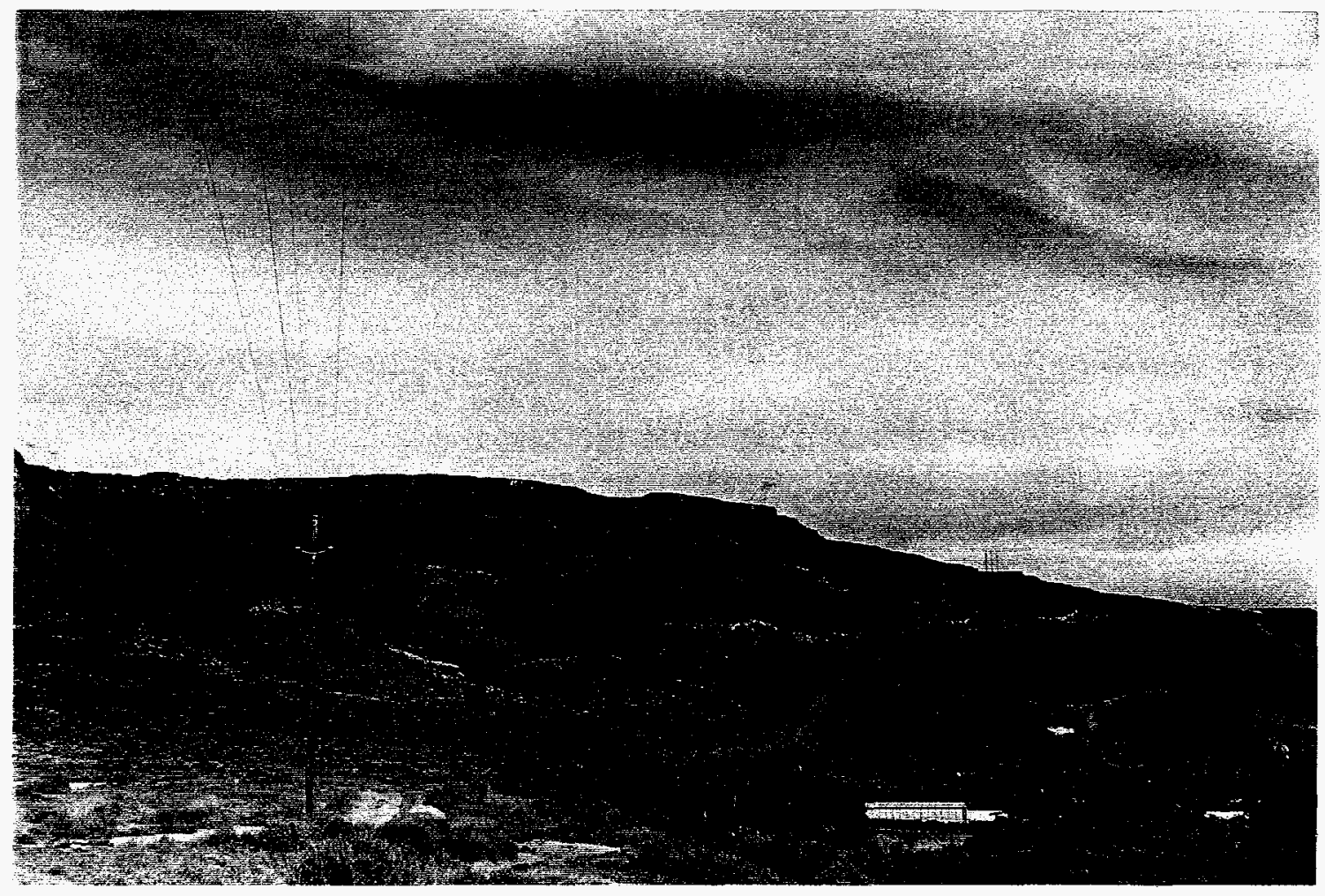

Plate 4.

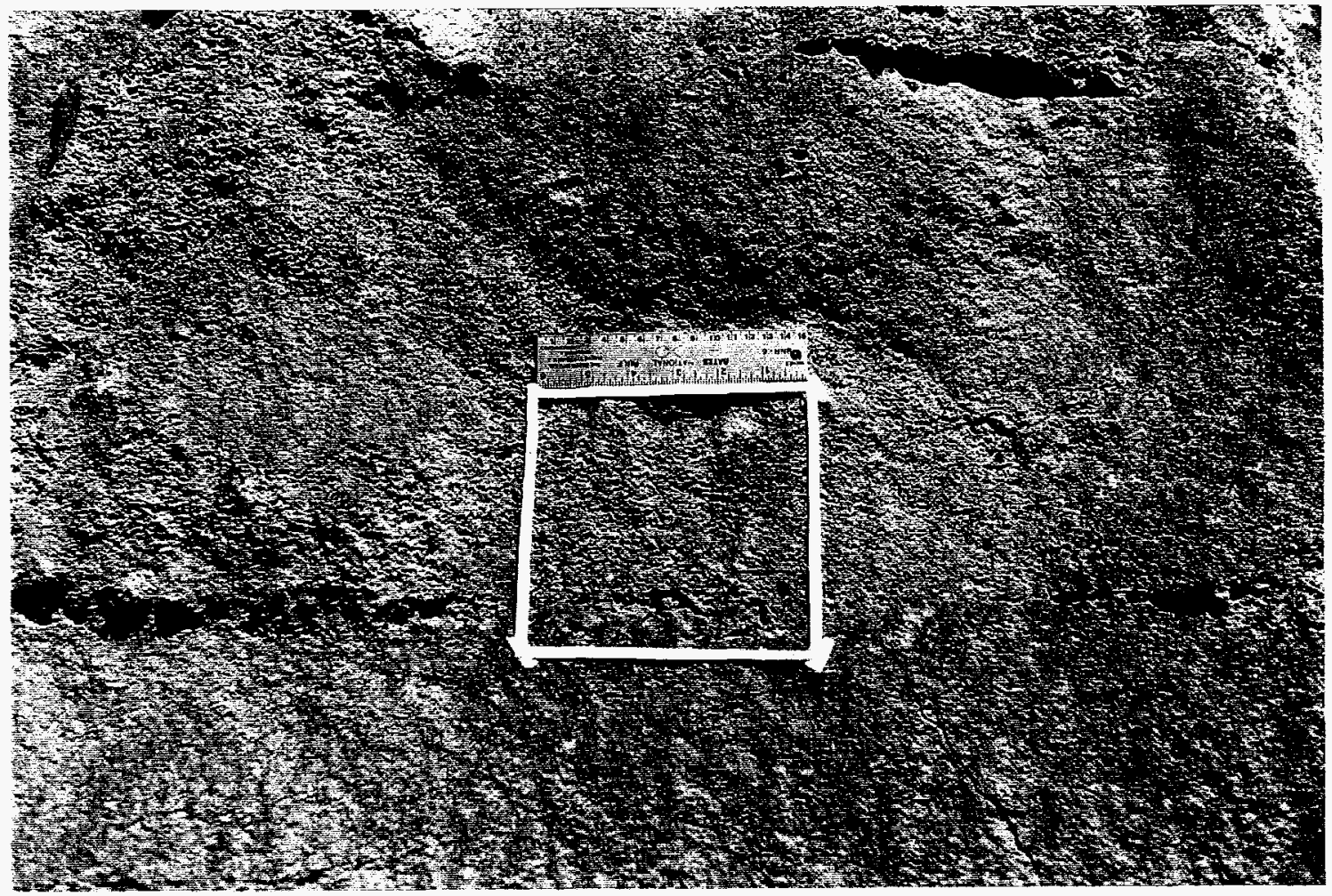




\section{CHAPTER 3. OUTCROP FEATURES}

\section{Size And Shape Of Basalt Lava Flows}

In general many factors govern the length and shape of basalt lava flows. They entail (1) viscosity of the lava; (2) the total volume of lava extruded; (3) the rate of effusion; (4) the slope of the underlying surface; and (5) the form of the topography (i.e. whether the lava flow is confined to a narrow valley or is able to spread widely outward from the vent). Formerly viscosity was considered to be the most important factor, but G. P. L. Walker (1973) in a study of Mount Etna and other volcanoes concluded that the rate of effusion of lava is most important and that viscosity has an indirect control in that it controls the thickness of a lava extrusion (Figure 13).

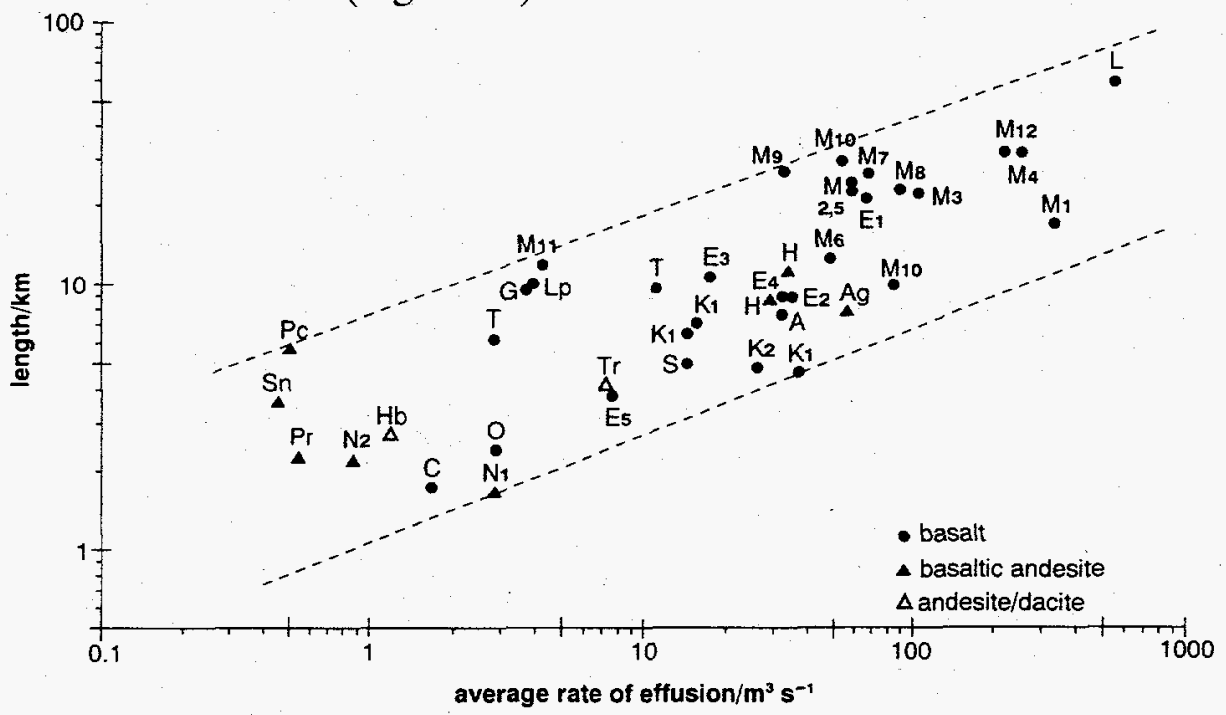

Figure 13. Plot of lava flow length against average effusion rate for lava eruptions (mostly basaltic) on various volcanoes. Basaltic lavas (solid circle): A, Askja (Iceland); C, Cerro Negra; E, Etna; G, Gituro (Congo); K, Kilauea; L, Laki (Iceland); Lp, La Palma; M, Mauna Loa; O, Oosima; T, Tenerife; S, Sakurajima. Basaltic andesite lavas (solid triangles): Ag, Mt Agung (Bali); H, Hekla; N, Ngauruhoe; Pc, Pacaya (Guatemala); Pr, Paricutin; Sn, Santiaguita (Guatemala). Andesite/dacite lavas, (open triangles): Hb, HibokHibok; Tr, Trident (After G. P. L. Walker, 1973). 


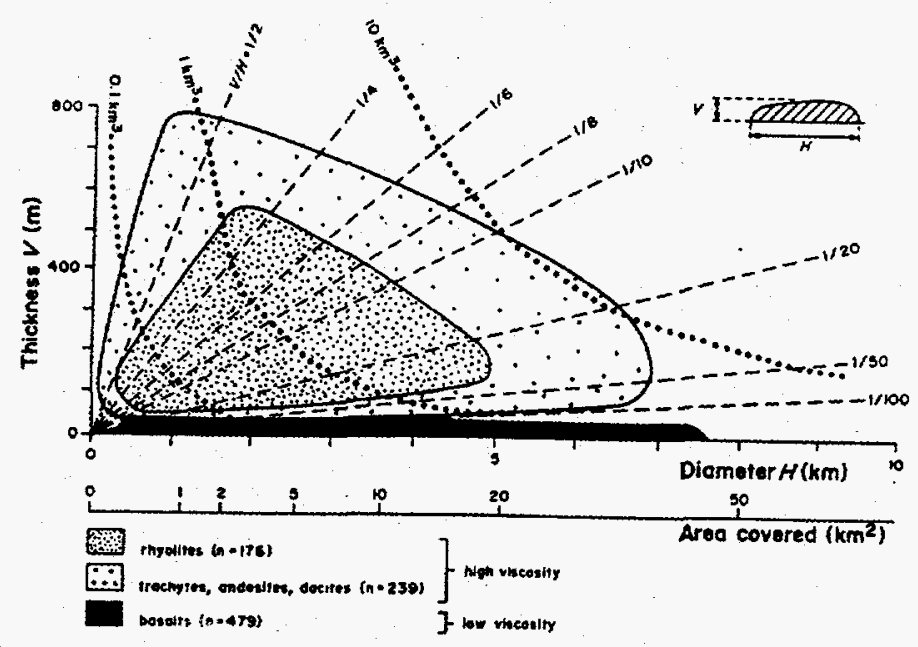

Figure 14. Dimensions of lavas of different compositions. The two scales along the $\mathrm{z}$-axis give the area covered by the extrusion and the diameter of a circle having this equivalent area. The broken lines give the aspect ratio $\mathrm{V} / \mathrm{H}$. The dotted lines give the volumes of circular disc-like bodies of the dimensions shown as a rough guide to the volumes of the lava extrusions (After G. P. L. Walker 1973).

Lavas of various compositions can have a wide variation in dimensions (Figure 14). The longest known Quaternary basalt lava flow is $130 \mathrm{~km}$ (81 mi) long (Walker, 1973), while lava flows of shield volcanoes in the Eastern Snake River Plain extend as much as $30 \mathrm{~km}$ (19 mi) from their vents (Kuntz, et al., 1992). Basalt lava flows of the order of $200 \mathrm{~km}$ (124 mi) long are known in the Columbia River plateau (Walker, 1973). A typical thickness for

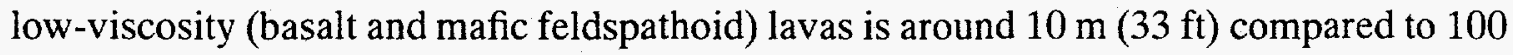
m (328 ft) for high-viscosity lavas (trachyte andesite/dacite rhyolite) (Walker, 1973). Lowviscosity lavas have aspect ratios (aspect ratios is the ratio of a flow thickness over its equivalent diameter (Figure 14)) typically greater than 50 compared to high-viscosity lavas flows, which are typically less than 50 , but commonly less than 8 (Walker, 1973).

In a study of the Box Canyon outcrops Knutson and others (1990) measured 372 flows to estimate their geometry. The flows they studied have a median flow thickness of about $3.7 \mathrm{~m}(12 \mathrm{ft})$, a median apparent outcrop length about $19.8 \mathrm{~m}(65 \mathrm{ft})$. They calculate a ratio 
of apparent length divided by maximum observed thickness. This ratio ranges from 6 to 35. At the INEL site itself the average thickness of basalt lava flows is generally about 3 m (10 ft) according to Nace and others (1956). Out of the 10 basalt flows measured in this study of Box Canyon a range of flow thickness and apparent lengths fell within reported values of Knutson and others' (1990) without any discrepancies (Table 1). At the Twin Falls outcrop another 10 basalt flows were measured with a median flow thickness of about

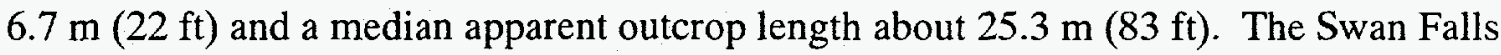
basalt outcrop yielded a measured median flow thickness of about $3.0 \mathrm{~m}(10 \mathrm{ft})$ with a median apparent length about $18.3 \mathrm{~m}(60 \mathrm{ft})$ for 10 distinct basalt lava flows. Thus the median values of apparent outcrop length and thickness are about the same for all three localities being about median $3 \mathrm{~m}$ thickness and $20 \mathrm{~m}$ median apparent length. An apparent length is designated because the outcrop displays the basalt lava flows in only two dimensions where in actuality the horizontal extent of the flow is generally larger. The general shape exhibited by the trace of basalt lava flow contacts in the Box Canyon cliffs is lensoidal in contrast to the more tabular shapes observed in the Twin Falls outcrop. The Swan Falls outcrop displayed a mix of both lensoidal and tabular shapes.

\section{Interface Between Basalt Lava Flows}

It is very common to have a weathered surface or sedimentary interbed between lava flows. These interbeds can be made up of various materials such as sand, loess, ash, or lake deposits or soil developed upon the underlying flow. Out of the ten basalt lava flows studied at the Box Canyon outcrop and Swan Falls outcrop nine are basalt-basalt contacts and one sediment-basalt contact. Out of the ten basalt lava flows studied at the Twin Falls outcrop eight are basalt-basalt contacts and two are sediment-basalt contacts. 


\begin{tabular}{|c|c|c|c|c|c|c|}
\hline $\begin{array}{c}\text { Basalt } \\
\text { Lava Flows }\end{array}$ & Flow A & $\begin{array}{c}\underset{(f t)}{\operatorname{arent}} \\
\text { t }\end{array}$ & ckness & Flow & $\begin{array}{l}\text { arent } \\
\text { (ft) }\end{array}$ & ngths \\
\hline 1 & B 5 & T 22 & S 3 & B 42 & T 74 & S 39 \\
\hline 2 & B 16 & T 33 & S 10 & B 64 & T 96 & S 78 \\
\hline 3 & B 4 & T 7 & S 7 & B. 37 & $\mathbf{T} 63$ & S 56 \\
\hline 4 & B 8 & T 10 & S 3 & B 56 & T 85 & S 43 \\
\hline 5 & B 19 & T 34 & S 9 & B 77 & T 98 & S 49 \\
\hline 6 & B 15 & T 22 & $\mathbf{S} 13$ & B 72 & T 81 & S 80 \\
\hline 7 & B 4 & T 21 & S 18 & B 42 & T 86 & S 59 \\
\hline 8 & B 7 & T 23 & $\mathbf{S} 10$ & B 79 & T 79 & S 76 \\
\hline 9 & B 19 & T 14 & S 15 & B 65 & T 71 & S 60 \\
\hline 10 & B 18 & T 23 & S 20 & B 69 & T 86 & S 87 \\
\hline Median & B 12 & $\mathbf{T} 22$ & S 10 & B 65 & T 83 & S 60 \\
\hline
\end{tabular}

Table 1. Table is showing data collected at the three outcrops. Ten basalt lava flows were measured at each outcrop and the apparent flow thickness and lengths measured (in feet). These values are reported with a letter first with $B=$ Box Canyon, $T=$ Twin Falls outcrop, and $S=S w a n$ Falls outcrop followed by their value.

Sedimentary interbeds are easily identified in the basalt outcrops. Sedimentary material fills any irregularities on the surface of a lava flow, sediment filled fractures and vesicles on the surface of the flow indicate the upper surface of the basalt flow had a long enough surface-exposure time for the deposition of the sedimentary material. In some cases the sedimentary material looks baked or is reddish in color or both (Plate 5). In all of the outcrops the contact between the interbeds and the basalts is very planar in relief and lacks undulations of more than a meter of relief (Plate 6). Rarely a thin pocket (no more than $0.3 \mathrm{~m}$ ( $1 \mathrm{ft}$ ) in thickness) of basalt rubble or breccia (a couple of $\mathrm{cm}$ in diameter) can 
be found in-between the basalt and the interbed (Plate 5).

Contacts between one basalt lava flow and another flow, seen in all of the outcrops studied, are close fitting and lack any appreciable amount (at the most $0.3 \mathrm{~m}(1 \mathrm{ft})$ thickness) of rubble or breccia (Plate 7). Upper surfaces of the basalt lava flows undulate a few $\mathrm{cm}$ in height and commonly display a reddish color (Plate 8).

In some instances a void opening (no more than a meter in height) occurs in-between the basalt flows that can be traced for 1 to 2 meters along the top of a lava flow. These openings pinch out or decrease in their overall height to a few centimeters along the top of the flows and typically are not interconnected with others found in the same lava flow. Rarely does the open space maintain its regular height of around a meter for more than $2 \mathrm{~m}$ ( $5 \mathrm{ft}$ ) or less along the top of the basalt lava flow (Plate 9) (Figure 15). Overall occurrences of these features are somewhat more common in thin flows than in thick lava flows. The openings between the lava flows is assumed to continue into the outcrop wall, but their overall dimensions inside the outcrop can only be estimated.

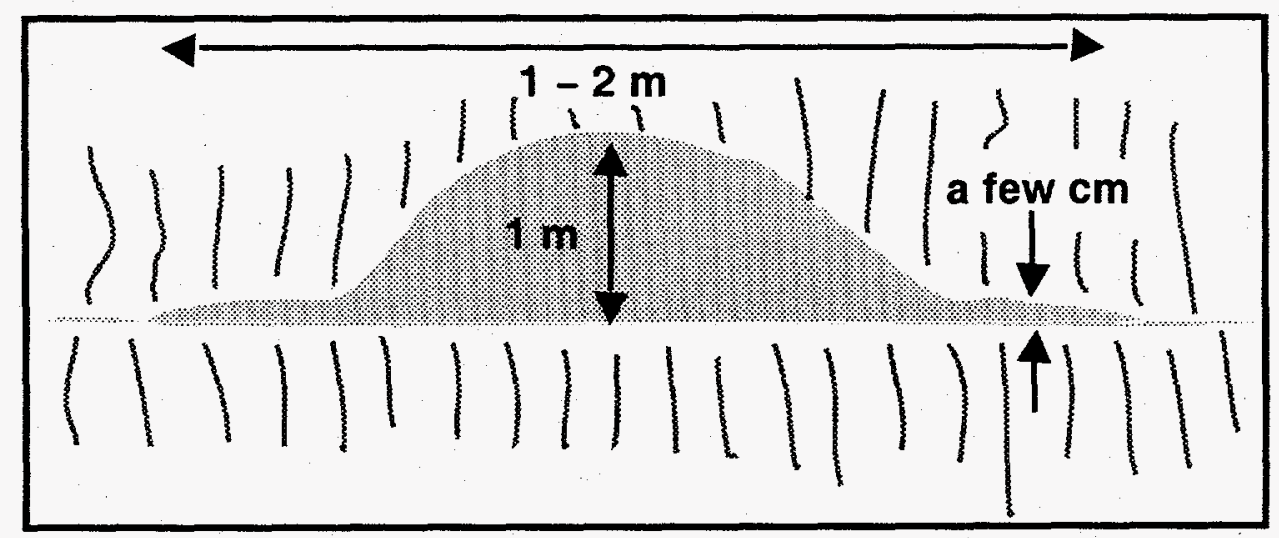

Figure 15. A sketch showing the detail of the small openings found at the contacts between two basalt lava flows. 


\section{Internal Features}

\section{$\underline{\text { Vesicles }}$}

Vesicle distribution was observed for the different basalt lava flows in each of the outcrop areas; in the top part of a basalt lava flow (from $15 \mathrm{~cm}(6 \mathrm{in})$ to 6 meters $(20 \mathrm{ft})$ in thickness) the vesicles have a certain size and shape hierarchy.

\section{Vesicle Zones Within Flow}

Based on the observations of the basalt lava flows in the three outcrops a model for SRP basalt lava flows was generated. The following descriptions use terminology of this model illustrated in Figure 23 (page 68).

\section{Upper Part of Flow (Upper Vesicular Zone)}

\section{Upper Vesicular Subzone}

The very top of the flow (the first couple centimeters to just over a meter) is basalt with very small vesicles 2 to $4 \mathrm{~mm}$ in diameter, nearly spherically in shape (Plate 10). The overall vesicularity is very large (greater than $50 \%$ by volume), and typically these vesicles are filled with fine grained material. How this material filled these vesicles is not known, but would indicate some sort of pathway from the surface of the lava flow for movement of fluids: either percolating water or air-suspended dust. These vesicles are very regular in their shape and have connecting pathways to other vesicles present only when two vesicles walls intersect each other or the rock is fractured generating a conduit to the individual vesicles.

\section{Transitional Subzone}

A layer about $15 \mathrm{~cm}(6 \mathrm{in})$ to $0.6 \mathrm{~m}(2 \mathrm{ft})$ below the very top part of the flow with large vesicularity and small vesicles, is discernible by its change in vesicularity and vesicle size. 
This layer is predominately made up of vesicles around 0.9 to $2 \mathrm{~cm}(0.4$ to 0.8 in) for the major axis and 0.7 to $1.7 \mathrm{~cm}(0.3$ to $0.7 \mathrm{in})$ in the minor axis and smaller vesicles slightly larger than the ones found at the very top of the flow. Overall shape of these vesicles is more elliptical than the perfectly spherical vesicles found at the top of the flow (Plate 11). The overall vesicularity is less than at the top of the flow. Unlike the top of the flow these vesicles are not usually interconnected and are never filled with fine material.

\section{Lower Vesicular Subzone}

Below the transitional subzone is another layer about $7.6 \mathrm{~cm}(3$ in) to $1.2 \mathrm{~m}(4 \mathrm{ft})$ in thickness that is identified by its vesicularity and vesicle shape. A size-and-abundance gradation of these vesicles can be found within this layer. The more numerous and smaller vesicles are found at the top of this layer, and they increase in size while decreasing in number towards the bottom of this layer. The overall vesicularity is less than the preceding two layers (Plate 12). These vesicles range 2 to $4 \mathrm{~cm}$ ( 0.8 to $1.6 \mathrm{in})$ in the major axis with 1 to $3 \mathrm{~cm}(0.4$ to $1.2 \mathrm{in})$ for the minor axis and are even more elliptical than in the previous vesicles (Plate 13 and 14). Although some of these vesicles can have major axis of greater than $10 \mathrm{~cm}(4 \mathrm{in})$. The vesicle outlines are irregular in nature and are sometimes lined with fine crystalline material. Interconnections are more common in these vesicles then the preceding ones with the larger vesicles intersecting smaller vesicles and fractures creating pathways (Plate 15).

\section{Bubble Train Subzone}

Below the lower vesicular subzone, typically $4 \mathrm{~m}$ from the surface but absent in some lava flows is the bubble train subzone. It can range up to $1.8 \mathrm{~m}(2 \mathrm{ft})$ in thickness and can be identified by occurrence of single larger vesicles all in a line (bubble train) which, in three dimensions, are a plane of larger vesicles. The vesicles are typically $2 \mathrm{~mm}(0.08 \mathrm{in})$ or less in diameter and are spherically shaped. These vesicles can be found on the outcrop 
wall as individual planar sheets $(0.1$ to $2.5 \mathrm{~cm}$ (0.04 to $1 \mathrm{in})$ thick) made up of single vesicles lined up one after the other in a line (Plate 16). Within these sheets are numerous microscopic intracrystalline void spaces in addition to the vesicle voids (Plate 17). Individual sheets have a spacing between them of about $3 \mathrm{~cm}(1.2 \mathrm{in})$ to $3 \mathrm{~m}(10 \mathrm{ft})$ of unvesiculated basalt rock with no stratigraphic or structural discontinuity. These sheets are parallel to the basalt flow top and usually can be traced along the outcrop for the entire length of the observable portion of the basalt lava flow in the outcrop or several tens of meters. Sheets are generally parallel to each other. It is not known how far these sheets extend into the outcrop since they are displayed on the outcrop wall as a linear feature on a two dimensional planar surface, but lateral extent clearly exceeds several tens of meters.

\section{Central Part of Flow (Central Zone)}

Below the upper part of the basalt flow into the center of the flow vesicles are rare to nonexistent (Plate 18). Lack of vesicles characterizes the center part of the basalt flow which can attain a thickness of $14 \mathrm{~m}(46 \mathrm{ft})$ in the outcrops studied. The center part of the basalt flow has occasional occurrences of vesicles that are thin sheet-like layers that range from 2 to $31 \mathrm{~cm}$ ( 0.8 to 12 in) in thickness made up entirely of small ( $2 \mathrm{~mm}(0.08 \mathrm{in})$ diameter spherical) vesicles. Like the previous sheet vesicle layers found in the upper part of the basalt lava flow these sheets are parallel to the top of the basalt flows and can be traced for the entire observable basalt flow found on the outcrop (Plate 19). The main differences between the two types of vesicle sheets is the larger thickness of the sheets in the central part of the flow as compared to those in the upper flow top. The sheet in the central part of the flow are also made up of thin vesicular zones rather than vesicles in a row, but the whole sheet is filled with vesicles of relatively the same small size (Plate 20).

\section{Amoeboid Plume Vesicle Zone in Central Part of Flow}

Also found in the central part of the basalt flow are irregular shaped patches of 
abundant small vesicles on the outcrop. Some are irregular in outline with an amoeboid shape to plume like with long linear vesicular arms coming out of the central vesicular zone for the amoeboid shaped ones (Plate 21 and Plate 22). The longest of these being approximately $1.8 \mathrm{~m}(6 \mathrm{ft})$.

\section{Pipe-Like Vesicles in the Lower Central Part of Flow}

Pipe vesicles occur just at the lowest portion of the un-vesiculated central part of a basalt flow; typically they range in size from $6 \mathrm{~mm}$ to $9 \mathrm{~cm}(0.24$ to 4 in) wide and are in the shape of vertical hollow tubes with bending of their bases. These tubes exhibit a rounded top and a tapered bottom (Plate 23).

\section{Bottom of the Flow (Lower Vesicular Zone)}

At the bottom of a basalt lava flow the vesicular zone is typically $14 \mathrm{~cm} \mathrm{(6} \mathrm{in)} \mathrm{to} 1.7 \mathrm{~m}$ (6.6 ft) thick. Increasing vesicularity occurs towards the base of the lava flow compared to it increasing towards the top. Vesicles also have an opposite vertical gradation of size when compared to the top part of the basalt flow (Plate 24). The vesicle size decreases downward to the bottom of the flow. In the upper part of a basalt lava flow vesicles decrease upward toward the top and this gradation of vesicle size is a very useful field observation for identifying upper and lower boundaries of flows. The overall size of the vesicles which are more elliptical then those found in the top of the basalt flow grade from 1 to $1.5 \mathrm{~cm}(0.4$ 0.6 in) major and 1 to $1.7 \mathrm{~cm}(0.4-0.7$ in) minor axis downward to 0.2 to $0.5 \mathrm{~cm}(0.08$ 0.2 in) major and 0.2 to $0.5 \mathrm{~cm}(0.08-0.2 \mathrm{in})$ minor axis at the bottom, over a distance of

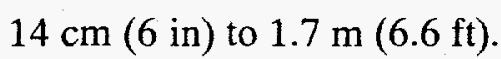

\section{Diktytaxitic Texture}

The term diktytaxitic was applied by Dickinson and Vigrass (1965) to a distinctive texture, found in some basalts, that is characterized by the presence of numerous angular 
voids interstitial to the crystals. These voids are due to a volume decrease that accompanies crystallization of the liquid or by the late-stage release of gasses by crystallization (Walker, 1989). Diktytaxitic textures commonly seen in the outcrops occur below and above the highly vesiculated portions of the basalt flow tops and bottoms. Sometimes it can be seen making up the entire central part of a basalt flow or more commonly found in bands $(3 \mathrm{ft}$ or less thick) of vesiculation in that part of a basalt flow. This texture is also found in thinner bands ( $3 \mathrm{~cm}$ thick) associated with vesicle rich laminate forming a crude line across the basalt outcrop. This will be discussed in greater detail later.

\section{$\underline{\text { Joints and Fractures }}$}

Joints are commonly defined as the cracks which divide rocks into separate volumes and along whose surfaces no significant movement has occurred (Faust, 1978). If significant movement has occurred they are called fractures. Fractures and joints are found throughout the basalt lava flows in every outcrop studied. Several different kinds of fractures and jointing are identified based on their general shape, size, and location in the basalt lava flows on the outcrops. Joints seen on the outcrop that have a directional parallelism are called joint sets. Combinations of genetically related joint sets which enclose space and form a more symmetrical pattern are defined here as a joint system.

\section{Joints in the Upper Vesicular Flow Top}

Joints of the upper vesicular flow top have a rectangular structure with joints that are both parallel and perpendicular to the flow top. Upper joints have a slab aspect that grades further into the basalt flow into a pseudocolumnar to columnar aspect (Figure 16). 


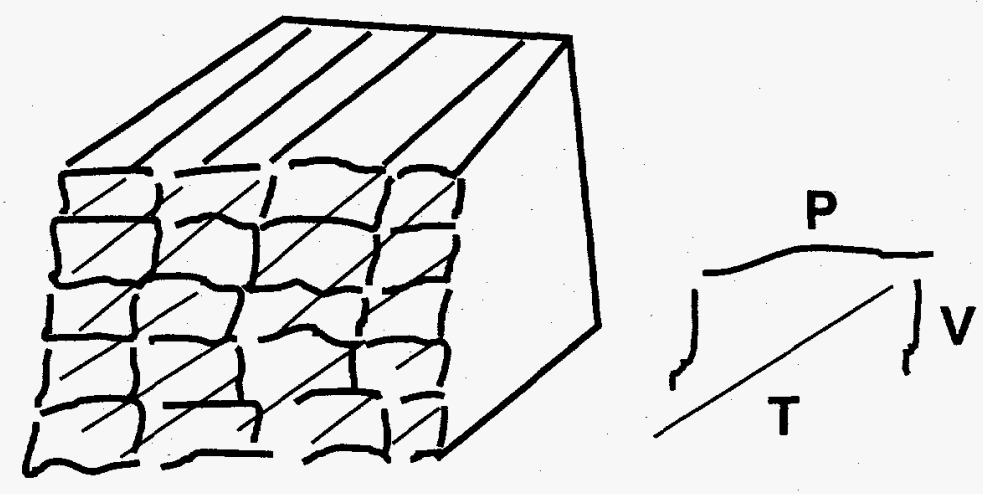

Figure 16. Hypothetical sketch showing the three types of joints seen in the upper vesicular flow top. $\mathrm{P}=$ parallel joints, $\mathrm{V}=$ vertical joints or perpendicular to "P" joints, and $T=$ transverse jointing.

The rectangular joint system commonly has a joint spacing of $0.3 \mathrm{~m}(1 \mathrm{ft})$. In this rectangular joint system a set of transverse joints about 45 degrees from the flow top is commonly found. Joints that are parallel to the flow top vary from a few centimeters to 1 $\mathrm{m}(3 \mathrm{ft})$ in length with apertures from 1 to $5 \mathrm{~mm}(0.04$ to $0.2 \mathrm{in})$. Vertical joints which are perpendicular to the parallel joints range from 2 to $13 \mathrm{~cm}(0.8$ to $5 \mathrm{in})$ in length with an aperture range from $1 \mathrm{~mm}(0.04 \mathrm{in})$ to $1 \mathrm{~cm}(0.4 \mathrm{in})$. The transverse joints range in apparent trace length from 1 to $3 \mathrm{~m}$ ( 3 to $10 \mathrm{ft}$ ) and have the largest apertures ranging from $5 \mathrm{~mm}$ $(0.2$ in) to $7 \mathrm{~cm}$ ( $3 \mathrm{in})$. Spacing between the transverse joints range from a few centimeters to $3 \mathrm{~m}$ or more (10 ft or more). This jointing make up the slab aspect which characterize the vesiculated upper part of the basalt flows at all of the three outcrop sites.

\section{Shelly Basalt at Flow Top}

In the case of the Swan Falls outcrop two other features occur, one of which is unique to this outcrop. This feature is in the form of shells or slabby basalt material piled on top of each other making up the top of about 3 flows at Swan Falls. These shells are arc-shaped slabs of pieces of vesicular basalt rock (Plate 25). Further observations revealed that their 
shape was only an arc in the two dimensional aspect of the outcrop wall and that upon observation of surface basalt flows revealed them to be curved shells in cross-section. Each arc had an apparent length that ranged from 20 to $31 \mathrm{~cm}$ ( 8 to $12 \mathrm{in}$ ) and a thickness from 3 to $8 \mathrm{~cm}$ ( 1 to 3 in). The underside of these features had drip and cast features while the tops have a frothy appearance (Plate 26).

\section{Spheroidal Joints at the Swan Falls Outcrop}

The one unique feature found in the Swan Falls outcrop and in no other outcrop are zones of spheroidal joints in the outcrop wall similar to spheroidal weathering in granite (Plate 27). Spherical core stone diameters are from $3 \mathrm{~cm}(1 \mathrm{in})$ to $1 \mathrm{~m}(3 \mathrm{ft})$ and are spaced somewhat randomly in the basalt outcrop wall. Spheroidal caps or decomposed shell-like material is found between these spheres. When the spheres are hit with a rock hammer concentric rock pieces spall off resulting in a solid rock core (Plate 28). These features make up the large portion of the $6 \mathrm{~m}+(20 \mathrm{ft}+)$ high outcrop wall. This form of basalt cannot be directly attributed to the upper vesicular flow top and may make up the entire basalt lava flow. The top and bottom of this tabular basalt unit are not exposed.

\section{Columnar Joint Zone}

Columnar jointing is not observed in every flow. Where it occurs it is usually beneath the vesicular flow top. Based on observations from all three outcrops columns are 5 to 6 sided and can be described as polygonal or crudely hexagonal (Plate 29). Vertical joints from 0.6 to $2 \mathrm{~m}$ ( 2 to $5 \mathrm{ft}$ ) long (apertures from a couple of $\mathrm{mm}$ to $5 \mathrm{~cm}(2 \mathrm{in})$ ) make up the sides of the columns while horizontal joints 0.3 to $0.6 \mathrm{~m}$ ( 1 to $2 \mathrm{ft}$ ) (apertures from $1 \mathrm{~cm}$ to $3 \mathrm{~cm}(0.4$ to $1.2 \mathrm{in}))$ form the basal and tops of the columns. The columns themselves range in diameter from $15 \mathrm{~cm}(6 \mathrm{in})$ to $30 \mathrm{~cm}(1 \mathrm{ft})$. Their height ranges from $2.4 \mathrm{~m}(4 \mathrm{ft})$ to $6 \mathrm{~m}$ $(20 \mathrm{ft})$. Some of these columns are not perfectly vertical and are bent all in one direction. This bending is only up to 20 degrees from the vertical observed in the three outcrops. In 
rare cases some of the tops of the columns displayed a spheroidal jointing pattern; this is in the form where the edges of the columns are destroyed leaving a sequence of concentric shells in stages of disintegration. Breaking these shells with a rock hammer reveals a hard central core of basalt rock. These shells make up a sort of cannon ball appearance that range in diameter from 5 to $15 \mathrm{~cm}$ (2 to 6 in). These are most pronounced at the Swan Falls outcrop. The basalt rock in which the spheroids are found has a yellowish color and it is commonly accompanied by dark black (alteration?) lines that cut across grains on the spheroidal area. Along with these column defining joints irregular breaks cut across the columns; some are only as long as the diameter of the columns while most can be traced for several meters across the columns (Plate 30).

\section{Joints in the Central Part of the Basalt Lava Flow}

Making up the central part of the basalt flow are joints with curved surfaces, that have varying curvatures, that give the rock masses a wedge shaped aspect. When viewing the joints they have the appearance of a helix (Plate 31). These curvilinear joints range from 1.5 to $3 \mathrm{~m}$ ( 5 to $10 \mathrm{ft})$ in height with apertures ranging from $1 \mathrm{~mm}(0.04 \mathrm{in})$ to $2 \mathrm{~cm}(0.8 \mathrm{in})$.

Besides the curvilinear joints, other joints can be seen that extend from the top to the bottom of the central part of the basalt flow which are normal to the surface of the basalt flow. These vertical joints sets give the outcrop an appearance of having a pseudocolumnar aspect to it. They range from 2 to $10 \mathrm{~m}(7$ to $33 \mathrm{ft})$ in length and have apertures from 0.5 to $3 \mathrm{~cm}(0.2$ to $1.2 \mathrm{in})$. Along with these joints are platy-prismatic joints (usually following the length of the vertical joints) which are really fracture cleavages superimposed on the curvilinear zone.

The vesiculated base of the basalt flows viewed at the three outcrops has a base that conforms with the top of an older flow giving it a slightly undulating surface or conforms with the top of a sedimentary layer.

Sheeting joints are a set of parallel, generally closely spaced joints which divide the 
rock into layers called sheets (Faust, 1978). In the outcrops studied the sheeting seemed to develop with the topography, and where it was horizontal the sheeting was horizontal. Sheeting cuts across the curvilinear joints giving the outcrop an appearance of having a step like nature to it. These joints can have large lengths in several meters and are highly variable in apertures from $5 \mathrm{~mm}(0.2 \mathrm{in})$ to $10 \mathrm{~cm}(4 \mathrm{in})$ and can be found throughout the different parts of the basalt lava flow.

Feather-fractures or plumose fractures are common on the joint surfaces in the central part of the basalt flow rather than the vesiculated portions. These are granulations on the surface of a joint-plane that trace out a delicate feathery or barb-like plumose structure; they have an axis with lines diverging from it in a feather-like appearance.

\section{Concluding Statement: Observations of Jointing in Basalt Outcrops}

In summary for the observations of the joints and fractures found in all three outcrops it can be said that many different types of joints are present that can be delineated by their overall size, orientation, and place in the basalt lava flow. Some general observations for all three outcrop locations are: more abundant joints are found in parts of the basalt flow that has columns compared to the parts that displayed more horizontal to moderately dipping joints in the central part of the basalt lava flow. Spacings for smaller aperture joints are predominately closer when compared to larger aperture joints.

\section{Color}

Typical overall color as seen in fresh outcrop exposure for the basalt flows studied in all three outcrop areas are gray $(0 \mathrm{~N} 5 / 0)$. Within this overall color are variations. These variations only occurred at the top and bottoms of the basalt lava flows. At the top of the basalt lava flow the color of the basalt is commonly a more dark red (2.5 YR 3/6). This reddish coloring is most pronounced at the very top of the basalt flow and decreased in intensity towards the interior of the basalt lava flow. The reddish color can penetrate 
several meters, but usually around a meter. A factor that gives the top portion of the basalt flow an appearance of having a lighter color than the interior is the result of fractures and vesicles being filled with either sedimentary material or the basalt being covered with a whitish shellac-like material (Plate 32). In the interior the color on surfaces is consistently gray. In the bottom of the basalt flow the color tends to a dark gray (N 3). Jones (1969) in his study of Columbia River Basalts and Snake River Basalts similarly found that the color for both predominately were in the N4 medium dark gray to N3 dark gray range. 
Plate 5. Picture taken at the Twin Falls outcrop of a basalt lava flow (dark colored material) over a sedimentary layer (light colored material). Notice the dark reddish-orange color of the baked sediment near the contact. Also observe the very straight close fitting nature of the contact.

Plate 6. Picture taken at the Twin Falls outcrop of a basalt lava flow over a sedimentary layer. Notice the close fitting contact and slight undulations of the contact. Ruler for scale is $15 \mathrm{~cm}(6$ in) long.

Plate 7. Picture taken at the Twin Falls outcrop of two individual basalt lava flows showing their contact (in the middle of the photo at about the location of the ruler). Note the close fitting nature of the contact and the vesicular flow top. Ruler for scale is $15 \mathrm{~cm}$ (6 in).

Plate 8. Picture taken at the Swan Falls outcrop showing two individual basalt lava flows and their mutual contact (in the center of the photo about where the ruler is located). Notice the reddish color and close fit. Ruler for scale is $15 \mathrm{~cm}$ (6 in) long.

Plate 9. Picture taken at the Twin Falls outcrop showing the contact between two basalt lava flows at position of the $15 \mathrm{~cm}(6 \mathrm{inch})$ ruler. Note that if any openings are found at the contact they pinch out further along the outcrop. Base of upper flow shows two drill holes from highway construction.

Plate 10. Picture taken at the Box Canyon outcrop of the top of a basalt lava flow showing the very small vesicles and large vesicularity. Estimated volume percent of vesicles is about $50 \%$. Ruler for scale is $15 \mathrm{~cm}$ (6 in) long. 
Plate 11. Picture from the Swan Falls outcrop showing the vesicle pattern just below the upper part of the basalt lava flow (top of flow is the break in the rock the creates the overhang at the top of the photo). Notice the more elliptical nature to the vesicles.

Plate 12. Picture taken at the Swan Falls outcrop showing the downward decrease in vesicularity and increase in vesicle size from the top of the basalt lava flow (seen at the upper half of the photo). Notice the larger size and more elliptical nature of the vesicles. Ruler for scale is $15 \mathrm{~cm}$ (6 in) long.

Plate 13. Picture from Swan Falls outcrop showing a large vesicle typical of those toward the center of a basalt lava flow. Notice the very elliptical nature of the vesicle and the fewer small vesicles compared to the vesicles illustrated in plate 10. Ruler for scale is $15 \mathrm{~cm}(6 \mathrm{in})$ long.

Plate 14. Picture of core with large vesicles from borehole 123 . Notice the more elliptical shape of the larger vesicles. Ruler for scale is $15 \mathrm{~cm}(6 \mathrm{in})$ long.

Plate 15. Picture from borehole 123 showing a close-up of a core piece from the upper part of the basalt lava flow. Notice that many of the vesicle walls are open to others allowing interconnecting pathways between them.

Plate 16. Picture from borehole 81 showing a piece of core with vesicles forming a bubble train across the core. Ruler for scale is $15 \mathrm{~cm}$ (6 in) long.

Plate 17. Picture from borehole 123 showing a close-up of a core with a bubble train. Ruler for scale is $15 \mathrm{~cm}$ (6 in) long. 
Plate 18. Picture from the Twin Falls outcrop showing the central part of a basalt lava flow. Notice lack of vesicles and fractures. Ruler for scale is $15 \mathrm{~cm}(6 \mathrm{in})$ long. Vertical grooves seen in the picture are artificial drill holes for blasting.

Plate 19. Picture from the Swan Falls outcrop showing a vesicle sheet at the position of the ruler. This sheet and those below it can be traced laterally along the observable outcrop of the lava flow. Ruler for scale is $15 \mathrm{~cm}$ (6 in) long.

Plate 20. Picture from Swan Falls outcrop showing a detailed close-up (of the same sheet with the ruler in plate 19) of a vesicle sheet. Notice the many small vesicles making up the individual sheet. Ruler for scale is $15 \mathrm{~cm}$ (6 in) long.

Plate 21. Picture from Box Canyon outcrop showing a vesicle plume on the basalt in the lower half of a basalt lava flow. Notice its "plume" like shape and somewhat vertical orientation. The object in the photo is about $0.91 \mathrm{~m}(3 \mathrm{ft})$ long.

Plate 22. Picture from borehole 80 showing several pieces of core that when put together illustrate a vesicle plume (in the middle of the core). Ruler for scale is $15 \mathrm{~cm}$ (6 in) long.

Plate 23. Picture from borehole 123 showing a piece of core with many hollow elongated vesicles or pipe vesicles on it. Ruler for scale is $15 \mathrm{~cm}(6 \mathrm{in})$ long.

Plate 24. Picture taken from the Twin Falls outcrop showing vesiculation pattern (about $30 \%$ ) at the base of a lava flow. Ruler for scale is $15 \mathrm{~cm}(6 \mathrm{in})$ long. 
Plate 25. Picture taken from Swan Falls outcrop showing vesicle rich shelly-like nature of basalt making up the top part of a basalt lava flow.

Plate 26. Picture from Swan Falls outcrop showing the underside of a shell showing drip features (small flake-like material projecting from the shell). Ruler for scale $15 \mathrm{~cm}$ ( 6 in) long.

Plate 27. Picture from Swan Falls outcrop showing unusual round basalt spheroidal cores, and shells of decomposed rock.

Plate 28. Picture from Swan Falls outcrop showing a detailed close-up spheroidally altered basalt. Ruler for scale is $15 \mathrm{~cm}$ (6 in) long.

Plate 29. Picture showing hexagonal columns from the Box canyon outcrop.

Plate 30. Picture of a column showing breaks along its surface both vertically and horizontally. Rock hammer (bottom of photo) for scale (Picture from Box Canyon outcrop).

Plate 31. Picture at the Swan Falls outcrop showing a curvilinear joint running down the outcrop. Ruler for scale $15 \mathrm{~cm}$ (6 in) long.

Plate 32. Picture at the Swan Falls outcrop showing white fine grained material overlying a basalt lava flow giving it an appearance of having an overall lighter color. Ruler for scale $15 \mathrm{~cm}(6 \mathrm{in})$. 
Plate 5.

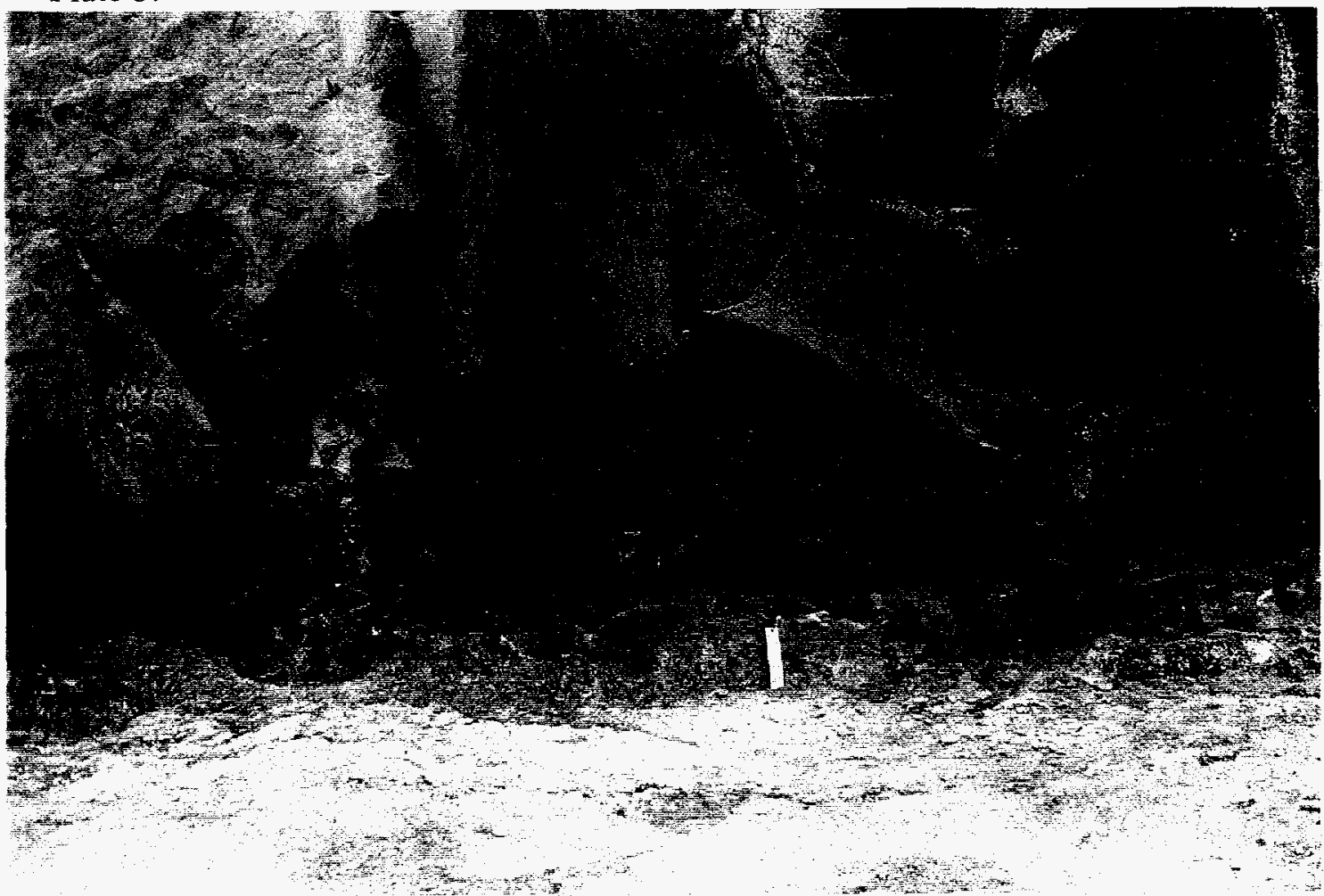

Plate 6.

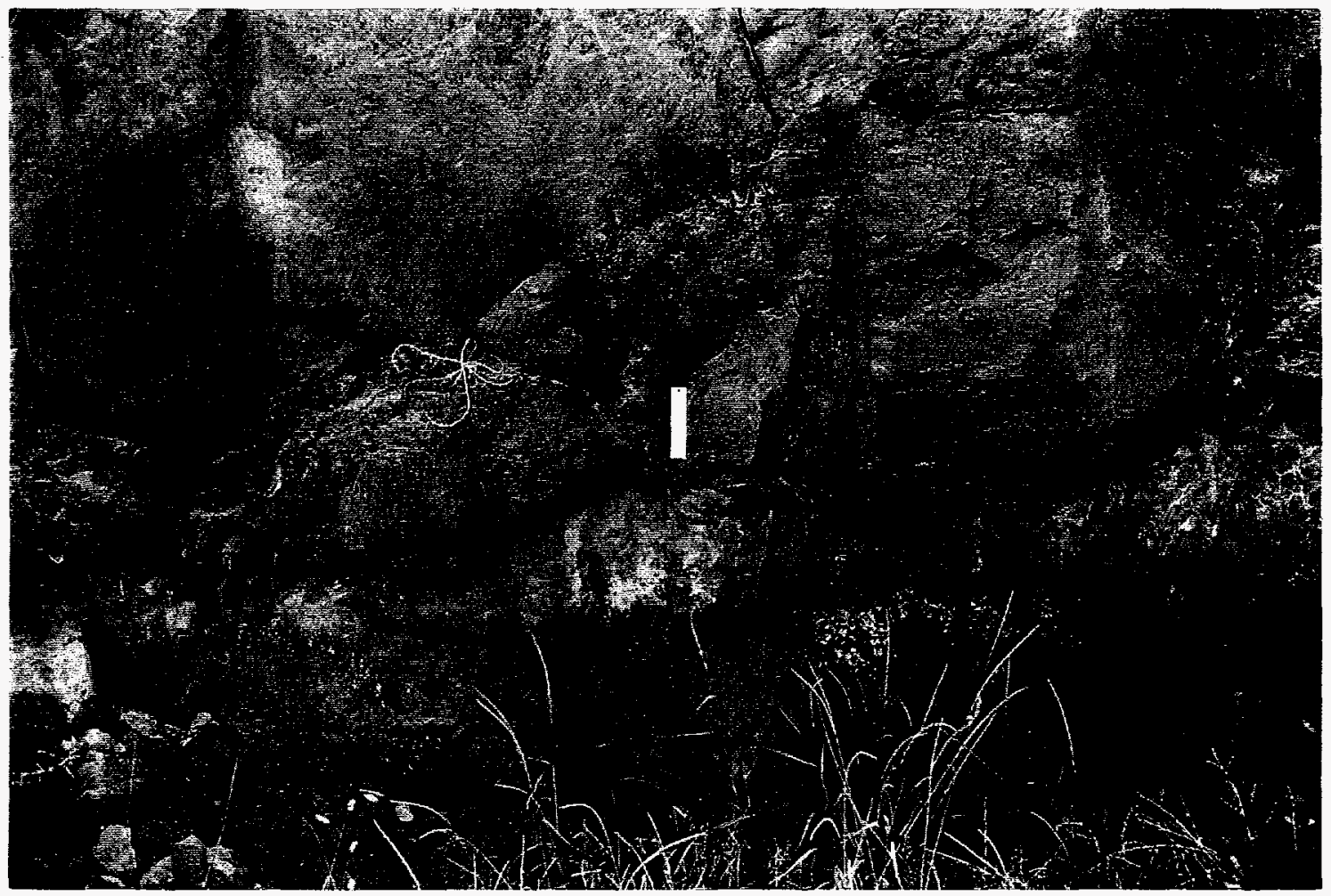


Plate 7.

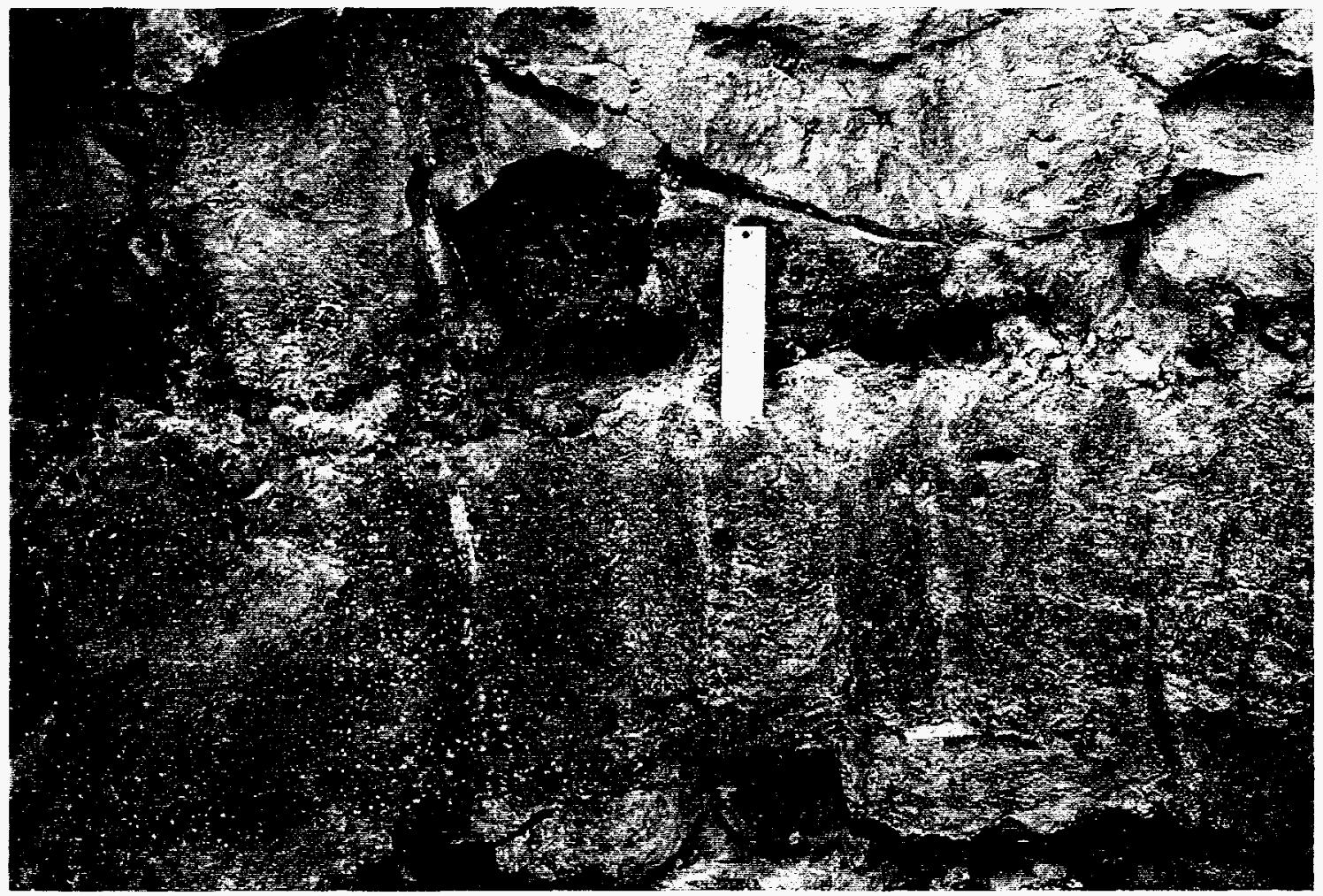

Plate 8.

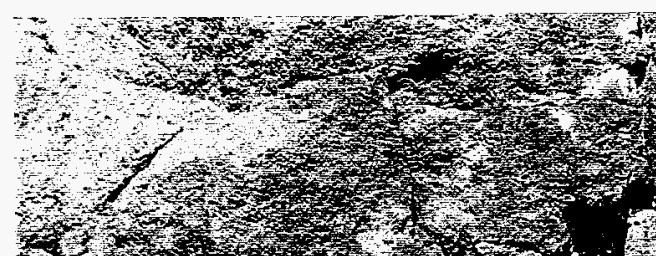

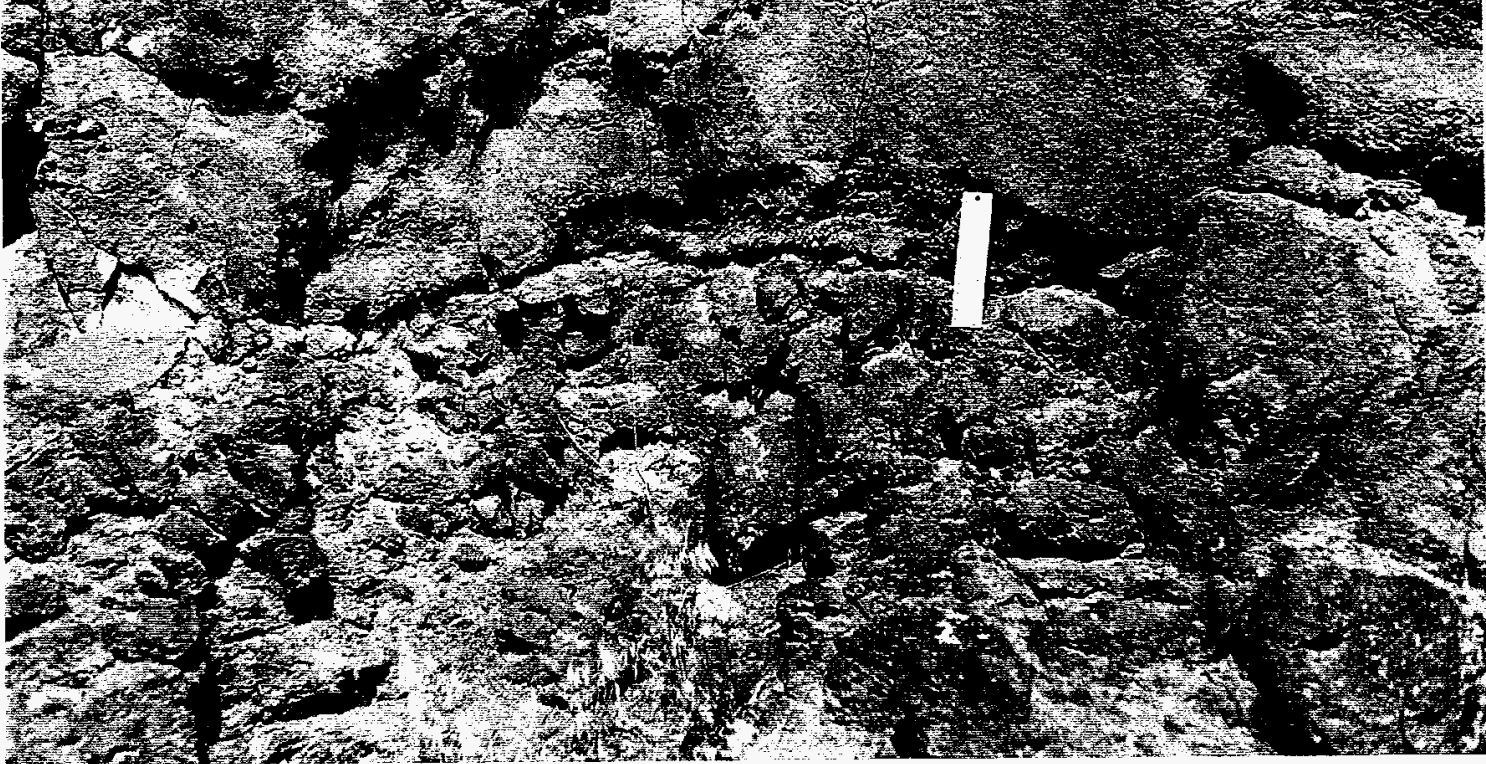

17.7.

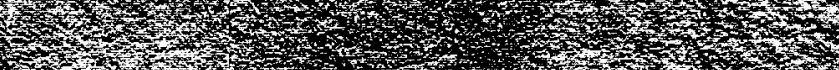

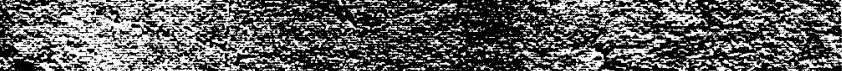

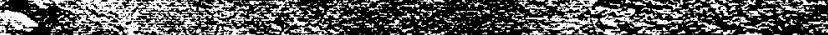


Plate 9.

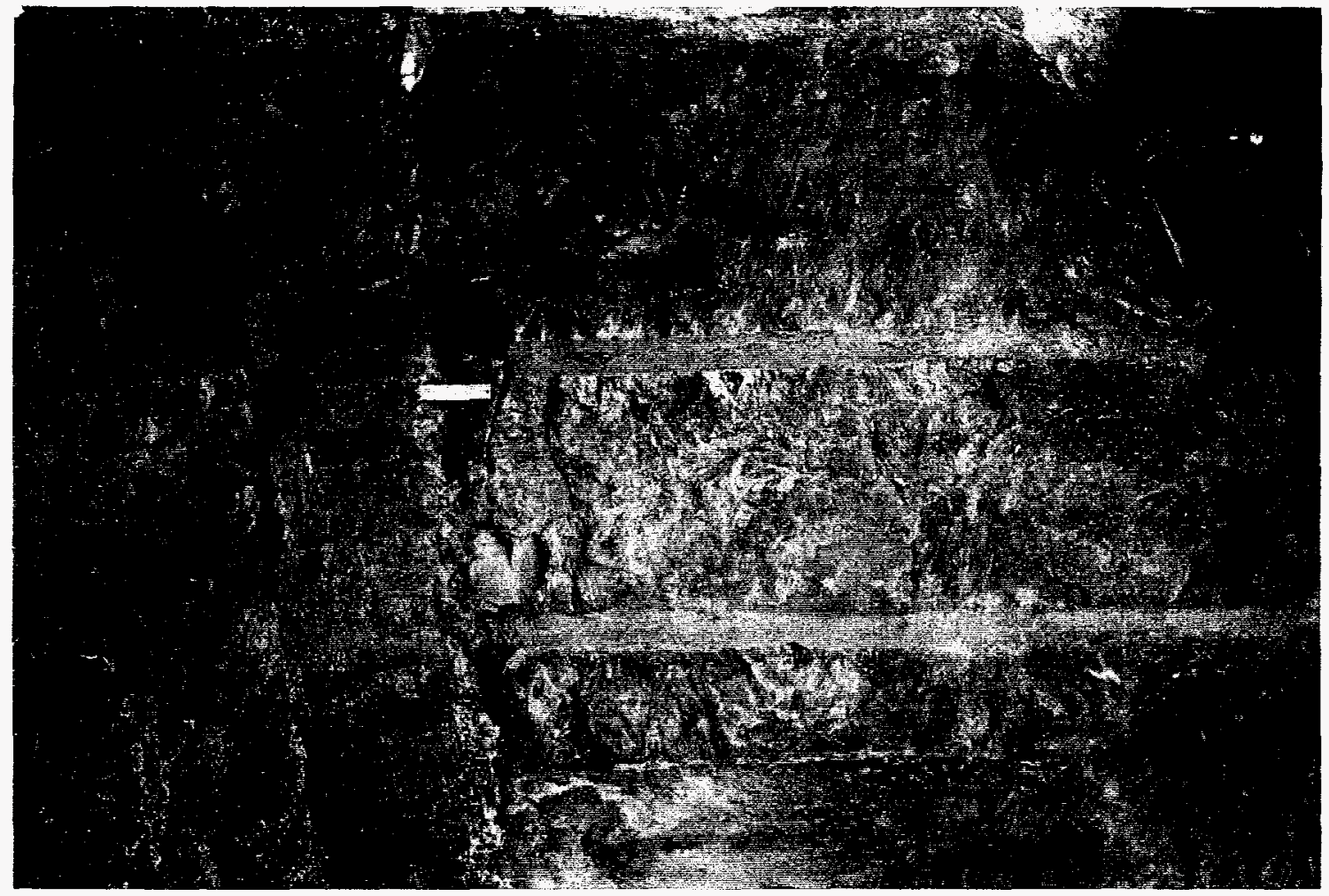

Plate 10.

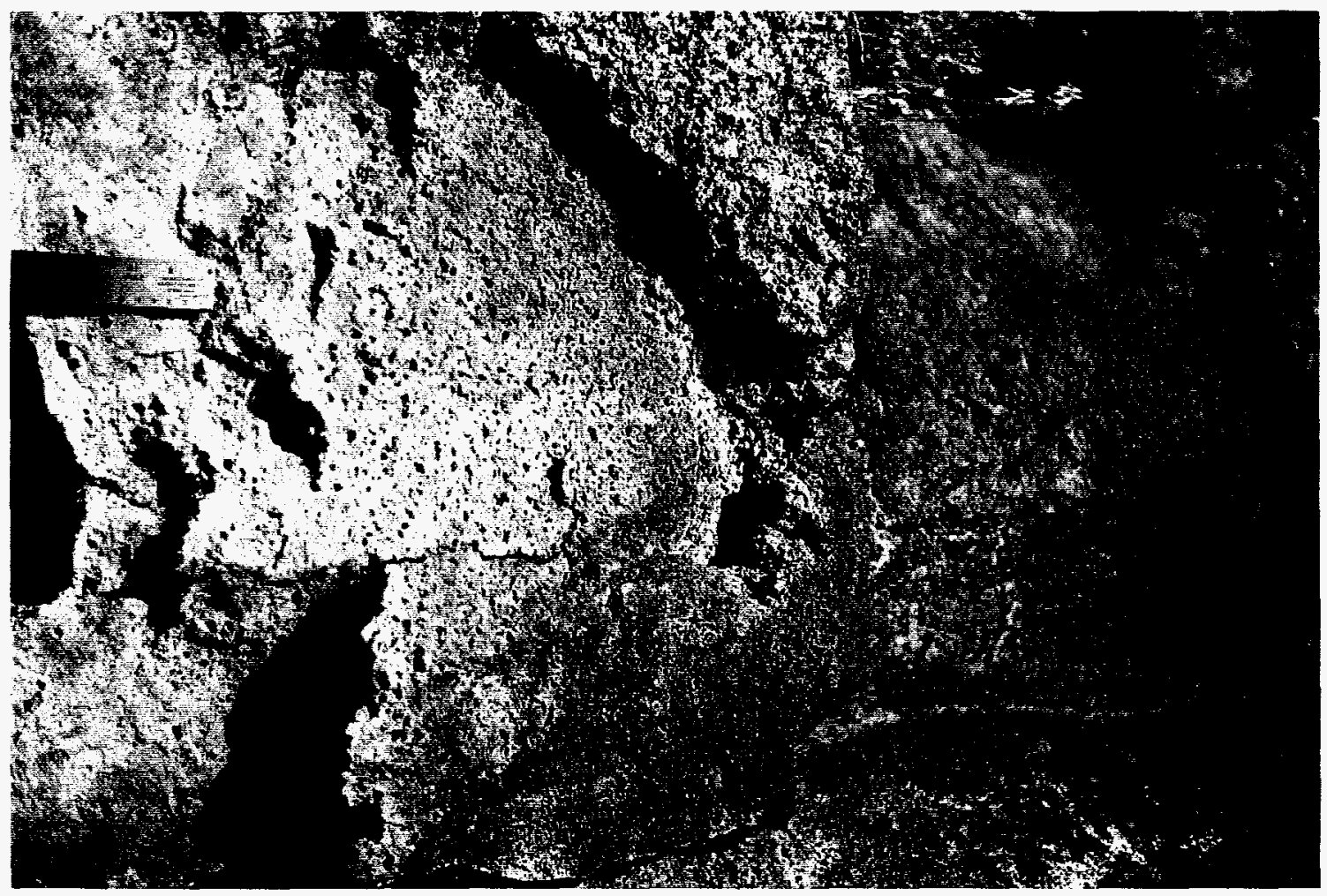


Plate 11.

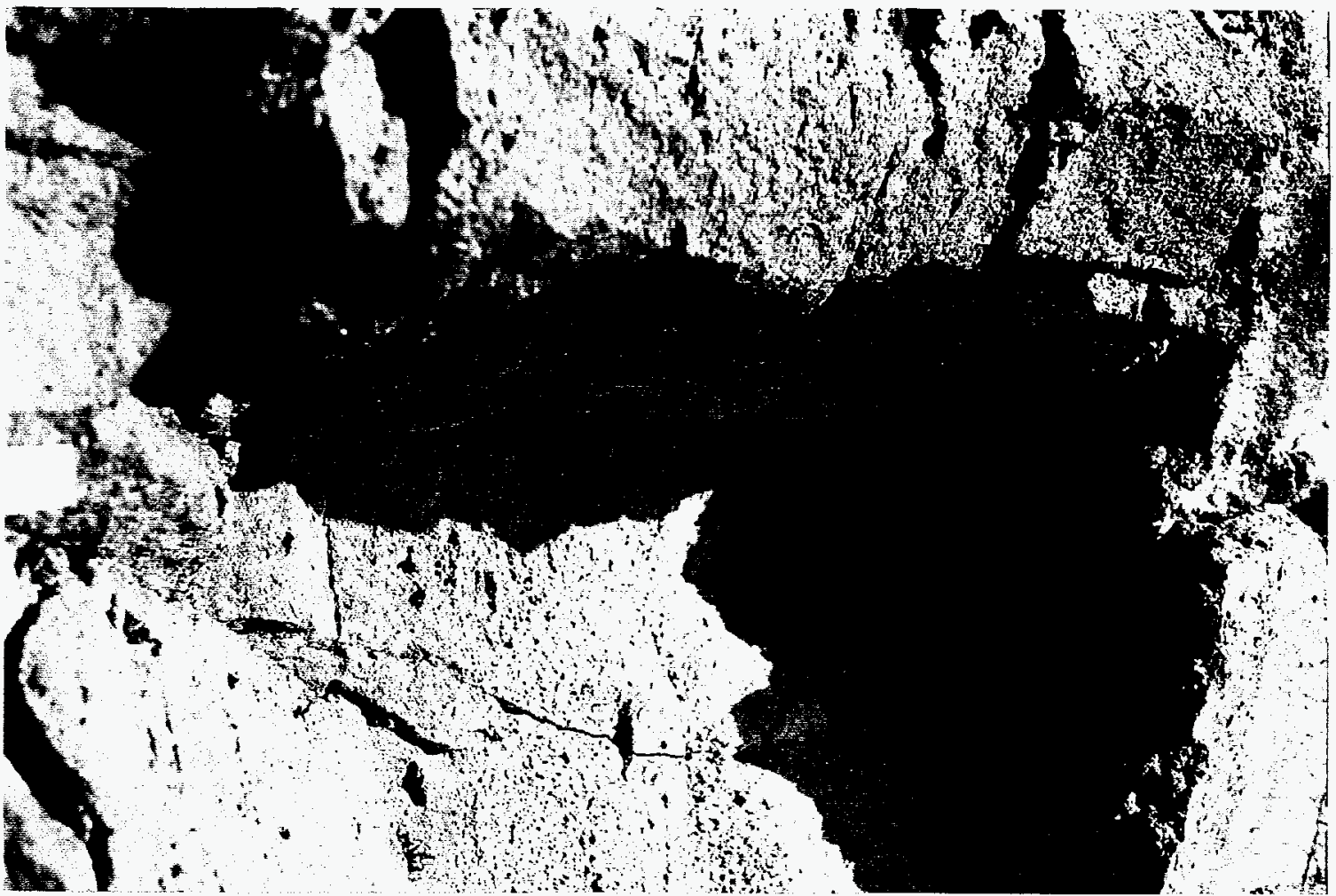

Plate 12.

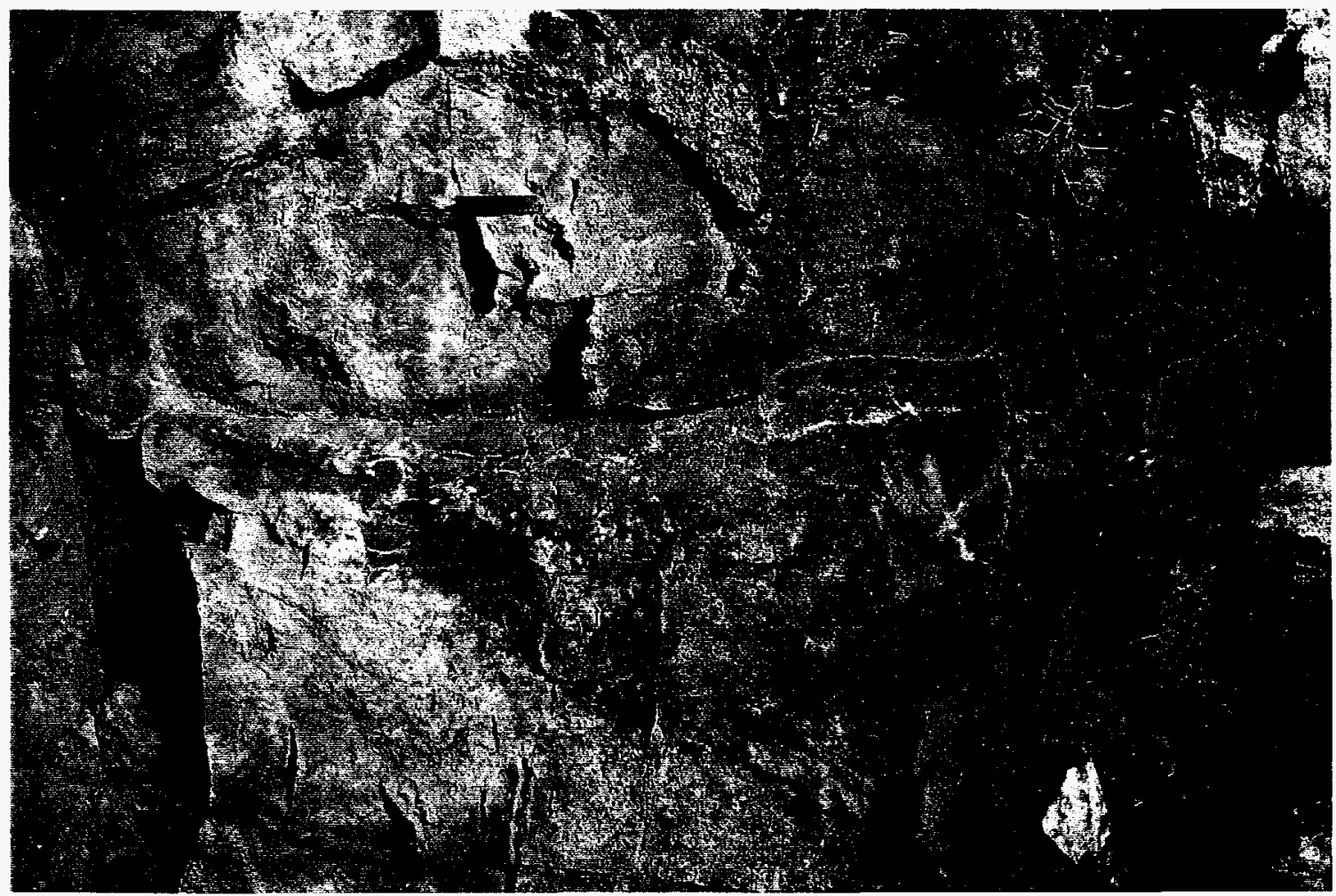


Plate 13.

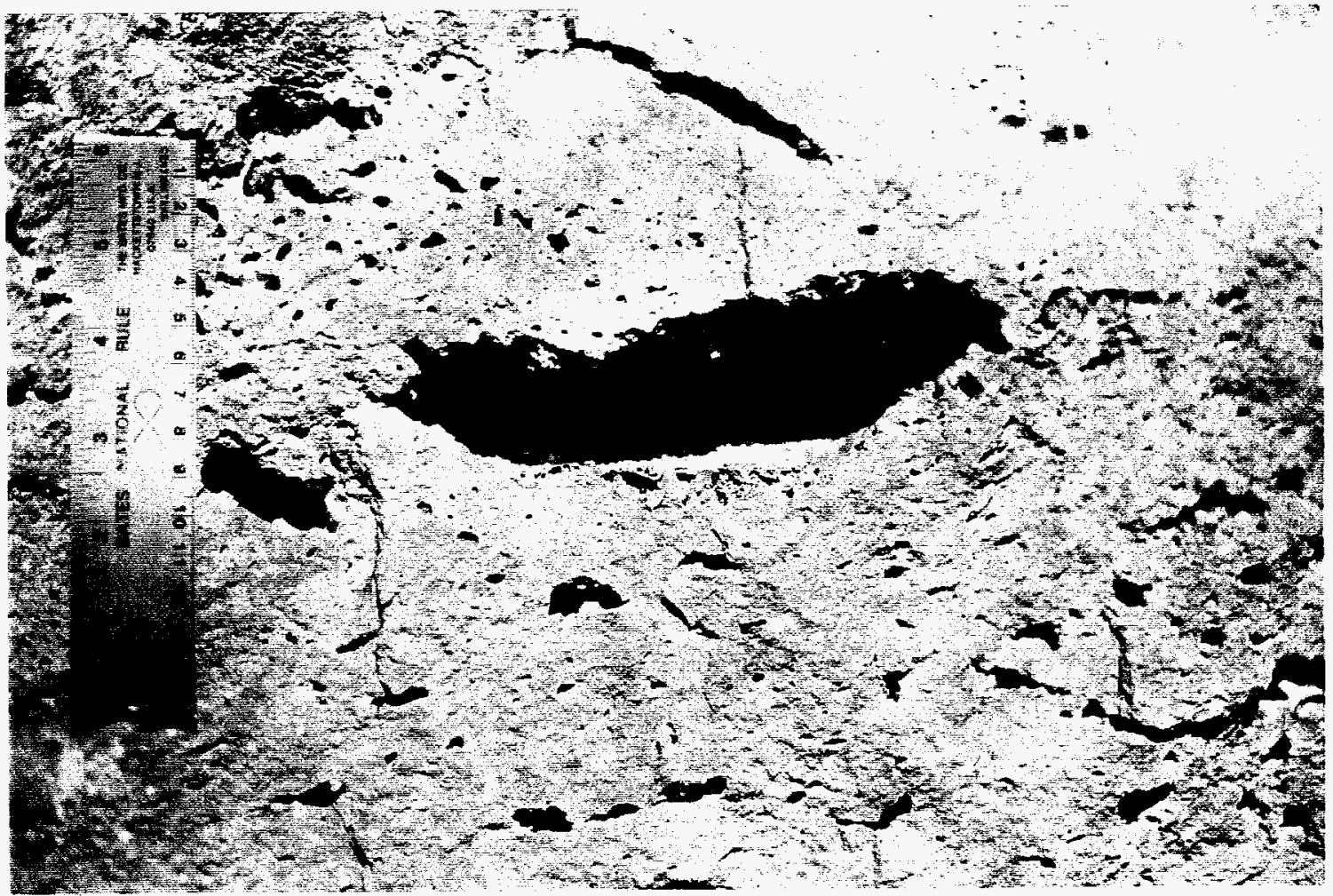

Plate 14.

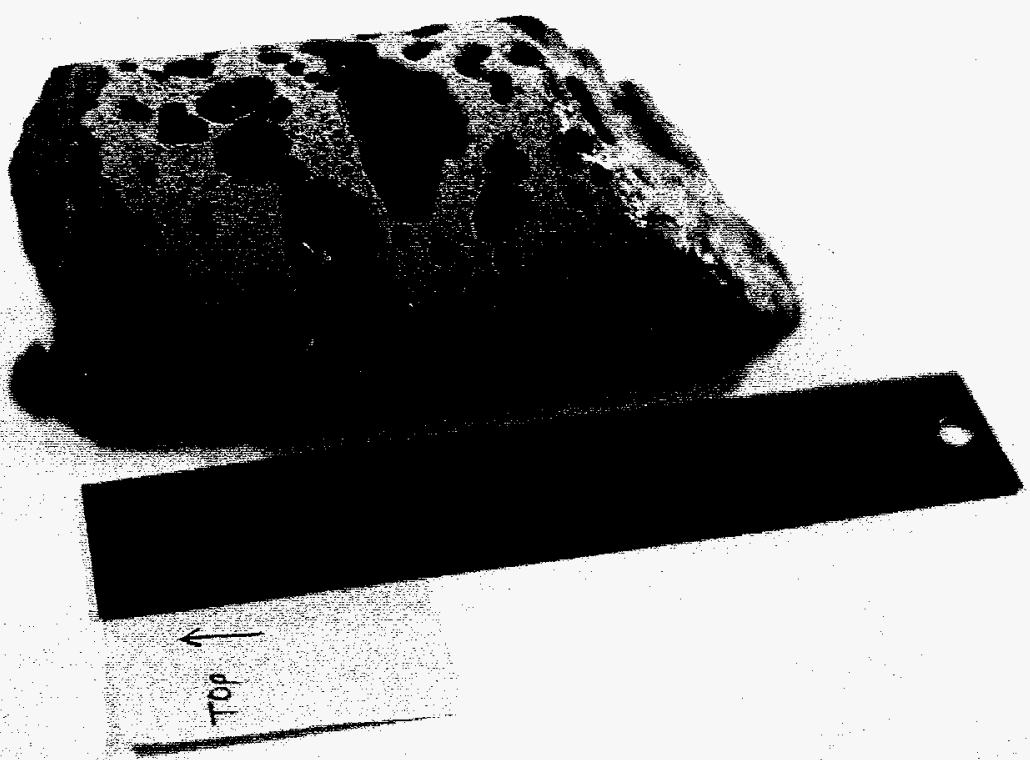


Plate 15.

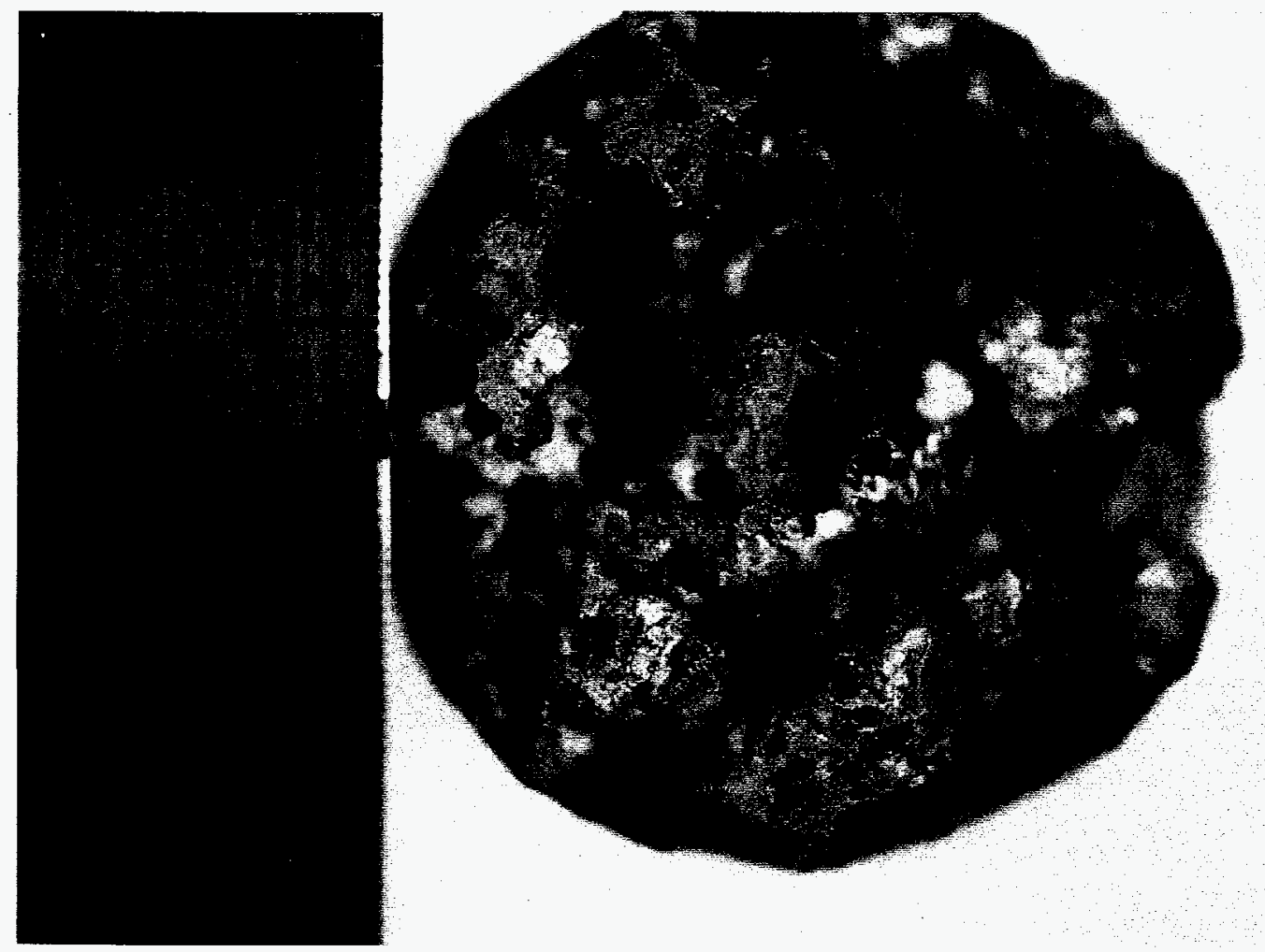

Plate 16.

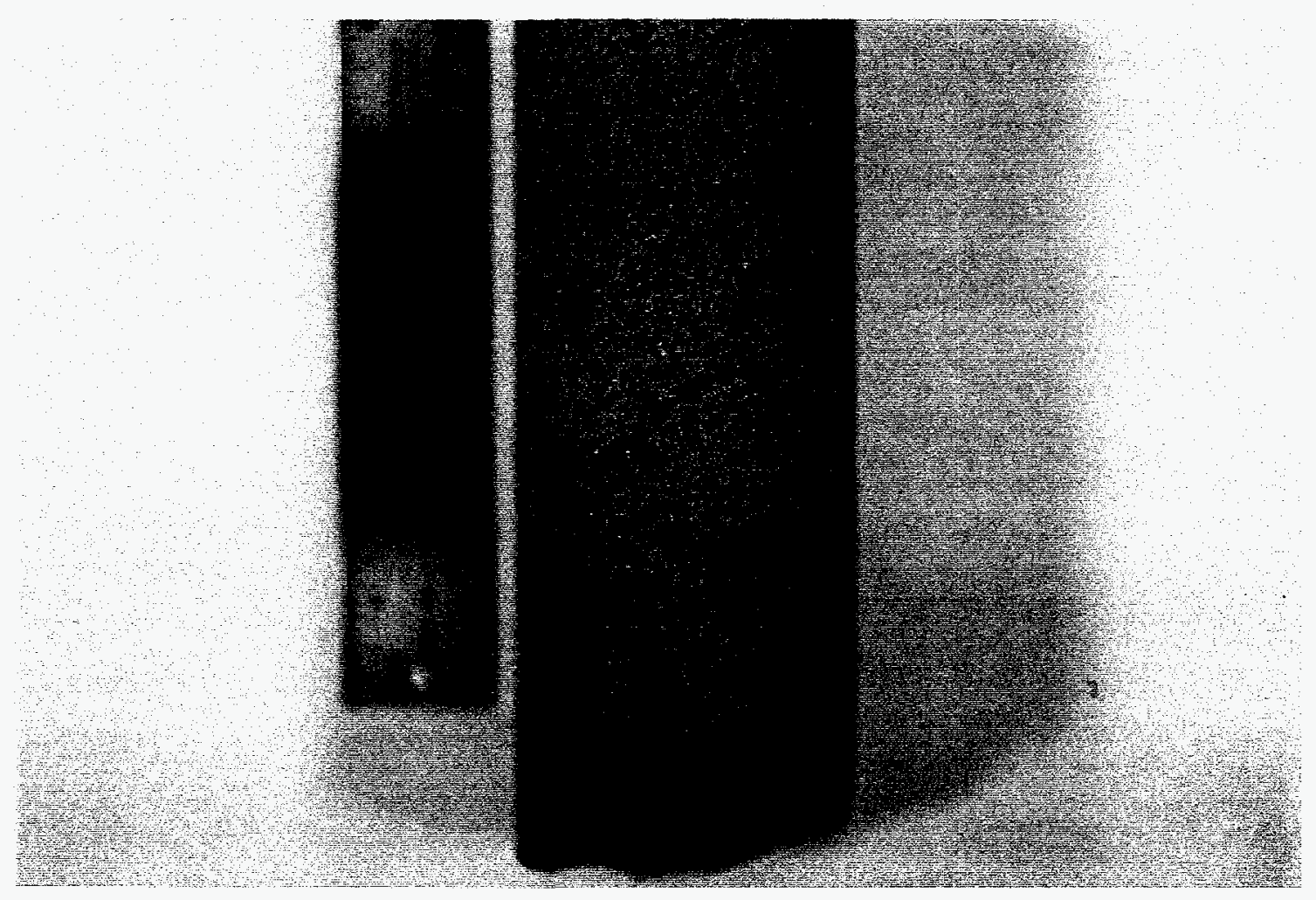


Plate 17.

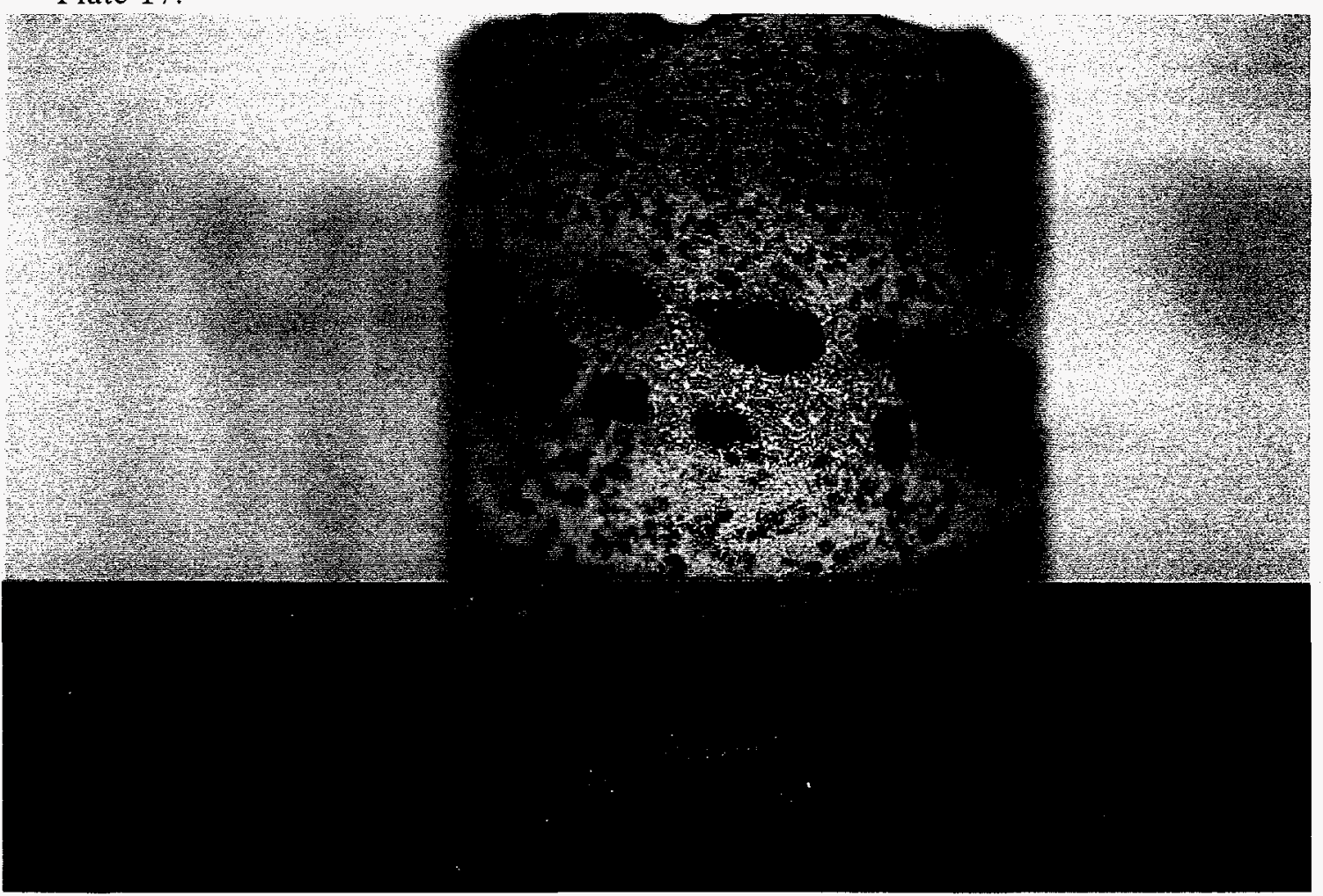

Plate 18.

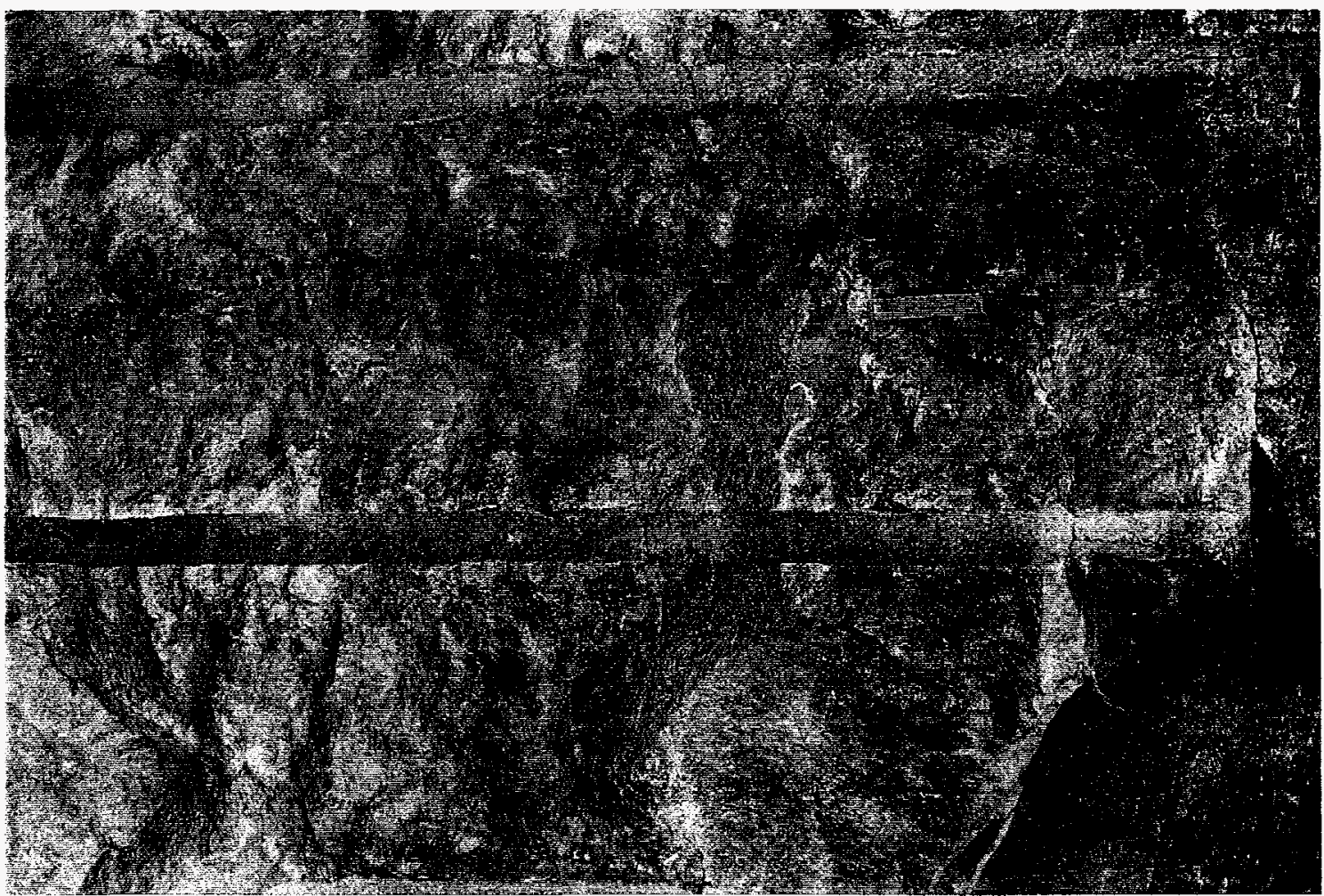


Plate 19.

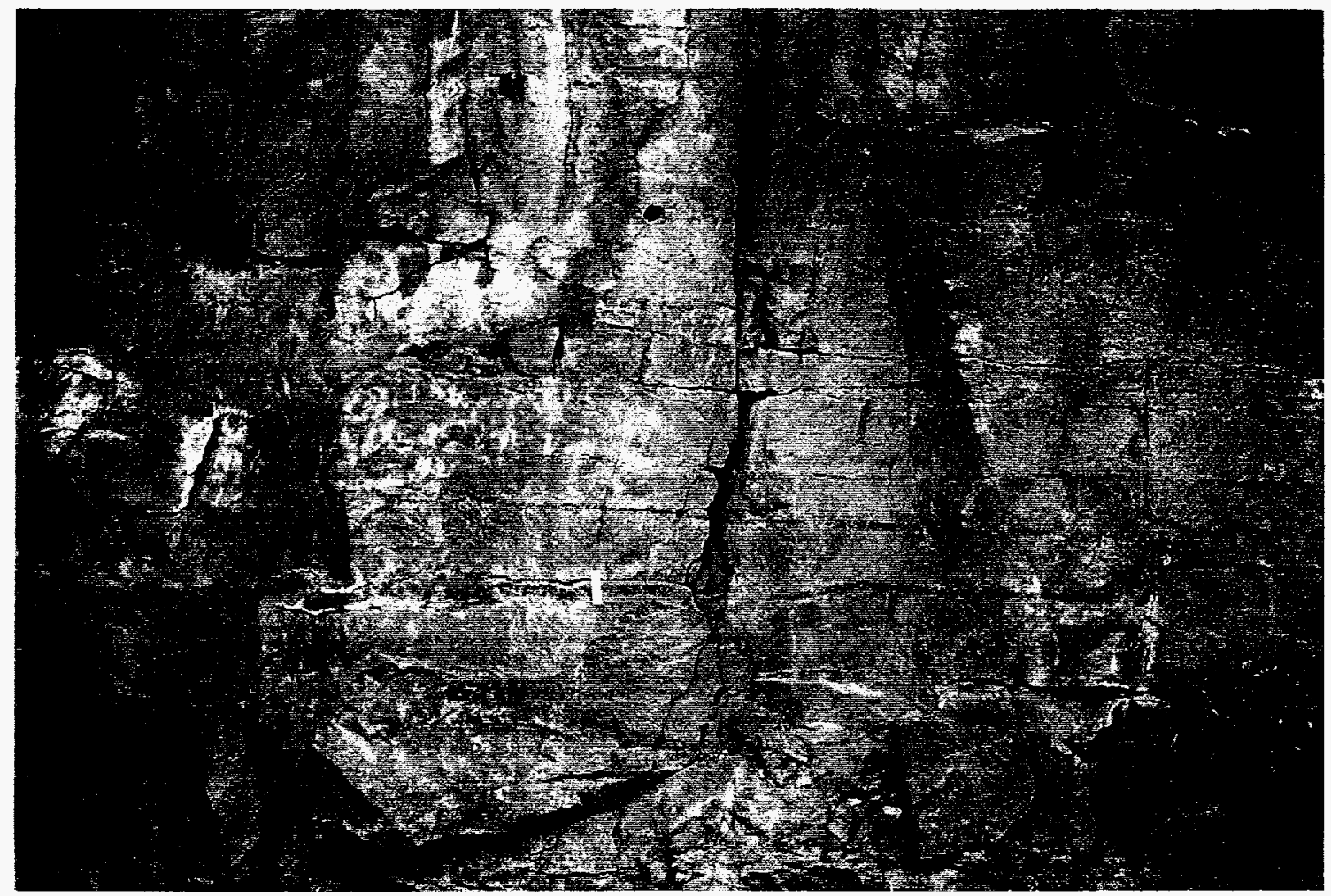

Plate 20.

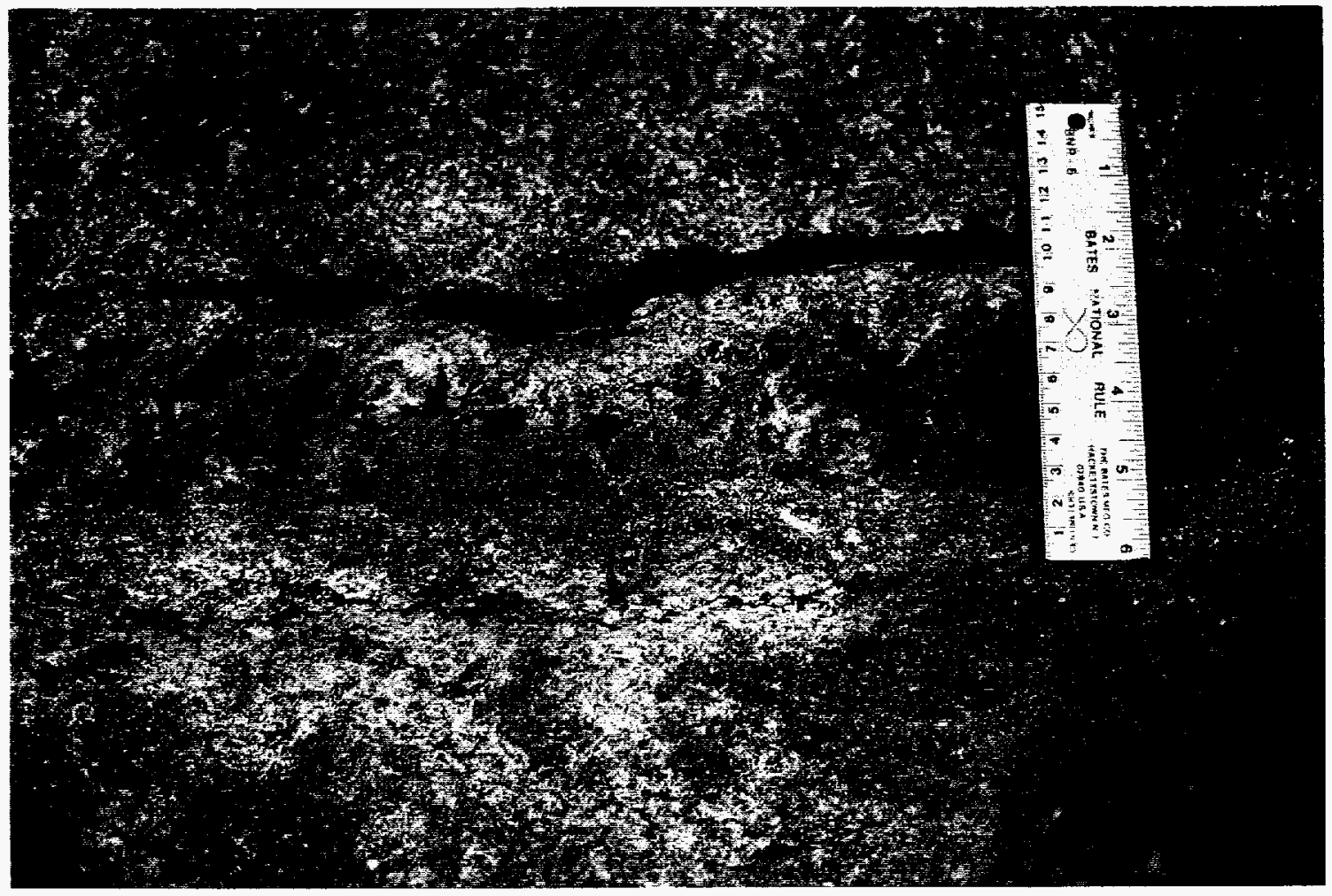


Plate 21.

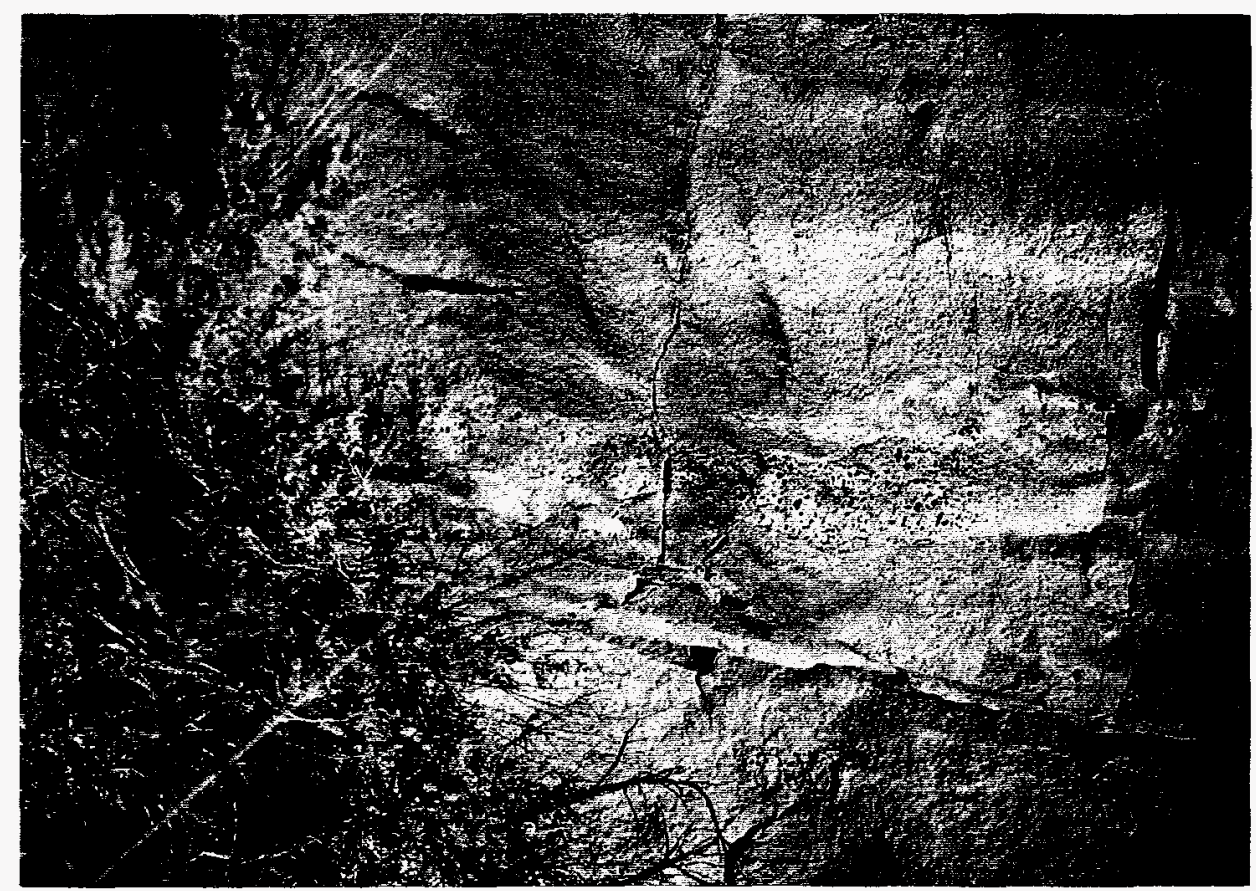

Plate 22.

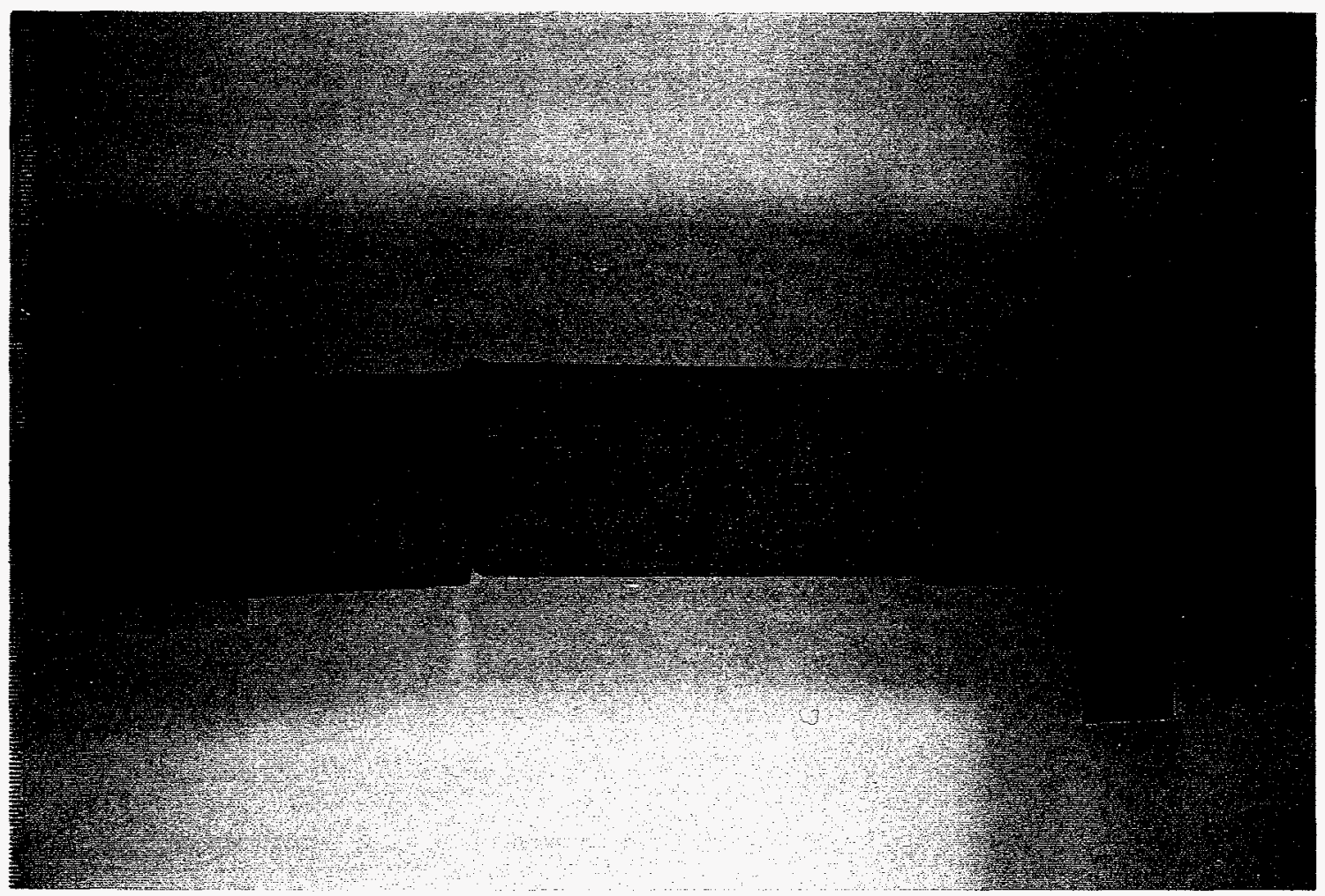


Plate 23.

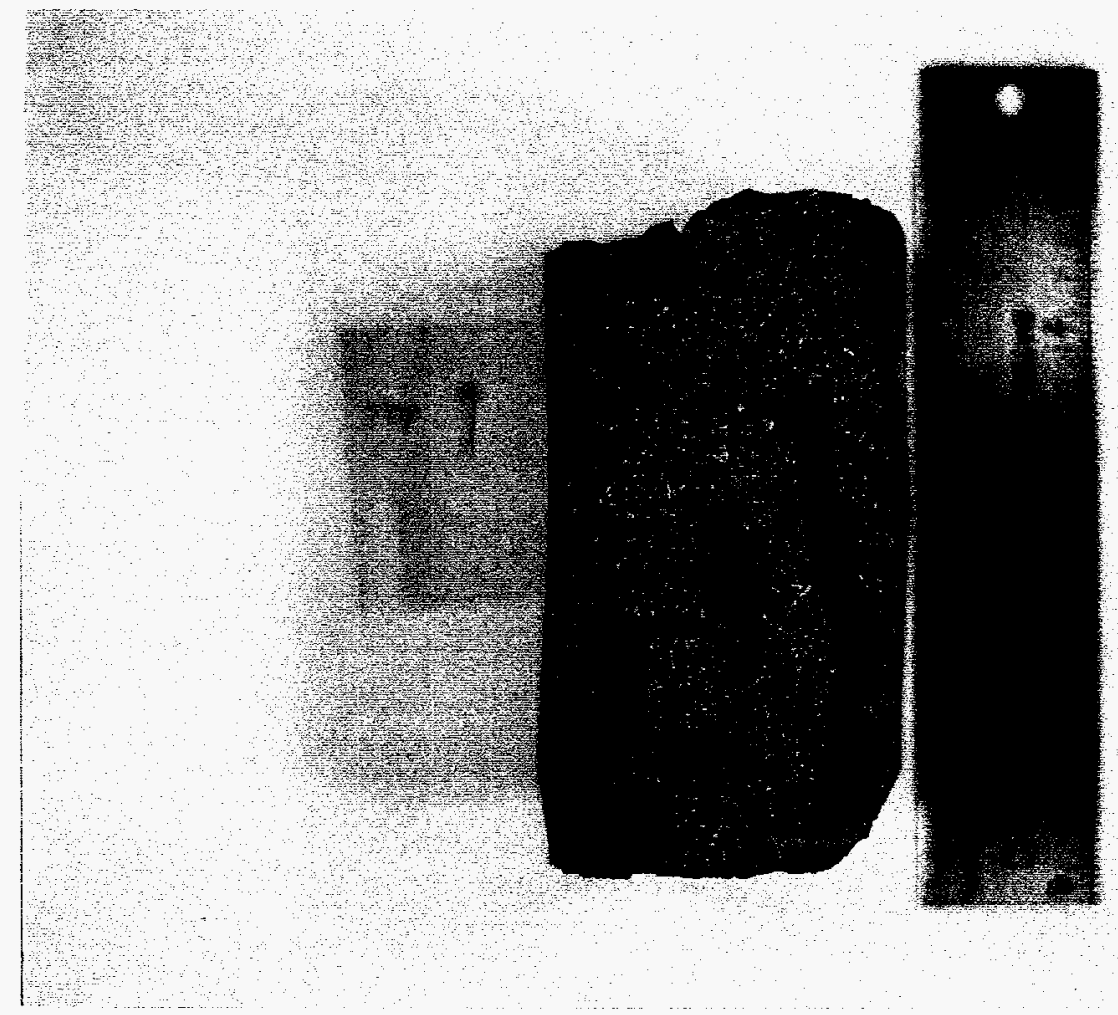

Plate 24.

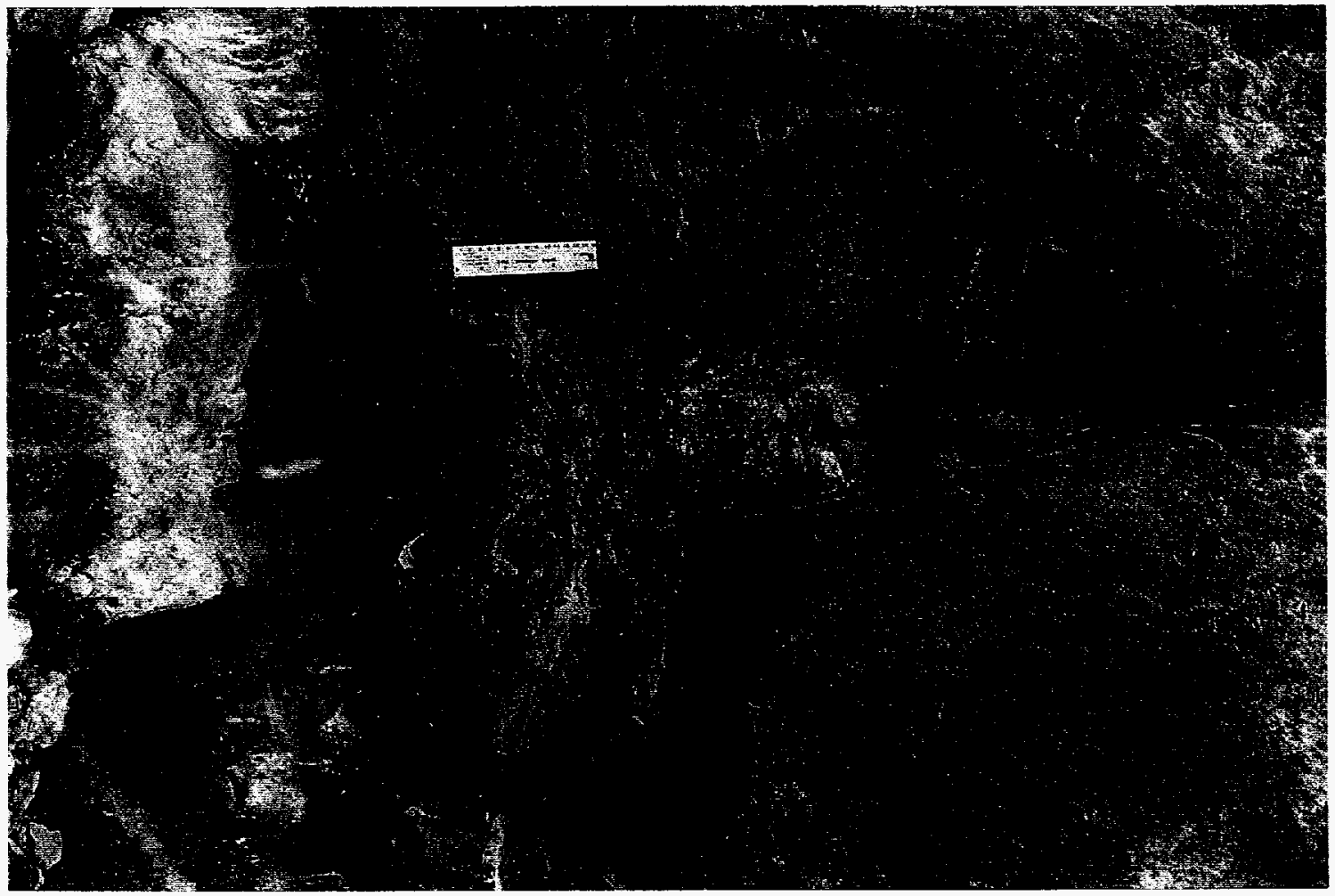


Plate 25.

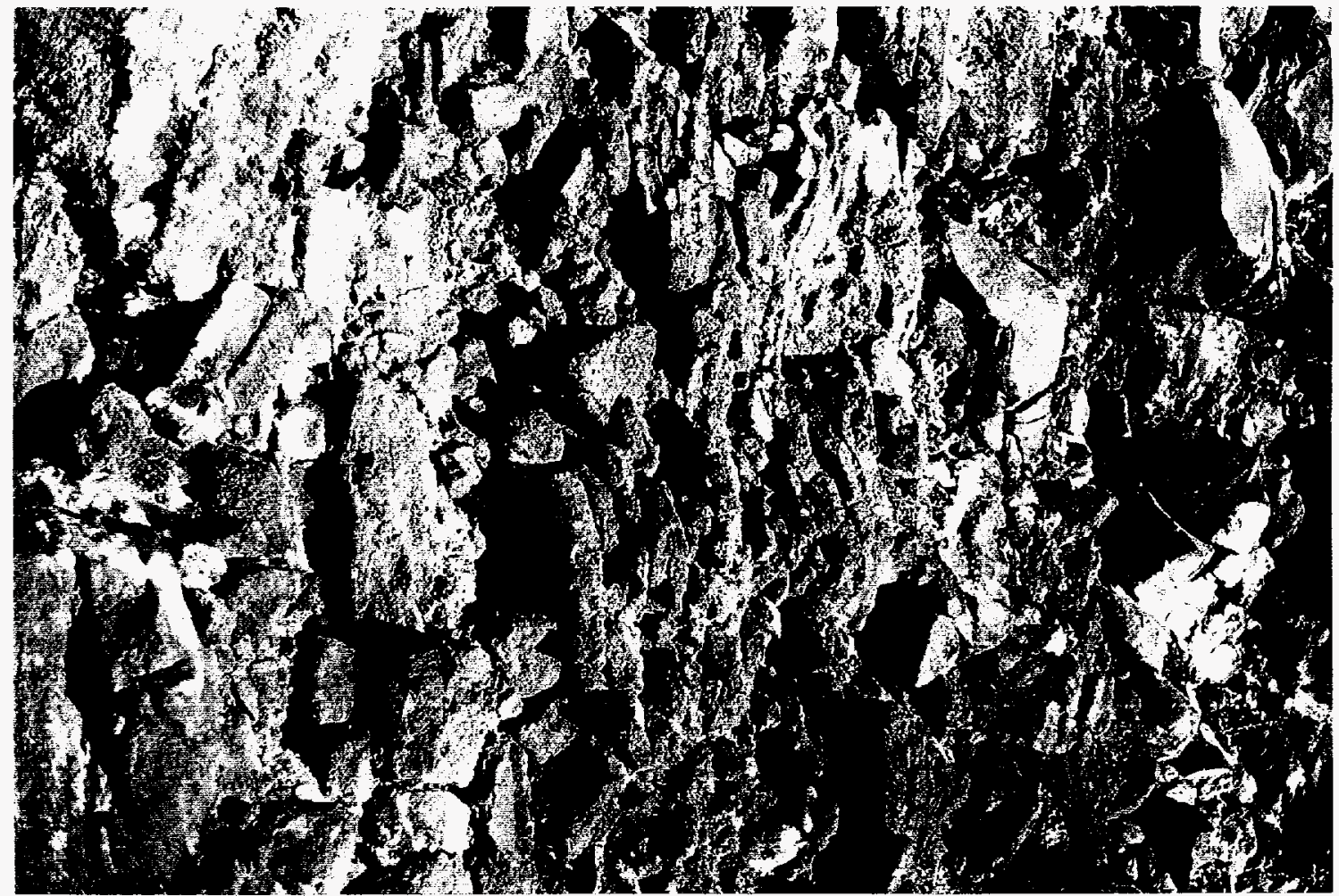

\section{Plate 26.}

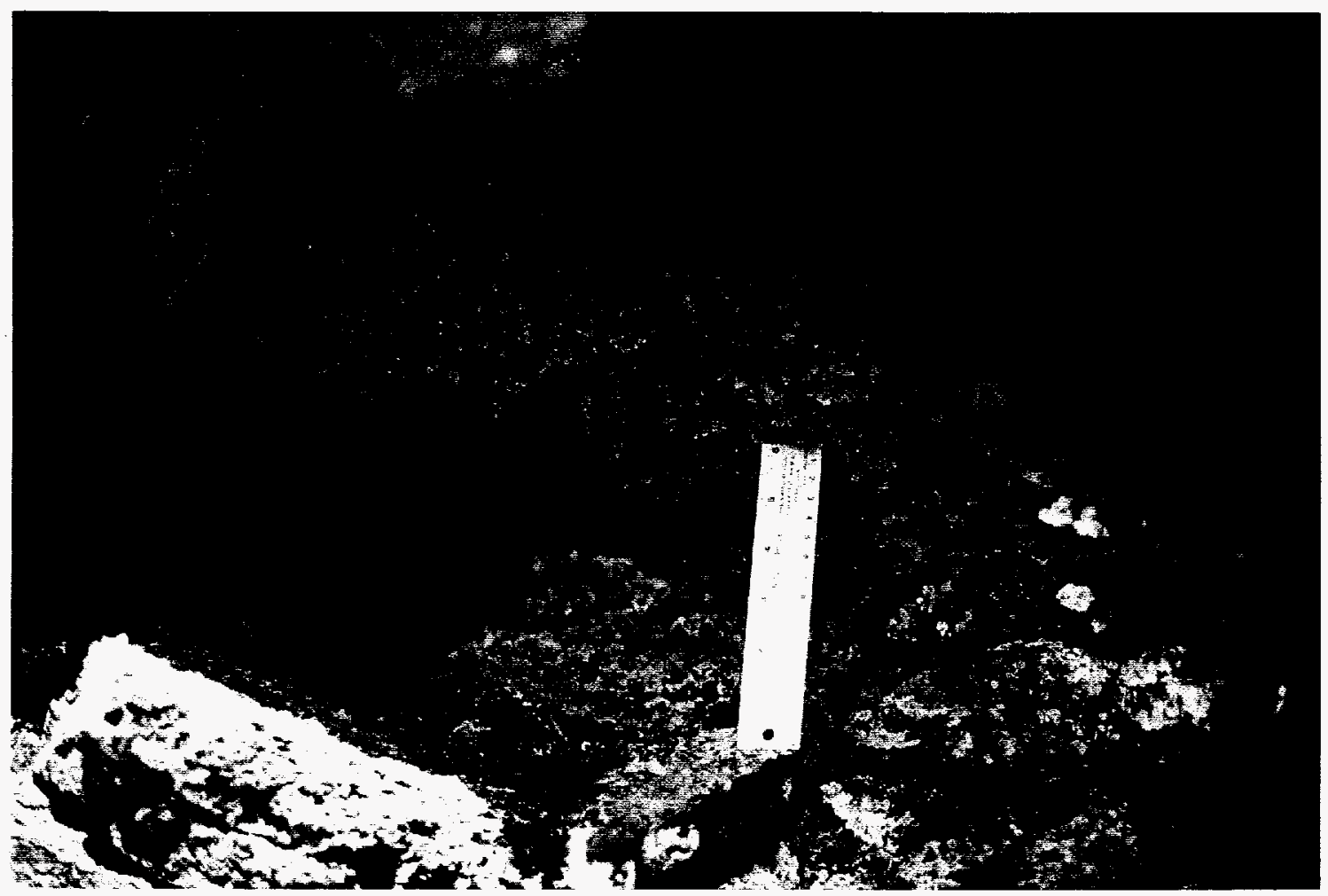


Plate 27.

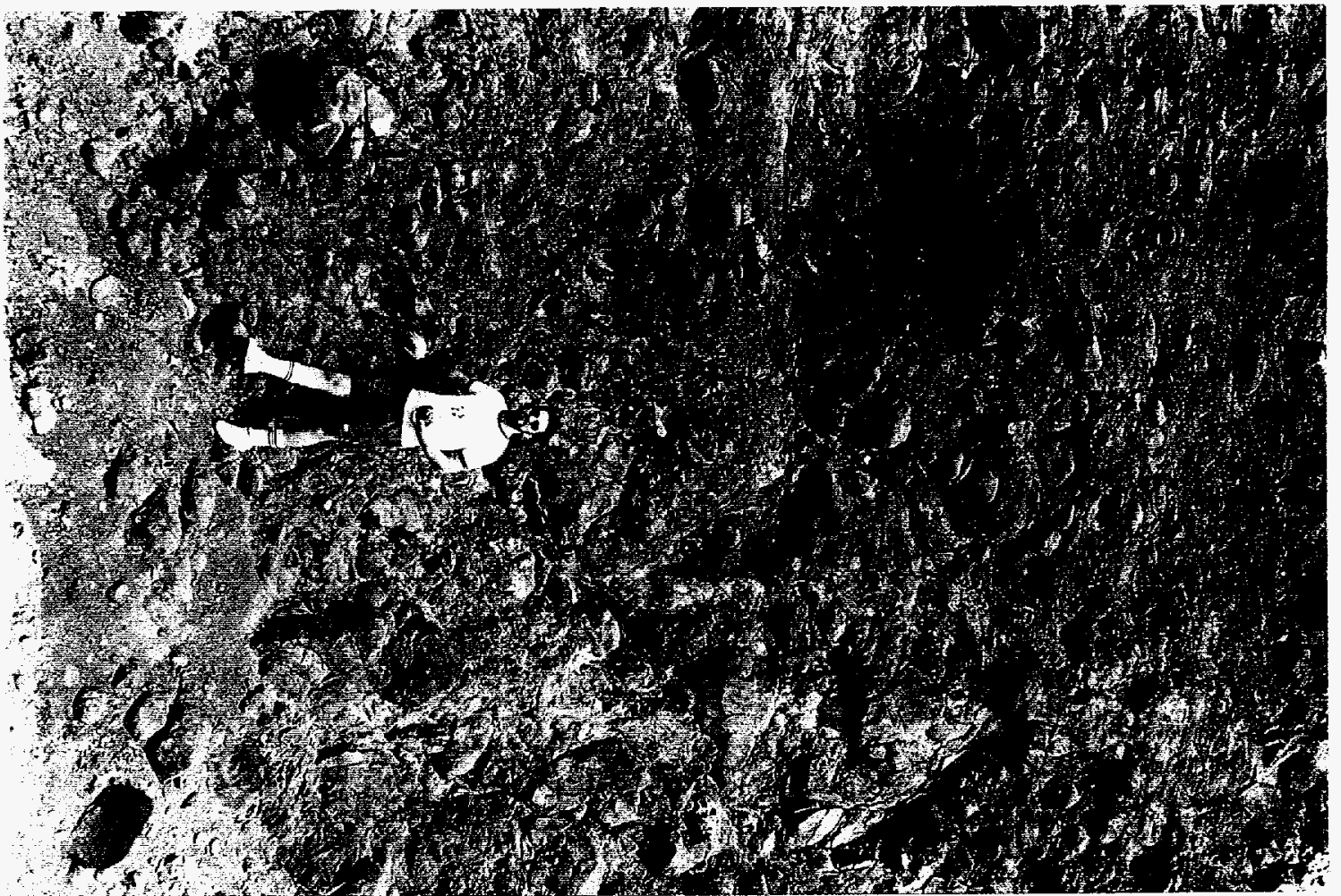

Plate 28.

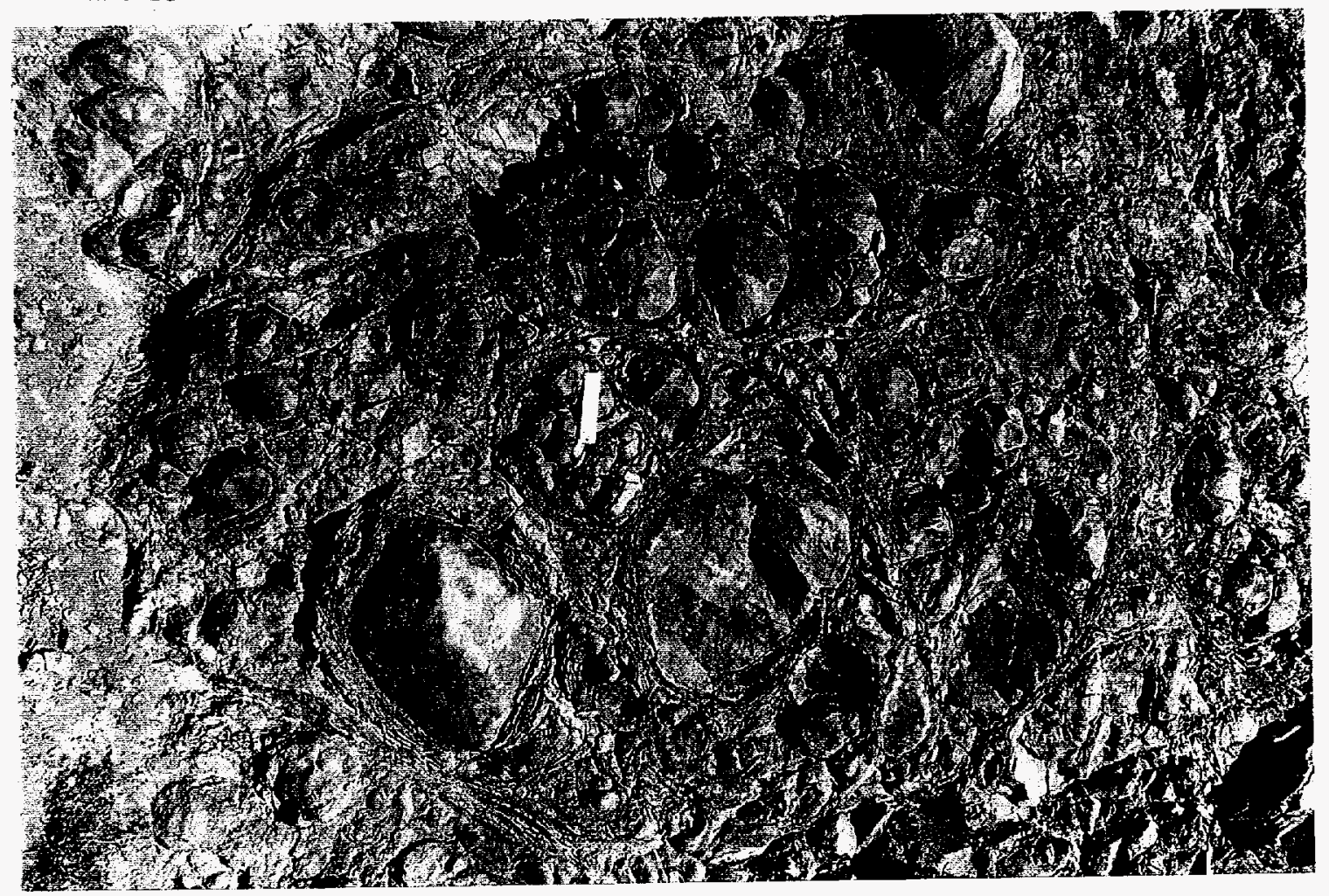


Plate 29.

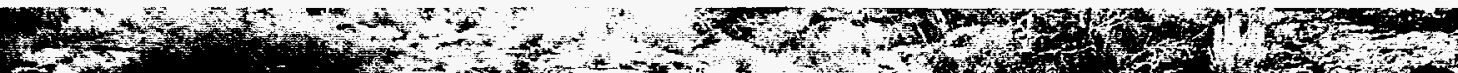

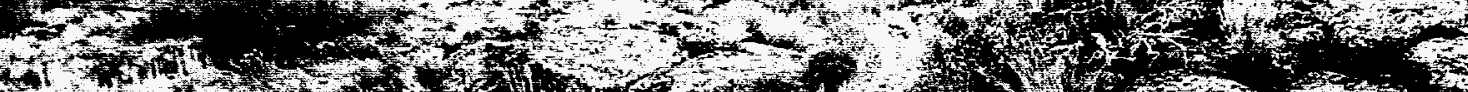

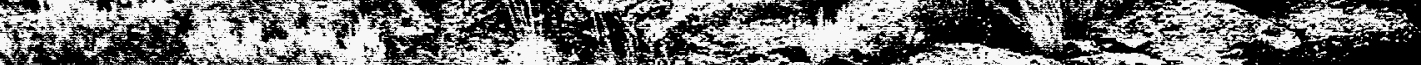

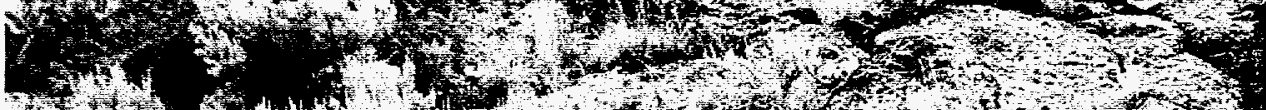

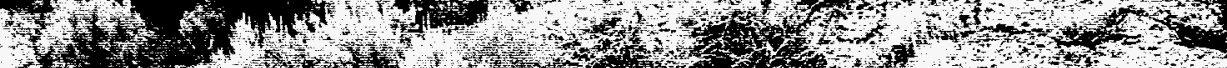

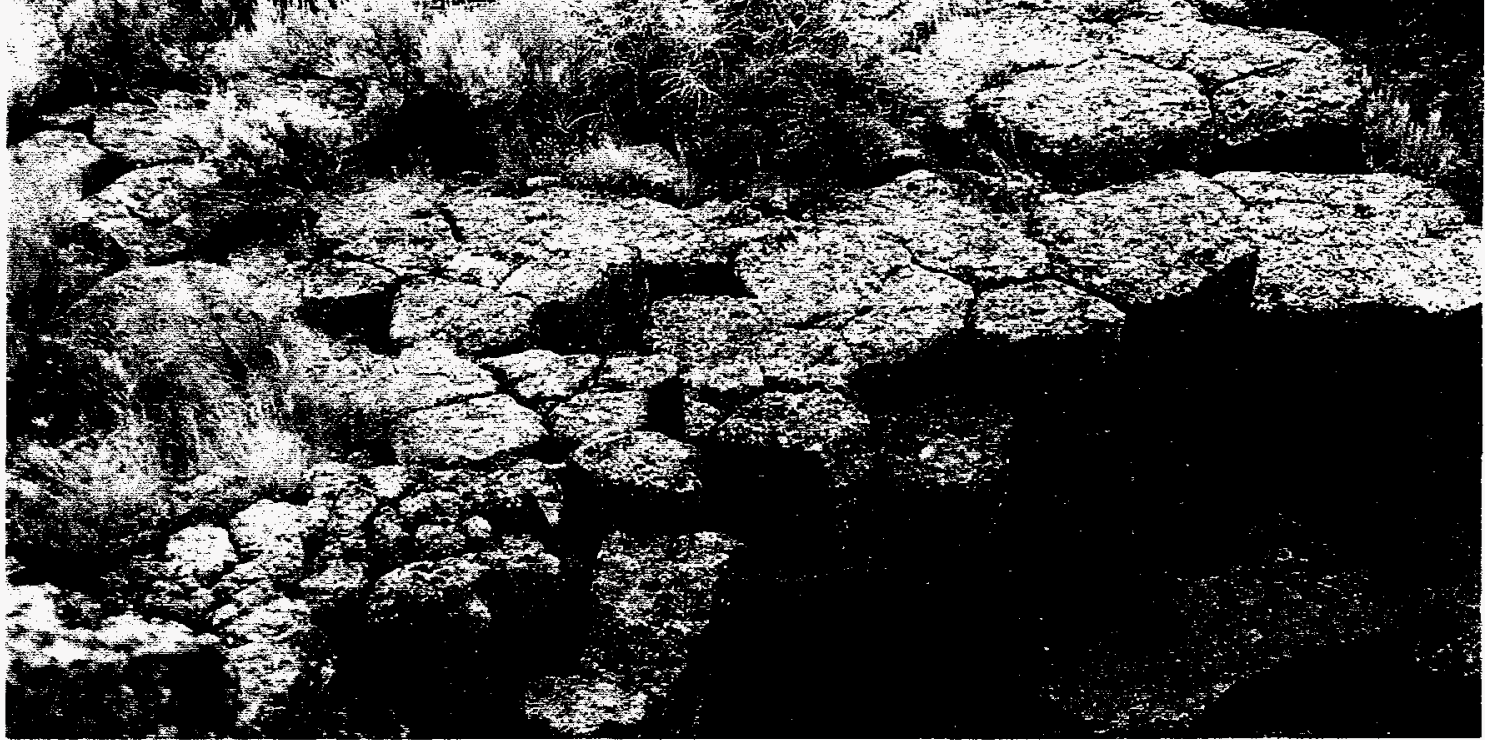

Plate 30.

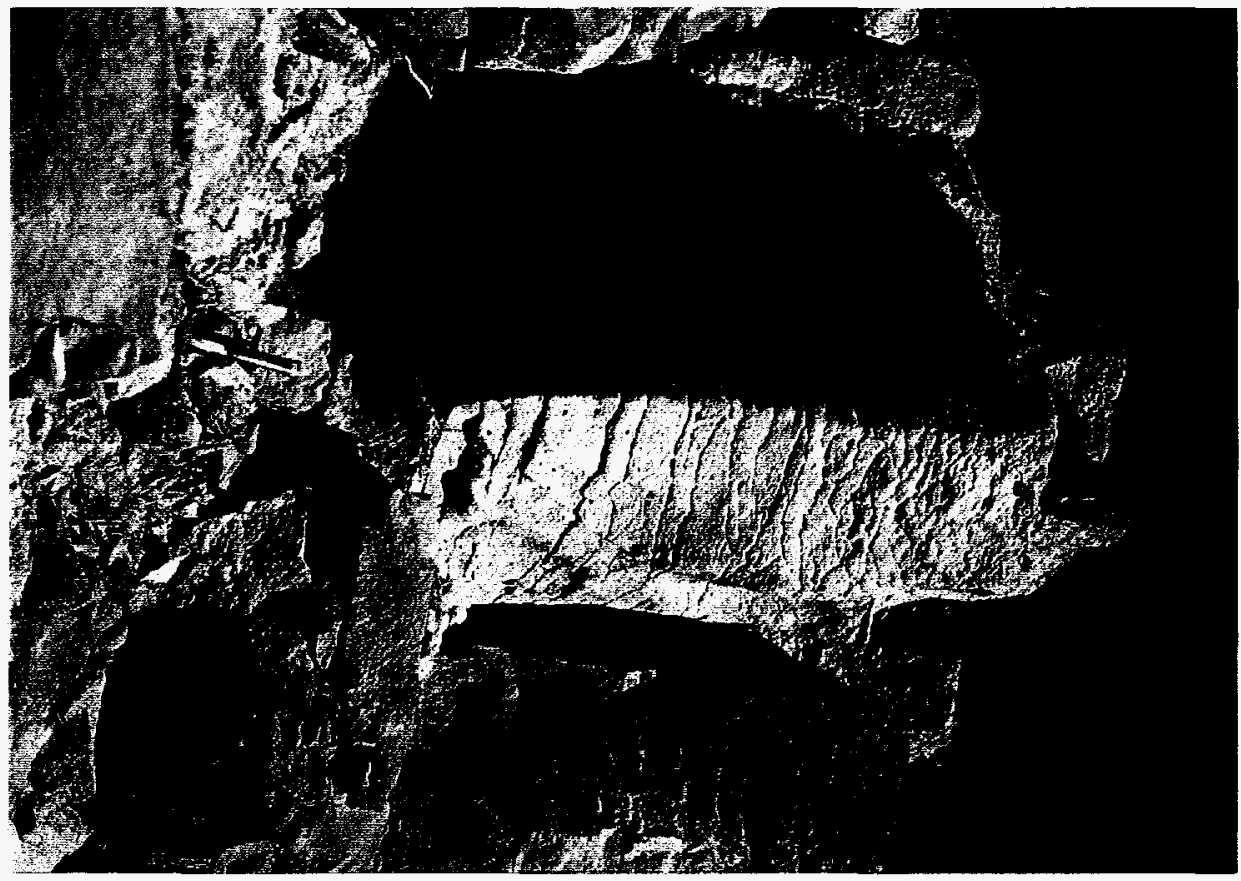


Plate 31.

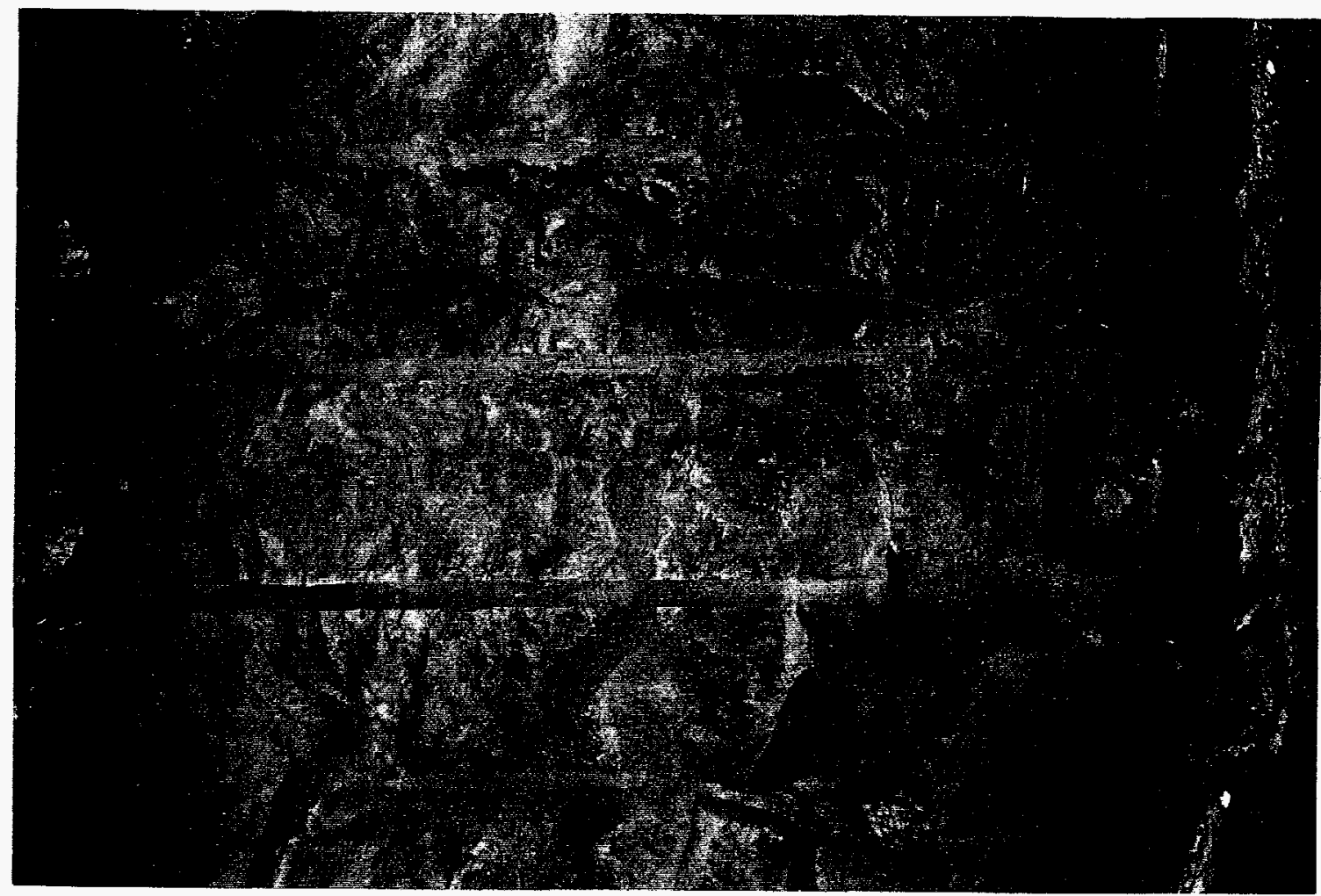

Plate 32.

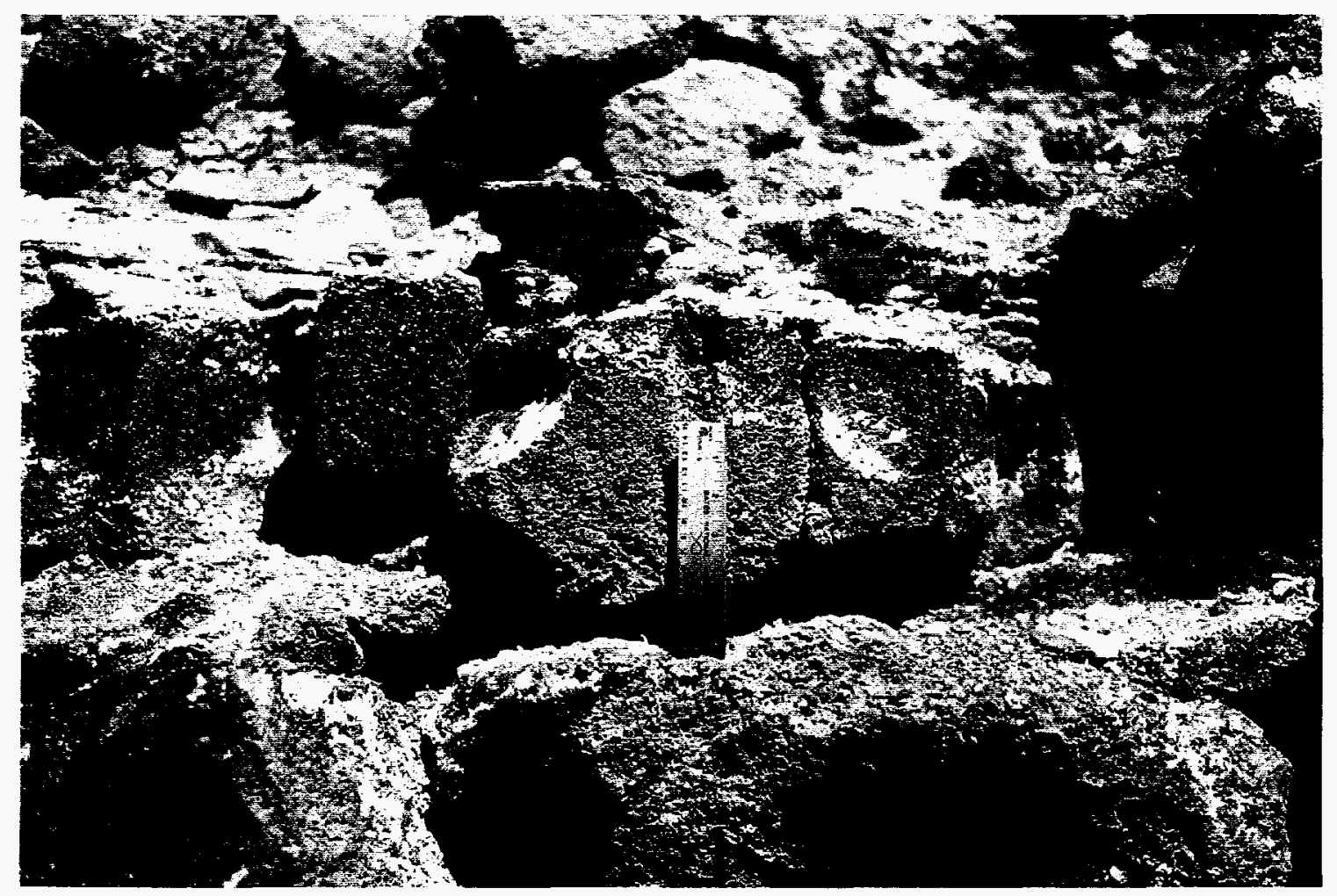




\section{CHAPTER 4. ANALYSIS OF OUTCROP FEATURES}

\section{Type Of Basalt Lava Flows Seen In Outcrop}

Basalt lava flows are traditionally classified into two types of flows based on their surface features. These two types are pahoehoe and aa lava flows. Pahoehoe lavas are characterized externally by smooth, hummocky, ropy, or festooned surfaces, and internally by lava tubes and nearly spherical vesicles (Macdonald, 1967). In contrast, aa lava flows are characterized by a central massive phase lying between clinkery fragmental top and bottom layers. The fragments are exceedingly irregular and spinose and the vesicles are less regular in outline than those of pahoehoe (Macdonald, 1967). These are both endmember types with all transitions between them. Pahoehoe and aa commonly form in the same lava flow. Pahoehoe may change down slope to aa, but the opposite has never been observed (Cas and Wright, 1988). Nearly all Hawaiian basaltic lava erupts as pahoehoe, and some changes to aa during flowage and cooling; factors governing the transition involve certain critical relations between viscosity and rate of shear strain (Peterson and Tilling, 1980). If the lava slows, cools, and stops in direct response to an increase in viscosity before these critical relations are reached, it remains pahoehoe but, if flow mechanics (flow rate, flow dimensions, slope, momentum, etc.) impel the lava to continue to move and deform even after it has become highly viscous, the critical relations may be reached and the lava changes to aa (Peterson and Tilling, 1980). Near the vents or source fissures the lavas are predominantly pahoehoe, but aa becomes more abundant at greater distances (Macdonald, 1967).

Pahoehoe lava forms by an initial vent outflow, or lava lake overflow becoming crusted 
over by congealed rock. The advancing fluid lava entirely fills a resulting lava tube. The tube divides into many smaller ones each of which advances by protrusion of successive lobate toes, somewhat in the manner of a moving amoeba (Macdonald, 1967) (Figure 17).
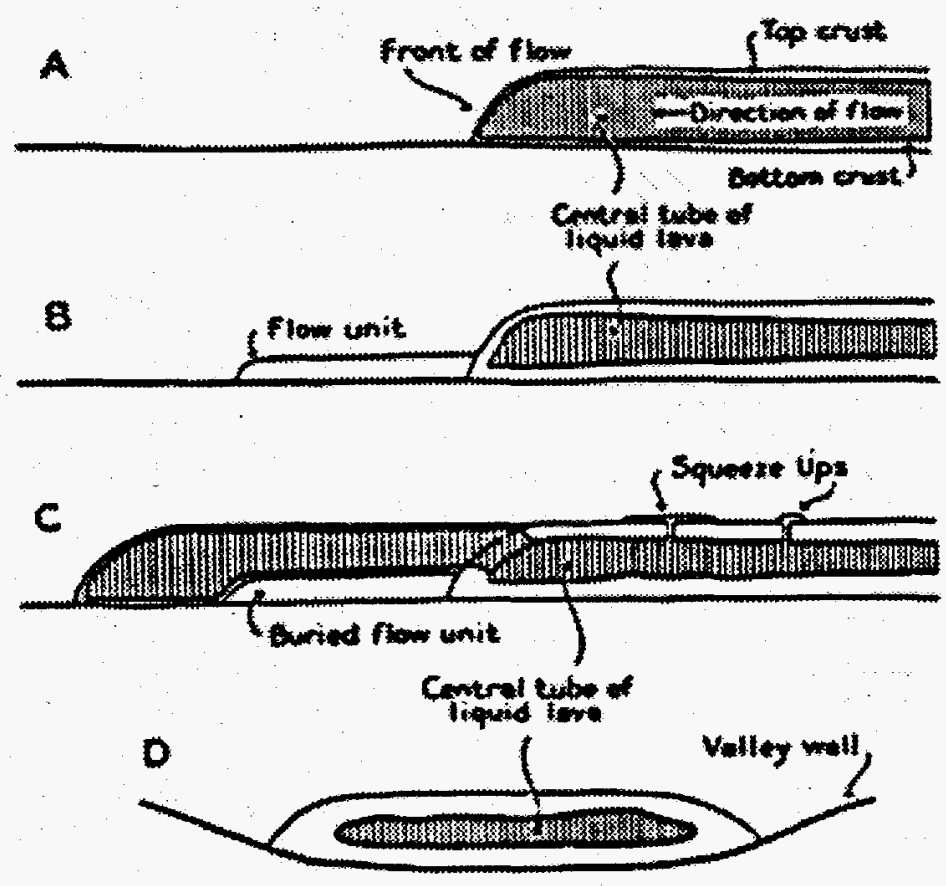

Figure 17. Longitudinal and transverse cross sections showing the central molten tube of lava whose motion downstream is the cause of the forward movement of the lava front. The " $\mathrm{A}$ " part shows the initial formation of the lava tube with a thin crust surrounding it. In " $\mathrm{B}$ " the initial burst of lava comes out of the tube in the form of a flow unit that then extends forward and solidifies. In "C" a larger molten lobe of lava bursts forth overlying the initial tongue. "D" shows the tube in transverse cross section showing the central liquid part of the tube and the others areas not shaded are the crusted part (After R. L. Nichols, 1936).

Large lava tubes evolve from lava channels by crust formation on the channel surface, although some tubes develop directly from the vent, and allow lava to be transported through them (Greeley, 1971) (Figure 18). 


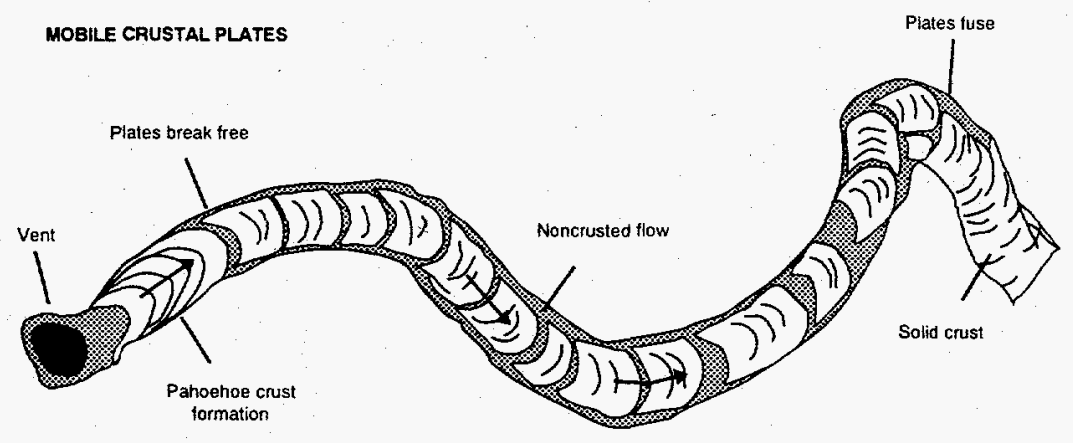

Figure 18. Figure illustrating lava tube formation in a lava channel. The surface of the lava in the channel starts to cool away from the source vent producing festooned pahoehoe crusts. Flowage beneath these crusts break them up into shield-shaped segments (plates) which move freely down the channel. These plates continue to drift down the channel until they jam together and fuse making a permanent solid ceiling under which lava continues to move (After R. Greeley, 1971).

Lava tubes can themselves have numerous channels that branch out from the main one with the main tube possibly reaching up to $16 \mathrm{~m}(53 \mathrm{ft})$ in diameter (Greeley, 1971). Most tubes are found in pahoehoe basalt (Greeley, 1971), but occasionally they occur in aa lava (Guest, et al., 1980) so they should be prevalent in basalts of the SRP. Lava tube caves have been reported in a number of places throughout the SRP and can be easily accessed. Yet with this in mind no lava tubes were identified in the outcrops, cores, and borehole TV logs. It seems more reasonable that since their scale is much larger than what the cores and boreholes can sample, that they would not be easily identified, however Well-drilling would be complicated if they were encountered and they would be recognized by the driller. It would seem easy to identify a lava tube in an outcrop by looking for a large opening of a hollow lava tube. This is not the case since open lava tubes, and open connectors of any kind between lava tubes, are unusual features. From the very nature of the way they develop, lava tubes cannot remain open unless the lava field forms an overall topographic slope that affords a sufficient gradient for lava to drain out of the tube after eruption ceases. Tubes do not develop within lava that remains ponded until solidification (Waters, et al., 
1990). The columnar nature of some of the observed basalt lava flows indicates a possible ponded origin for some flows. Surface texture and the lava being pahoehoe also points to a more gradual slope rather than a steep one. Greeley (1982) in his study of the SRP came to a conclusion that the SRP represents a new category of volcanism called basaltic-plains volcanism and is an intermediate form between basaltic flood eruptions and Hawaiian volcanism. Plains volcanism is envisioned as low shields with slopes of about $0.5^{\circ}$ that coalesce resulting in the present day SRP thus having a shallow slope. The predominant lava that Greeley says would result would be pahoehoe basalt in the form of flow units. Furthermore, flowing lava, like water, spills into any opening available so it is quite normal that a walk downstream within a lava-tube system will reveal that each lava tube and its distributaries are likely ponded to the roof with the lava of final flow that entered the tube (Waters, et al., 1990). Studies of partially eroded shield volcanoes indicate that lava tubes containing a filling of congealed lava are much more abundant than open lava tubes: open lava tubes being more common among the youngest lava flows in a volcanic pile. Most older open lava tubes may have been filled with the lava from later eruptions (Waters, et al., 1990). It has been estimated that only 10 to 20 percent of the lava tubes of a flow drain and remain accessible to an explorer (Waters, et al., 1990). With this in mind it would seem unusual to find an open lava tube in an outcrop of old lava flows that have been ponded. This may not hold true for all of the basalt lava flows observed in outcrops, cores, and TV logs. Perhaps they just have not been identified. Although it seems then there is a large amount of evidence pointing to filled lava tubes there are exceptions. Lava tubes play an important role in the emplacement of basalt flows in the SRP although not as common as in Hawaii. According to Greeley more than one fifth of the flows in Hawaii involve lava tubes and channels. Also three large reported lava tubes have been explored in the past at the INEL with one being open for a $213 \mathrm{~m}$ (700 ft) long, $31 \mathrm{~m}(100 \mathrm{ft})$ wide, and $18 \mathrm{~m}(60$ $\mathrm{ft})$, deep, the second is $11 \mathrm{~m}(35 \mathrm{ft})$ long, and $3 \mathrm{~m}(10 \mathrm{ft})$ deep, and the third one is $6 \mathrm{~m}(18$ 


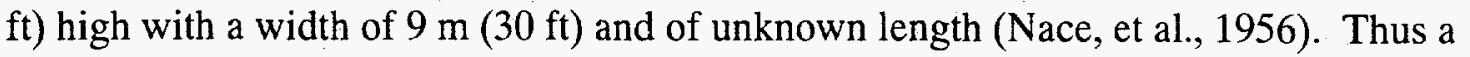
discrepancy exists between many lava tubes that should be present and the lack of identification of tubes in outcrops. This author admits that the possibility for the lack of identification of lava tubes in the outcrops is due to the limited area of cliff exposure examined. Whatever the case may be these lava tubes may also result in enlarged diameter portions in the borehole TV logs and caliper logs.

Pahoehoe flows are further subdivided by the nature of their frozen flow top whether it is filamented, corded, festooned, entrail-like, elephant-hide, slabby, shelly, and many more variations of appearance. Corded pahoehoe have surfaces that are marked by a series of small cordlike ridges, commonly aligned perpendicular to the direction of flow (Fink and Fletcher, 1978) (Plate 33). These small cords, usually an inch or less in diameter, may be superimposed on still larger ropelike convolutions of the crust (Macdonald, 1967). The most ropy structures are located in flows confined to channels. In general, the rope forms congeal in places where the velocity of the lava surface decreases, and the resultant pile-up of material causes compression parallel to the direction of flow (Fink and Fletcher, 1978). Less commonly, liquid lava flowing beneath the plastic crust drags it into ropy festoons, which are convex in the direction of motion. This type of surface is best termed festooned pahoehoe (Macdonald, 1967).

Slab pahoehoe forms from the draining of the liquid from beneath a thin crust, followed apparently by some movement of the flow as a whole, which results in fracturing of the crust and titling and heaping of the fragments. The fragments of crust are 0.3 to 1.5 $\mathrm{m}(1$ to $5 \mathrm{ft})$ in length and width, and 5 to $20 \mathrm{~cm}$ ( 2 to 8 in) thick (Macdonald, 1967). The upper surfaces exhibit the minor features characteristic of any pahoehoe flow, but their lower surfaces are exceedingly rough and spinose. The plates are tilted, jumbled, or imbricated, in a manner similar to the plates of ice in an ice pack (sea ice) (Macdonald, 1967). Near some vents, especially on the upper slopes, floods of gas-rich pahoehoe have 
developed a plexus of small tubes and blisters (Macdonald, 1967). This type of basalt lava flow is called shelly pahoehoe. Some were originally filled with fluid lava that drained away, but others apparently were never entirely filled with liquid but were inflated by gas pressure. The crust above these small tubes and blisters ranges from about $5 \mathrm{~cm} \mathrm{(2} \mathrm{in)} \mathrm{to}$ $0.3 \mathrm{~m}(1 \mathrm{ft})$ in thickness with the blisters ranging in diameter from a millimeter to about 1 $\mathrm{m}(3 \mathrm{ft})$, and in height to about $0.6 \mathrm{~m}(2 \mathrm{ft})$. The shells from blisters range in thickness from about $1 \mathrm{~mm}(0.04 \mathrm{in})$ to $2 \mathrm{~cm}(0.8 \mathrm{in})$.

Aa lava formations summarized from Macdonald, (1967) form by a flow that is fed by a main lava river that flows down a surface or an open channel. On either side of the main lava river, and particularly at the advancing toe of the flow, the pasty central layer of the flow pushes outward. Locally and for short distances, the movement may be quite rapid, but generally the most active front portion of the flow advances only a few tens or at most a very few hundreds of meters a day. The advance of the flow front generally occurs as the black clinkery front of the flow steepens and bulges, eventually resulting in instability and a slab of clinkery rock peels off the front, breaks up, and tumbles to the foot of the bank which is then followed by a slide of finer debris. Where the block separates from the flow front it reveals a glowing hot face of pasty lava in the interior of the flow. It is in this lava paste that the flow movement principally occurs, material in this pasty layer moving toward the front or sides of the flow beneath a relatively much less mobile surface layer of bristling clinker. The top of the flow generally moves also, but less rapidly, dragged along by the flow of the pasty material beneath. The exposed glowing paste is quickly chilled to a clinkery flow front, which again remains relatively immobile until bulging makes it unstable. The flow thus tends to advance over a layer of its own debris, formed by collapse of the repeatedly bulging front.

Aa lava flows generally have a 0.3 to $3 \mathrm{~m} \mathrm{(1} \mathrm{to} 10 \mathrm{ft}$ ) layer of fragmental material at their bases and tops (Macdonald, 1967). Distal aa lava flows contain few vesicles the 
reasons for this being that aa flow units have an average thickness on any given slope angle four times that of average pahoehoe flow unit and still move at the stage of cooling and crystallization when all but the thickest pahoehoe flow units have become totally static (Walker, 1989). This gives ample opportunity for the vesicles to be eliminated by shearing (Walker, 1989).

An idea of a basalt lava flow facies can be understood by classifying the various basalt flow types based on their relative position from their source vent. Although this author has not seen a formal paper outlining a basalt flow facies except for a brief mention from Knutson and others (1990) the following description is assumed based on the before mentioned work and the readings of other related material (Figure 19). A proximal basalt-flow facies

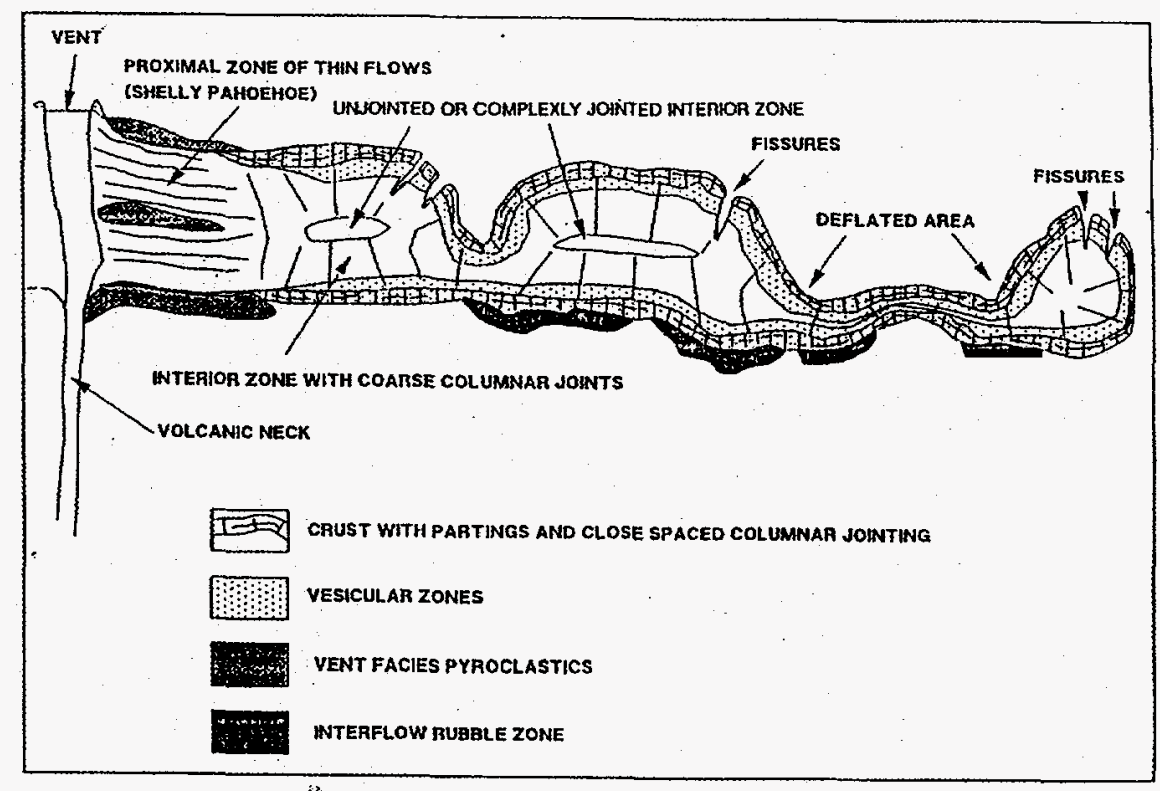

Figure 19. An idealized section of a basalt lava flow showing the changes that occur an account of distance from a vent (After Knutson et al., 1990).

is one where the basalt lava flow is made up of a zone of thin highly vesicular and oxidized lava, cavernous shelly pahoehoe with interlayered vent facies of pyroclastics and agglutinate. The thin lava from the vent grades outward into thicker ropy to slab pahoehoe flows with upper and lower crusts, upper and lower vesicular zones, columnar-jointed, and 
massive interiors for a medial facies. The distal facies exhibit numerous terminations of lava flows and irregularly-shaped lobes or fingers that extend outward from the main body of the flow. Slab pahoehoe lava is the most prevalent here. Pahoehoe lava may also change to aa lava at this point.

Based on observations of the basalt lava flows at the three outcrops the classification of these flows was determined to be entirely pahoehoe. One reason for this is the shape of the vesicles which were very regular, a characteristic of a pahoehoe lava. Also basalt lava flows seen in the outcrops are definitely very vesicular indicating that they were pahoehoe rather than aa lava. An appreciable amount of clinker type of material is absent from the basalt flow tops and bottoms also indicating that they are of pahoehoe origin rather than aa. Kuntz and others (1992) have studied the many surface basalt fields and have come to the conclusion that typical basaltic lava flows of the Eastern Snake River Plain are slab pahoehoe and shelly pahoehoe with aa and block-lava flows being rare. Jones (1969) as well as Whitehead (1992) and Nace and others (1956) have also come to a similar conclusion that pahoehoe lavas are the abundant type of basalts of the Snake River Plain.

Most basalt lava flows seen in outcrop have a gentle undulation with occasional ropy material on their surfaces indicating that they are corded or festooned pahoehoe. This ropy material thus indicates areas in the outcrop where the basalt flows were constricted in channels and indicates a medial facies. Further evidence for a medial facies idea can be supported by the basalt flows in the outcrops exhibiting an upper and lower vesiculated zone with a central interior and corresponding columnar zone (features common in the medial facies). Very rare in both Box Canyon and Swan Falls, and absent from the Twin Falls outcrop, are material (that shows up as arcs in cross-section), making up the surfaces of the basalt flows, which indicate that they were slab pahoehoe or shelly pahoehoe. The larger size and crusts of the upper and lower surfaces of this material indicates that they are more likely to be slab pahoehoe rather than shelly, but others fall into the shelly range and 
a definitive statistical analysis was not made to determine a overall dimension. The significance of this is that they indicate a more distal basalt facies, although as mentioned these features are rarely seen in the three outcrops studied. The lack in outcrops studied of any interlayered vent facies of pyroclastics and agglutinate material would indicate that they are not of the proximal facies.

\section{Flow-units}

Some authors distinguish between lava flows and lava flow-units. Because these terms are so ingrained in the literature their usage is reviewed here as it relates to this thesis. Flow-units (sometimes called lava tongues) are small lenticular bodies from 30 to more than $90 \mathrm{~m}(100$ to more than $300 \mathrm{ft})$ in transverse dimension and from 3 to more than $6 \mathrm{~m}$ (10 to more than $20 \mathrm{ft}$ ) thick, while in longitudinal section they may be as much as half a kilometer long (Nichols, 1936) (Figure 20). Jones (1969) has identified
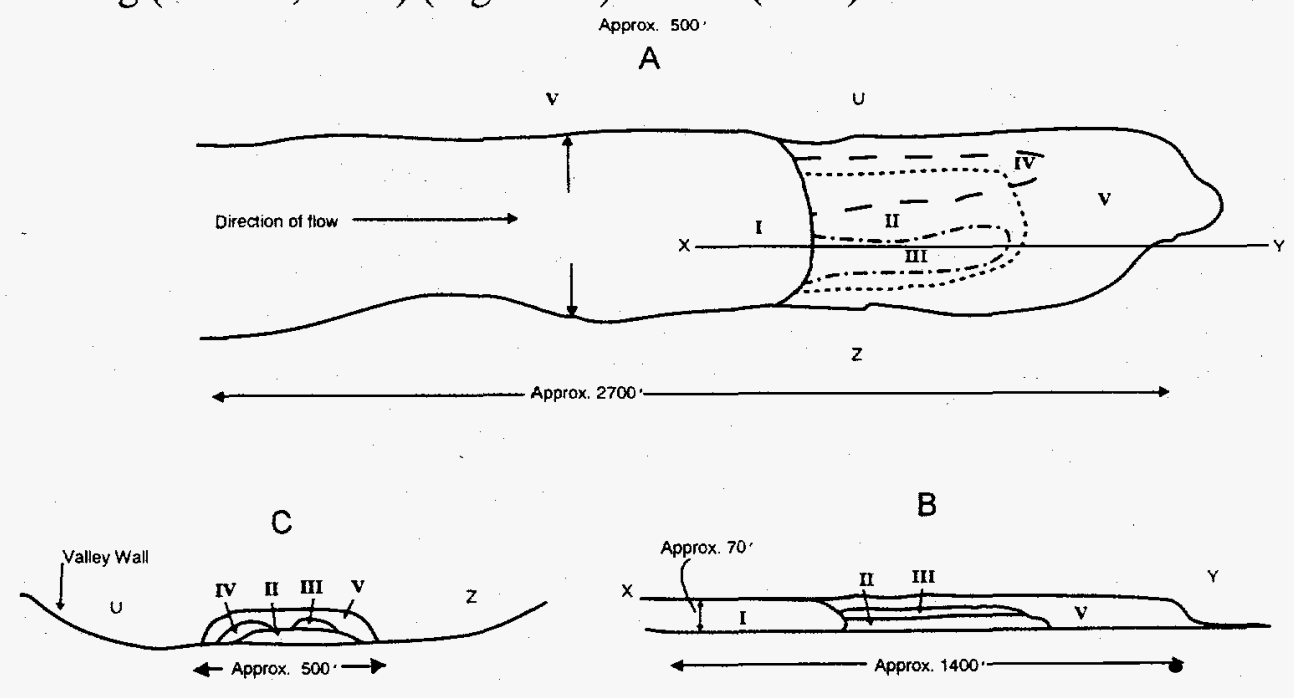

Figure 20. Three diagrammatic sketches showing tongues (flow-units) in plan and in transverse and longitudinal section. $A$ is the tongue in plan: $B$ is a longitudinal cross section along line $x y$ of $A$; while $C$ is a transverse section along line $U Z$ of $A$. The "I" flow can be thought of as a "parent flow" from which flow-units II, III, IV, and V evolve from (After R. Nichols, 1936). 
flow-units in the Columbia River Basalts with thickness ranging from 1.5 to $12 \mathrm{~m}$ (5 to 40 $\mathrm{ft}$ ). Contacts between them are close-fitting and irregular with an oxidized appearance (Nichols, 1936). Some criteria for distinguishing flow-units in outcrops are: (1) observable contacts; (2) distribution of vesicles (a thin vesicular zone about a few inches to a few feet can be found at the bottom versus a thicker vesicular zone from 1 to $3 \mathrm{~m} \mathrm{(4} \mathrm{to} 10 \mathrm{ft}$ ) that can be found at the top of the flow-unit); (3) columnar jointing; (4) sheeting; (5) short timeinterval between flow-units (no weathering, erosion, or deposition between flow-units, as the time interval between the eruption of units is too short perhaps a fraction of an hour or possibly a day or so); (6) limited size of flow-units (with successive flows it is often possible to trace individual flows for miles; with flow-units, owing to their limited size they do not persist for great distances); and (7) petrography (successive flows may differ petrographically, but flow-units are in general similar petrographically except for differences produced by differential cooling) (Nichols, 1936).

The simplest type of flow is when lava moves and solidifies as a single mass. Walker (1970) termed these simple lavas, as those which are composed of a single flow compared to lava flows composed of many small flow-units which he termed compound lava flows. He suggested that higher effusion rates controlled whether a simple or compound lava flow was generated with higher effusion rates generating simple lavas and slow effusion rates generating compound lava flows (Figure 21). A compound lava flow is developed by the eruption of lava which moves along a surface and starts to develop a cooled exterior with a still viscous interior. Not long after emplacement of the initial parent flow increasing hydrostatic pressure from the molten interior lava trying to advance forward initiates small ruptures at many points along the front part of the flow. Preserving their liquidity for a short period, tongues shoot out of the rupture and advance forward and quickly cool. Immediately after this other tongues of hot lava overflow the previous ones. 

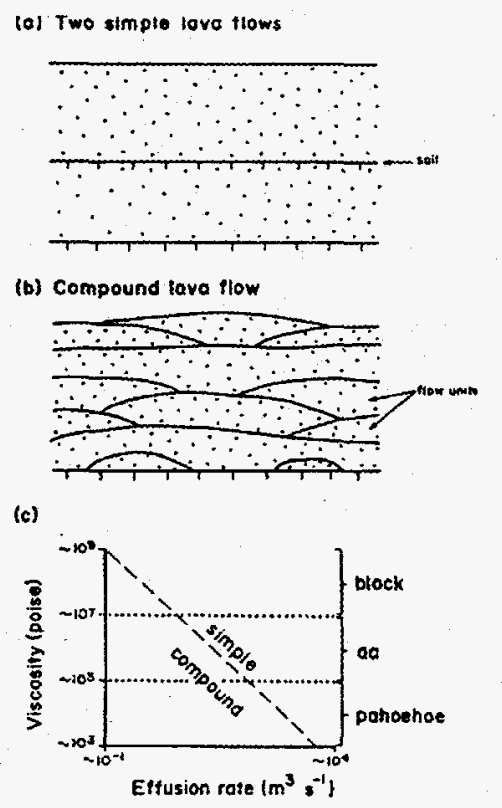

Figure 21. Simple and compound lava flows shown. Simple lava flows (a) lack flowunits that are found in compound lava flows (b). The plot (c) shows the control effusion has on generating simple or compound lava flows (After Cas and Wright, 1988).

This process is repeated over and over advancing the overall basalt lava flow (Nichols, 1936). In this manner a single compound flow can be made up of a series of many small flow-units.

Observations of the basalt flows in the three outcrop areas, based upon their overall shape, size, and the close fitting contacts without sedimentary material would lend evidence to classifying many of the separate flow entities as flow-units. Others have sedimentary interbeds above and below them or large thickness, thicker vesicular zones, columnar jointing, etc. clearly indicating a long time period between eruptive events and indicating that they are flows and not flow-units. Separate basalt flows are few as seen in all three of the outcrop areas compared to the number of flow-units present. Using Walker's (1970) terminology then these would be compound lava flows which are typically associated with pahoehoe rather than aa lava flows (Walker, 1970). 


\section{Nomenclature of a Basalt Flow and its Internal Features}

\section{Previous Work}

The internal structures of subaerial basalt flows in several localities worldwide are characterized by laterally persistent patterns of cooling joints know as "entablature" and "colonnade" (Tomkeieff, 1940). Colonnade typically occurs in the lower or upper third of a flow and consists of relatively well-formed basalt columns that are commonly perpendicular to the base of the flow (Long and Wood, 1986). The entablature overlies the lower or basal colonnade typically occupying the interior one-third to upper one-half of a basalt lava flow and is distinguished by irregular to hackle-like columns, which may form radiating patterns or otherwise deviate from an orientation perpendicular to the base of a basalt flow (Long, and Wood, 1986). Many authors have labeled varying thicknesses of internal structures of a basalt lava flow with the terms entablature and colonnade (Figure 22).

\section{Proposed Model for Snake River Plain Lava Flows}

What is proposed here is to further subdivide the present nomenclature used for identifying basalt internal structures to help in understanding and describing them. The nomenclature thus proposed was adapted from Faust (1978) from his observations and descriptions of the New Jersey Watchung basalt flows. It was felt that other authors lacked the necessary subdivisions of the separate internal structures to adequately describe the details that are present in the basalt. Some terms used in present literature conflict with each other and may not have been intended for general use, but for more specific cases. The author realizes that the purposed terminology would only be applicable to certain types of pahoehoe basalt flows. 


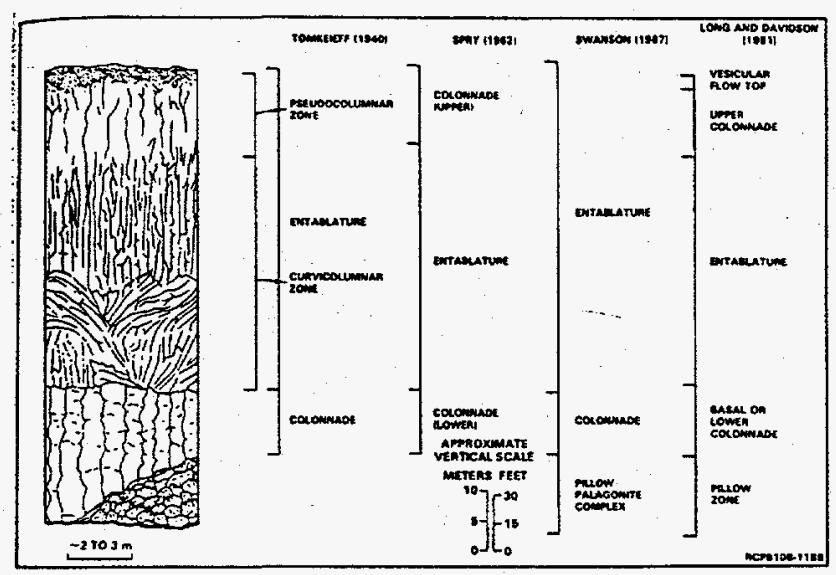

Figure 22. Nomenclature used in previous studies for a typical intraflow structures in a basalt flow. Fractures in this figure are represented in a stylized manner and are not to scale (After Long and Wood, 1986).

Based on the observations made on the three outcrops an idealized basalt lava flow model was generated that used a set of nomenclature that would be standard for the most common basalt lava flows found in the three outcrops (Figure 23). An upper vesicular zone, a sometimes absent columnar zone, central zone, and lower vesicular zone make up the idealized basalt lava flow. The upper vesicular zone is further subdivided by four subzones an upper vesicular subzone, transitional subzone, lower vesicular subzone, and bubble train subzone. The overall distinction between the different zones and subzones are based on the vesicle shape, size, vesicularity, and fractures present. The columnar zone is not always developed, but in some flows a zone of columnar jointing 0.6 to 1.5 meters ( 2 to $4.9 \mathrm{ft}$ ) thick lies beneath the upper vesicular zone (flow top). 


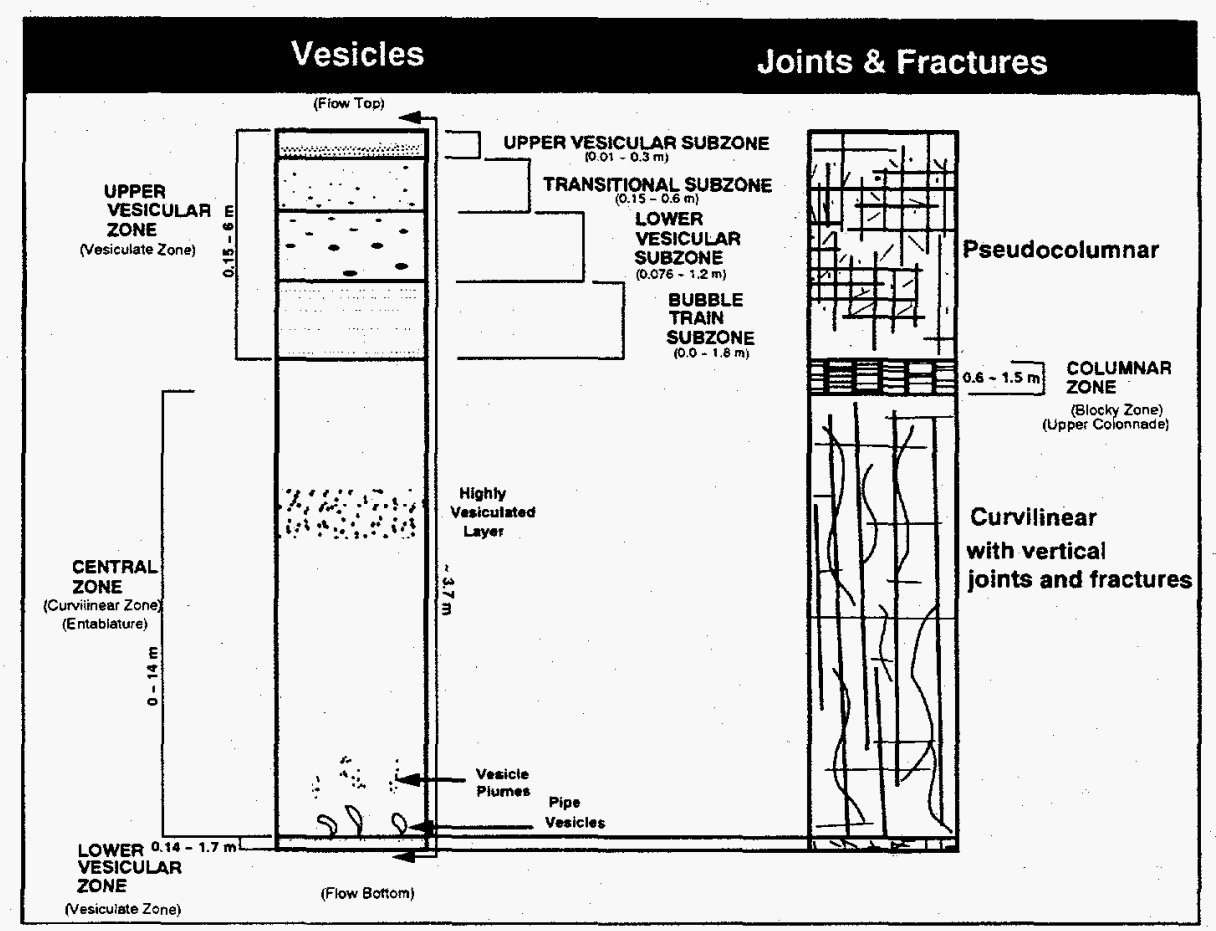

Figure 23. Model of SRP basalt lava flows showing differences in both vesicles and joints and fractures in an individual lava flow. This drawing was generated from observations of basalt lava flows in three outcrop areas. The terms in parenthesis under the labeled zones are the most commonly used labels for these particular locations in a basalt lava flow. Features shown on the basalt column are not to scale.

The central zone is the thickest 0.3 to $14 \mathrm{~m}(1$ to $45.9 \mathrm{ft})$ and the lower vesicular zone is always very thin 0.14 to $1.7 \mathrm{~m}(0.5$ to $5.6 \mathrm{ft})$, in comparison the upper vesicular zone $15 \mathrm{~cm}$ (6 in) to $6 \mathrm{~m}(20 \mathrm{ft})$. Entablature can be used as a synonymous term for the central zone however the jointing in this zone is different from that described by Long and Wood (1986). Likewise the columnar zone is synonymous with the term upper colonnade defined by Long and Wood (1986). Certain zones may be absent in a given basalt lava flow such as the bubble train subzone, columnar zone, and lower vesicular zone depending on the basalt lava flow thickness. Lower colonnades are also absent in the three outcrop areas. It is not known why lower colonnades are not found, but it is most likely due to basalt flow thickness. 


\section{Upper Vesicular Zone Vesicles}

\section{Upper Vesicular Subzone}

The upper vesicular subzone makes up the thinnest portion of the upper vesicular zone and has the greatest vesicularity. This subzone ranges from $1 \mathrm{~cm}(0.4$ in) to $0.3 \mathrm{~m}(1 \mathrm{ft})$ in thickness. The size of the vesicles are very small (average diameter $0.3 \mathrm{~cm}(0.1 \mathrm{in})$ and are nearly spherical in shape (Plate 10). Numerous fractures found in this subzone are filled with a characteristic light-colored material. In the upper vesicular subzone the basalt typically has a reddish color or a white coating which contrasts with the dark gray to black color in the central zone. The light colored material is related to surface exposure and infiltrating of water and dust.

\section{Transitional Subzone}

The most prominent features in the transitional subzone are the vesicles. Both the size and number of the vesicles change towards the center of a basalt flow. The overall vesicularity is intermediate between the upper vesicular subzone and the lower vesicular subzone (Plate 11). Large and small vesicles can be found here, but medium sized vesicles are the predominant types (average diameter $1.1 \mathrm{~cm}(0.4 \mathrm{in})$. Large and medium vesicles outnumber the smaller ones. The medium-sized vesicles tend to occur towards the center of the subzone and occur before the larger vesicles in the lower vesicular subzone. Medium-sized vesicle shapes are oblate spheroids, and are more spherical in shape than the larger vesicles. This subzone is usually thicker $(0.15-0.6 \mathrm{~m})$ than the upper vesicular subzone but thinner than the lower vesicular subzone and the bubble train subzone below it.

\section{Lower Vesicular Subzone}

Vesiculation is overall less in the lower vesicular subzone than in the upper vesicular subzone and the transitional subzone. These vesicles are of a larger type (typical diameter 
$3.2 \mathrm{~cm}$ (1.3 in). Small and medium vesicles can also be present (Plate 12). Not only is the size of the vesicles different, but the overall shapes of vesicles change in that they are more oblate than in all previously mentioned vesicle zones. They seem to have the shape of an airfoil or a "whale's back" with a flat bottom and curved top. Some of these vesicles may have secondary crystalline material filling the inside of their void. These fillings are termed "amygdules" (Macdonald, 1967).

\section{Bubble Train Subzone}

The bubble train subzone is the lowermost and thickest (around $1.8 \mathrm{~m}(5.9 \mathrm{ft})$ thick subzone making up the upper vesicular zone. Bubble trains within this zone are thin (ranging from 0.1 to $2.5 \mathrm{~cm}(0.04$ to 1 in) thick) laminae composed of small vesicles that are parallel to the top of a basalt lava flow. In outcrop these vesicle rich laminae form crude lines across the basalt surface. These trains occur also within some zones of diktytaxitic texture. These bubble trains can also be seen to crosscut larger vesicles meaning that the bubble trains formed after the larger vesicles (Plate 34).

The trains are very common in the upper portion of this subzone; however, the number of trains decreases towards the center of the flow becoming very rare in the dense central zone. Spacing between trains varies greatly from $3 \mathrm{~cm}(1 \mathrm{in})$ to $3 \mathrm{~m}(10 \mathrm{ft})$ or more. In outcrop the bubble trains maybe traced along the entire length of the flow outcrop for distance of $100 \mathrm{~m}$ or more.

\section{Upper Vesicular Zone Jointing}

The upper vesicular zone as a whole has a rectangular aspect with a joint system forming a slab aspect that grades to a pseudocolumnar to columnar aspect. The rectangular joint system is made up of a jointing that is parallel to the flow top and jointing that is vertical or perpendicular to the parallel jointing (Figure 16). Within the rectangular joint 
system are transverse joints at an angle of about 45 degrees with the flow top. These joints cut across the four subzones grading into the columnar zone.

\section{Columnar Zone}

The thickness of the columnar zone can vary greatly and usually makes up only a small portion of the basalt flow (Plate 29). The relative location of this zone within a basalt flow is also highly variable; it commonly occurs just below the flow top or occasionally at the flow bottom. At the bottom it is called the colonnade (Tomkeieff, 1940). In some basalt flows it is completely absent. In the outcrops studied the columnar zone usually is present in the upper portions of a basalt flow and is sometimes vesiculated in its upper portions. Columnar jointing and lack of appreciable amounts of vesicles distinguishes the columnar zone from the other zones. Vertical joints make up 5 to 6 sided polygonal or hexagonal

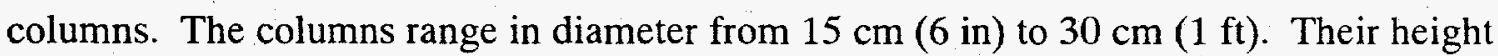
ranges from $2.4 \mathrm{~m}(4 \mathrm{ft})$ to $6 \mathrm{~m}(20 \mathrm{ft})$.

\section{Central Zone Vesicles}

The central zone makes up the thickest portion of the basalt flow. It can range from 0 to $14 \mathrm{~m}$ ( 0 to $46 \mathrm{ft})$ in thickness. This zone is generally without vesicles except for the occurrence of very pronounced regions of vesicles. These vesicular regions can range up to 0.31 meters $(1 \mathrm{ft}$ ) in thickness (Plate 15$)$. Vesicles commonly are absent above and below these regions as well as throughout the central zone. More rare are areas of extreme vesiculation that have a plume shape. Other vesicular features are very irregular in outline such as irregular amoeba-like shapes with long linear vesicular arms coming out of the general mass (Plate 21). Unlike the bubble trains, the plumes are not very long, with the longest

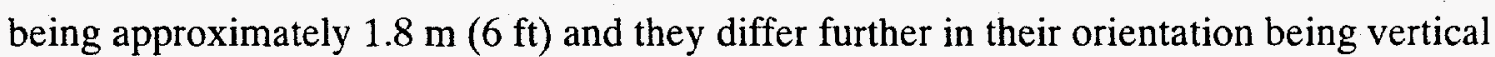
(perpendicular to the flow top) rather than the bubble-trains which are horizontal (parallel

to the flow top). Plumes are found more commonly in the lower part of the central zone. 


\section{Central Zone Jointing}

As described earlier in chapter 3 the central zone is made up of curvilinear joints that have the appearance of a helix ranging from 1.5 to $3 \mathrm{~m}(5$ to $10 \mathrm{ft})$ in height with apertures ranging from $1 \mathrm{~mm}(0.04 \mathrm{in})$ to $2 \mathrm{~cm}(0.8 \mathrm{in})$. Vertical joints perpendicular to or slightly at an angle to the flow top are also typical in this zone. These joints extend from the top to the bottom of the central part of the central zone. Vertical joints combined with the curvilinear joints give the central zone a pseudocolumnar aspect.

\section{$\underline{\text { Lower Vesicular Zone }}$}

Vesicles in the lower vesicular zone have an opposite arrangement when compared to the upper vesicular zone. The vesicle size decreases closer to the bottom of the flow as compared to the increase in size of the vesicles towards the center of the flow in the upper zone (Plate 24). Overall size of the vesicles is smaller than those found in the upper vesicular zones. Vesicularity also increases towards the bottom of the lower vesicular zone opposite to the upper vesicular zone where the vesicularity is the greatest at the top and decreases towards the bottom. At the bottom of this zone many small vesicles are present, yet the relative number is fewer than the vesicles found at the flow top. Ranging from 0.14 to $1.7 \mathrm{~m}(0.5$ to $5.6 \mathrm{ft})$ thick this is usually the thinnest zone that can be found in a basalt flow. The overall color of this zone is also different in that it is usually a darker color than the rest of the basalt flow.

Large hollow tubes raging in size from 3 to $8 \mathrm{~cm}$ (1 to 3 in) long and orientated perpendicular to the flow bottom (i.e. vertical) are also found just at the lowest point of the central massive zone signaling the start of the lower vesicular zone. These tubes exhibit a rounded top and a tapered bottom. The diameter of the rounded tops are usually less than $1 \mathrm{~cm}$. The tapered bottom points in the direction of the bottom of the basalt lava flow. 
Usually jointing in this zone is a result of extension of jointing in the central zone, but overall rock at the base of the flow lacks much jointing.

\section{Summary}

In some flows a zone of columnar jointing 0.6 to $1.5 \mathrm{~m}$ ( 2 to $4.9 \mathrm{ft}$ ) thick lies beneath the upper vesicular zone (flow top), but may not always be developed. The central zone is the thickest 0.3 to $14 \mathrm{~m}$ ( 1 to $46 \mathrm{ft}$ ) and the lower vesicular zone is always very thin 0.14 to $1.7 \mathrm{~m}(0.46$ to $5.6 \mathrm{ft})$, in comparison the upper vesicular zone. Entablature can be used as a synonymous term for the central zone likewise the columnar zone is synonymous with the term upper colonnade defined by Long and Wood (1986), but since not all flows have columnar zones these terms may not be widely applicable.

\section{Origin of Vesicle Zones}

The vesicle arrangement in the outcrops is characterized by a highly vesiculated flow top and bottom and a flow interior which is almost free of internal vesicles. So persistent is this arrangement that it can be used as a way to identify ones location in a basalt lava flow at an outcrop as described in the nomenclature section. In this study the term "vesicle" refers to megascopic, predominantly spheroidal voids to distinguish them from irregular, intercystalline voids.

The genetic implication of using the term vesicle indicates that these features were formed from a viscous liquid, such as the basaltic magma, which exsolves a gaseous phase to form bubbles. When a body of lava cools and solidifies it loses its original gas content by the formation of bubbles that rise out of the lava. Gas bubbles, owing to their buoyancy, rise at a rate determined by their size and the viscosity of the lava (Sahagian, 1985).

Coalescence can occur if the sizes and velocities of bubbles vary; consequently the initial size distribution of bubbles in a lava flow is modified during solidification (Sahagian, 1985). The bubble distribution is initially uniform throughout a flow. Bubbles start to rise 
when a lava body is still liquid. Crystallization begins from the top and bottom with the larger bubbles rising faster than the smaller, thus overtaking them and leading to coalescence and creation of yet larger bubbles (Sahagian, 1985). Large bubbles will move more rapidly than small bubbles which follows from a consideration of the term $\mathrm{r}^{2}$ in Stoke's law where $v=$ the rising velocity of the gas, $r=$ radius of the bubble, $\left(p_{\text {melt }}-p_{\text {gas }}\right)=$ difference

$$
v=\frac{2 r^{2} \cdot g\left(p_{m e l t}-p_{g a s}\right)}{9 n}
$$

in densities, $\mathrm{g}=$ acceleration of gravity, and $\mathrm{n}$, the viscosity (Faust, 1975). As the crystal fronts move, they encounter rising bubbles with the bottom front moving in the same direction as the rising bubbles, and "chase" them so that any bubble caught by the crystal front remains frozen in its location (Sahagian, 1985) (Figure 24). Since the crystal front advance slows with time, it becomes less effective at catching bubbles as a result, the final bubble concentration at the bottom of the flow should be a local maximum, decreasing upwards (Sahagian, 1985). The time dependent behavior of the upper crystal front is similar to that of the lower front, but unlike the lower front, it moves in the opposite direction of the rising bubbles thus the very top of the flow should be expected to trap and freeze in the initial bubble size distribution. Thus the lower vesicular zone has a maximum vesicularity equal to the initial vesicularity, and the upper zone has a minimum of the initial vesicularity. With time, a central liquid region diminishes in vesicularity because the lower crystal front catches and keeps bubbles from replenishing the overlying layer resulting in the liquid portion developing a region devoid of bubbles (Sahagian, 1985). 

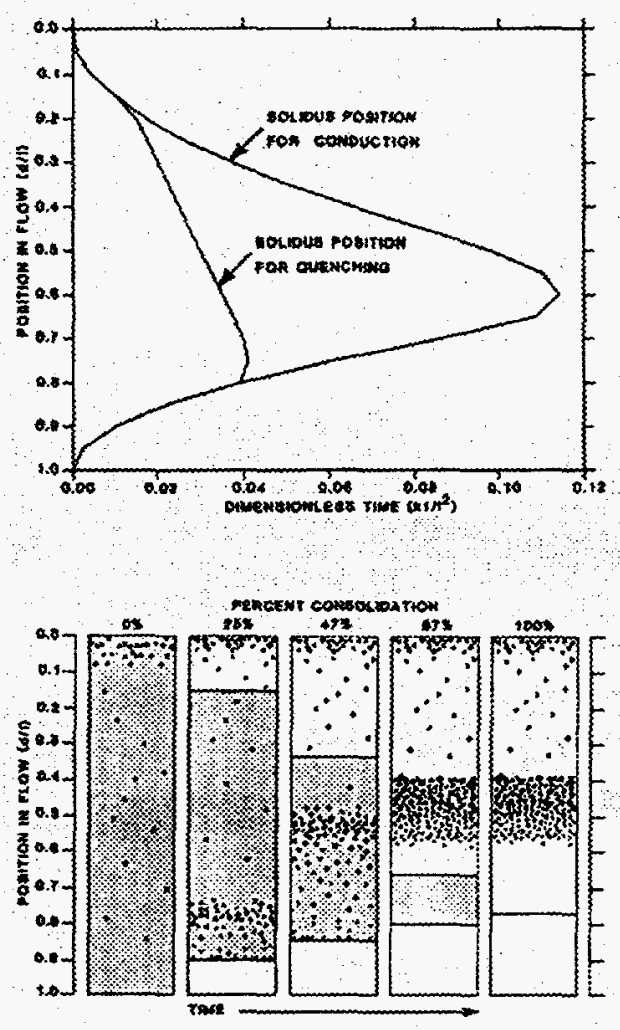

Figure 24. Advancing crystal front movement is shown leaving various layers of vesiculation. Top plot shows solidus position vs. time for cooling of flow entirely by conduction and by quenching of entablature by combined conduction-convection, based on thermal model of Long and Wood (1986); $\mathrm{d}=$ depth in flow, $\mathrm{l}=$ flow thickness, $\mathrm{k}=$ thermal diffusivity, $\mathrm{t}=$ time. Apices of curves are theoretical meeting points of solidification fronts. Lower figure shows the sequential development of flow-top and internal vesicular zones relative to positions of upper and lower solidification fronts at various stages of consolidation. Shading indicates melt; white indicates solid. For simplicity, all bubbles are assumed to migrate at 1.5 times rate of upper solidification front based on $\mathrm{d} / \mathrm{l}=0.4$ for top of vesicular zone (After McMillan et al., 1987).

If this is the correct model for vesicle formation then it explains the presence of the various vesiculated zones and subzones as well as the formation of the vesiculated layers in the central zone. Sahagian, et al., (1989) model then predicts the formation of an upper and lower vesicle-rich zone separated by a vesicle-poor interior with the upper zone being broader, more vesicular, and having larger bubbles than the lower zone (Sahagian, et al., 
1989). This is what is seen in all of the basalt lava flows in the three outcrops; an upper and lower vesicular zone with the upper being broader, more vesicular, and having the largest vesicles.

Very large vesicles found in the lower vesicular subzone are unique in their size and shape. Large vesicles are usually the result of coalescing of many smaller vesicles (Walker, 1989), but the large size of those seen in outcrop might hint to another mechanism. One possible origin of these features could be gas blisters. Gas blisters form where the vesicles became so closely-spaced that they coalesce, and the upper section of the lava parts from the lower section and was up-arched (Walker, 1989). Formation of vesicles the size found in the lower vesicular subzone may take several generations of coalescence. Floor and roofs of the large vesicles have a distinctive bubble-wall texture consisting of disrupted vesicles, sometimes with filaments or spike-like extensions where the floor separated giving them a superficial resemblance to drained-out lava tubes (Walker, 1989). These textural features on the floors and roofs of the large vesicles found in the outcrops would further support the idea that they were gas blisters.

The bubble train subzone could be interpreted to form where relatively late flowage took place in the basalt lava. Shearing causes vesicles to grow, and promotes ascension towards the top of a zone where they tend to be concentrated (Walker, 1989). Some of these late-flowage zones contain a second generation of very small vesicles, many of which have diktytaxitic spaces within the groundmass crystal mesh representing the final release of gases during crystallization, after the lava movement had ceased (Walker, 1989). Field observations of the diktytaxitic texture and size of the bubble train sheets indicate that this is a likely origin. Walker (1989) also noted that these "zones" of late flowage commonly parallel the flow-unit boundary. This feature was observed in outcrop at the three separate locations of this study. He also noted that the thickest flow-units show evidence for the most extensive late flowage. This late flowage is thought to be the result of a "flow pulse" 
(generated by a new bud surging forth from a crusted front resulting from hydrostatic pressure build-up) that is transmitted through solidifying flow-units. This concept is supported by the observation of basalt lava flows found in each of the three outcrop locations that the thickest flow-unit was usually the one to have these bubble-train features, while in thinner basalt flow-units these are usually poorly developed or absent.

\section{Columnar Structure}

Columnar structures in basalt are very common around the world and are readily identified in outcrops. The attitude, size, shape, and regularity of the columns depend upon the viscosity of the lava, the temperature of the lava, the rate of cooling, the regularity of cooling, and the homogeneity of the lava (James, 1920). The greatest controlling factor in the formation of the columns is contraction due to cooling (James, 1920). When basalt lava begins to cool, parts of it contract about centers, and parts between extend somewhat under tension. If thermal contraction overcomes the elastic or viscous extension then the basalt cracks. In a perfectly homogeneous rock the easiest relief of tension within an isotropic layer of lava is by the formation of numerous regularly spaced centers having three fractures that make angles of 120 degrees with each other. Thus hexagonal columns are formed, but this is the ideal condition dependent upon slow, uniform shrinkage of a homogeneous material. In many basalt outcrops a slight dominance of pentagons over hexagons exists (Beard, 1959) (Figure 25). The cracks would then extend down into the hot solid rock only a short distance to that point where the tension was equal to the extensibility and would extend downward following this front (James, 1920). If this is true then slower cooling would produce greater contraction and larger columns. Columns are perpendicular to the isothermal planes and where two cooling surfaces are inclined to one another a major joint plane separates two sets of columns (James, 1920). Columns curve toward higher temperatures, and curved columns form where isotherms are not parallel to one another. 


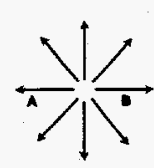

(e)

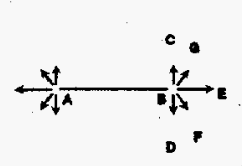

(b)

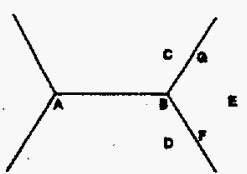

(c)

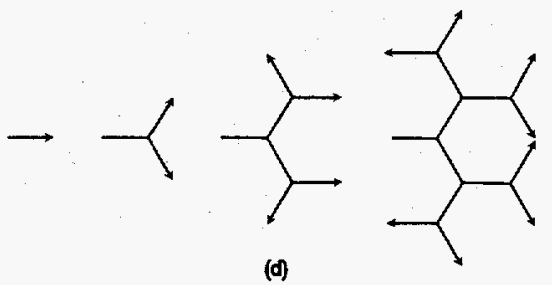

(d)

Figure 25. Hypothetical method of continual fracture propagation yielding hexagonal patterns. (a) area where tensile stress is equal in all directions; (b) fracture AB relieves tension in direction parallel to $C D$, length of arrows indicate the magnitude of the tension still unrelieved; (c) a pair of fractures in the BG and BF directions; (d) continuation of process produces hexagonal patterns (After J. Meints, 1986).

The reason for this is that the cooling in one direction is more rapid than in another and the columns bend in the direction of greatest cooling (James, 1920) (Figure 26).

The ball-and-socket structure and the "Dutch cheeses" structures are briefly summarized from James (1920). Cross joints are secondary features that divide up the columns.

Vertical columns shrink as the rock cools, while horizontal contraction causes a widening of the vertical joints while tension in other directions is relieved by cracking. Necessarily centers of contraction are distributed equally along each column and particles will concentrically be drawn toward these points. This causes concentric weakening and cracking as well as a well-defined horizontal joints between two centers of contraction (Figure 27). These concentric cracks give the columns a ball-and-socket structure or an onion structure giving them the appearance of distinct spheroids due to the concentric spheres of contraction. "Dutch cheeses" structures in the columns are just the oblate spheroids seen piled one above the other giving them the appearance of cheeses stacked on each other. 


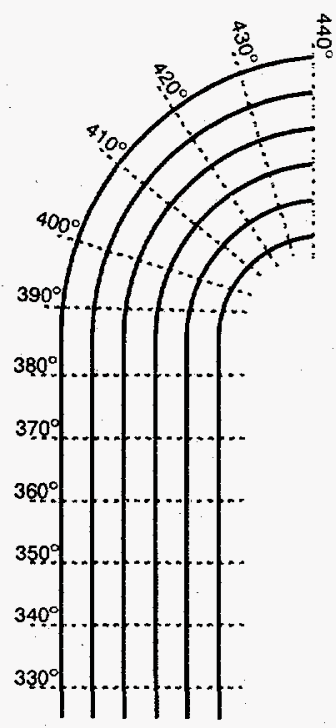

Figure 26. Figure showing the relation of the attitude of the columns to the isothermal planes.

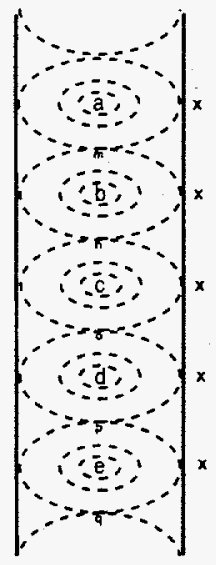

Figure 27. Dutch cheese structure. The shape of the spheroids depends on the balance between the difference in tension between "ax" and "am", which tends to make the spheroid oblate and the downward pressure of the column tending to make the spheroid prolate (After A. James, 1920).

The spacing of columnar jointing has been documented to increase toward the interior (Aydin and DeGraff, 1988). The spacing of cooling joints that grow down from the top of a lava flow is smaller than the spacing of those that grow up from the base (Pollard and 
Aydin, 1988). This has been attributed to a faster cooling rate at the flow top (Long and Wood, 1986). Outcrop observations tend to support this idea.

Columns observed from the outcrops are caused by contraction from a slowly cooling basalt lava body. The fact that not many columns are bent indicates that most of the basalt lava flows were cooling on horizontal topography.

\section{Spheroidally Jointed Basalt}

The solid rock spheres that were only found in the Swan Falls outcrop could be the ball-and-socket structures or "Dutch cheeses" described by James (1920). What seems to contradict this idea is the lack of evidence pointing towards the spheroids being uniformly stacked on each other. Rather what was observed is varying diameter spheroids randomly positioned in the outcrop wall. The more plausible explanation for these objects is spheroidal weathering with exfoliation occurring as mineral volumes expand under weathering or hydration. Weathering results in an alteration front of solutions which advances from the joints in the columns towards the center of them (Augustithis, 1978). The advancing hydration front in conjunction with spheroidal weathering and exfoliation of the basalt columns results in boulders with an unaltered basalt core and a clay-rock cover. Evidence of chemical weathering about the spheroids is the soft friable material (although no analysis was carried out on this material). This and the random distribution in this author's opinion would indicate that the features shown in Plates 27 and 28 are the result of spheroidal weathering with exfoliation.

\section{Jointing: Non-Columnar}

Jointing throughout the basalt outcrop is either derived from: tectonic processes, weathering, contraction due to the cooling of a still molten lava, or a combination of processes (such as three mutually perpendicular joint sets combining to form a rectangular parallelepiped). It is very difficult to distinguish between the different types in the field. 
Cooling joints are always present. Cooling joints are limited to certain zones while tectonic joints are not and can cut across several zones. Cooling joints are more rectangular in shape and usually are perpendicular to the flow surface (Pollard and Aydin, 1988). Using the idea of superposition, tectonic joints might be those that cut across preexisting cooling joints. Joint geometry used by itself only defines the joints, but does not indicate the geologic process which produced them. To identify tectonic joints one needs to use all of these relationships to distinguish between tectonically derived joints and cooling joints.

The vesiculated top of the basalt lava flow has a pseudocolumnar aspect to it caused by joints which represent cooling joints, consisting of a flat surface (basal plane) and rectangular forming joints. The origin of the transverse 45 degree fractures is not understood.

Several types of joints are identified in the central part of the basalt lava flow. Curvilinearly jointed rock is the most prominent feature in this part of the basalt flow. The origin of these joints is given by Faust (1978) who assumes that they are the result of convective heat transfer processes forming pseudocolumnar joints that when broken show a helicoidal surface whose bounding surfaces are former convection cells. Thus the curvilinear joints are related to the class of surfaces know as helicoids. The pseudocolumnar joints are produced by a combination of a cooling joint system and a set of parallel planar vertical joints. Platy-prismatic joints are fracture cleavage which is made up of a fracture cleavage superimposed on preexisting cooling joints of the curvilinear type.

Sheeting joints are also found in the center and throughout the basalt lava flow. Sheeting joints generally form as a result of physical weathering which removes the superimposed load from the rock it exposes (Faust, 1978). This removal of overburden permits the rock to dissipate its stored strain energy chiefly in the formation of cracks oriented parallel to the ground surface (Faust, 1978). 
Feather-Fracture

Feather-fractures or plumose fractures commonly are on shear joint surfaces as a pattern that includes an axis, plumes or barbs diverging from the axis, and a border or fringe composed of two sets of intersecting fracture planes (Figure 28). Experimental work suggests that the "cleavage fracture" of mild steel, is analogous to that of feather-fracture in rocks and is characteristic of brittle failure, producing no distortion, and requires expenditure of only small amounts of energy (Roberts, 1961).

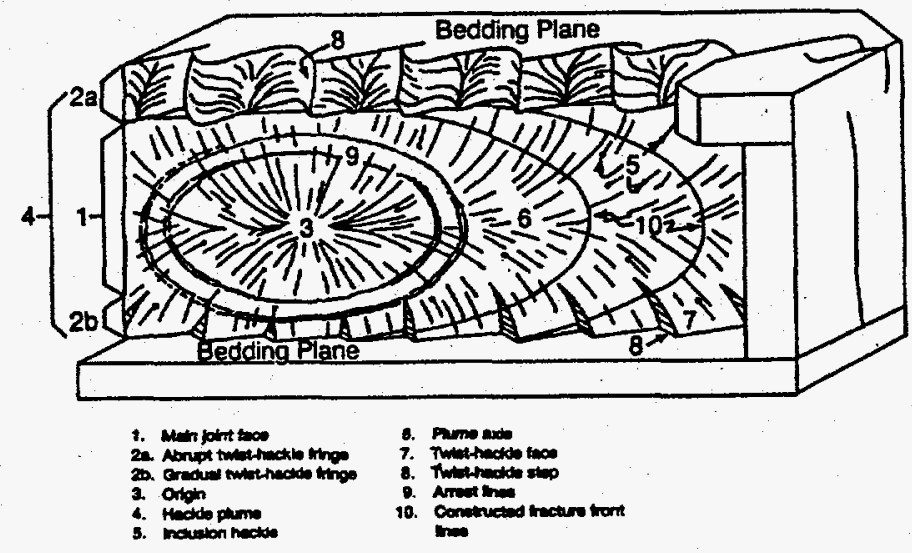

Figure 28. Feather-fracture or hackle plume is seen here with its associated surface structures (After Kulander et al., 1990).

Feather-fractures are common on fracture surfaces (typically found on the vertical to transversely-oriented fractures) at the three outcrop locations. Feather-fracture patterns can be used to determine fracture centers in rock masses accurately, but in the scale of this work the centers were not found for feather-fractured basalt rock at the three outcrop locations.

Joint propagation direction can be determined from a set of joints that initiate at a source and decrease in number away from it by elimination. Joint systems near the base of lava flows show upward elimination, indicating an upward overall growth direction (Pollard and Aydin, 1988). The upward elimination of the joints at the bottom of the basalt 
flows as well as the downward elimination of the cooling joints at the surface of the basalt lava flows are observed for the basalt lava flows at the three outcrops. This is reflected in the decrease in number of joints counted along the scan lines near the center of the basalt flow as compared to joints along scan lines near the top and bottom of them.

\section{Color}

The color changes found in the basalt rock are due to alteration processes before and after solidification and partly due to the secondary changes in colors on surface from vesicles and joints being filled with different colored material compared to the adjacent basalt. Many colors have been reported for basalts from shades of gray, purple, red, to black varieties. Gray and black shades are primary colors that reflect variations in the essential mineral and glass composition of the rocks while purple shades are produced by gas reaction in the lava during emplacement and by subsequent minor chemical weathering (Deutsch and West 1952). Olivine is a mineral susceptible to alteration processes and particularly to weathering being the first mineral to be altered (Augustithis, 1978). Olivine alters mostly into chlorite $\left(9\left(\mathrm{Mg}_{8} \mathrm{Si}_{4} \mathbf{O}_{16}\right)->4\left[\mathrm{Mg}_{12} \mathrm{Si}_{8} \mathbf{O}_{20}(\mathrm{OH})_{16}\right]\right)$ with some hematite and quartz produced as alteration products. A large amount of $\mathrm{Mg}$ is expelled from the olivine alteration to chlorite (Augustithis, 1978). Low-Mg chlorite has a greenish color. Olivines can also alter to brown chlorite due to the replacement of $\mathrm{Mg}$ by Fe and possibly of $\mathrm{Al}$ by $\mathrm{Fe}$ (Augustithis, 1978). Iddingsitization can also occur from the expelled $\mathrm{Mg}$. Iddingsite consists essentially of goethite, amorphous silica and magnesia with some smectite. This Iddingsitization process is a hydrothermal metasomatism of lava transversed by volcanic gas resulting in the alteration of olivine (Augustithis, 1978). Since these alterations are on the olivine minerals the color contribution is only on mineral grainsize scale. Iron mobilization and movement on the other hand, is more prevalent in coloring the rock since it is capable of traveling over the basalt resulting in diffusion rings. The hematite gives the basalt a reddish color and limonite a yellow-brown color. Alteration 
of the basalt produces large losses of $\mathrm{Mg}, \mathrm{Ca}, \mathrm{Na}$, and $\mathrm{K}$ with smaller losses of $\mathrm{Si}$ forming smectite, halloysite and kaolinite with enrichments of Ca and Fe (Augustithis, 1978).

Overall reddish color in the basalt is mainly due to the oxidation of some of the iron in the rock, chiefly at the time of cooling. This color is very prominent where the gas escapes on the surface of the basalt flow. Enrichments of $\mathrm{CaCO}_{3}$ and $\mathrm{CaSO}_{4}$ also form a sort of "white-wash" coloring the basalt a whitish color.

The fillings of fractures, joints, and vesicles can form from circulating groundwater. Sedimentary material fills in open spaces at the top of a basalt flow. Vesicular cavities can have prismatic pyroxenes, quartz, zeolites, calcite, and monomineralic substances filling them, with calcite and quartz being the most common filling substance (Augustithis, 1978). With these present and usually lighter colored material filling joints and fractures an overall pseudo-lighter color can be derived for the tops of basalt lava flows. Secondary calcite has been known to be abundant in basalt rocks at the INEL with the calcite filling the vesicles and replacing parts of glass (Nace, et al., 1956). Adding this effect with the reddish oxidation the overall color is a reddish to light gray rather than a straight black color. The lower vesiculated basalt flow bottom has an overall darker appearance than the rest of the basalt flow in outcrop. No petrographic study was carried out to look at the mineral distributions in the basalt flows seen in outcrop. 
Plate 33. Picture of ropy pahoehoe lava flow looking down on its surface.

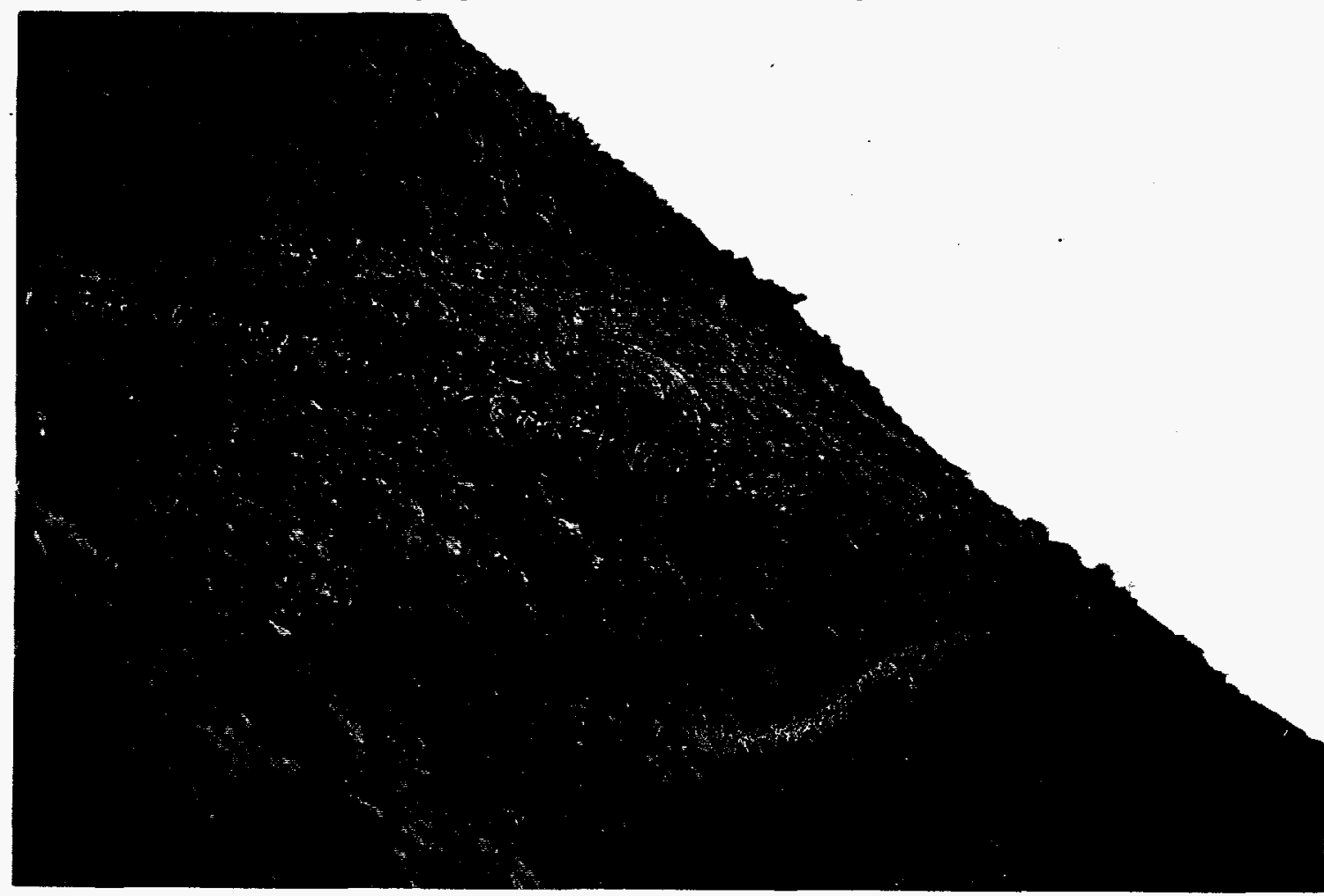

Plate 34. Picture of a basalt core at the INEL showing a bubble train crosscutting a larger vesicle.

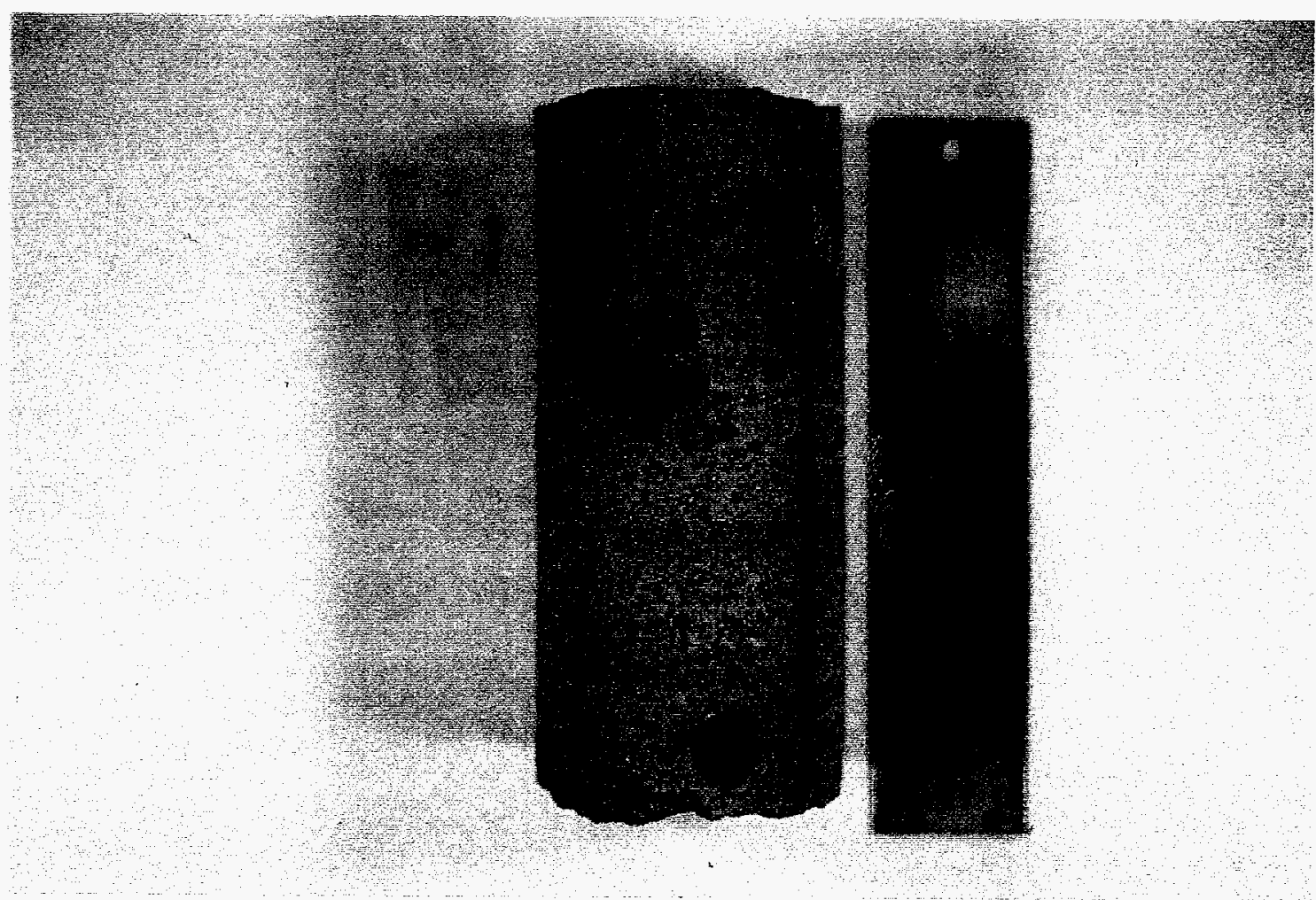




\section{CHAPTER 5. DATA COLLECTION METHODS: BOREHOLE TELEVISION}

\section{Purpose And Objectives}

A purpose of this study is to use the borehole television camera to examine boreholes with walls open to the basalt and to determine if basalt lava flow features seen in outcrops and cores can be identified in TV images. The appearance of hydrologically significant basalt lava flow features on TV log images is illustrated in this study. It is hoped that these illustrations will aid others in interpretation of TV logs and broaden their use in understanding the subsurface hydrogeology at INEL.

\section{Location}

Over 50 borehole TV logs were viewed from many different sites at the INEL (Figure 2). The sites included are the Idaho Chemical Processing Plant (ICPP), Test Reactors Area (TRA), Radioactive Waste Management Complex (RWMC), and the New Production Reactor (NPR). Most logs had 31 to 61 meters (100 to $200 \mathrm{ft}$ ) of exposed borehole wall of basalt and sedimentary interbeds. The choice of the different boreholes was determined by the availability of the logs to the author and special interest in the boreholes at the ICPP. Borehole TV logs were viewed to find common and dissimilar features and quantitative measurements were taken from the images. Many photographs were taken of these TV images. Twelve specific boreholes were singled out for detailed quantitative analysis of the features found in the borehole TV logs. These boreholes are USGS 41, 42, 43, 44, 45, 46, $47,48,57,80,81$, and well number 123 . All of these are located at the ICPP (Figure 3). All quantitative measurements are taken from the portions of the borehole below the water 
level although visual inspection was given to all portions of the boreholes for all borehole studied.

\section{Equipment}

Borehole TV cameras have been used before to inspect the insides of pipes, tubing, and boreholes which could not otherwise be satisfactorily observed (LeRoy, et al., 1977). A typical borehole TV camera is made up of a long pipe housing a TV camera with its own source of illumination in the form of an internal lamp (Figure 29). The operation of the tool Borehole Television

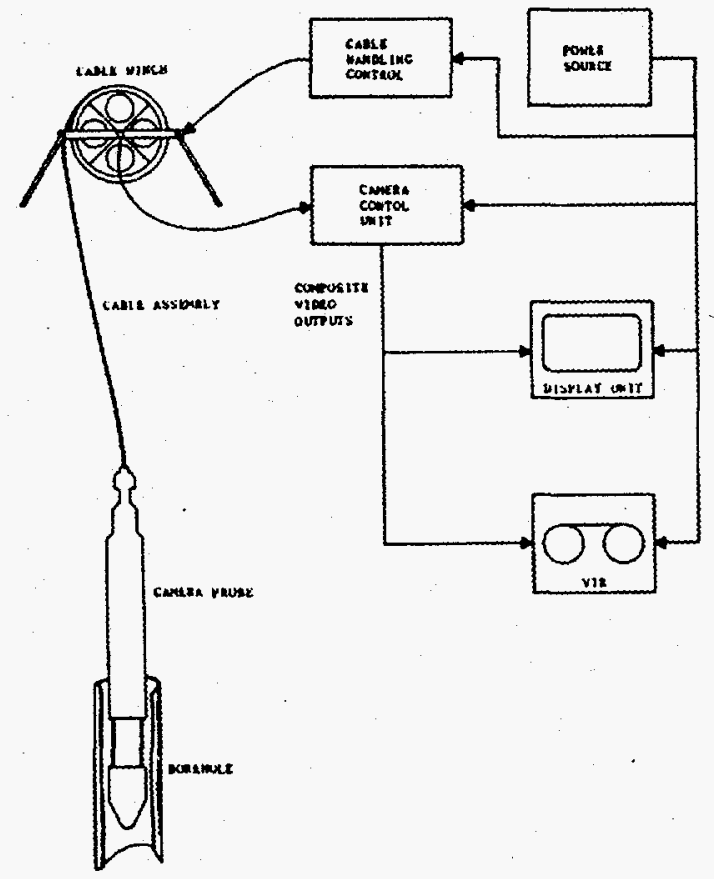

Figure 29. Schematic diagram of the borehole TV camera set-up.

is to simply lower the camera down the borehole. The speed at which the camera is lowered, the lamp's intensity control, camera scanning, focusing power iris adjustments, and sensitivity are all controlled by equipment on the surface. As the camera is lowered picture information gathered by the TV camera is recorded simultaneously by a video-cassette- 
recorder (VCR). A running depth value for every foot is recorded along with the borehole TV images on the video cassette. Real-time viewing of the borehole camera images can be seen by the operator on a TV monitor on the surface (Figure 29). Underwater viewing as well as open air records can be made in the borehole. Normally, the borehole camera views the borehole wall in a radial direction (end view) looking down the tool length as if your eye is looking straight down the borehole at the end of the tool, but attachments and various other models can allow radial viewing of the side wall (Figure 30). This side viewing
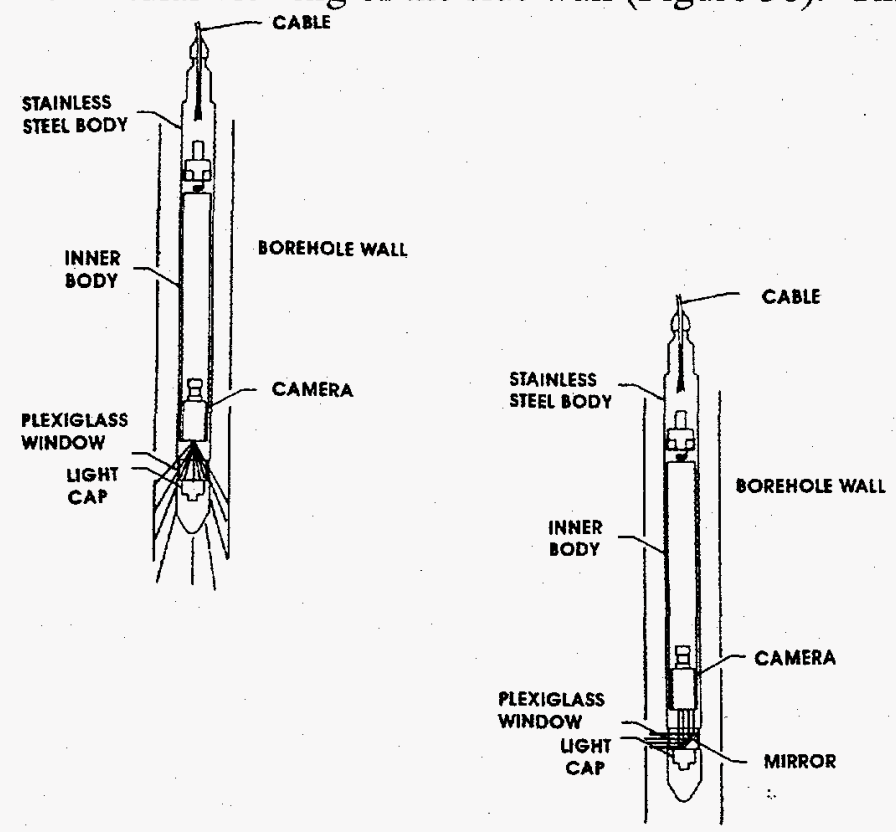

Figure 30. Borehole TV tool shown in two styles of operation: Tool on the left is in a "end" looking view looking straight down a borehole while the tool on the right is in a "radial" looking view using a side mirror.

of the wall is done with a 45 degree mirror in front of the camera lens placed such that the borehole or pipe is viewed as if the "eye" of the camera is situated at the probe looking at the side of the wall rather than down the borehole. Provision for rotating the TV camera with the mirror assembly or rotating the mirror allows direct radial viewing of the walls of the hole in 360 degrees (LeRoy, et al., 1977). With television resolution it is possible to observe cracks and other features down to less than $0.5 \mathrm{~mm}(0.02 \mathrm{in})$. Still pictures can be 
saved from the VCR tapes which can be later enhanced by modern photographic techniques or image processing methods on a computer to highlight features of interest in the pictures.

The borehole TV logs were obtained from and logged by the U.S. Geological Survey personnel at the INEL who have logged over 200 boreholes at the INEL with borehole TV tools. Two different borehole TV cameras are used by the USGS. One is a Cam 200 black and white television camera by LAVAL Underground Surveys. It is 3 to $1.588 \mathrm{~cm}$ ( 1 to $0.625 \mathrm{in}$ ) in diameter by 43 to $1.91 \mathrm{~cm}$ (17 to $0.75 \mathrm{in})$ length with TV line resolution of 360 (horizontal lines) $\times 350$ (vertical lines). The other camera in use since 1993 is a WC-9941 color camera $8 \mathrm{~cm}$ ( 3 in) outside diameter with a single conductor wireline that is also made by LAVAL Underground Surveys. TV line resolution is $350(\mathrm{H}) \times 360(\mathrm{~V})$. The camera is about 71 to $0.64 \mathrm{~cm}$ (28 to $0.25 \mathrm{in})$ long with a $8 \mathrm{~cm}(3 \mathrm{in})$ diameter.

Logging of boreholes entails lowering the tool down a borehole at a constant rate of speed while the information being scanned by the lens is recorded by a VCR machine onto VHS tapes. These tapes are later viewed on a TV and individual pictures were taken at paused sections of the VHS tape off of the TV screen.

Pictures of TV images are obtained by taking still photographs with a Minolta X-9 single-lens-reflex 35-mm camera on a tripod with 100 and 200 speed Fuji color film, shutter speeds were from $1 / 15 \mathrm{sec}$. to $1 / 60 \mathrm{sec}$, and iris stops from $\mathrm{f} / 1.7$ to $\mathrm{f} / 8$ were used (Figure 31).

Artifacts occur on the pictures in this thesis as a result of the borehole TV camera operation and the picture recording process. One feature appear as dark lines cutting across the picture that have no physical representation to the borehole or the TV camera and are not shadows. They may also be faintly colored. These lines are an artifact of taking a photograph of a TV screen with a paused VCR. A dark circular object (present in all images) usually in the center of the picture represents the metal top cap of the lighting unit (Figure 30) which sets underneath the camera (Plate 35). Two dark lines that are 90 degrees from 

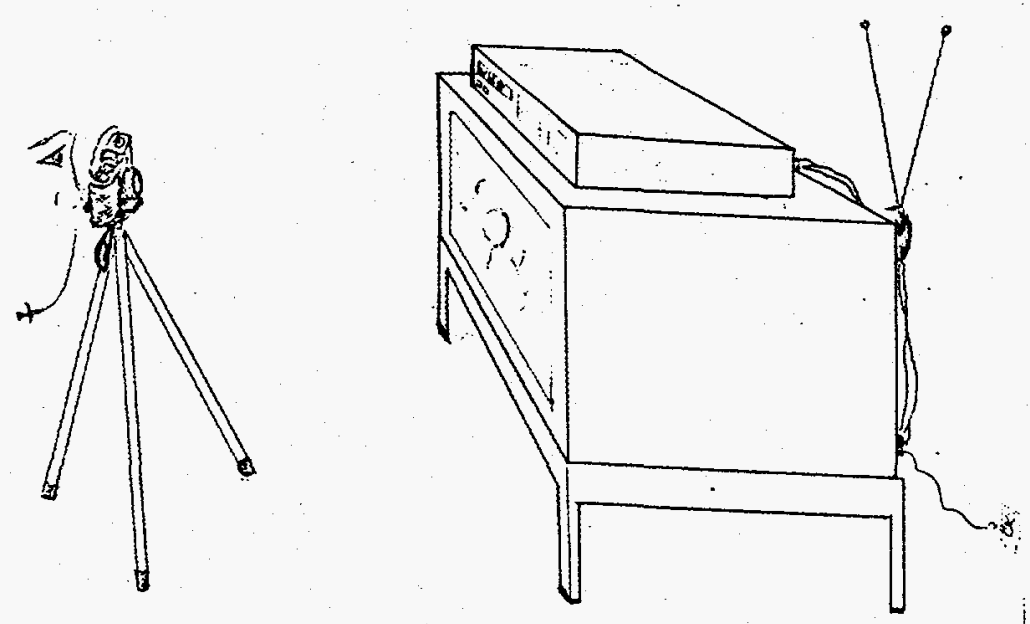

Figure 31. Artists sketch of camera-VCR-TV setup to obtain still photographs from the borehole TV camera logs. Note objects are not to true scale.

each other are the result of two wires in front of the camera lens.

\section{Calibration And Measurements Taken Off Photographs}

\section{Calibration}

Basalt lava flow features such as vesicles and fractures were measured off of the still photographs taken from paused sections of borehole TV logs. Since the view recorded by the camera is one looking down the borehole with an end-looking view the resulting still photograph is distorted. This distortion is really a problem of perspective generated from looking down a cylinder and trying to project the cylinder on a two dimensional surface (the photograph). One can get a feel for this if a person was to look down a road parallel to a series of telephone poles. The nearest telephone pole looks relatively large compared to a telephone pole in the far distance. Not only does size of the poles look different, but it "appears" to the observer that the poles closest to the observer have larger distances between them compared to the telephone poles that can be seen farther away which seem to have relatively no distance between them. This analogy can used for the photographs 
taken from the borehole TV logs. Features near the center of the image (optic center) are diminished in size, for they are an image of the more distant borehole wall. Whereas features appearing toward the edges of the image are relatively magnified for they are of the near part of the borehole cylindrical wall. Relative corrections can be made knowing how much distortion occurs to a reference unit as recorded on the picture. Two measuring devices (a $8 \mathrm{~cm}$ ( $3 \mathrm{in})$ by $71 \mathrm{~cm}(28 \mathrm{in})$ rod with $2.5 \mathrm{~cm}$ (1 in) wide black taped increments

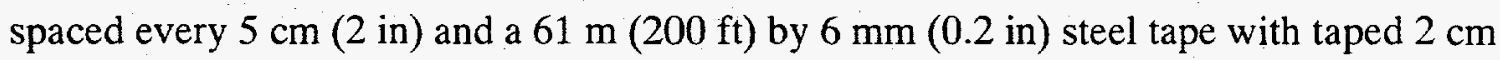
(0.8 in) sections) were used as standards and were lowered down a $15 \mathrm{~cm}(6 \mathrm{in})$ diameter casing in a borehole (USGS 55) at the INEL (Plate 35). They were recorded by the two different TV cameras (the color and black/white cameras of the USGS) on a VHS tape. This TV image is photographed and the relative distortion measured. Measuring of the appearance of taped increments determines the relative distortion by measuring changes in "radial distances" (the distance from the optic center on the photographs to the tape increment) and changes in "arc lengths" (the distance along an arc approximated by a straight line of the taped increments) (Figure 32). These true changes are plotted versus their position from the optic center of the image for both changes in arc length (Figure 33) and for changes in radial distances (Figure 34). A nonlinear relationship was found for true dimensions relative to their position to the optic center. If a linear relationship was found then a simple correction factor (the slope of the straight line) could have been used. Even an approximation of the nonlinear curve by a straight line would not correctly determine the geometric relationships of objects on the photographs. A different approach was used to correct for the distortion. A template was used to measure objects on the photographs, but the templates are specific to the indicated borehole diameter, type of camera, and size of photograph. 


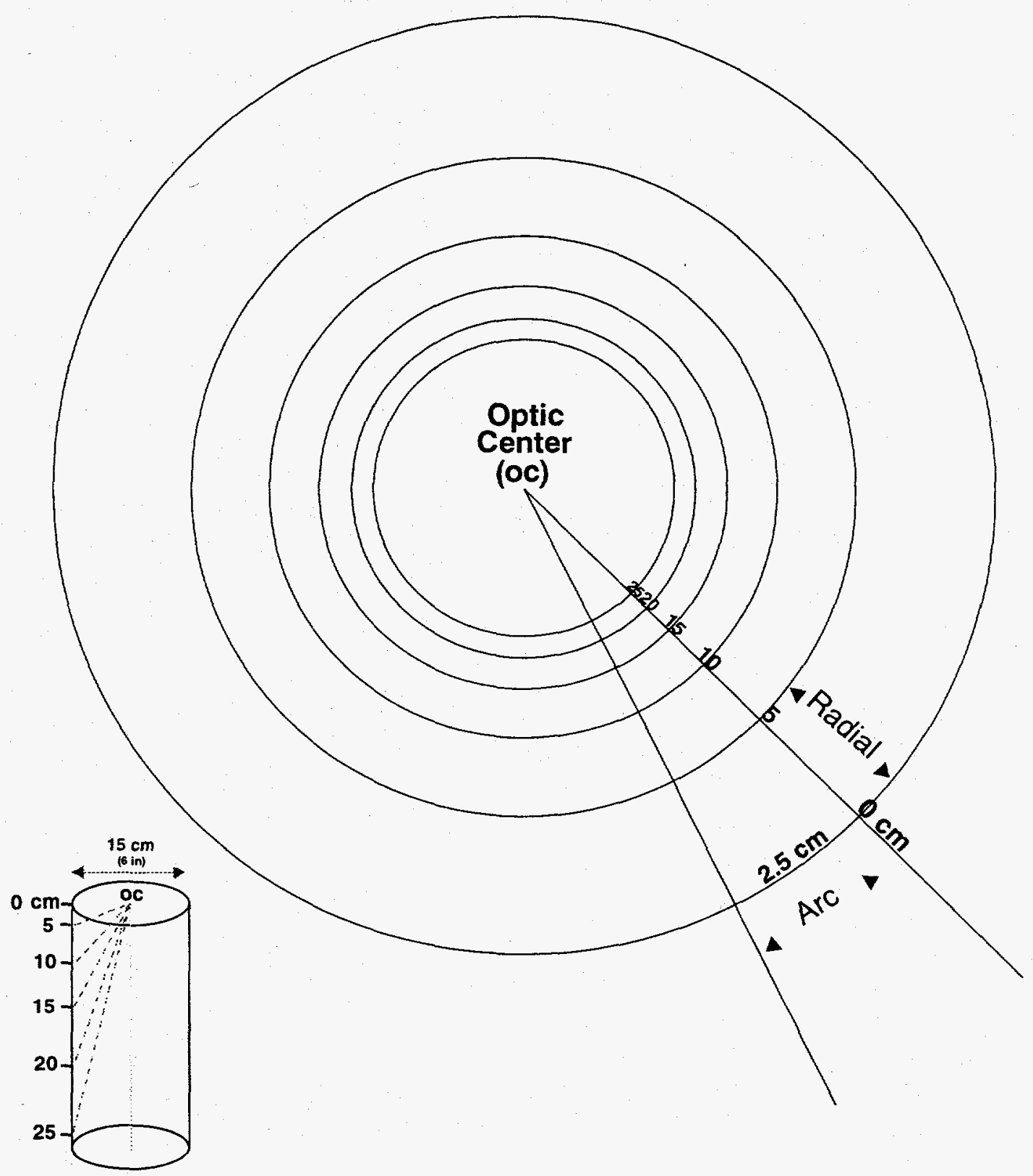

Figure 32. Figure showing the template generated from a $15.2 \times 10 \mathrm{~cm}(6 \times 4$ in) photograph of a paused section of a borehole television log taken by a color LAVAL Underground Surveys (WC-9941) camera. The TV log is from well USGS 55, a $15 \mathrm{~cm}$ (6 in) diameter borehole, in which I placed a tape measure at the time of logging. The radial and arc length distances labeled are the true distances known from the measuring device, but the view is of the distorted or "perspective" generated from the picture. This template is used to find the true sizes of objects seen on the picture. 


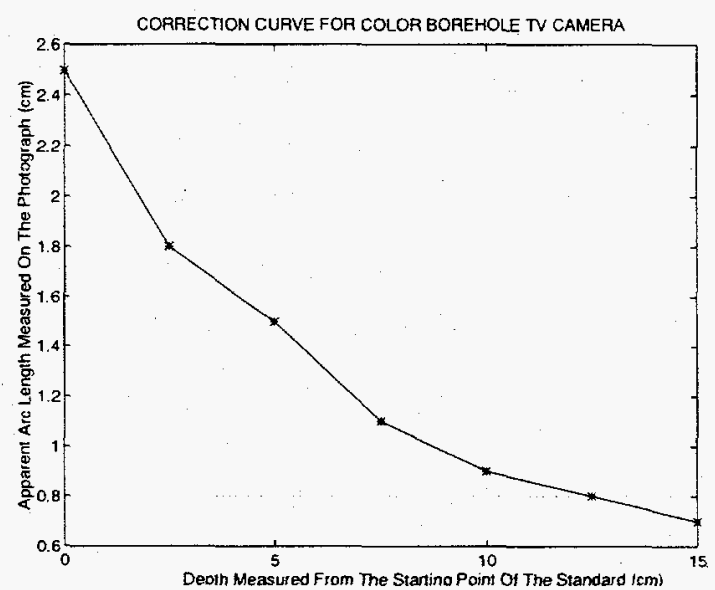

Figure 33. Figure showing the nonlinear relationship between the apparent changes in the arc length, due to the distortion or "perspective" on the photograph, to its true arc length measured towards the optic center on the calibration photograph.

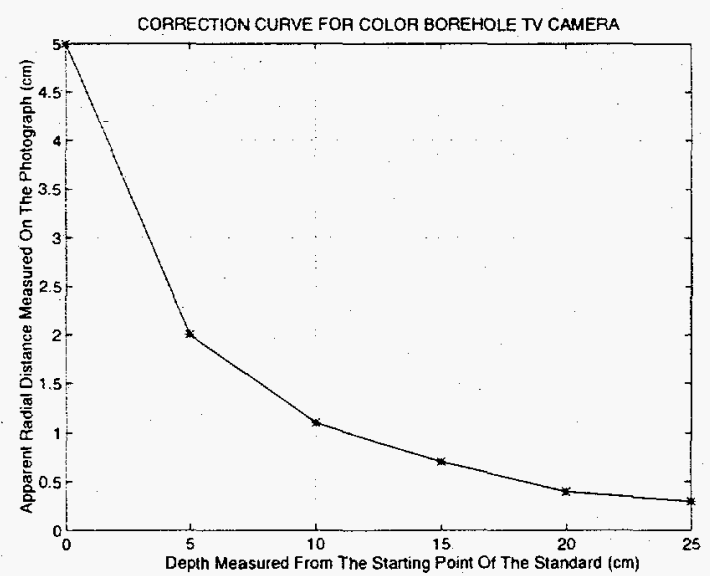

Figure 34. Figure showing the nonlinear relationship between the apparent changes in the radial distance, due to the distortion or "perspective" on the photograph, to its true radial distance from the optic center of the calibration photograph.

A template is be generated for each borehole TV camera used (one for the color camera and another for the black/white one used in this study) the template is good for similar borehole diameters and picture sizes. Boreholes diameters at the INEL are generally $15 \mathrm{~cm}$ (6 in), but some $25 \mathrm{~cm}(10 \mathrm{in})$ and $31 \mathrm{~cm}$ (12 in) boreholes are present. The template is made up 
of a series of circles in circles about a common center (the optic center on the photograph) with the labeled increments on the circles (Figure 32). The real arc lengths of the tape increments and radial distances are known (because they are measured directly without using any pictures or borehole cameras). Their apparent arc lengths and radial distances can be measured on the photograph. The true length of an object on another photograph (of the same size (a 15.2 by $10 \mathrm{~cm}$ ( 6 by 4 in)) can thus be found by comparing it with a similar size object found on the template. In order to find the true dimensions of a feature on the borehole wall one simply places the template with its optic center positioned on top of the optic center of the photograph. Since the distance from the center of a circle does not change and any objects arc length on the circle stay the same any place on the circle one would just have to have the unknown object fall on one of the templates circles or inbetween two circles. If the object of unknown dimension falls on the template circle the distortion value for that circle can be used to correct for the unknown apparent arc length and radial distance by measuring the unknown on the photograph and comparing it to the true size of the object on the template. Sizes of objects that fall in-between two circles would then have to be interpolated between the two known distortion values. It is assumed that the unknown objects measured are orientated in the same way as the measured increments, otherwise the correction can not be made. If this is not the case then the problem breaks down further into finding the third side of a triangle with one of its corner on the edge of one of the known tape increments (one circle) and one side of the triangle on another circle, thus straddling the unknown object (Figure 35).

This triangle is a reference for the geometric relationships found on the template. What is needed is to rotate the template over the photograph about the optic center on the photograph so that the unknown object on the photograph is in-between two known objects labeled on the template. 


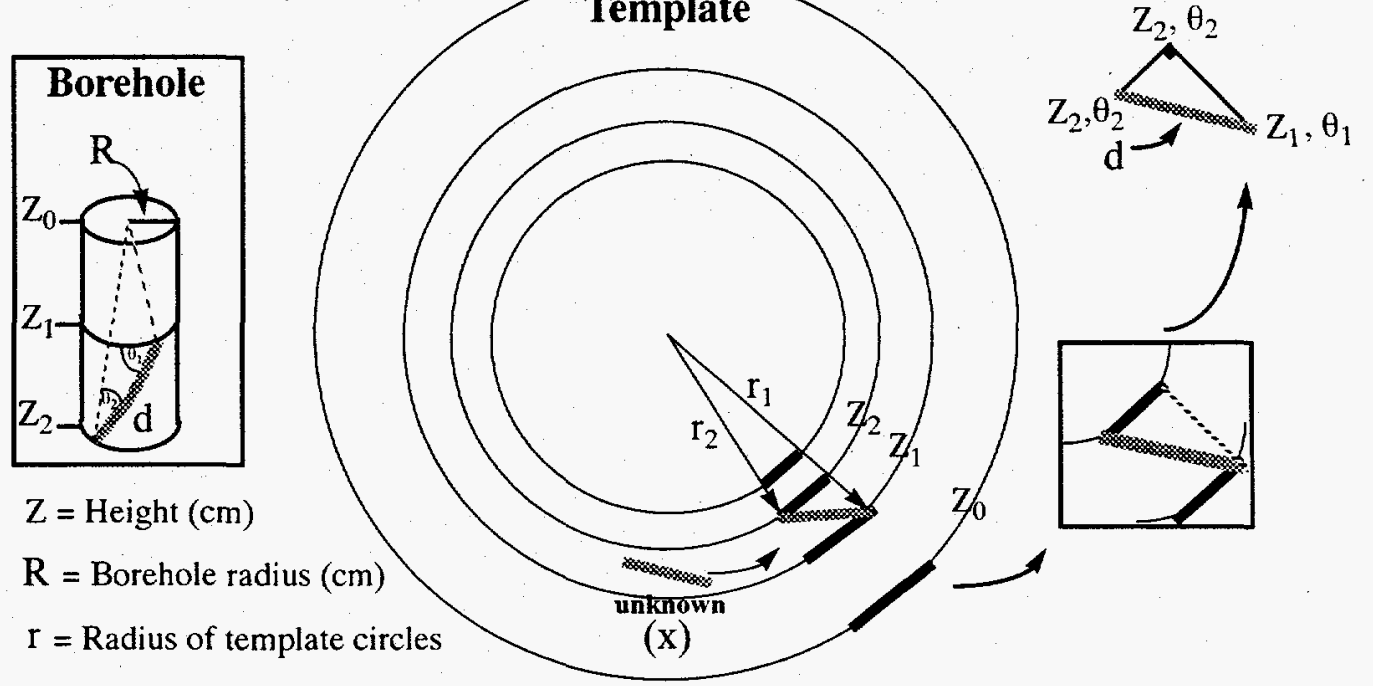

Figure 35. Figure illustrating (template not to scale) how an unknown object that is not orientated the same way as the marked increments on the template can be used to find its true dimensions by finding the third side of a reference triangle. First the template is rotated so that the unknown object is in-between two known marked increments. Then the reference triangle can be generated by finding $\Delta \mathrm{Z}$ and $\mathrm{R}$. $\mathrm{Z}$ represents the position along the borehole where the circle on the template resides or the "height" location along a cylinder, $\Delta \mathrm{Z}$ is just the difference between $\mathrm{Z}_{1}$ and $\mathrm{Z}_{2}$. The first circle on the template is assumed to be at a zero elevation. $\mathrm{R}$ is the true borehole radius that is usually known. The small $r$ is equal to the different radius of the circles on the template. The circles are centered on the optic center of the borehole TV camera. The $\theta$ designations are the polar coordinates of the triangle. The length of the unknown object is given by the variable $d$ and its accompanying trigonometric relation.

Each circle on the template has a circumference of $2 \pi r$ with $r$ equal to the radius of the circle who has an origin being the optic center. If we think of a triangle cutting through a cylinder the simple trigometric relations can be used to find the unknown side of the triangle " $d$ ".

What is needed then is to find " $\mathrm{x}$ " by using this formula;

$$
d=\left[r^{2}-2 r^{2} \cos \theta_{2}+r^{2} \cos ^{2} \theta_{2}+r^{2} \sin ^{2} \theta_{2}+\Delta Z^{2}\right]^{1 / 2}
$$

This is just solving Pythagorean's theorem on the triangle. The above equation could 
be rewritten like this;

$$
d^{2}=\left[(r)^{2}-\left(r \cos \theta_{2}\right)^{2}+\left(r \cos \theta_{2}\right)^{2}+\left(r \sin \theta_{2}\right)^{2}+(\Delta Z)^{2}\right]
$$

This can then be simplified further to:

$$
\begin{gathered}
d^{2}=\left[r^{2}-2 r^{2} \cos \theta_{2}+r^{2}+\Delta Z^{2}\right] \\
d^{2}=\left[2 r^{2}\left(1-\cos \theta_{2}\right)+\Delta Z^{2}\right]
\end{gathered}
$$

Using the template and corresponding formulas one should then be able to take photographs from the borehole TV logs and get quantitative values for objects seen along the borehole wall.

\section{Measurements Off Of Photographs}

Once a template is generated for each TV camera and different diameter borehole it can be used to quantitatively find values for features along the borehole wall such as vesicles, fractures, and joints. Major and minor axis of vesicles along the borehole wall as seen by the borehole TV camera are measured for every half of a foot. Since many times the depth record is displayed in the lower right hand corner of the TV screen on the TV logs it allowed measurements good to the foot depth it displayed. A method to measure depth readings for less than a foot is needed for the scale that this study required. The solution to this problem is to divide the distance between two depth readings on the video tape into individual frames. This can only be done with a VCR that is able to advance and pause on each frame of the video tape (freeze frame). As an example if there are 12 video frames from some depth reading say 150 to 151 feet then if a feature needed to be measured at 150 feet 6 inches it is simply a matter to advance the video tape to the 6 th frame to get the desired depth. The number of frames in-between depth readings, is controlled by how fast the borehole TV camera is moving down the borehole and tape recording speed. Usually 
the borehole TV camera is lowered down a borehole at a constant rate of speed, but this is not always the case.

Fractures and joints seen on the borehole wall are measured. Fracture parameters that can be measured are the observable trace length along the borehole wall, the average aperture along the fracture's observable trace length, the relative orientation, fracturefilling material, and the nature of terminations were noted. Method of recording relative orientations of fracture is discussed previously. Areas along the borehole wall that deviated from the normal diameter of the borehole are noted as well as any areas made up of rubblelike material.

Color of the borehole wall can be the result of the color of the basalt rock, TV color, hue, and intensity settings, color settings on the borehole TV camera, varying lighting, murkiness of the water, and photographic development. Determinations on colors of the basalts seen on the borehole TV camera logs were recorded in relative values of dark, light, or in some cases a specific reoccurring color. Changes in color occurring on the borehole TV logs are usually the result of the geology. Color changes are noted but the absolute colors are not determined. Other features noted in the borehole TV logs are such features as borehole casing, well tools lost down wells, a pen, fibrous filamentary material attached to the borehole wall (perhaps algal growth or iron deposition), casing perforations, and other non geologic features. 


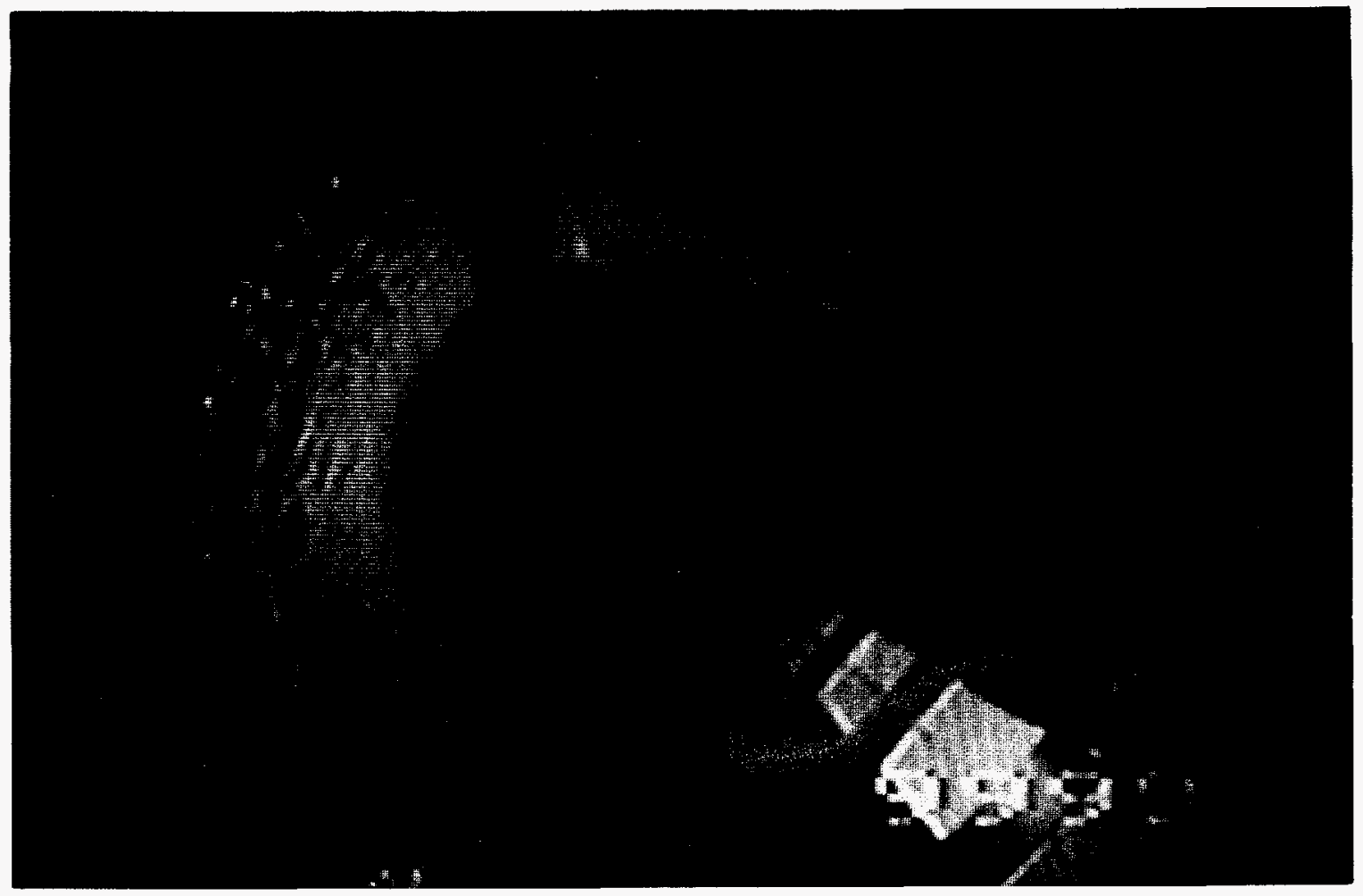

Plate 35. Picture of borehole 55 showing the standard used to help calibrate the TV camera. Black taped marks on the standard are $2.5 \mathrm{~cm}(1 \mathrm{in})$ thick and are spaced every 5 $\mathrm{cm}$ ( 2 in). Picture taken is in an air filled hole above the water level. Hole is $15 \mathrm{~cm}$ (6 in) in diameter. 


\section{CHAPTER 6. BOREHOLE TV FEATURES}

\section{Basalt Lava Flows}

The twelve boreholes examined at the ICPP have individual basalt flows and basalt flow-units that range from 0.6 to $31 \mathrm{~m}$ ( 2 to $100 \mathrm{ft}$ ) in thickness. Each basalt flow usually has a vesicular flow top and bottom with a dense predominately unvesiculated central part. Basalt flows are determined by these changes in vesiculation or by sedimentary interbeds present in-between basalt lava flows. The following pictures were selected by viewing over 50 borehole TV logs and are used to best illustrate features that are common in most basalt lava flows seen in TV logs.

\section{Interface Between Basalt Lava Flows}

Interfaces in-between basalt lava flows observed in outcrops are also observed on the borehole TV logs. Four different types of contacts are identified. One type of contact, the most rarely encountered, is two basalt lava flows contact with no physical breaks between them. Only a change in vesiculation is present to indicate that one basalt lava flowed and solidified and was overlain by another. The second type of interface in-between two basalt lava flows is in the form of an irregular opening or break usually only a couple of centimeters wide (Plate 36). No fragmental material of clinkery or other type is found inbetween these breaks. Since the borehole wall is a void in these locations the lateral distance to which this break extends beyond the borehole wall is not known. The most common type of basalt lava flow contact, prevalent throughout the borehole TV logs, are contacts made up of broken basalt fragments and an enlarged borehole diameter.

Fragmental material usually varies from a 3 to $10 \mathrm{~cm}$ ( 1 to $4 \mathrm{in})$ in diameter. Most 
fragmental material have a number of sharp edges rather than rounded edges and have a blocky appearance rather than a "popcorn" or spherical shape. These types of contacts vary from a couple of centimeters to at most 0.3 to $0.6 \mathrm{~m}$ ( 1 to $2 \mathrm{ft}$ ) in thickness. The second most common type of interface in-between basalt lava flows is in the form of interbeds of unconsolidated light colored material, presumed to be windblown soil carbonate, or sediment. These interbeds range from 0.6 to $4 \mathrm{~m} \mathrm{(2} \mathrm{to} 14 \mathrm{ft})$ in thickness and the light colored material usually fill in irregularities in the basalt (Plates 37 and 38).

\section{Internal Features}

Described here is the appearance of basalt flow features on borehole TV images. The features are discussed in terms of a general model of flow features shown in Figure 36. 


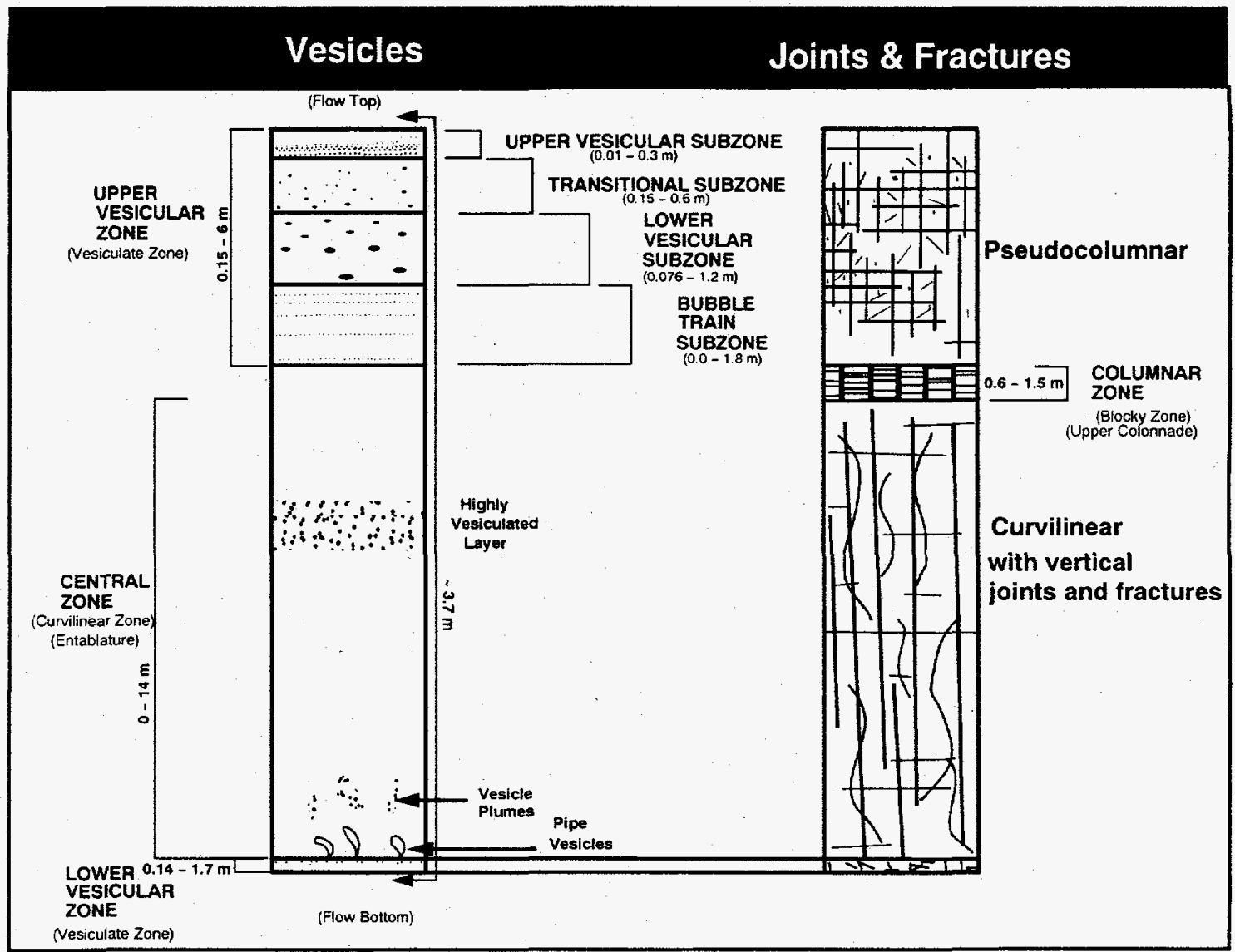

Figure 36. Model of SRP basalt lava flows showing differences in both vesicles and joints and fractures in an individual lava flow. This drawing was generated from observations of basalt lava flows in outcrop. The terms in parenthesis under the labeled zones are the most commonly used labels for these particular locations in a basalt lava flow. Features shown on the basalt column are not to scale.

\section{$\underline{\text { Vesicles }}$}

Vesicles are observed on TV images of basalt borehole walls. These vesicles have a range in vesicle dimensions, gradation of vesicularity, and certain arrangements within a basalt lava flow. All of these aspects of the vesicles are very similar to the observations of basalt lava flows in outcrops.

Starting at the very top of a basalt lava flow (Upper vesicular subzone) the vesicles are 
very small (ranging from $2-3 \mathrm{~mm}(0.08$ to $0.1 \mathrm{in})$ and nearly spherical in shape. The overall vesicularity is very great. The thickness of basalt rock that exhibits these vesicles varies from $1.5 \mathrm{~cm}(0.6 \mathrm{in})$ to $0.2 \mathrm{~m}(0.7 \mathrm{ft})$ in thickness (Plate 39). Below this, within the part classified as the transitional subzone the vesicle abundance decreases towards the center of the basalt lava flow whereas vesicle sizes increase. Small vesicles are still present toward the interior although in lesser numbers. The vesicles in the transition subzone are typically elliptical in appearance with the long axis horizontal, parallel to the basalt flow top. The predominate vesicle size ranges from $0.5-1 \mathrm{~cm}(0.2-0.4 \mathrm{in})$ for the major axis and $0.3-0.8 \mathrm{~cm}(0.1$ to $0.3 \mathrm{in})$ for the minor axis (Plate 40$)$, with the larger vesicles being found towards the center of the basalt lava flow. This layer with this particular vesiculation pattern usually ranges from $10 \mathrm{~cm}(4 \mathrm{in})$ to $0.4 \mathrm{~m}(1 \mathrm{ft})$.

Below the transitional subzone is the lower vesicular subzone with larger vesicles and even less vesicularity than the previous layers. Vesicles increase in size while decreasing in number towards the center of the basalt lava flow (Plate 41). Typical sizes of the vesicles range from $1-3 \mathrm{~cm}(0.4-1 \mathrm{in})$ for the major axis and $0.9-2 \mathrm{~cm}(0.4-0.8 \mathrm{in})$ for the minor axis with the major axis mostly parallel to flow top. It is not unusual for these vesicles to have crystalline material inside them. These materials can be seen as the camera passes the vesicles as a "twinkling" effect sort of like a moving beam of light hitting a mirror. Vesicles at the very bottom of this layer increase in size resulting in vesicles that fall into the range of $2-8 \mathrm{~cm}(0.8-3 \mathrm{in})$ for the major axis and 1.5 to $3 \mathrm{~cm}(0.6$ to $1 \mathrm{in})$ for the minor axis. Vesicles in the lower vesicular subzone usually have a fairly flat bottom and a broad rounded top like the hump back on whales (Plate 42). The thickness of this layer is highly variable, but usually falls in-between $4 \mathrm{~cm}(1.6 \mathrm{in})$ to 2 meters $(7 \mathrm{ft})$.

Below this layer is the bubble-train subzone with vesicles that on the TV logs appear to be all lined up with one vesicle next to its neighbor in a horizontal line like a string of pearls (Plate 43). Vesicles are usually less than $2 \mathrm{~mm}(0.08$ in) in diameter with individual 
vesicular "trains" ranging from $1 \mathrm{~mm}(0.04 \mathrm{in})$ to $1 \mathrm{~cm}(0.4 \mathrm{in})$ in thickness. The spacings between these vesicle trains are from $2 \mathrm{~cm}(0.8 \mathrm{in})$ to 3 meters $(10 \mathrm{ft})$. The overall range of the thickness of the layer containing these vesicular patterns is 0 to 5 meters $(16 \mathrm{ft})$.

Below the previously described vesicular zone vesicles are very scarce. Only certain types of vesicular patterns occur in the central part of the basalt lava flow. One such vesicular pattern is a layer within the central part of the basalt lava flow that has abundant vesicles with no vesicles above or below it. No discontinuity of the basalt in any way is seen at the tops and bottoms of these vesicular layers. On TV logs these features appear as vesicular "rings" in the central part of a basalt lava flow. These rings or layers have thicknesses from less than a meter to $1 \mathrm{~m}(4 \mathrm{ft})$ (Plate 44).

In some cases at the top of the central part of the basalt lava flow is a pattern in the shape of a stripe or plume containing numerous small vesicles within an otherwise non or low vesicularity part of the basalt lava flow. This is usually shaped in a long (length ranging from a few centimeters to $0.9 \mathrm{~m}(3 \mathrm{ft})$ in length) plume like arrangement with the rounded plume part pointing in the direction of the basalt flow top (usually straight up the borehole) and the tapered end pointing in the opposite direction (Plate 45). Although this is the typical shape of these features many exceptions to this are found having a wide variety of shapes and orientations. These features indicate proximity to the vesiculated basalt flow bottom.

The lower vesicular zone ranges from $8 \mathrm{~cm}(3 \mathrm{in})$ to $2 \mathrm{~m}(6 \mathrm{ft})$. Vesicles found here have an inverse arrangement compared to the vesicles found at the top of the basalt lava flow with vesicles decreasing in size and increasing in vesicularity towards the bottom of the basalt lava flow. Vesicles at the top of this layer range from 0.7 to $1 \mathrm{~cm}(0.3$ to $0.4 \mathrm{in})$ for the major axis and 0.4 to $1.4 \mathrm{~cm}(0.2$ to $0.6 \mathrm{in})$ for the minor axis. These grade into ever increasing amounts of smaller vesicles with the smallest being $3 \mathrm{~mm}(0.1 \mathrm{in})$ in diameter. 
$\underline{\text { Fractures }}$

Basically two different types of fractures can be observed in the borehole TV logs of basalt lava flows at the INEL. One type of fractures are ones that are very linear in vertical, horizontal, and oblique orientations. These fractures have varying apertures from a few millimeters to at most 1.5 centimeters $(0.6$ in). They occur throughout the borehole, but tend to be found in the upper and central parts of a basalt lava flow. These fractures are predominately in a vertical orientation and as observed in drill hole can range from a $15 \mathrm{~cm}$ (6 in) to $0.6 \mathrm{~m} \mathrm{(2ft)}$ in length and could be longer since they might extend out of the borehole Oblique fractures which are rare (usually 3 to 7 are found in a borehole section of typically $61 \mathrm{~m}(200 \mathrm{ft})$ of basalt) and usually less than one meter of the length is intersected by the borehole. Apertures on these oblique fractures are the same for the vertical fractures. These types of fractures are usually found by themselves in the central part of a lava flow with the smallest fracture spacing observed in boreholes being less then

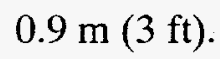

Almost as numerous as the vertical fractures are the horizontal fractures that typically cut circular or arc-like traces across the borehole. Apertures on these range from 1 to $4 \mathrm{~mm}$ (0.04 to 0.2 in). They usually occur throughout the basalt lava flow, but are more prevalent in the central part. The horizontal fractures are usually found in groups of 2 to 20 with fracture spacings ranging from 0.2 to $1 \mathrm{~cm}(0.08$ to $0.4 \mathrm{in})$. The number of these horizontal fractures start off being few which increase in number only to be followed by a decrease. These patterns can span over a 0.6 to $2 \mathrm{~m}$ ( 2 to $6 \mathrm{ft}$ ) interval along the borehole wall.

The second type of fracture expression seen in the TV logs of the borehole walls are planar surfaces or blocks of rock. When a fracture cuts across a borehole its trace is left as a discontinuity along the borehole wall. This second type of fracture discontinuity seen in the TV logs is a flat plane along the borehole wall that is recessed into it like a framed picture with the plane being the picture and the borehole wall the frame (Plate 46). The 
planar feature is also basalt rock, but its appearance is not like its surroundings. The cylindrical borehole wall surrounding the plane, usually has a different texture, lacks of vesicles, or has a different color compared to the plane recessed in the borehole wall. These features are mostly vertical to subvertical and range from less than a meter to $2 \mathrm{~m}(6 \mathrm{ft})$ or more in length. They seem to occur anywhere in a basalt lava flow and usually one could find 3 to 8 in a borehole with typical $61 \mathrm{~m}(200 \mathrm{ft})$ open-hole section of basalt.

A third type of fracture pattern is one that forms blocks and has the appearance of "bricks" on a wall or "tiles". This expressions is rare and can usually be found in 1 out of 5 boreholes. These blocks are usually 0.5 to 2 centimeters square ( 0.2 to 0.8 in squares)

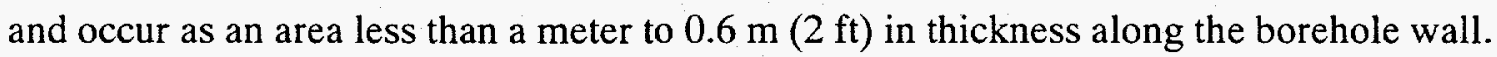
This area is a patch along the borehole wall, usually not covering the entire circumference of the borehole wall, which is made up of the blocks stacked end to end in a very geometric square pattern. These squares are not perfect with many of the blocks edges broken or rounded. These features usually are encountered at the lower central portion to bottom of a basalt lava flow (Figure 37).

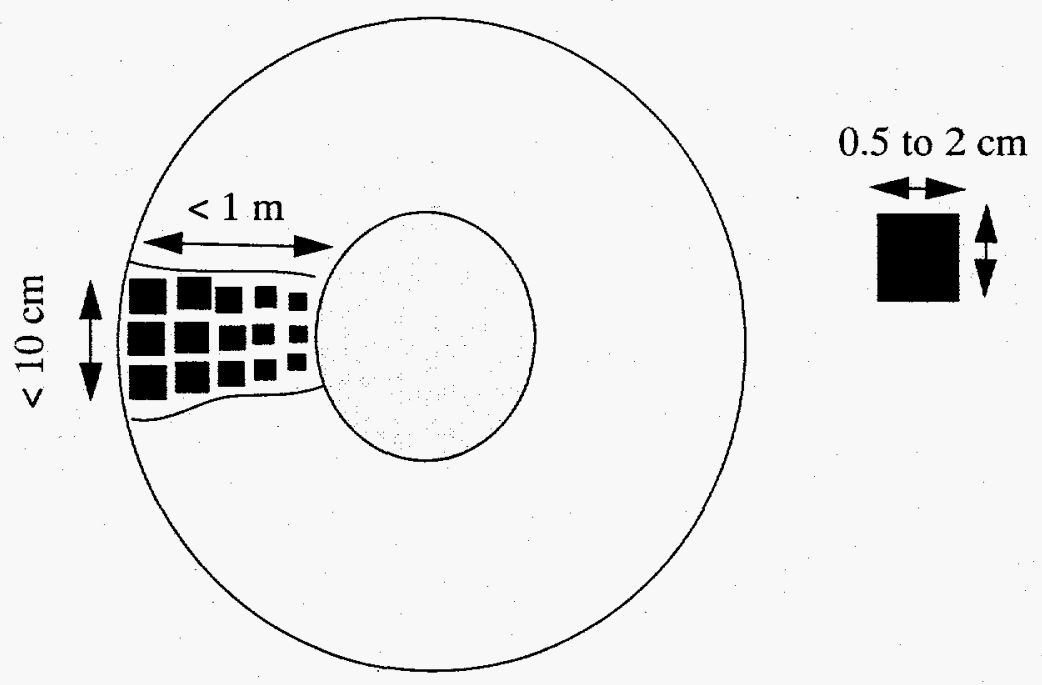

Figure 37. Figure showing the third type of fractures that appear as bricks or tiles on the surface of the borehole wall. These features are rarely seen in boreholes and the bricks are not perfect squares, but are rounded or broken at their corners. 


\section{Deviations From Normal Borehole Diameter}

The 12 open-hole boreholes studied in detail at the INEL were drilled a nominal $15 \mathrm{~cm}$ (6 in) in diameter starting from water level on down to the end of the borehole. Upon observing the borehole TV logs three main types of features are the result of deviations from the normal borehole diameter.

The first type of feature is in the form of large intervals (the entire borehole wall for distances along the borehole from less than a meter to $2 \mathrm{~m}(5 \mathrm{ft}))$ of the borehole wall that have a "cavernous" appearance to it (Plate 47). These cavernous openings are enlarged borehole diameters a few centimeters while others are enlarged beyond the field of view of the camera leaving an black opening where the borehole wall should be. These openings can be measured up to $43 \mathrm{~cm}$ (17 in) the limit of the caliper logs. Numerous basalt debris with sharp edges can be seen on the floor of these "cavernous" openings (Plate 48). These features are shaped in a "cavernous" form, but while the other was more of a spherical shape these have a very geometrical appearance with angular walls. The angular features on TV images resemble a "keyhole" with vertical fractures defining a "key" like opening along the borehole wall (Plate 49). They are generally found at the upper portions to center of a basalt lava flow.

\section{Columnar}

Columnar outlines seen on the borehole TV logs are characterized by the very regular vertical fracture surfaces defining the borehole wall into partial hexagonal columns. These features are generally found in the upper portions of the basalt lava flow and span an interval ranging from 0.6 to $2 \mathrm{~m}$ ( 2 to $6 \mathrm{ft}$ ) in thickness. Usually 4 to 5 columns are defined with fractures that have apertures of less than a centimeter. It is difficult to distinguish these features from the "keyhole" deviations and other fractures on account of their similarity (Plate 50). Differences are the columnar outlines found predominately in the upper part of 
the flow. The semi-hexagonal to polygonal in outline of the TV imaged borehole wall contrasts with the keyhole openings. Keyhole openings can occur anywhere and lack the semi-hexagonal nature in outline.

\section{Discussion of Columnar Features}

The borehole wall at these supposed columnar intervals looks very hexagonal with 4 to 5 partial hexagons with vertical defining fractures present. The degree to which these columns and fractures exist can be very variable making it difficult to identify as a columnar zone. The fact that these structures appear in the upper half of the lava flows either just below the vesiculated upper portion or closer to the top of the flow supports the idea that they are the expression of columns. Much of the rock is broken in place as seen on the TV logs. In the places where one would expect to see the columnar zone if it is present in the basalt. The coring or drilling process may not adequately sample the columns in the basalt flow. It seems logical that a drill bit moving through such a section of numerous vertical and horizontal fractures, may leave it a section of broken rock rather than as hexagonal columns.

\section{Color}

Some color changes are noted from the borehole TV logs. Since the true colors are not known only reference colors will be given. The appearance of basalt rock is generally a gray to greenish-gray for most of the flow. At the top of these flows the basalt can take on a more reddish color. Some vesicles and fractures filled with lighter colored material make the overall color of the basalt seem lighter. Some reddish to orange colors are also seen on TV images of the basalt usually in the center. This coloration does not cover the entire borehole wall but can been seen as patches on the basalt. 
$\underline{\text { Reasons For Color Changes }}$

The lighter colored material seen in the upper portions of the basalt lava flows is obliviously due to fractures and vesicles being filled with fine grained material. This is not to surprising since the same sort of features are observed in outcrops and cores. Many vugs are present and could be observed like those in outcrops and cores. Others (Knutson et al., 1990, Lanphere et al., 1994, Whitehead, 1992) have noted that caliche, clay, ash, and minor zeolites have lined vesicles at the INEL. The reddish color seen on the upper portions of the basalt lava flows and in others places can be accounted for by the oxidation of the top of the basalt flow from the incorporation of atmospheric oxygen within the lava. If this is true for the reddish color found at the top of the basalt flows, it may not account for the reddish color seen along the borehole wall in other places which may be a secondary color resulting from some later oxidation of iron in the borehole that stains the outside of the basalt. Reasons for this supposition are found in the areas along the borehole wall where this color change occurs. In these areas the color can be found cutting across fractures and vesicles indicating that the color formed after fracture and vesicles.

\section{Other Features Observed On Borehole TV Logs}

Some other features can be found in the borehole TV Logs that do not fit the general categories already listed. Many of these are features are oddities in the casing or are tools stuck or dropped down the wells (Plate 51). Two other features are not so easily explained. One feature appears as strange twisted crystalline strands found in two borehole TV logs. Crystalline strands seemed to coat and protrude from the borehole wall as twisted white colored crystals (Plate 52). A second feature occurring in three wells, was a series of indentations on the borehole wall in the pattern of a spiral. Sometimes the spiral would have broad twists and later on tighten. Other times these spirals would gradually turn into 
vertical grooves (Plate 53). The latter feature is found in the central part of the borehole wall that lacked any fractures or vesicles and may be an artifact of drilling.

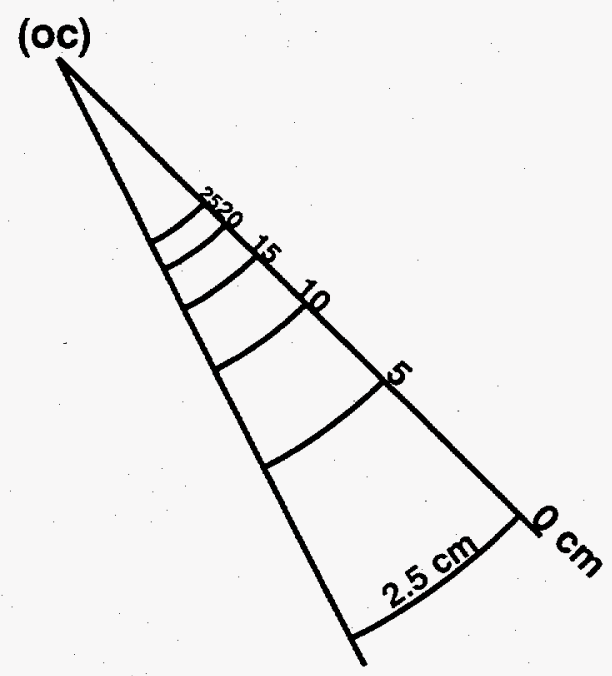

Figure 38. Figure showing a part of the template in Figure 32. This can be used for a "scale" on the following pictures.

Plate 36. Picture of borehole 46 (ICPP) at a depth of $553 \mathrm{ft}$ of a basalt flow contact between two basalt lava flows seen as the lighter colored rock vs. the darker reddish colored rock. The circle in the center of the picture and all following borehole TV pictures is not a basalt feature or part of the borehole, but instead is the light cap on the video camera (Figure $30)$.

Plate 37. Picture of borehole 46 (ICPP) depth $546 \mathrm{ft}$ showing sediment interbed (light colored material) basalt (dark colored material) contact. The gray colored bands found at the lower left part of the photo and upper right corner are not part of the borehole, but are artifacts of the developing process of the photograph. 
Plate 38. Picture of borehole 50 (ICPP) depth $366 \mathrm{ft}$ showing basalt (dark colored) sedimentary contact (light reddish colored material). Notice the very straight contact between the two. The light reflective material is due to the light from the TV camera reflecting off of water coating the borehole wall because this is an air-filled borehole. The dark lines about 11:00 and 2:00 from the dark circle in the center of the photograph are not part of the borehole, but are due to two electrical wires on the borehole TV camera lens.

Plate 39. Picture of borehole VVE-1 (RWMC) depth $66 \mathrm{ft}$ of the upper vesicular subzone showing a large number of very small vesicles ( 2 to $3 \mathrm{~mm}$ ).

Plate 40. Picture of borehole ID-8 (NPR) depth $46 \mathrm{ft}$ showing vesicles in a transitional subzone. Notice the larger size and more elliptical vesicles present then those seen in plate 39. Also the overall vesicularity is less than in plate 39.

Plate 41. Picture of borehole VVE-3 (RWMC) depth $202 \mathrm{ft}$ showing some vesicles in the lower vesicular subzone. Notice that they are larger and fewer in number compared to those found in plate 59. Also notice that their shape is more drawn out.

Plate 42. Picture of borehole VVE-1 (RWMC) depth $72 \mathrm{ft}$ showing "whale-back" vesicles the largest type of vesicles found in viewing TV logs at the INEL. The dark line cutting across the photo from the lower right corner to the upper left corner is not part of the borehole, but is an artifact of picture developing and has no physical representation in the borehole.

Plate 43. Picture of borehole VVE-1 (RWMC) depth $20 \mathrm{ft}$ showing bubble trains. The dark line cutting across the photo is an artifact of developing the photograph and is not part of the borehole. 
Plate 44. Picture of borehole 44 (ICPP) depth $634 \mathrm{ft}$ showing a "ring" or layer of vesicles in the center part of a basalt lava flow. There is a conspicuous lack of vesicles above and below these layers.

Plate 45. Picture of borehole 80 (ICPP) at a depth of $536 \mathrm{ft}$ showing a "vesicle plume" or area of vesicles on a borehole wall. These features are typically found at the lower half of the central zone above the lower vesicular zone.

Plate 46. Picture from borehole 46 (ICPP) at a depth of $644 \mathrm{ft}$ showing a flat planar surface of the borehole wall caused by spalling along a fracture.

Plate 47. Picture of borehole 46 (ICPP) depth $575 \mathrm{ft}$ showing a large "cavernous" opening in the borehole wall.

Plate 48. Picture of borehole VVE-3 (RWMC) at a depth of $164 \mathrm{ft}$ showing a "cavernous" opening with basalt rock debris in its floor. The dark line from the middle right part of the photograph is not part of the borehole, but is an artifact of the picture developing process.

Plate 49. Picture of borehole 46 (ICPP) at a depth of $476 \mathrm{ft}$ showing a "keyhole" borehole opening. Notice the very geometrical like shape to the opening.

Plate 50. Picture of borehole 46 (ICPP) depth $494 \mathrm{ft}$ showing what is thought to be the columnar zone in a basalt lava flow. 
Plate 51. Picture of borehole 50 (ICPP) depth 393 showing some sort of tool (upper right hand side of the photo) stuck in the borehole.

Plate 52. Picture of borehole IC-7 (NPR) at a depth of $68 \mathrm{ft}$ showing some very unusual white colored fibrous material in the borehole. The dark lines from the top and bottom of the photo are not part of the borehole, but are two metal rods on the TV camera.

Plate 53. Picture of VVE-10 (RWMC) at a depth of $190 \mathrm{ft}$ showing unusually spiral grooves in the borehole wall. 
Plate 36.

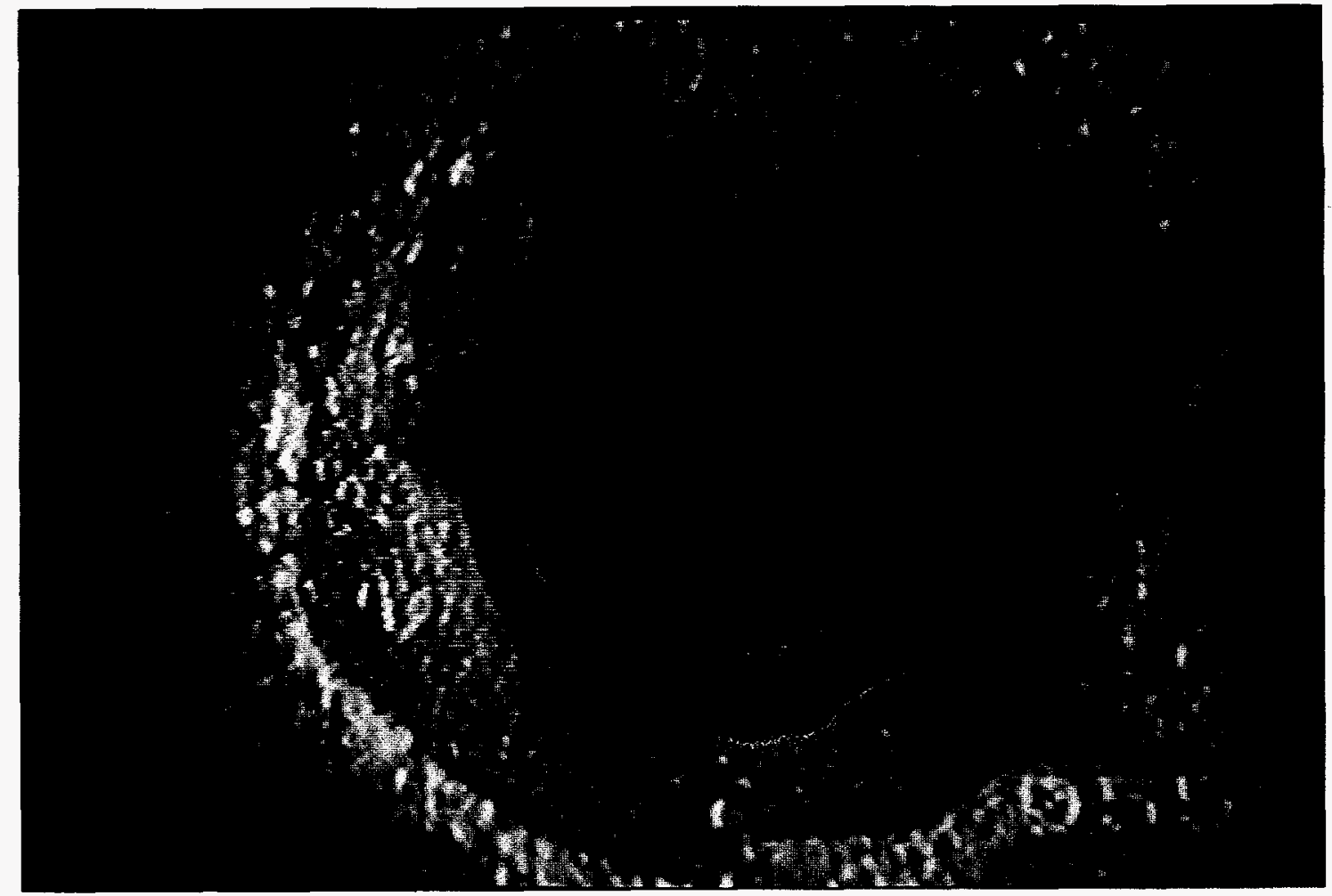

Plate 37. 
Plate 38.

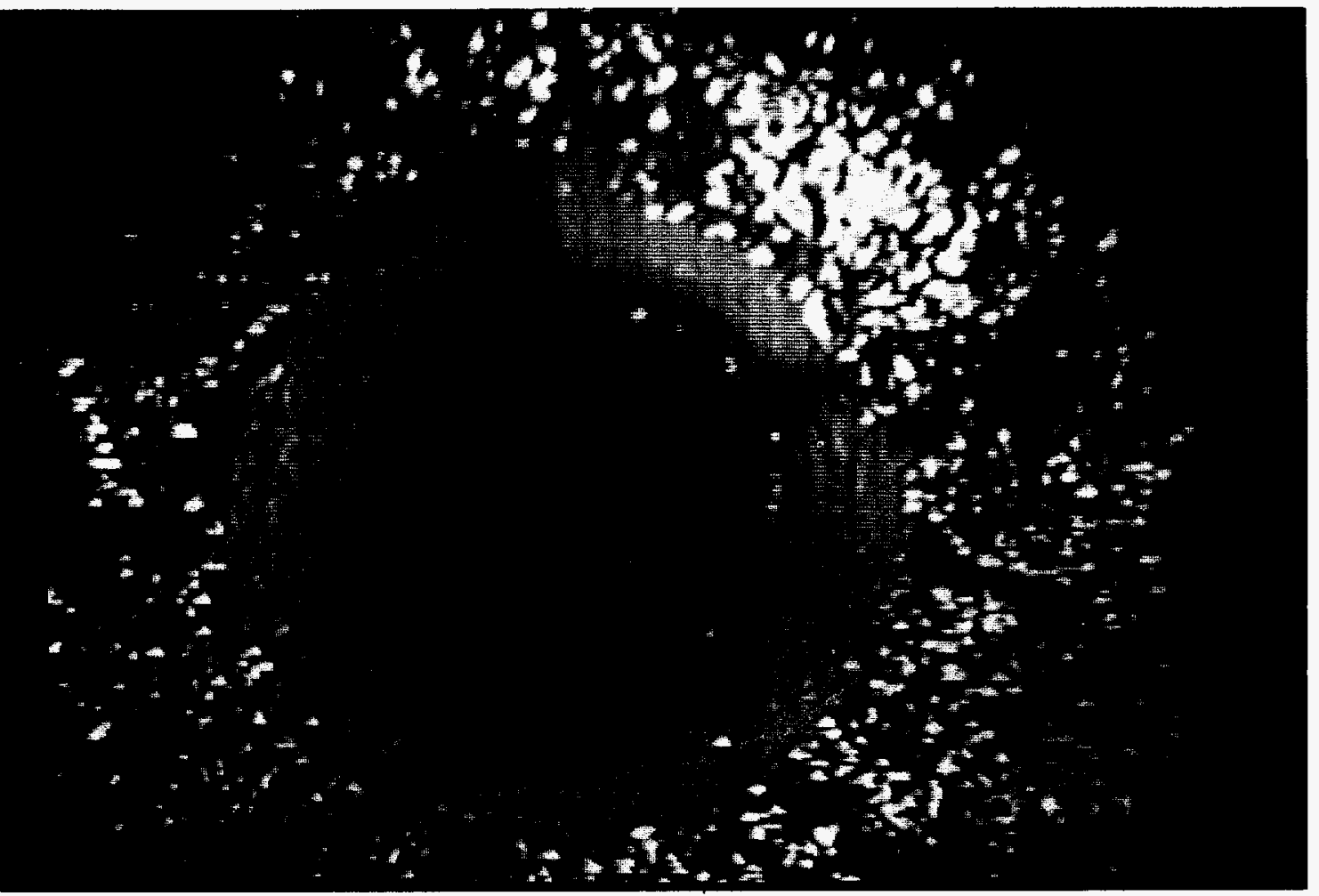

Plate 39.

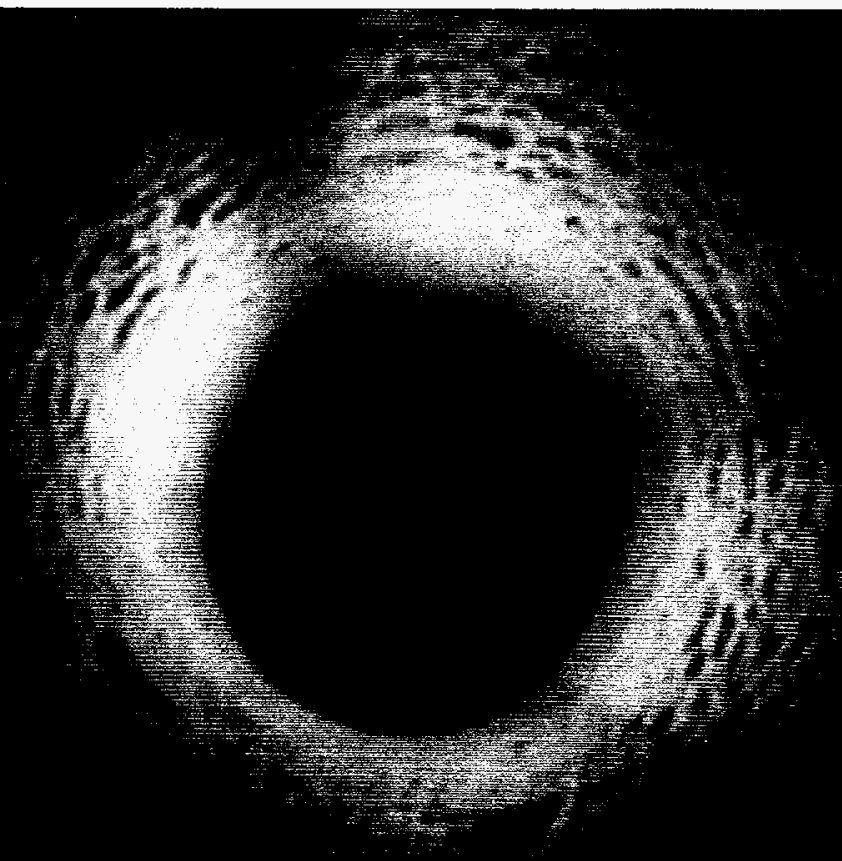


Plate 40.

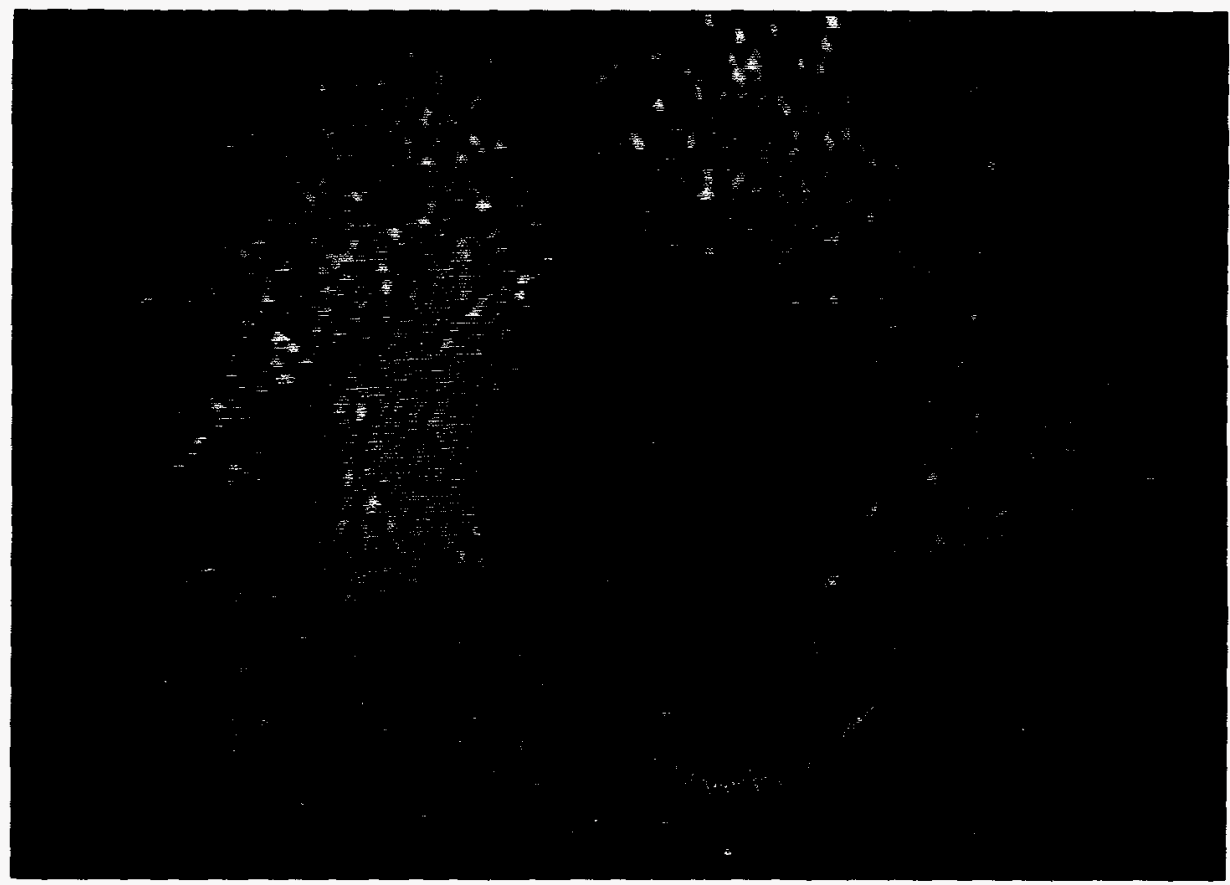

Plate 41.

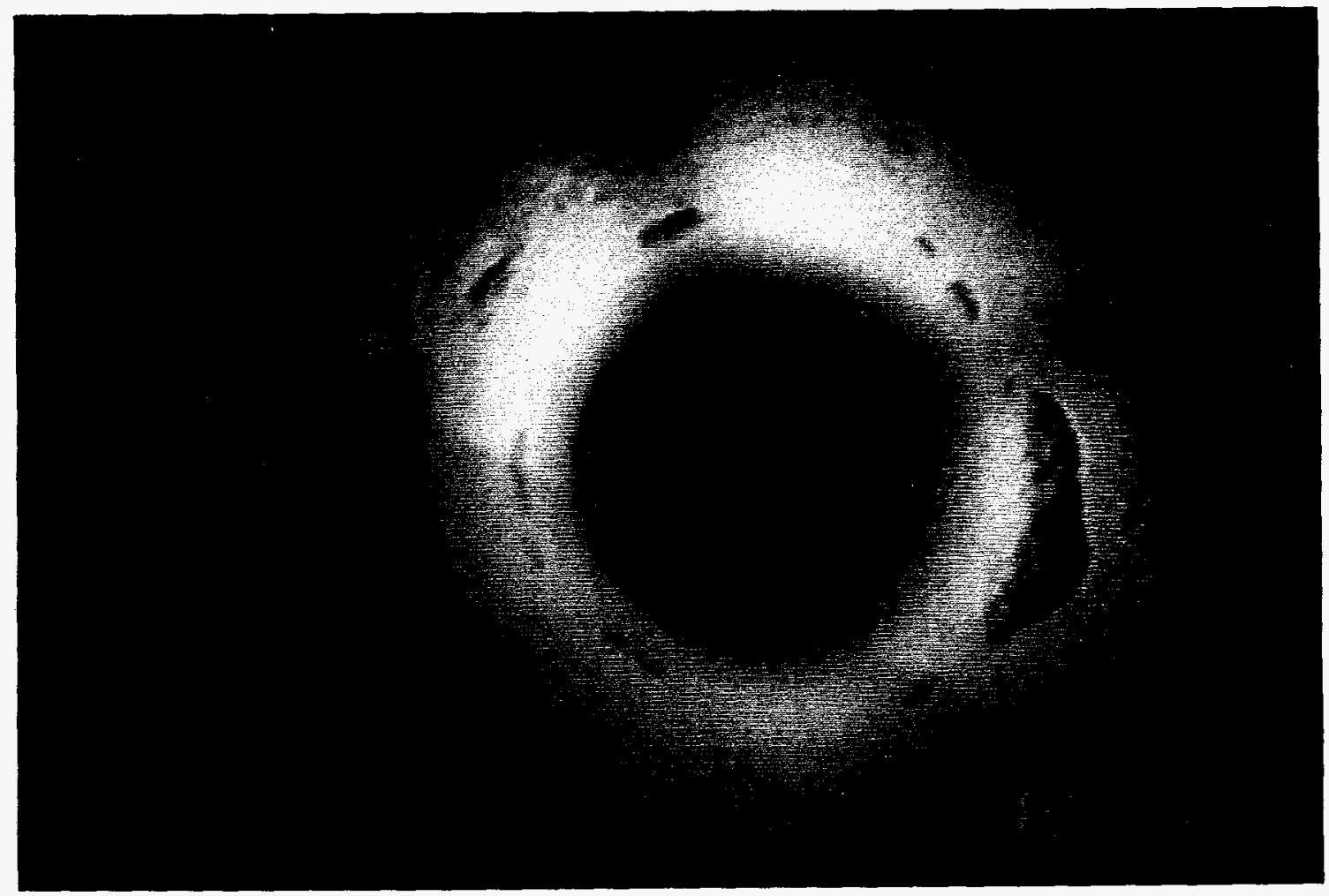


Plate 42.

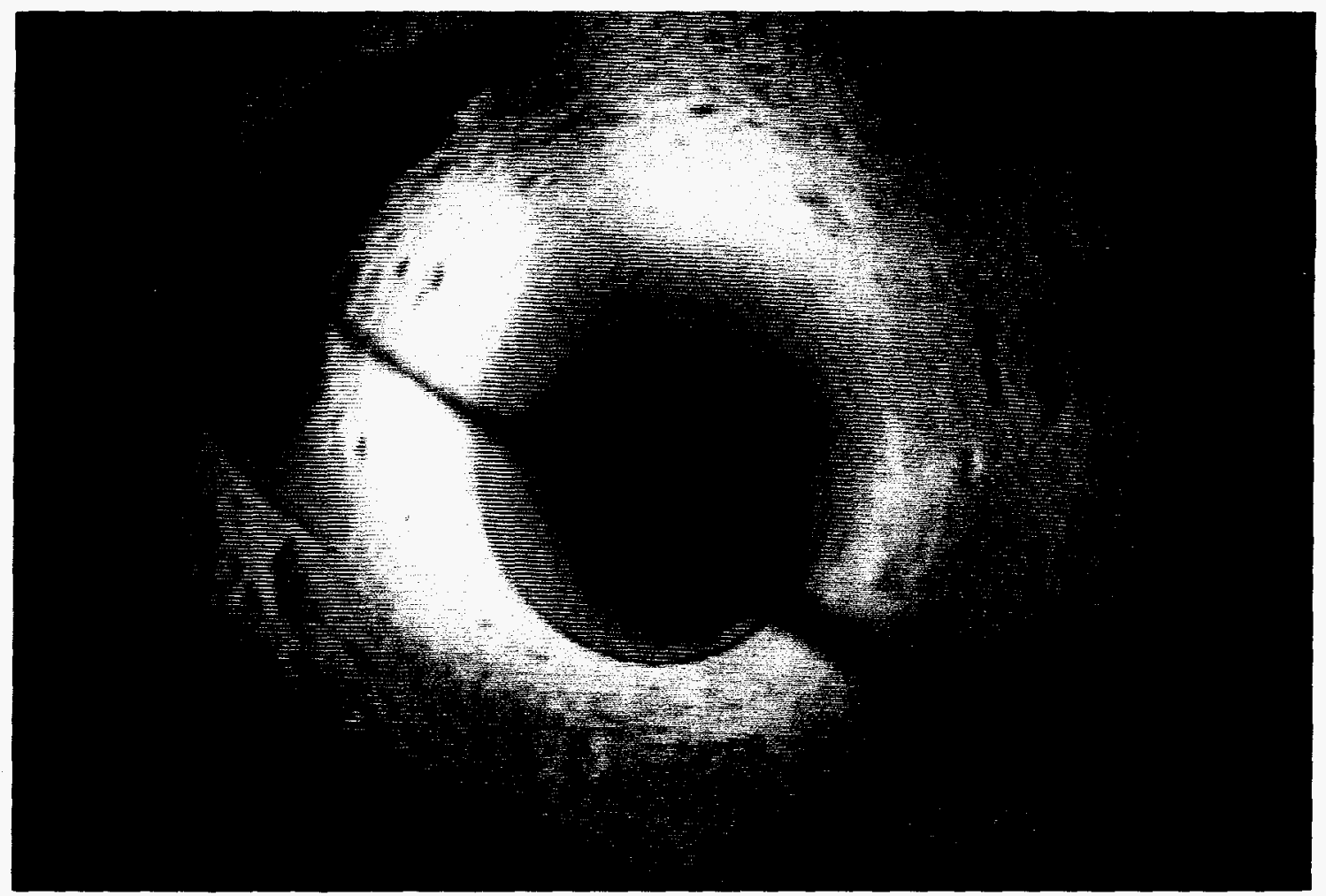

Plate 43.

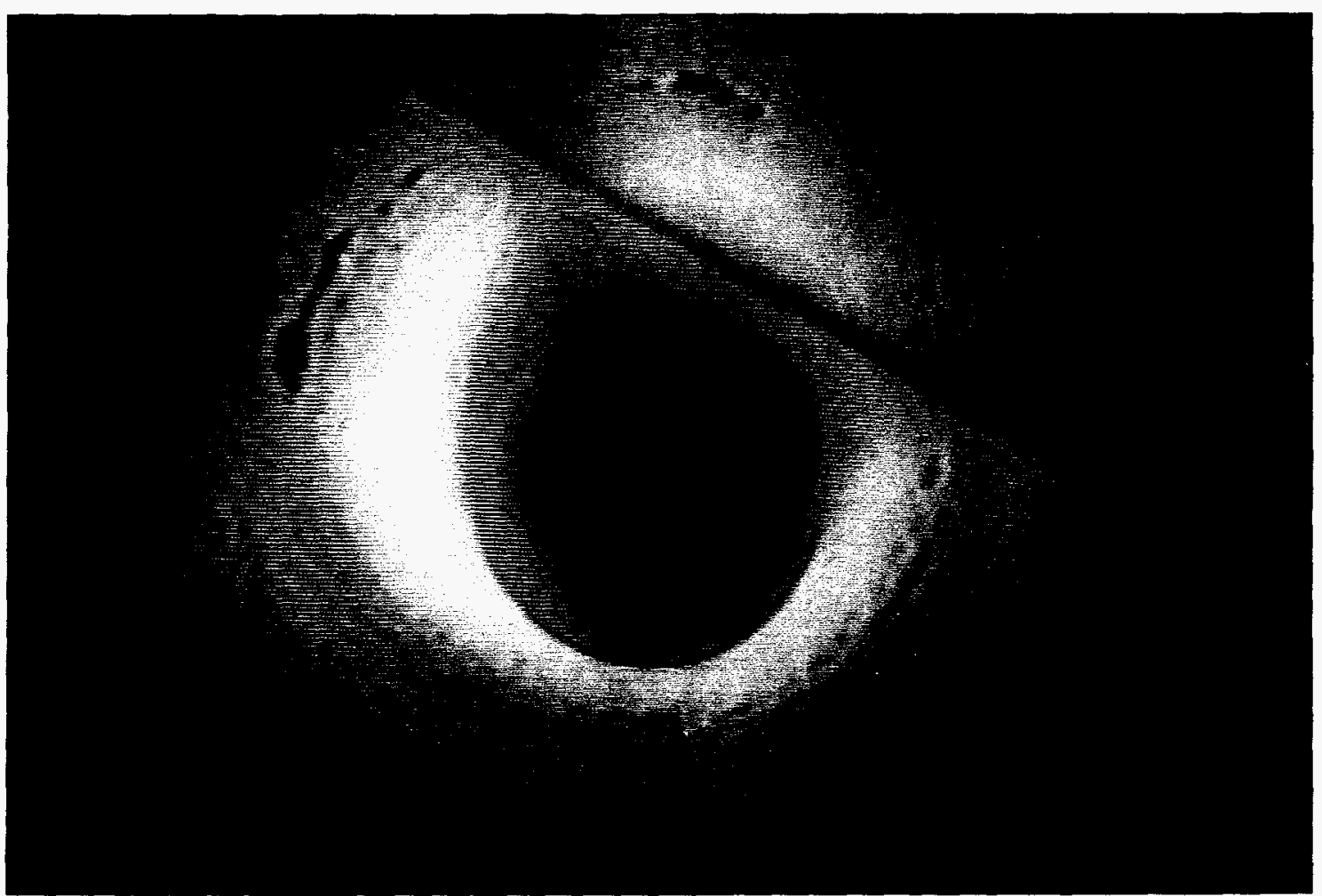


Plate 44.

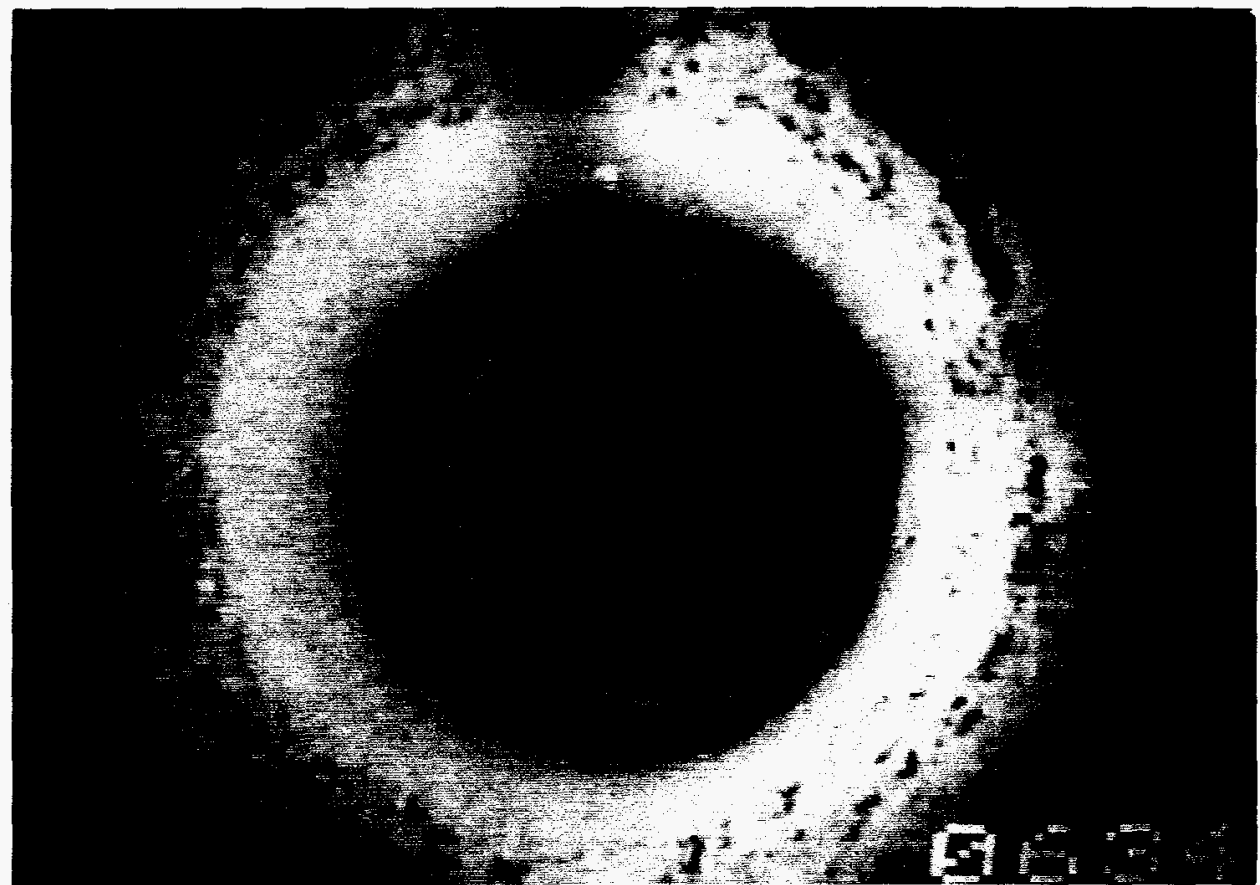

Plate 45.

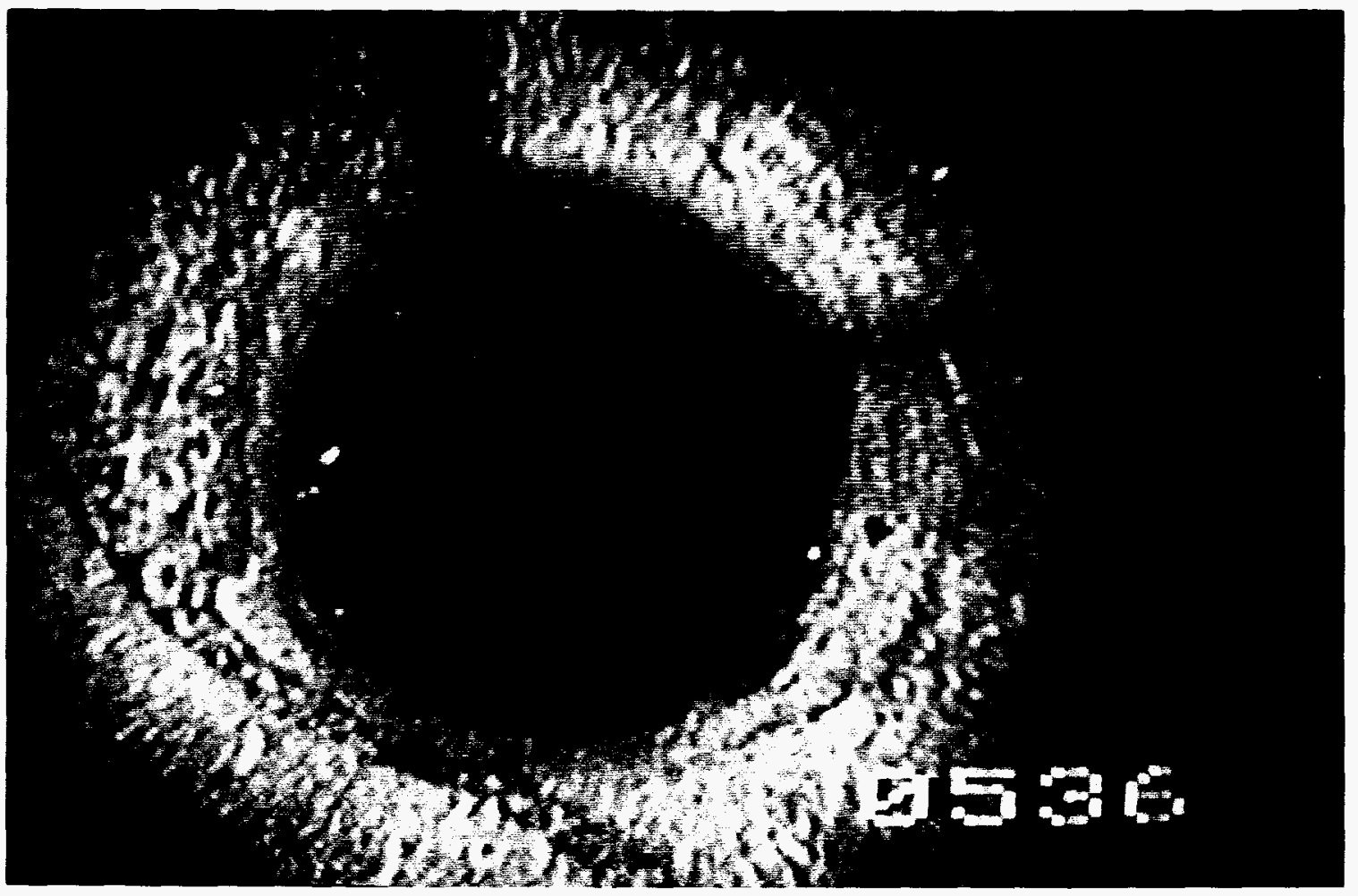


Plate 46.

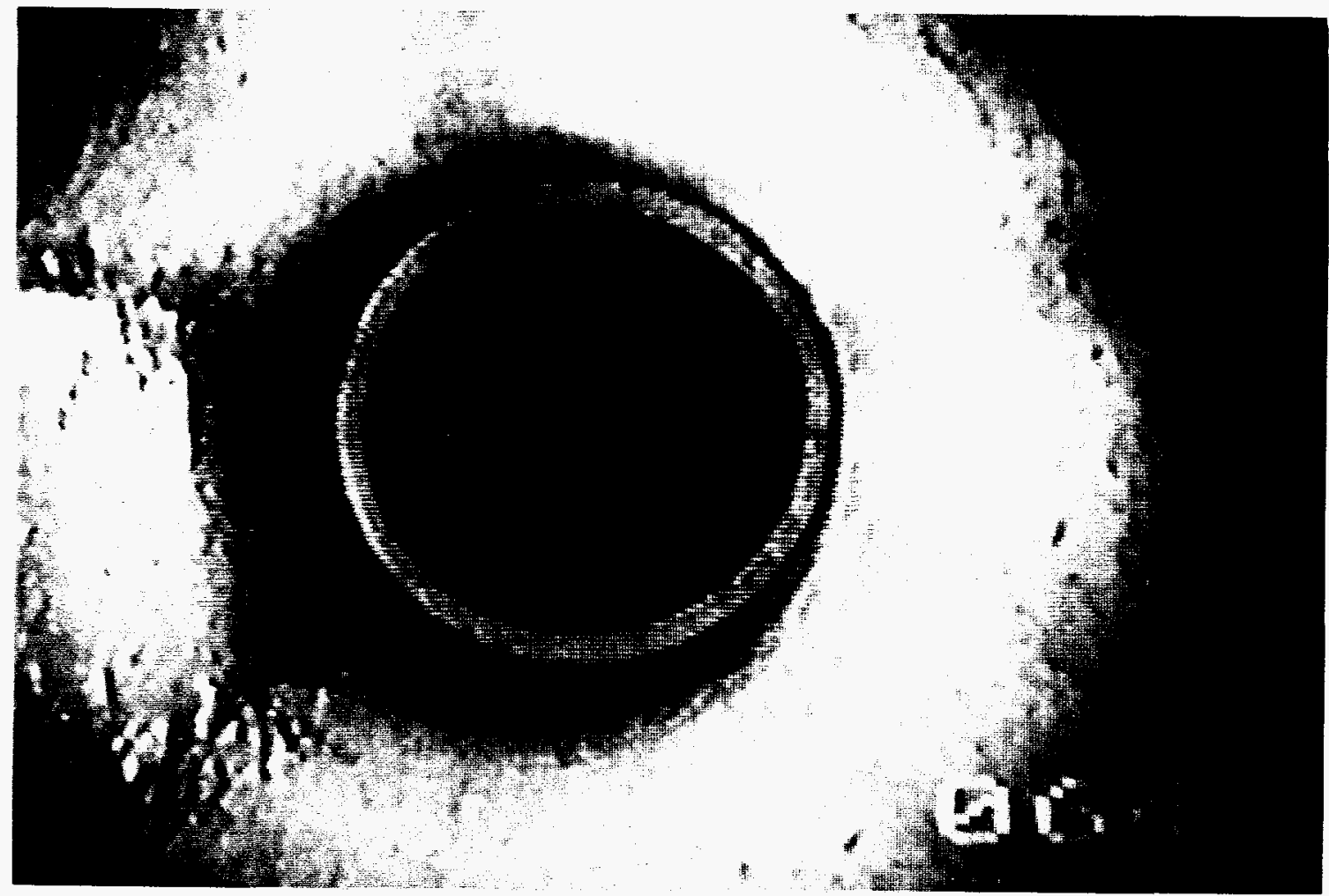

Plate 47.

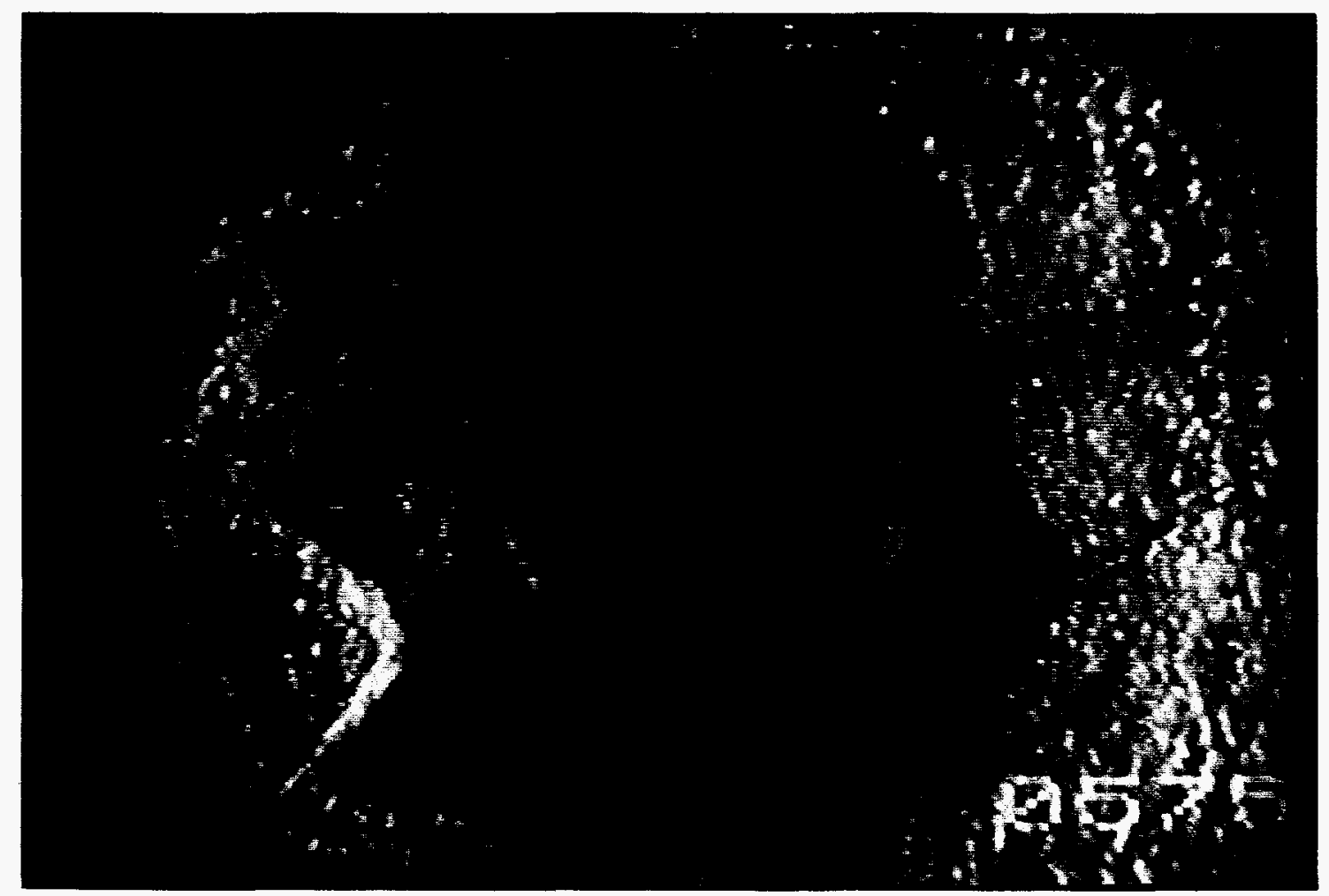


Plate 48.

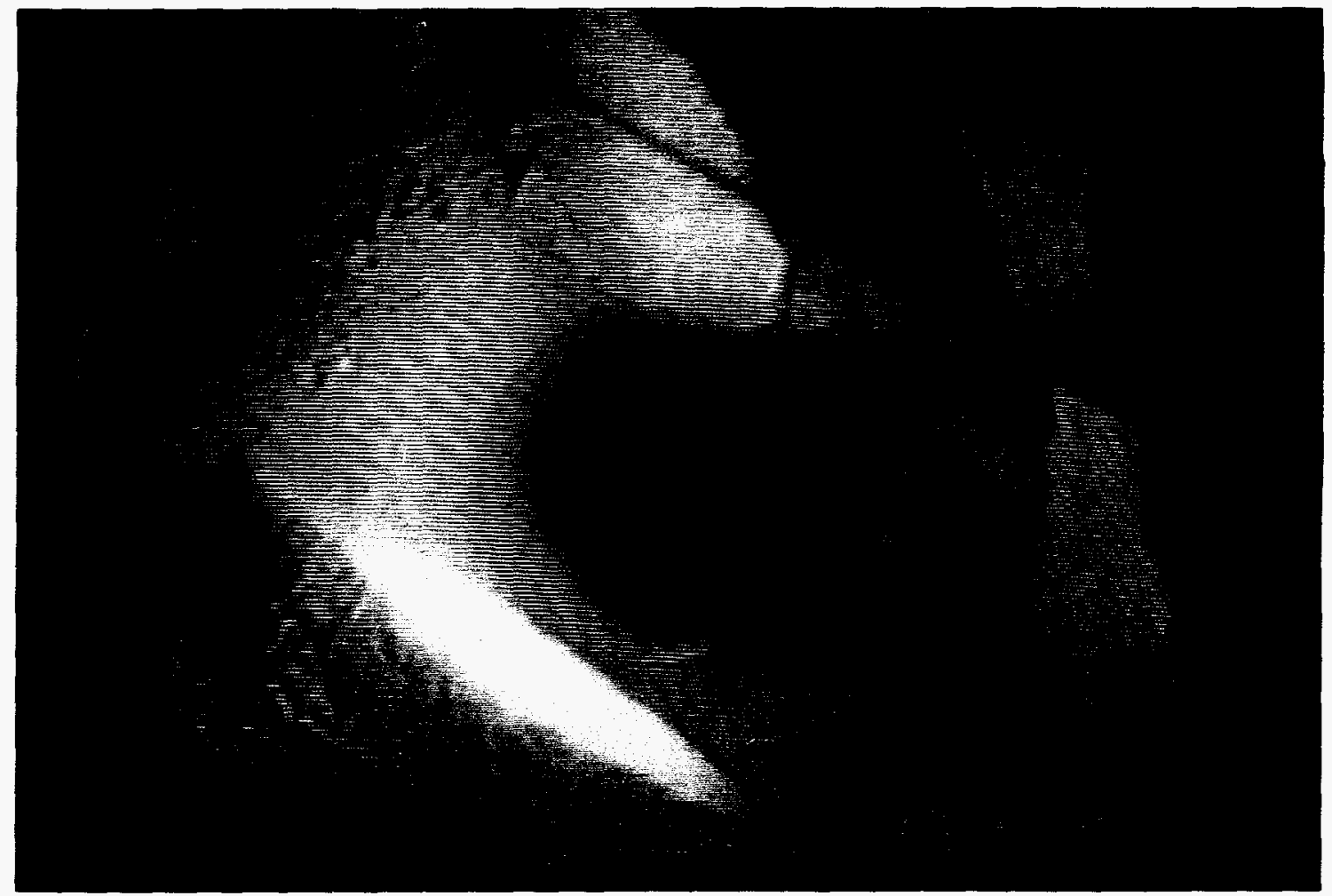

Plate 49.

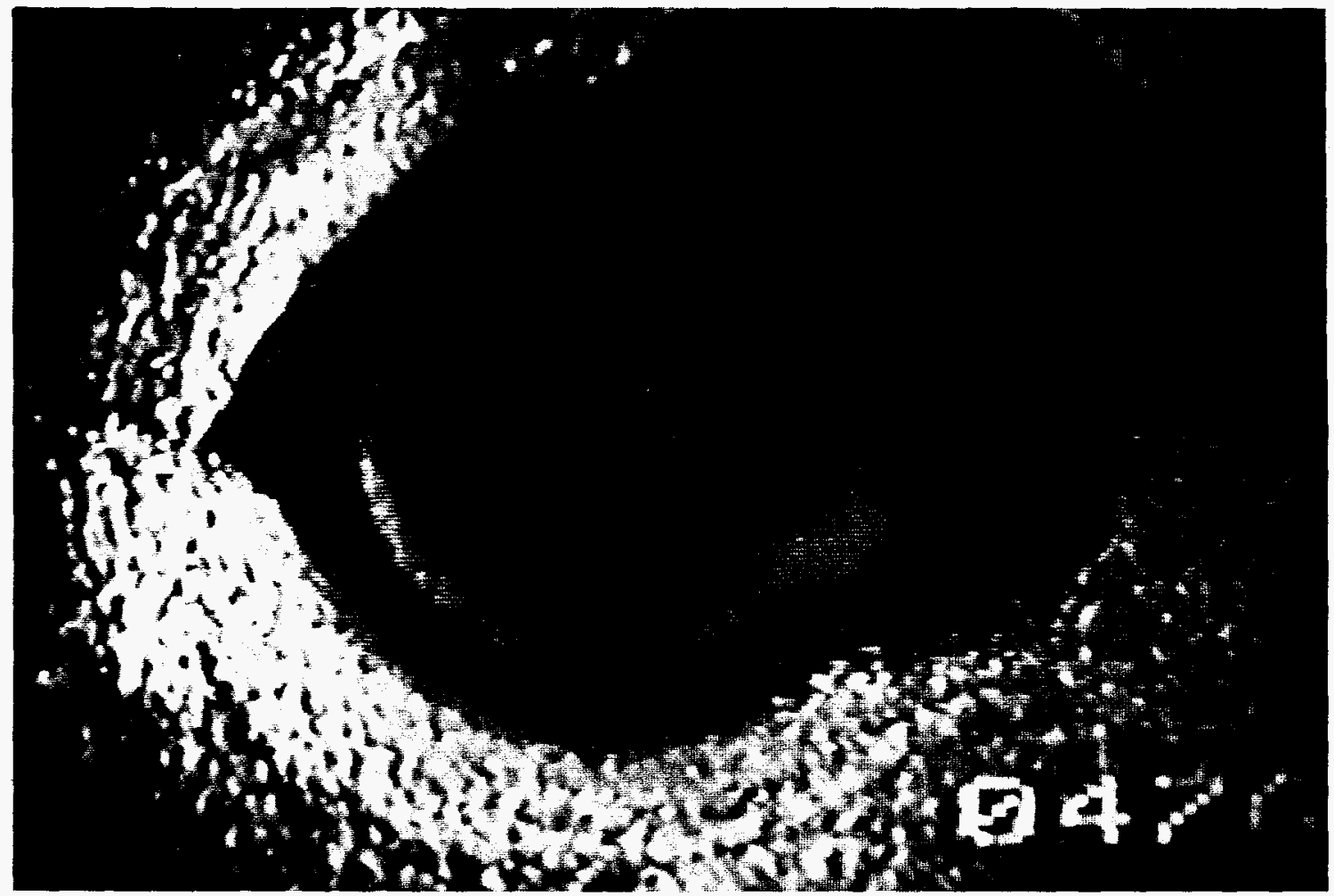


Plate 50.

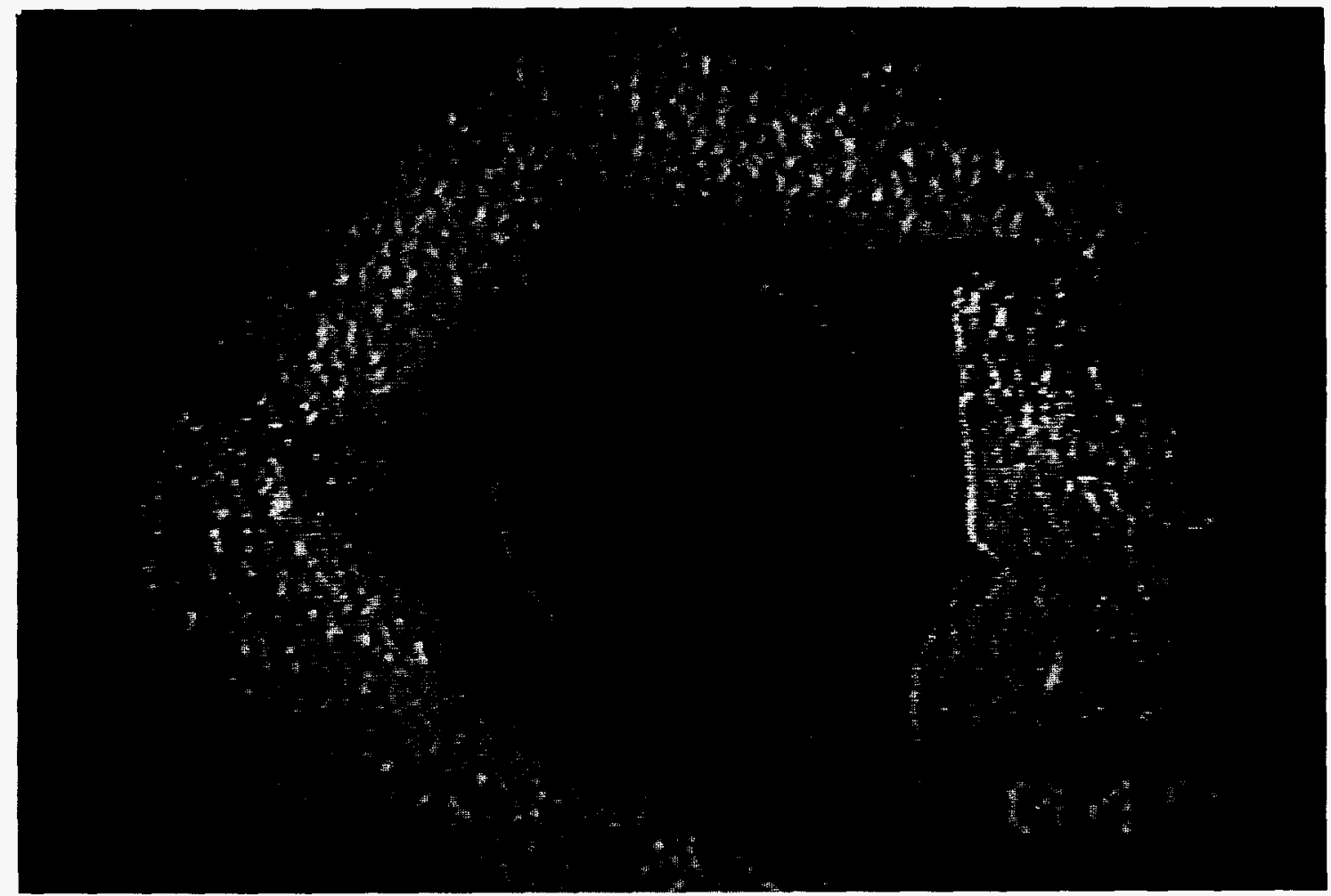

Plate 51.

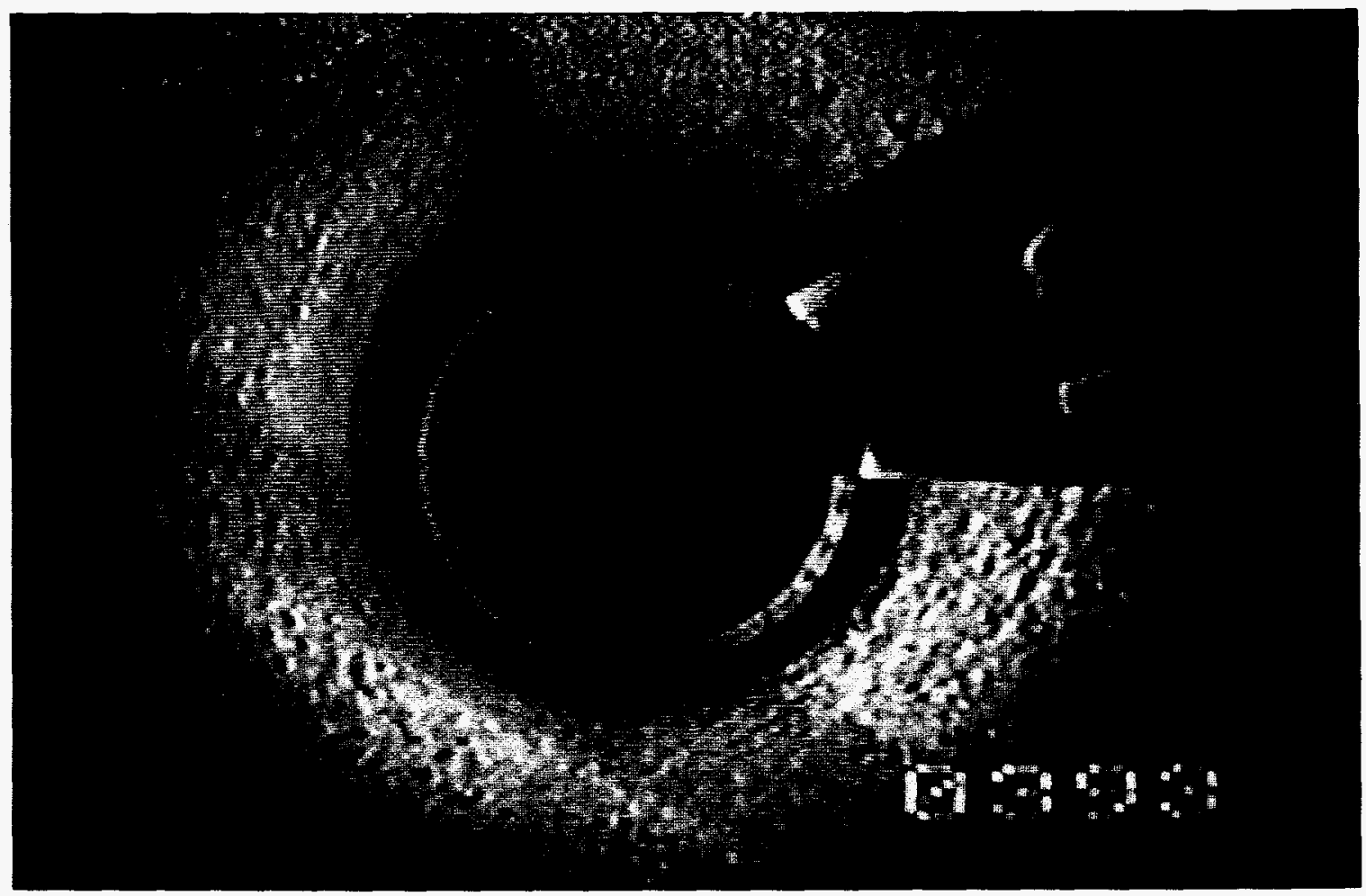




\section{Plate 52.}

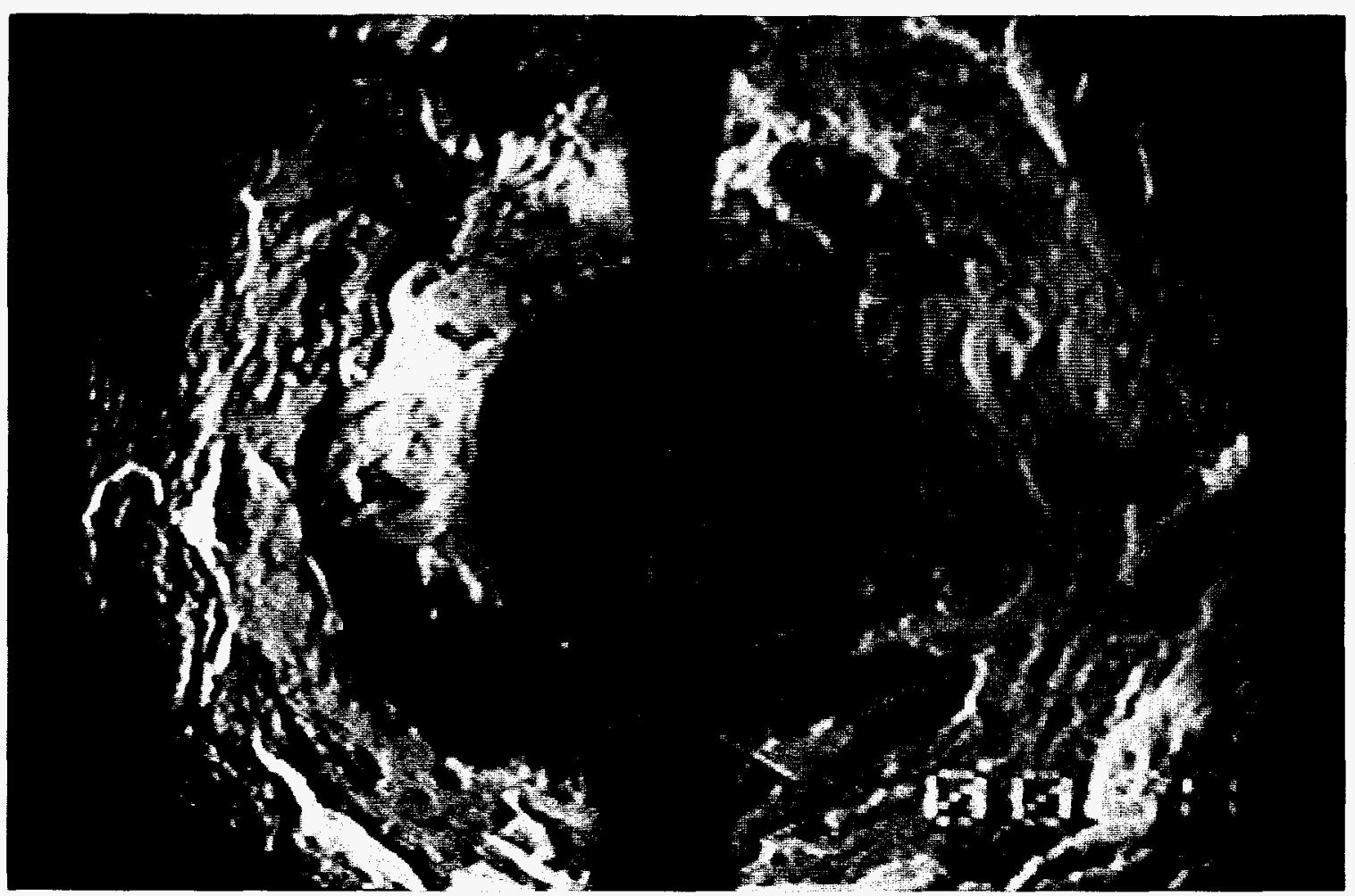

Plate 53.

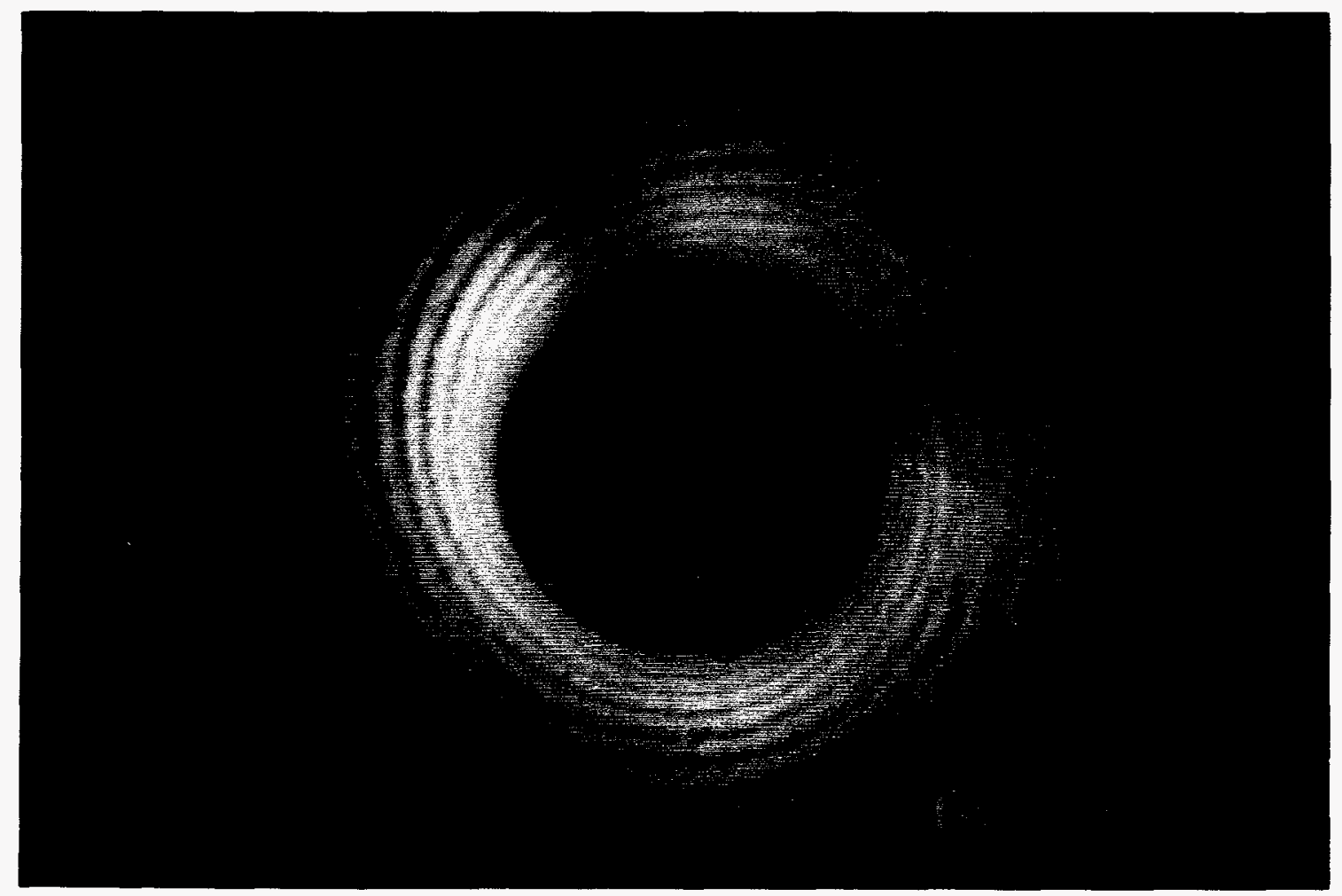




\section{CHAPTER 7. ANALYSIS OF BOREHOLE TV FEATURES}

\section{Basalt Lava Flows}

Basalt lava flows can be classified as pahoehoe or aa lava (theses are the only two forms). Rarely seen in borehole TV logs are broken rock fragments sitting in a caved-like portion that has ropy features on it like those found on the surface of a pahoehoe lava flows. Considerable amounts of broken rubble material exist at the contact between some lava flows. Rubble is up to two meters in thickness for some basalt lava flows. Only one lava flow found in the core of USGS 123 at depth $123 \mathrm{~m}(123 \mathrm{ft})$ had an aa appearance to it. The cored basalt was of low density with some vesicles present. The basalt fragments (less then a $4 \mathrm{~cm}$ in diameter) are sharp edged and very reddish in color. This compared to the usually denser more vesiculated rounded edged clumps of a more grayer color material that is commonly inbetween most lava flows seen in cores and outcrops. The author does not propose the idea that only pahoehoe lava flow types occur in the subsurface just that based on the author's observations the lava flows seen in the borehole TV logs are pahohoe lava flows.

Some lava-flow contacts have sedimentary interbeds while others based on their contacts and size are classified as flow-units (see page 63 for the distinction between lava flows and flow units). From outcrop and core studies the flow-units seen in the TV logs appear to not differ in any appreciable manner although it is apparent that there are more flow-units then basalt flows in the TV logs.

It would be tough to classify where the individual basalt flows at INEL (ICPP vicinity) would fit into a basalt flow facies (Figure 19). Some lack a developed central part and are 
very thin indicating a more proximal zone while others are very thick with possible columnar features indicating a more medial to distal facies. Indications of an interlayered vent facies of pyroclastics and agglutinate appeared to be lacking in most boreholes examined suggesting that basalt section at ICPP is not a proximal facies. Knutson and others (1990) in their study of surface and drill cores at the RWMC concluded that none of the lava flows exhibited proximal facies. From surface observations two lava flows represented distal facies. It is likely that deeper flows at the RWMC are also distal or intermediate facies. Lanphere and others (1994) studied twenty-two lava flows in cores at the ICPP and concluded that their emplacement was relatively close to a vent. Based on the number of observable basalt lava flows seen on borehole TV logs of the ICPP area a more distal to intermediate facies would be more likely then a proximal one.

\section{Interface Between Basalt Lava Flows}

The various interfaces found between the basalt lava flows observed on the borehole TV logs are comparable to those found in the outcrops and cores. More fragmental material and the presence of openings are found in the borehole TV logs versus in cores and outcrops.

Interbeds observed for the basalts near or on the INEL have been noted by various authors (Knutson, et al., (1990), Lanphere, et al., (1994), Anderson (1989 \& 1991), Ackerman (1991), etc.). Although no detail analysis was made on these features they are prevalent in all of the studies of outcrops, cores, and TV logs. Reed (1994) studied the mineralogy and depositional sources of the sedimentary interbeds at 19 sites beneath the INEL. He found that the interbeds contained sediment with the percentages for quartz, feldspar, and carbonate ranged from 37 to 59, 26 to 40, and 5 to 25 , respectively. Mineralogical data indicated that the samples collected correlate with surficial sediment samples from the present day Big Lost River suggesting that the sources for the sediments at and near the INEL have remained relatively consistent for the last 580,000 years (Reed, 1994). 


\section{Basalt Flow Model Applied to Borehole TV Observations}

The nomenclature proposed for the basalt lava flows seen in outcrops (Chapter 4) can be applied to the basalt lava flows observed in the borehole TV logs. Identification of columnar zones in the cores is uncertain while the observations from the TV logs indicated that column-like openings and defining fractures are present, but a definite identification of these areas as columnar parts of basalt flows was tenuous. The author believes that the observations made of these features in the TV logs are more "convincing" than those found in cores because large fracture systems cannot typically be observed on the cores.

\section{Vesicles}

Vesicles seen in the borehole TV logs appear to be the same type seen in outcrops and cores. A characteristic large vesicle in the middle of the upper vesicular zone the author would like to term "whale-back" for the vesicle general shape and for the extreme size. These largest vesicles occur in the lowest portion of the lower vesicular subzone, but are not always present, especially in thin basalt lava flows.

\section{Fractures}

Partings seen in the boreholes could have two possible origins. One class of origins are geologic processes that acted upon the basalt in the past before drilling. The second origin for some fractures could be the result of the drilling process. A combination of these two processes could also occur whereby fractures developed before drilling interact with the drill bit causing initial destruction of the fracture zone. In some cases drilling operation information was recorded (such as dynamiting the borehole). Vertical and horizontal fractures dominate inclined fractures. The number of horizontal fractures recorded for cores is larger then those found in outcrops and TV logs and a fair amount of them may be induced fractures rather than natural. The fractures seen in the TV logs tend to have fewer horizontal fractures then in the cores and resemble more closely the outcrops. Apertures 
were measured in the TV logs and outcrops, but could not be reliably measured in the cores.

A flat planar borehole wall generated from drilling fractures has varying textures that can be explained (Figure 39).

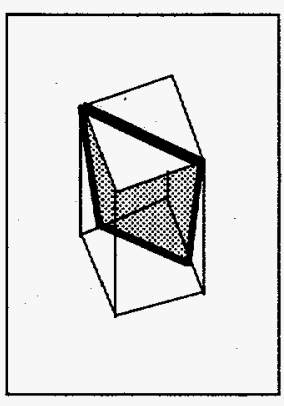

A

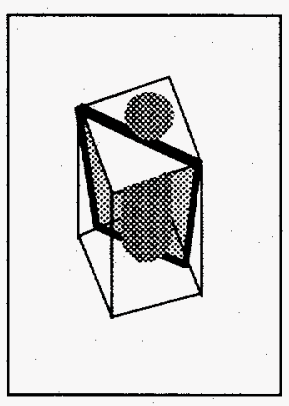

B

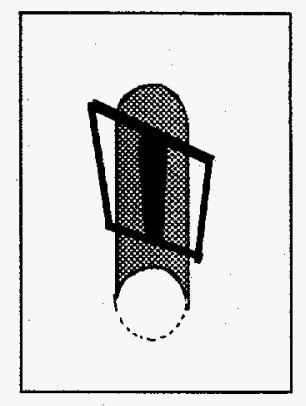

$\mathrm{C}$

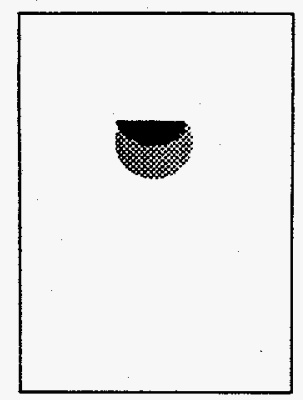

$\mathrm{D}$

Figure 39. Figure showing an illustration of what possibly might be the cause of the boreholes with planar walls. In illustration "A" a block is cut by a fracture shown in the darker color. Later in " $\mathrm{B}$ " the same block has a hollow drill hole in it that intersects the plane of the fracture. In illustration " $C$ " the borehole wall is shown with the black area being the trace of the fracture intersected in diagram " $B$ ". Illustration " $D$ " shows a planar view looking down the borehole showing that the plane of the fracture intersects the hole along its edge and thus in a three dimensional perspective the borehole wall will have a recess in it where the fracture plane is found.

The flat planar feature of the fracture looks texturally different because of fine grained material possibly drilling mud that lines the fracture surface thus masking any original features it may have had. This also gives it a lighter color than the surrounding borehole wall.

\section{Deviations From Normal Borehole Diameter}

Deviations from the normal borehole diameter noticed in the borehole TV logs could have formed in a couple different ways. First a series of fractures when drilled create a larger opening in the borehole from pieces of rock that spalled off from the fractures. 
Another method could be drilling through the columnar zone. Since this zone is made up of various vertical and horizontal fractures the columns might break up upon drilling leaving a larger opening in the borehole wall. Small deviations from the normal borehole diameter could just be the result of the drilling process itself, but this would result in only minor deviations and not "cavernous" features. Another possible explanation of cavernous parts is an actual lava tube. 


\section{CHAPTER 8. DATA COLLECTION METHODS: IMPELLER FLOWMETER}

\section{Purpose And Objectives}

One objective of this study is to use the impeller flowmeter to identify the position in a borehole where fluid enters and exits. The second objective is to find out how much fluid is moving and at what rate of speed. The third objective is to determine in which parts of the basalt lava flow these fluid movements occur. Finally, this chapter describes an conceptual model of how fluid moves in the saturated zone of basalt lava flows in the ESRP.

\section{Location}

Wells USGS 44, 45, and 46 at the ICPP (Table 2), are the locations where the impeller flowmeter was run at (Figure 3).

\begin{tabular}{|c|c|c|c|}
\hline $\begin{array}{c}\text { Well } \\
\text { Name }\end{array}$ & Latitude & Longitude & Altitude \\
\hline USGS 44 & 433408 & 1125621 & $1499 \mathrm{~m}(4919 \mathrm{ft})$ \\
\hline USGS 45 & 433402 & 1125617 & $1500 \mathrm{~m}(4920 \mathrm{ft})$ \\
\hline USGS 46 & 433406 & 1125614 & $1499 \mathrm{~m}(4917 \mathrm{ft})$ \\
\hline
\end{tabular}

Table 2. Table showing location of the three wells at the ICPP.

The focus of the following work will be directed at four wells at the ICPP while also drawing from the information found in other published results from wells at the ICPP. 


\section{Equipment And Methods}

Impeller flowmeter logging was conducted with Boise State University's Series 3000 Mount Sopris Instruments Company 4-conductor wireline unit with data acquisition using the ACQUIRE software and interface electronics. A bi-directional Halliburton (formerly Gearhart Owen, Mineral Logging Service) $3.65 \mathrm{~cm}$ (1.4375 in) diameter impeller flowmeter with a low-density plastic impeller spinning on jewelled pivots was used in the boreholes (Figure 40). The impeller has an embedded magnet that allows the electronics in the sonde to sense the direction of spin and change polarity of the pulses according to spin direction. The following is from Wood and Bennecke (1994).

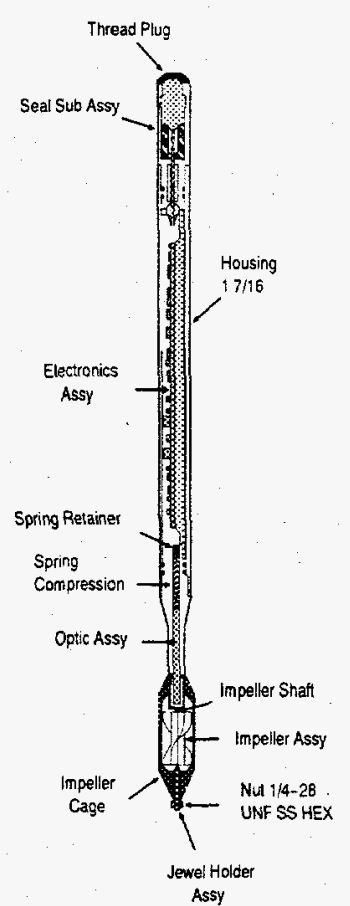

Figure 40. Figure showing Halliburton bi-directional impeller flowmeter.

These pulses are counted by data acquisition software and values recorded at each depth sample point as counts per second (cps). When an impeller flow-meter is moving through a fluid at a constant rate of speed the propeller will rotate at a constant rate generating a 
constant cps value if no flow is present in a well. If the tool is moving in a well at a constant rate and flow is present then it well be recorded as an increase or decrease in cps. The impeller has a stall speed of about $3 \mathrm{~m} / \mathrm{min}(11 \mathrm{ft} / \mathrm{min})$ for down-wash flow, and about $2 \mathrm{~m} /$ $\min (8 \mathrm{ft} / \mathrm{min})$ of up-wash flow. In order to detect small flows the tool is trolled at speeds of 5 to $8 \mathrm{~m} / \mathrm{min}$. (15 to $25 \mathrm{ft} / \mathrm{min}$ ). The least noisy signal is obtained on down trolled runs (up-wash). Noise level is about 0.6 to $0.9 \mathrm{~m} / \mathrm{min}$ ( 2 to $3 \mathrm{ft} / \mathrm{min}$ ) on account of the somewhat jerky nature of the revolutions of the impeller. Some of the spikyness and noise experienced using this flowmeter may be from turbulence and horizontal flows as reported by Young (1992). He used a Haferland Geophysical flowmeter with a lightweight impeller to test the effects of turbulence on the performance of his flowmeter. He found that turbulence and non-uniform flow caused by the transition of horizontal flow to vertical flow in a well may affect the response of a borehole flowmeter. He tested this by recirculating about $8 \mathrm{~L} / \mathrm{min}(2 \mathrm{gal} / \mathrm{min})$ through a $5 \mathrm{~cm}$ ( $2 \mathrm{in})$ O.D. pipe while injecting water through a horizontal opening (inflow $7.30 \mathrm{~L} / \mathrm{min}(1.93 \mathrm{gal} / \mathrm{min})$ ) and withdrawing the water $53 \mathrm{~cm}$ (21 in) above the opening from another horizontal orifice. His test included taking flowmeter measurements at locations below, at, and above the injection locations of the water. He found that as the flowmeter is raised past the inflow, the meter obstructs the pathway of injected water. During this obstruction, some of the inflow may be diverted downward and return as upward flow on the other side of the pipe. This obstruction and diverted water results in a erratic response for the flowmeter. Oscillatory response from the flowmeter is attributed to eddies that produce spiral flows that contribute to rotating the impeller (Young, 1992). Spinner flowmeters are available that can measure vertical borehole water velocities of $2 \mathrm{~m} / \mathrm{min}(7 \mathrm{ft} / \mathrm{min})$ and greater, and some spinners have been made with stall speeds as slow as $0.6 \mathrm{~m} / \mathrm{min}$ ( $2 \mathrm{ft} / \mathrm{min}$ ) although many geologic formations have slower flow rates (Hess, 1986). 


\section{Calibration}

Calibration is obtained by trolling at various speeds in casing or depth intervals where fluid is not moving in the borehole. Such intervals show a constant cps value when the tool is moved through it. Thus the impeller flowmeter is run at a constant velocity giving constant cps values. This procedure is repeated, but at different rates of speed giving a range of cps values for their complementary cable speeds. These values are plotted with cps vs. cable speed ( $\mathrm{ft} / \mathrm{min})$. For a properly functioning tool there is a linear relationship between impeller revolutions (cps) and cable speed, and a constant related to the stall speed of the impeller.

This relationship is:

$$
\left[(c p s)\left(\frac{1}{\text { slope }}\right)\right]+\text { cons } \tan t=F V
$$

Where $F V$ is the fluid velocity in the borehole.

Since calibration runs are completed at varying speeds a best fit line is drawn through them and extended to the cable speed axis. The intersection of the extended line to the axis is done to obtain an add-on constant related to, but not always equal to the stall speed. This is done by adding the intercept value to the cps-cable speed relationship:

$$
\left[\text { xintercept }+(c p s)\left(\frac{1}{\text { slope }}\right)\right]=F V
$$

When computing the fluid velocities from raw logs the cable speed at the time of logging must be subtracted from this equation to takeout the cable speed effect:

$$
\left\{\left[\text { xintercept }+(\text { cps })\left(\frac{1}{\text { slope }}\right)\right]-\text { CableSpeed }\right\}=F V
$$


This then is the calibration formula for the impeller flowmeter which was used in the boreholes. The Mt. Sopris ACQUIRE system records both cable speed and cps, so that a borehole flow can be calculated from the depth indexed ASCII row of the computer recorded data.

Interawell flows detected by the flowmeter, in terms of $\mathrm{ft} / \mathrm{min}$ can be converted to volumetric flow, by multiplying by the cross-sectional area of the borehole, which for a 6 inch well is $0.20 \mathrm{ft}^{2}$, and for an 8 inch well is $0.35 \mathrm{ft}^{2}$. To give flow in terms of $\mathrm{ft}^{3} / \mathrm{min}$ one cubic foot is 7.5 gallons, so that for a 6 inch well, $1 \mathrm{ft} / \mathrm{min}=1.5 \mathrm{gal} / \mathrm{min}$; and for an $8 \mathrm{inch}$ well, $1 \mathrm{ft} / \mathrm{min}=2.6 \mathrm{gal} / \mathrm{min}$. Or another way to figure out the flow volume, $\mathrm{Q}$, in $\mathrm{L} / \mathrm{min}$, may be determined from the following equation where $V=$ flow velocity $(\mathrm{m} / \mathrm{min})$ and $\mathrm{D}=$

$$
Q=785 \times 10^{-6} \times V \times D^{2}
$$

borehole diameter (mm) (Hess, 1986). The "785" arises from $\pi / 4$ in calculating the crosssectional area of the borehole. A uniform volumetric flow fluctuates with borehole diameter, so that in break-out intervals or constrictions seen on caliper logs, the flow will vary on account of borehole size (Wood and Bennecke, 1994).

\section{Impeller Flowmeter Measurements}

Records obtained from the impeller flowmeter gives a running account of the changes in fluid velocities in the borehole and directions of these fluid movements. Fluid in the borehole can be entering the borehole, exiting it, or traveling up or down the borehole.

\section{Influences From Nearby Well CPP-2}

USGS wells 44,45 , and 46 all fall under the influence of a nearby pumping well CPP2 which turns on and off with an approximate cycle of 2 hours on and 3 hours off. The well is $730 \mathrm{~m}(2400 \mathrm{ft})$ away and pumps about $11,700 \mathrm{~L} / \mathrm{min}(3100 \mathrm{gal} / \mathrm{min})$. The times of the 
on and off periods are not constant since CPP-2 produces water for the ICPP and the amount of demand constantly changes. CPP-2 rotates into production with another well CPP-1 (Figure 3) (about $152 \mathrm{~m}(500 \mathrm{ft}$ ) apart from each other) on a monthly basis. Since only CPP-2 was quasi-periodically running at the time of logging it will be the sole well discussed. CPP-2 fills up a tank in the Chemical Plant with water (pump on) and when the level of water in the tank reaches its limit it shuts off the pump. Water that is taken out of the container brings the water level down which then activates the pump to turn on.

Detailed times of when this pump turned on and off were kept during logging of the nearby wells to see if it had any effect on the fluid movement in the boreholes.

\section{Repeatability of Flowmeter Runs}

Flowmeter logs were run repeatedly in the same well during on and off pumping times from CPP-2. The flow patterns observed in these numerous runs reflect a very repeatable signal from the fluid movement in the boreholes and not some transitory pattern. In otherwords flow in the well sets up a stable regime within a few minutes of the pump on or off cycle of CPP-2 (Figure 41). 


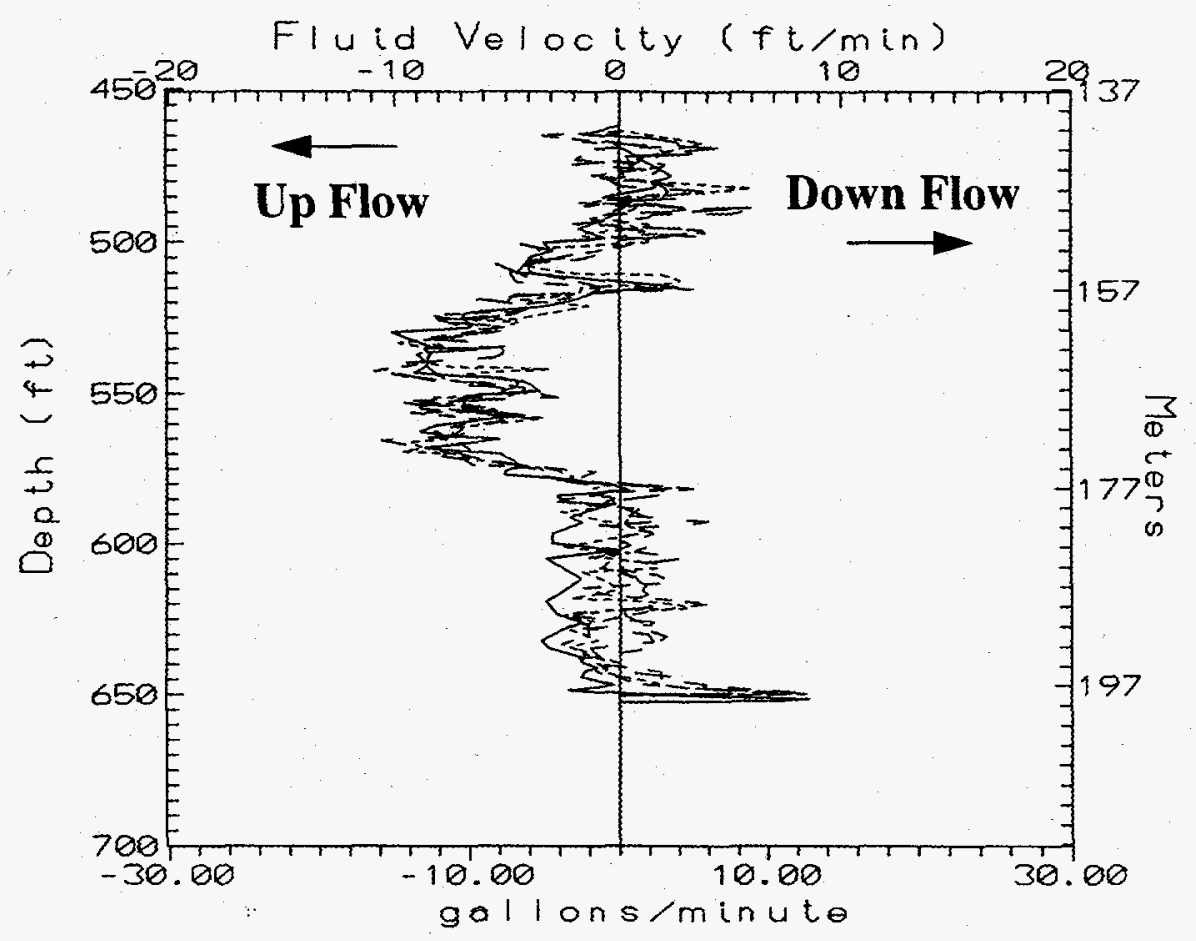

Figure 41. Figure of multiple ( 5 separate) flowmeter runs in the same well (USGS 46) one after the other (about every 19 minutes). Notice that the overall pattern stays the same. Fluid velocity is the velocity that fluid is moving in the borehole. The line at zero velocity shows where no flow occurs in the borehole. The negative velocities in this figure denote upward fluid movement while the positive values indicate downward fluid movement in the borehole. Flowmeter runs were made when the CPP-2 pump was off. 


\title{
CHAPTER 9. IMPELLER FLOWMETER RESULTS
}

\author{
Fluid Movement In Boreholes Studied
}

\section{Well USGS 44}

Well USGS 44 was cable-tool drilled to a depth of $198 \mathrm{~m}(650 \mathrm{ft})$ in 1957 . Twenty centimeter ( 8 in) steel casing extends from the surface to $141 \mathrm{~m}$ (461 feet) below which is

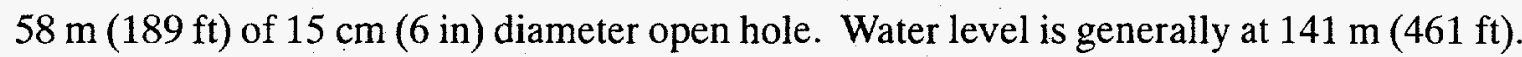

When the pump is on and off the flowmeter log shows stagnant water from 141 to 156 $\mathrm{m}$ (461 to $512 \mathrm{ft}$ ) (Figure 42). When the pump is off flowing water enters the borehole through a $3 \mathrm{~m}(10 \mathrm{ft})$ thick zone from 168 to $165 \mathrm{~m}(550$ to $540 \mathrm{ft})$ and then travels up the borehole at a rate of $2.1 \mathrm{~m} / \mathrm{min}(7 \mathrm{ft} / \mathrm{min})$ or a volumetric flow rate of $40 \mathrm{~L} / \mathrm{min}(11 \mathrm{gal} /$ $\mathrm{min}$ ). Water exits the borehole at a 1 -m (4-ft)-thick zone from 157 to $156 \mathrm{~m}$ (515 to 512 $\mathrm{ft})$. Below 168 the water appears to be stagnant on the flowmeter log although there appears to be a slight upward flow at about $0.9 \mathrm{~m} / \mathrm{min}(3 \mathrm{ft} / \mathrm{min})$ from $168 \mathrm{~m}(550 \mathrm{ft})$ to $175 \mathrm{~m}(575$ $\mathrm{ft}$ ), but this is so close to the noise level for the flowmeter one cannot be certain of the flow.

When the pump was turned on the flow pattern seen from 168 to $156 \mathrm{~m}$ reverses so that water first enters at $156 \mathrm{~m}$ and travels down the borehole to leave at $168 \mathrm{~m}$. The “pump-on" fluid velocity is $5.2 \mathrm{~m} / \mathrm{min}(17 \mathrm{ft} / \mathrm{min})$ or a volumetric flow rate of $98 \mathrm{~L} / \mathrm{min}$ (26 gal/min), considerably greater and in the opposite direction to "pump-off" conditions. 


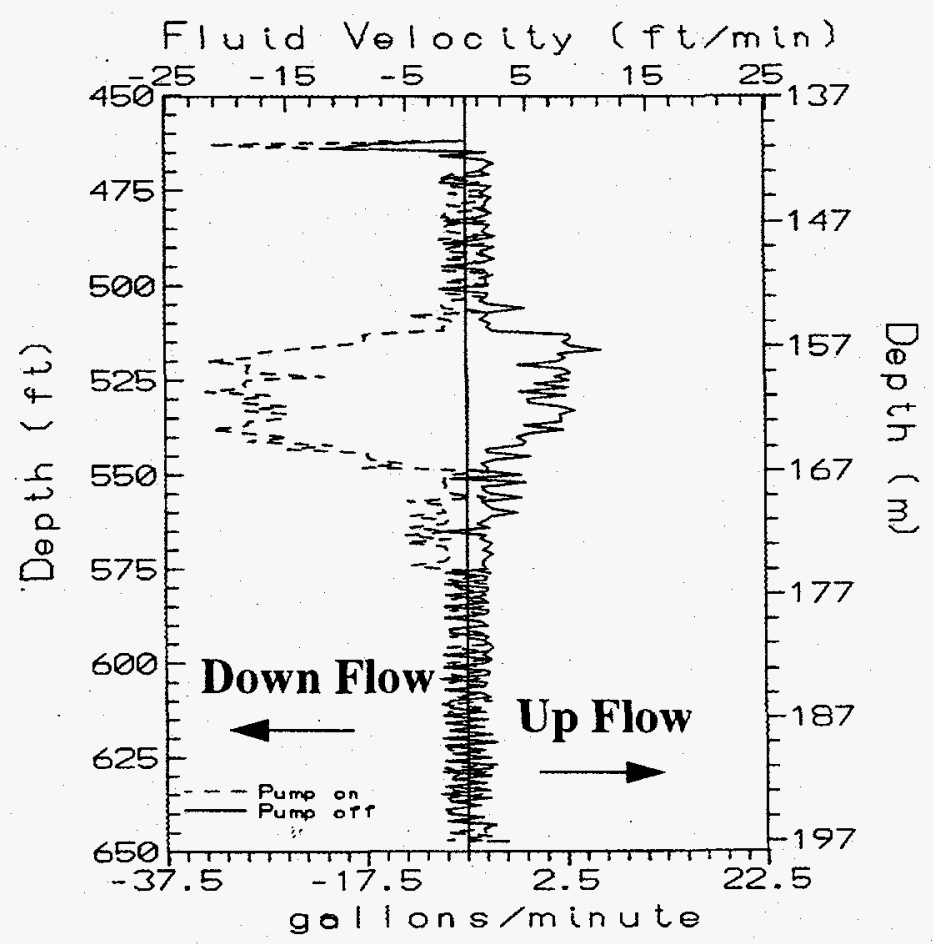

Figure 42. Figure showing impeller flowmeter log of well USGS 44 from water level to bottom of borehole. This plot shows two separate logging runs one during the time when the pumping well (CPP-2) was not running (the solid line) and the other when it was pumping (the dashed line). Velocities are given from zero line (the center line down the plot). Positive flow value is an indication of upward fluid movement in this borehole while a negative flow value are an indication of downward fluid movement.

Borehole TV camera interpretation and impeller flowmeter work are combined to create a log of permeable zones and are interpreted in terms of basalt flow features and stratigraphy (Appendix C-50). This interpretive log and similarly derived logs of surrounding wells are used to construct a geological cross section of the ICPP area emphasizing identified permeable zones and basalt flow features.

The $1 \mathrm{~m}$ ( $4 \mathrm{ft}$ ) thick permeable zone from 156 to $157 \mathrm{~m}(512$ to $515 \mathrm{ft})$ is characterized by the upper vesicular zone of a basalt lava flow seen in the borehole TV log (Appendix C50). At $156 \mathrm{~m}(512 \mathrm{ft})$ the contact between two basalt lava flows can be seen with a gap (3 $\mathrm{cm}$ wide) between the lower vesicular zone and the upper vesicular zone occurring at 156 
$\mathrm{m}(512 \mathrm{ft})$. From $156 \mathrm{~m}(512 \mathrm{ft})$ on down to $157 \mathrm{~m}(515 \mathrm{ft})$ there are many horizontal openings (several centimeters wide) in the wall. At $157 \mathrm{~m}(515 \mathrm{ft})$ there are no more openings or breaks seen in the borehole wall just the vesicles from the upper vesicular zone.

Water enters (water enters when pump CPP-2 is off and water exits when CPP-2 is on) the borehole farther down from 165 to $168 \mathrm{~m}(540$ to $550 \mathrm{ft})$. At $165 \mathrm{~m}(540 \mathrm{ft})$ is a hexagonal shaped opening from $165 \mathrm{~m}(540 \mathrm{ft})$ to $165.5 \mathrm{~m}(543 \mathrm{ft})$ indicating a columnar zone. This is then followed by the central zone with numerous vertical fractures and lacking in vesicles. The bottom of this basalt lava flow occurs at $166 \mathrm{~m}(545 \mathrm{ft})$, based on the vesicle distribution present, with a caved interval below it from $166.4 \mathrm{~m}(546 \mathrm{ft})$ to $167.3 \mathrm{~m}(549 \mathrm{ft})$. This caved interval is in the upper vesicular zone of a different underlying basalt lava flow. At $168 \mathrm{~m}(550 \mathrm{ft})$ where the water stops entering the borehole the wall becomes more competent and less fractured. The interval below $168 \mathrm{~m}(550 \mathrm{ft})$ is interpreted as the central zone based on the lack of vesicles and numerous fractures.

\section{Well USGS 45}

Well USGS 45 was cable-tool drilled to a depth of $198 \mathrm{~m}(651 \mathrm{ft})$ in $1957 ; 20$ centimeter $(8 \mathrm{in})$ steel casing extends from the surface to $141 \mathrm{~m}(461 \mathrm{ft})$ below which is 57 $\mathrm{m}(190 \mathrm{ft})$ of open hole, in diameter $15 \mathrm{~cm}$ (6 in). Water level is generally at $142 \mathrm{~m}(466 \mathrm{ft})$.

The flowmeter log of USGS 45 does not indicate such large intrawell flows (> $1 \mathrm{~m} /$ min) as seen on adjacent wells 44 and 46 . However the excursions seen on flowmeter revolutions (cps) are reproducible indicating flow in the well. Flows appear stable and unaffected by the ICPP production well pump cycle.

The flowmeter log shows stagnant water from water level at 140 down to $145 \mathrm{~m}$ (460 to $475 \mathrm{ft}$ ) (Figure 43). Flowing water enters the borehole at 145 and flows down the borehole at a rate of $1.8 \mathrm{~m} / \mathrm{min}(6 \mathrm{ft} / \mathrm{min})$ or a volumetric flow rate of $34 \mathrm{~L} / \mathrm{min}(9 \mathrm{gal} / \mathrm{min})$. At $156 \mathrm{~m}(510 \mathrm{ft})$ the water exits the borehole. Water appears stagnant in a 4.6 meter $(15 \mathrm{ft})$ thick zone from 156 to $160 \mathrm{~m}(510$ to $525 \mathrm{ft})$. At $160 \mathrm{~m}(525 \mathrm{ft})$ the water enters the bore- 
hole and flows down at a rate of $1.5 \mathrm{~m} / \mathrm{min}(5 \mathrm{ft} / \mathrm{min})$ or a volumetric flow rate of $28 \mathrm{~L} / \mathrm{min}$ (8 $\mathrm{gal} / \mathrm{min})$ until it exits at $163 \mathrm{~m}(535 \mathrm{ft})$. Water below $163 \mathrm{~m}$ appears stagnant to a depth of $168 \mathrm{~m}(550 \mathrm{ft})$ where water enters the borehole. The water flows down the borehole at a rate of $1.2 \mathrm{~m} / \mathrm{min}(4 \mathrm{ft} / \mathrm{min})$ or a volumetric flow rate of $23 \mathrm{~L} / \mathrm{min}(6 \mathrm{gal} / \mathrm{min})$ and then exits at $175 \mathrm{~m}(575 \mathrm{ft})$. Water below $175 \mathrm{~m}$ is stagnant to the bottom of the borehole.

The pump cycle of well CPP-2 was monitored while logging took place of this well and indicated no effect on the rate and direction of the water in the borehole. In Figure 43 the dotted line representing the impeller flowmeter run when the pumping well was on seems to duplicate the same pattern of the impeller flowmeter run when the pump was off (the solid line).

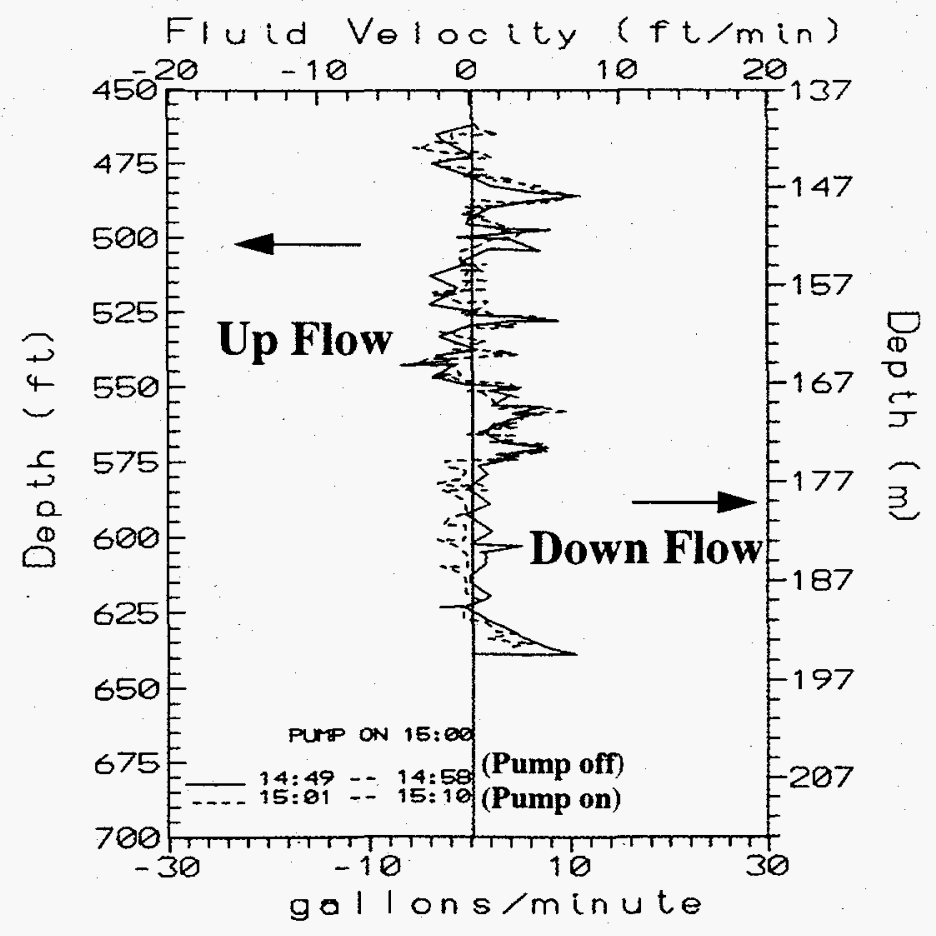

Figure 43. Figure showing impeller flowmeter log of well USGS 45 from water level to bottom of borehole. This plot shows two separate logging runs one during the time when the pumping well (CPP-2) was not running (the solid line) and the other when it was pumping (the dashed line). Velocities are given from zero (the center line down the plot). Positive flow value is an indication of downward fluid movement in the borehole while a negative flow value are an indication of upward fluid movement. 
Observations of the borehole TV logs $145 \mathrm{~m}(475 \mathrm{ft})$ where water enters the borehole show the transition between the upper vesicular zone and the central zone of a basalt lava flow. There are no physical breaks or fractures at this point just a change in vesiculation. At $147 \mathrm{~m}(483 \mathrm{ft})$ is a $0.6 \mathrm{~m}(2 \mathrm{ft})$ caved interval from $147.8 \mathrm{~m}(485 \mathrm{ft})$ to $148.4 \mathrm{~m}(487 \mathrm{ft})$, but this has no discernible effect on intrawell flow. Water exits the borehole at $156 \mathrm{~m} \mathrm{(510}$ ft) doing so at the upper vesicular zone near the change to the central zone (also a zone without fractures). Water entering the borehole at $160 \mathrm{~m}(525 \mathrm{ft})$ occurs at the contact between two lava flows where the borehole perimeter displays a keyhole appearance from $160 \mathrm{~m}(525 \mathrm{ft})$ to $161 \mathrm{~m}(528 \mathrm{ft})$. Flow exits at the central zone at a depth of $163 \mathrm{~m}$ (535 $\mathrm{ft})$, at what appears to be a vesicular ring. At $168 \mathrm{~m}(550 \mathrm{ft})$ where the water enters the borehole a sediment interbed if found from 167 to $171 \mathrm{~m}$ (547 to $561 \mathrm{ft}$ ). The exiting point at $175 \mathrm{~m}(575 \mathrm{ft})$ is in the lower vesicular zone near the contact between an upper vesicular zone and the following lower vesicular zone. It should be emphasized again that all the above flows are small and unaffected by the pump cycle.

\section{Well USGS 46}

Well USGS 46 was cable-tool drilled to a depth of $198 \mathrm{~m}(651 \mathrm{ft})$ in 1958 , twenty

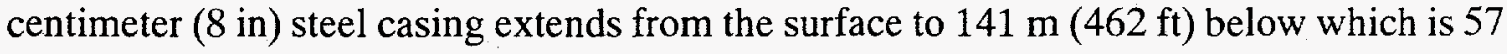
$\mathrm{m}$ (189 ft) open hole in diameter $15 \mathrm{~cm}$ (6 in) open hole. Water level is generally at $151 \mathrm{~m}$ $(459 \mathrm{ft})$.

Well 46 was logged through the on-off pump cycle at well CPP-2. When the pump is off, a small flow of about $0.9 \mathrm{~m} / \mathrm{min}(3 \mathrm{ft} / \mathrm{min})$ appears to enter at $147 \mathrm{~m}(483 \mathrm{ft})$ and flow downward and exit at $147 \mathrm{~m}(483 \mathrm{ft})$ and flow downward and exit at $151 \mathrm{~m}(495 \mathrm{ft})$.

Upward flow derived from a point lower down the hole also appears to exit at $151 \mathrm{~m}$ (495 $\mathrm{ft})$. The greatest flow enters the hole at $177 \mathrm{~m}(580 \mathrm{ft})$ and flows upward at about $2.4 \mathrm{~m} /$ $\min (8 \mathrm{ft} / \mathrm{min})$, to about $156 \mathrm{~m}(513 \mathrm{ft})$, at which point about $0.9 \mathrm{~m} / \mathrm{min}(3 \mathrm{ft} / \mathrm{min})$ exits. From $156 \mathrm{~m}(513 \mathrm{ft})$ to the exit point at $152 \mathrm{~m}(500 \mathrm{ft})$ the flow appears to gradually 
diminish to about $1.4 \mathrm{~m} / \mathrm{min}(4.5 \mathrm{ft} / \mathrm{min})$ and then abruptly stops and reverses at $140 \mathrm{~m}(459$ $\mathrm{ft})$. So in summary for pump-off conditions, flow entry points appear to be $147 \mathrm{~m}(483 \mathrm{ft})$

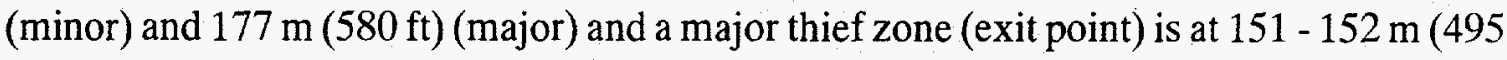
$-500 \mathrm{ft})$

When the CPP-2 pump is turned on, the overall flow reverses to a down flow of about $0.9 \mathrm{~m} / \mathrm{min}(3 \mathrm{ft} / \mathrm{min})$ starting at about $141 \mathrm{~m}(462 \mathrm{ft})$. The upper zone at $147 \mathrm{~m}(483 \mathrm{ft})$ continues to yield a small down flow of increasing overall flow to $1.5 \mathrm{~m} / \mathrm{min}(5 \mathrm{ft} / \mathrm{min})$. The flow rate diminishes at $151-152 \mathrm{~m}(495-500 \mathrm{ft})$, probably on account of enlarged borehole diameter $31 \mathrm{~cm}$ ( 12 inches), and resumes at about $1.5 \mathrm{~m} / \mathrm{min}(5 \mathrm{ft} / \mathrm{min})$ down to about 162 $\mathrm{m}(530 \mathrm{ft})$ where additional flow abruptly enters the hole boosting the downward flow from $1.8 \mathrm{~m} / \mathrm{min}(6 \mathrm{ft} / \mathrm{min})$ to almost $4.3 \mathrm{~m} / \mathrm{min}(14 \mathrm{ft} / \mathrm{min})$. Downward flow diminishes at 164 $\mathrm{m}(537 \mathrm{ft})$ and then abruptly exits at $177 \mathrm{~m}(580 \mathrm{ft})$.

In summary the zone at $177 \mathrm{~m}(580 \mathrm{ft})$ has a greater hydraulic head and yields flow to zones above when pump is off. When pump is on, this zone must have a direct connection to the pumped interval of well CPP-2, because the head drops and it becomes a thief zone or exit zone.

Flowmeter logs were run continuously through the times when the pumping well turned on and off and consequently are able to have a running time of how long it took for the change in the fluid regime to occur after the pump tuned on or off. With the flowmeter logs it is determined that this change in the fluid pattern could be detected in less than 30 seconds after the pumping well changed. In addition, head changes were recorded in isolated portions of well 46 with a packer which showed that there is a response to the pump turning on and off generally occurring with 10 to 15 second delay (Johnson, et al., 1994).

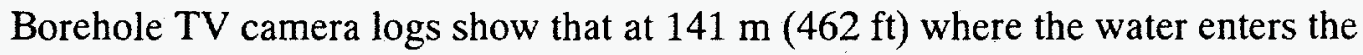
borehole (in the pump-on situation) is in the upper vesicular zone with a keyhole cave feature from $141.1 \mathrm{~m}(463 \mathrm{ft})$ to $142 \mathrm{~m}(466 \mathrm{ft})$. 


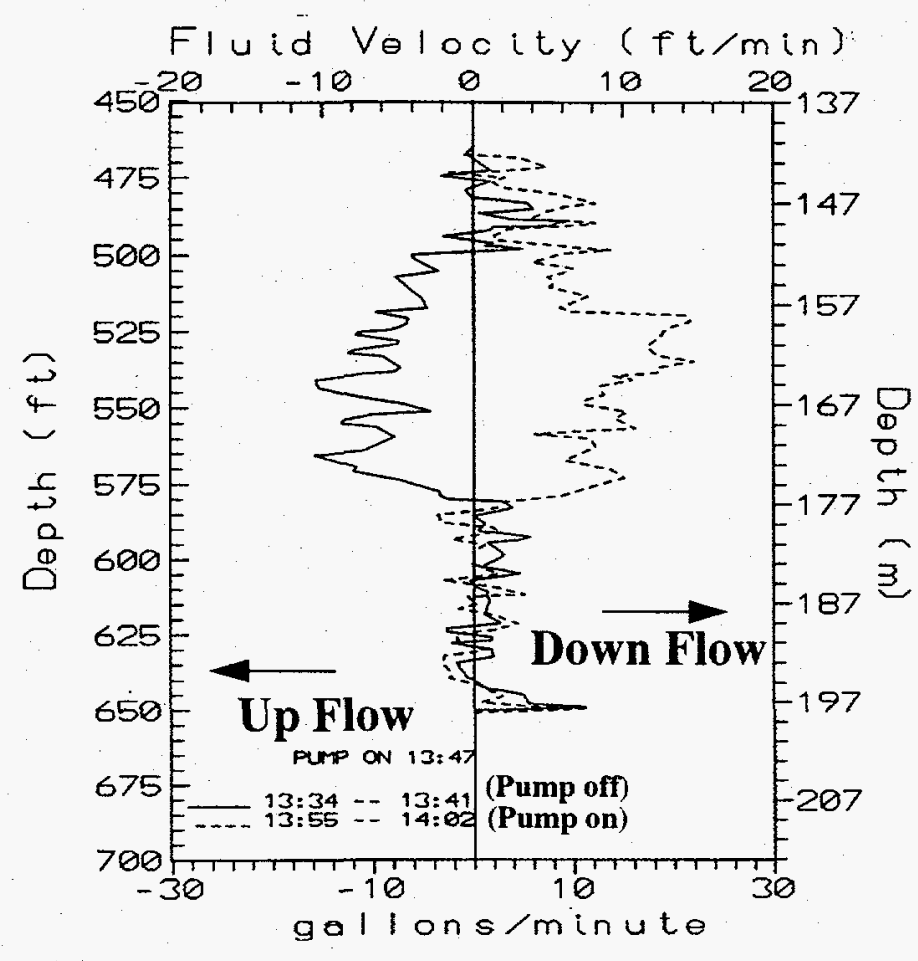

Figure 44. Figure showing impeller flowmeter log of well USGS 46 from water level to bottom of borehole. This plot shows two separate logging runs one during the time when the pumping well (CPP-2) was not running (the solid line) and the other when it was pumping (the dashed line). Velocities are give from zero (the center line down the plot). Positive flow value is an indication of downward fluid movement in the borehole while a negative flow value are an indication of upward fluid movement.

Water exists the borehole at the lower portion of the upper vesicular zone at $152 \mathrm{~m}(500 \mathrm{ft})$. Many vertical fractures occur here with a large vertical planar type fracture that has an opening that closes up downward. This fracture starts a few meters before $152 \mathrm{~m}$ and closes up at $153 \mathrm{~m}(502 \mathrm{ft})$. At $153 \mathrm{~m}(502)$ where some water exits a ring feature can be found along the wall. Further down the borehole wall at $164 \mathrm{~m}(537 \mathrm{ft})$ where there is a deviation

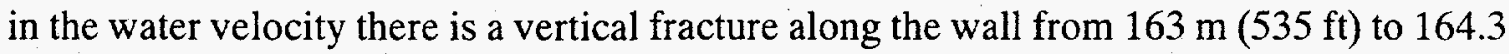
$\mathrm{m}(539 \mathrm{ft})$. The water entering and exiting the lower portion of the borehole at $177 \mathrm{~m}(580$ $\mathrm{ft}$ ) is located in the upper vesicular zone with no fractures or caves present. 


\section{Analysis Of Impeller Flowmeter Results}

\section{Relationship of Fluid Flow to Basalt Lava Flow Features}

Others have also looked at fluid movement in wells at the INEL. Morris and others (1964) and Barraclough and others (1965) used an tracejector sonde containing an iodine 131 tracer to detect the flows in wells all over the site (Table 3). The tracejector sonde using

\begin{tabular}{|c|c|c|c|c|c|}
\hline $\begin{array}{c}\text { Well } \\
\text { Name }\end{array}$ & $\begin{array}{c}\text { Morris } \\
1964\end{array}$ & $\begin{array}{c}\text { Barraclough } \\
1965\end{array}$ & $\begin{array}{c}\text { Bennecke } \\
\text { \& Wood } \\
1992\end{array}$ & $\begin{array}{c}\text { Morin \& } \\
\text { Others } \\
1993\end{array}$ & $\begin{array}{c}\text { Wood \& } \\
\text { Bennecke } \\
1994\end{array}$ \\
\hline \hline 37 & & & & & \\
\hline 42 & & & & & \\
\hline 43 & & & & & \\
\hline 44 & & & & & \\
\hline 45 & & & & & \\
\hline 46 & & & & & \\
\hline 48 & & & & & \\
\hline 49 & & & & & \\
\hline 51 & & & & & \\
\hline 52 & & & & & \\
\hline 59 & & & & & \\
\hline 82 & & & & & \\
\hline 83 & & & & & \\
\hline Site 14 & & & & & \\
\hline
\end{tabular}

Table 3. Showing the different wells and authors studying fluid movement in them at the INEL. Morris and Barraclough used tracejector sonde, Bennecke and Wood used an impeller flowmeter, Morin and others used an heat pulse flowmeter. This table only reflects wells that also have borehole TV camera logs other wells not listed lack of TV camera logs for them.

radioactive material is a combination of a gamma-ray unit and an ejector unit. The position of the two units is interchangeable and can be assembled for measuring either upward or downward circulation of borehole fluids. The procedure for operating the sonde is to lower the sonde into a borehole, to a particular depth of interest, which is hypothesized to be the flow area. A minute amount of tracer is discharged from the ejector portion of the probe. The tracer travels from the ejector to the detector point; the travel time is calculated from a 
stopwatch. Very slow borehole fluid velocities of a few meters per day have been measured by using tracer techniques (Hess, 1986). However, the use of radioactive solutions in groundwater is now subject to strict regulations, brine solutions are useful only in fresh water, and both techniques are subject to considerable measurement errors caused by the differences in density between the trace solution and the borehole fluid (Hess, 1986). Both Barraclough and others (1965) and Morris and others (1964) have done a large number of wells in various locations around the site. This work gives a general magnitude of intrawell flow and stratigraphic position in the wells studied where permeable parts of the borehole wall can be identified.

Morin and others (1993) used a heat-pulse flowmeter. In principle it is much like the tracejector sonde. It has a combination of temperature sensors and a heating grid. The two temperature sensors are set on either side of a heating grid. The heat-pulse flowmeter is to lowered into a well, to a particular spot of interest. A small pulse of heat is discharged a small pulse of heat which either travels up or down to the temperature sensors. The time it takes to travel to either sensor is used to calculate the velocity. The thermal flowmeter used by Morin and others had a inflatable packer system which served as a flow concentrator, channeling flow from a larger cross-sectional area to a smaller one and increasing the sensitivity of the instrument to very slow fluid velocities (Morin et al., 1993). Some heatpulse flowmeters have a useful flow-measuring range of 0.06 to $10 \mathrm{~m} / \mathrm{min}(0.2$ to $33 \mathrm{ft} / \mathrm{min})$ (Hess, 1986).

The heat-pulse flowmeter was used on the wells at the ICPP (Table 4). First measurements were taken when CPP-2 was not pumping. Then measurements were taken while a submersible pump was pumping in the well that is being measured. The pumping rate was $83 \mathrm{~L} / \mathrm{min}$ ( $22 \mathrm{gal} / \mathrm{min})$. Flow values ranged from 0 to $14 \mathrm{~L} / \mathrm{min}(0$ to $3.8 \mathrm{gal} / \mathrm{min})$ without pumping and 0 to $44 \mathrm{~L} / \mathrm{min}$ ( 0 to $11.7 \mathrm{gal} / \mathrm{min}$ ) during pumping (pumping about 83 $\mathrm{L} / \mathrm{min}(22 \mathrm{gal} / \mathrm{min}))$ in the well 44,0 to $3.4 \mathrm{~L} / \mathrm{min}(0$ to $0.9 \mathrm{gal} / \mathrm{min})$ 


\begin{tabular}{|c|c|c|c|}
\hline $\begin{array}{l}\text { Depth } \\
\text { (feet) }\end{array}$ & $\begin{array}{l}\text { Elevation } \\
\text { (feet) }\end{array}$ & $\begin{array}{c}\text { Flow without } \\
\text { pumping }\end{array}$ & $\begin{array}{l}\text { Flow with } \\
\text { pumping }\end{array}$ \\
\hline WELL 44 & & $\mathrm{gpm}$ & gpm \\
\hline 480 & 4,439 & 0.2 up & 11.7 up \\
\hline 495 & 4,424 & 0.1 up & 11.7 up \\
\hline 515 & 4,404 & 3.2 up & 8.3 up \\
\hline 523 & 4,396 & $3.8 \mathrm{up}$ & 8.3 up \\
\hline 556 & 4,363 & 0.1 up & $0.8 \mathrm{up}$ \\
\hline 568 & 4,351 & 0.1 up & 0.3 up \\
\hline 578 & 4,341 & 0 & 0 \\
\hline 610 & 4,309 & 0 & 0 \\
\hline 632 & 4,287 & $\overline{0}$ & \\
\hline \multicolumn{4}{|l|}{ WELL 45} \\
\hline 475 & 4,445 & 0 & $12.8 \mathrm{up}$ \\
\hline 504 & 4,416 & 0.5 up & 10.6 up \\
\hline 517 & 4,403 & 0.9 up & 10.6 up \\
\hline 531 & 4,389 & 0.9 up & $10.6 \mathrm{up}$ \\
\hline 558 & 4,362 & \begin{tabular}{|l|}
0.9 up \\
\end{tabular} & 10.6 up \\
\hline 574 & 4,346 & diameter-varies & inconsistent \\
\hline 590 & 4,330 & \begin{tabular}{|l|}
0.4 up \\
\end{tabular} & 0 \\
\hline 602 & 4,318 & 0.7 up & \\
\hline 617 & 4,303 & 0.7 up & 0 \\
\hline 632 & 4,288 & 0.7 up & \\
\hline \multicolumn{4}{|l|}{ WELL 46} \\
\hline 471 & 4,446 & $\overline{0}$ & 5.3 up \\
\hline 486 & 4,431 & 0.4 up & 1.2 up \\
\hline 505 & 4,412 & $6.1 \mathrm{up}$ & 5.1 down \\
\hline 526 & 4,391 & 8.4 up & 9.2 down \\
\hline 550 & 4,367 & 8.4 up & 12.1 down \\
\hline 562 & 4,355 & 8.4 up & 12.1 down \\
\hline 572 & 4,345 & 6.0 up & 6.8 down \\
\hline 580 & 4,337 & 0 & 0 \\
\hline 608 & 4,309 & 0 & \\
\hline 615 & 4,302 & 0.1 up & 0 \\
\hline 640 & 4,277 & 0.1 up & \\
\hline
\end{tabular}

Table 4. Heat-pulse flowmeter measurements in wells 44,45 , and 46 at the INEL done by R. Morin and others (1993). Depth is below land surface and elevation is above sea level. Flow within the boreholes that were measured are given in gallons per minute. A submersible pump was deployed in the same wells with a pump rate of 22 gallons per minute. 
without pumping and 0 to $48.5 \mathrm{~L} / \mathrm{min}(0$ to $12.8 \mathrm{gal} / \mathrm{min})$ when pumping was carried out in well 45 , and 0 to $31.8 \mathrm{~L} / \mathrm{min}$ ( 0 to $8.4 \mathrm{gal} / \mathrm{min}$ ) without pumping and 0 to $45.8 \mathrm{~L} / \mathrm{min}$ ( 0 to $12.1 \mathrm{gal} / \mathrm{min}$ ) during pumping in well 46 (Morin, et al., 1993).

Upon comparing work of Morin and others (1993) with the impeller flowmeter work of this study it becomes apparent that overall larger rates of flow are recorded in the impeller flowmeter work compared with the heat-pulse flowmeter work. The heat-pulse flowmeter work was carried out on the three wells without an internal pump, but it was not determined if the nearby pump CPP- 2 was on or off when measurements were taken. This makes comparison of the two works difficult. The heat-pulse flowmeter data generally matches the impeller flowmeter data on well USGS 44. The heat-pulse flowmeter record detected a possible small upflow 1.1 to $3.0 \mathrm{~L} / \mathrm{min}(0.3$ to $0.8 \mathrm{gpm})$ occurring from $168 \mathrm{~m}$ (550 ft) to $175 \mathrm{~m}(575 \mathrm{ft})$. Heat-pulse flowmeter data from USGS 45 does agree with the impeller data. When the heat-pulse flowmeter shows a small $2.7 \mathrm{~L} / \mathrm{min}(0.7 \mathrm{gpm})$ upflow from $193-180 \mathrm{~m}(632-590 \mathrm{ft})$ whereas no flows were recorded for this interval from the impeller flowmeter work. However this low flow is below detection limit on the impeller flowmeter. The heat-pulse flowmeter runs on well USGS 46 matched well with the impeller flowmeter work shown in Figure 44.

Examining the locations of the permeable areas located by the flowmeter methods it becomes apparent that the areas within a basalt flow that are the most likely to be permeable are located at the flow contacts, the upper and lower portions of the upper vesicular zone, the columnar zone when present, and the central zone. The flowmeter work identified the basalt flow contacts, upper vesicular zone, central zone, basalt-sediment beds contacts, and lower vesicular zone as regions most likely to be permeable (Table 5). 


\begin{tabular}{|c|c|c|c|c|c|c|}
\hline 42 & $\mathbf{4 4}$ & $\mathbf{4 5}$ & $\mathbf{4 6}$ & $\mathbf{4 7}$ & $\mathbf{4 8}$ & $\mathbf{5 9}$ \\
\hline \hline $4450 \mathrm{UV}$ F & $4407 \mathrm{LV} / \mathrm{UVF}$ & $4445 \mathrm{UV} / \mathrm{Ct}$ & $4455 \mathrm{UV} \mathrm{F}$ & $4436 \mathrm{LV}$ & $4282 \mathrm{Ct} \mathrm{F}$ & $4394 \mathrm{UV}$ \\
\hline $4338 \mathrm{UV} / \mathrm{LV}$ & $4404 \mathrm{UV}$ & $4410 \mathrm{UV} / \mathrm{Ct}$ & $4417 \mathrm{UV} \mathrm{F}$ & $4314 \mathrm{UV} \mathrm{F}$ & & $4378 \mathrm{Ct}$ \\
\hline & $4379 \mathrm{Ct} \mathrm{F}$ & $4395 \mathrm{LV} / \mathrm{UV}$ & $4380 \mathrm{Ct} \mathrm{F}$ & & & $4345 \mathrm{UV} \mathrm{F}$ \\
\hline & $4369 \mathrm{UV}$ & $4385 \mathrm{Ct}$ & $4337 \mathrm{UV}$ & & & $4315 \mathrm{Ct}$ \\
\hline & & $4370 \mathrm{SED} \mathrm{F}$ & & & & \\
\hline & & $4345 \mathrm{UV} / \mathrm{LV}$ & & & & \\
\hline
\end{tabular}

Table 5. Table of wells at the ICPP that shows permeable intervals within them and their corresponding basalt lava flow features. The permeable zones are located by impeller flowmeter work or trace injector sonde work. Permeable zones are given as elevations in feet above sea level and are intervals within the well where fluid is either entering the well or exiting it. The matched up basalt flow features were found by visual inspection of their corresponding TV logs. The symbols UV $=$ upper vesicular zone; $\mathbf{C t}=$ central zone; $\mathbf{L V}=$ lower vesicular zone; SED = sediment interbed; $\mathbf{F}=$ fractures present; $/$ = contact between two separate basalt lava flows or flow-units; UV/LV or any form of two basalt features separated by a " " are contacts between those basalt lava flow features.

Table 5 shows that zones of fluid flow work identified as the most permeable. The zones are upper vesicular zones with fractures ( 5 times), followed by the upper vesicular zones without fractures ( 4 times), central zone with and without fractures ( 3 times each), and the lower vesicular zone without fractures scoring last ( 1 time). This makes the upper vesicular zone the most likely place in a basalt lava flow to be permeable with the central zone coming in second. Previously mentioned work looking at outcrops, cores, and TV logs indicated that the upper vesicular zone was probably very permeable along with the basalt flow contacts and columnar zone. The basalt flow contacts are listed 6 times as major permeable areas identified by the fluid flow work making them equal with the central zone, but looking back at the outcrop work previously described it was found that most contacts do not have a large lateral extent. Rather the contact opens and closes along the basalt lava flow surface. A sequence of flow units in a given epoch of extrusion has many horizontal or gently sloping zones of openings that have small lateral extent, and in general these seem to be poorly interconnected vertically Jones (1961) observed. The flowmeter work as well 
as the TV log work has vertical resolution of approximately $0.3 \mathrm{~m}(1 \mathrm{ft})$ which might shift some of the upper vesicular zone designations to basalt flow contacts, but not enough to justify them being the most commonly permeable basalt feature found in these wells. As mentioned before the columnar zone was also identified as permeable and also very hard to locate in cores and TV logs this is the reason it is not used in table 5. Since the columnar zone is usually found after the upper vesicular zone and before the central zone it is possible that the areas labeled as upper vesicular zones with fractures, central zones with fractures, and the contact between an upper vesicular and central zone with fractures are in fact columnar zones.

\section{Determinations of Hydraulic Conductivity}

When flows in wells are present, the flowmeter logs can detect permeable zones within the well. The well can be pumped to induce flow, and the impeller flowmeter trolled to identify permeable zones. It is tempting to try to derive hydraulic conductivity or transmissivity over narrow intervals using a flowmeter, and measuring pumpage. Others have done just that to determine hydraulic conductivity from the impeller flowmeter logs (Rehfeldt, et al., 1989, Moltz, et al., 1989, Boggs, et al., 1990, and Morin, et al., 1993 and 1988). Most use some sort of transient expression developed by Cooper and Jacob (1946) and modified for the borehole, either the Cooper-Jacob equation

$$
K=\frac{Q}{2 \pi H\left(\left(h_{0}-h\right) p\right)} \ln \left[\frac{2.25 K H t}{R^{2} S}\right]^{1 / 2}
$$

or the Cooper-Jacob straight-line equation which is derived from the Cooper-Jacob equation by differentiating with respect to time (i.e. taking the slope of a drawdown vs. $\log$ time area). 


$$
T=\frac{2.30 Q}{4 \pi \frac{\partial S}{\partial(\log t)}}
$$

Where $\mathrm{K}=$ hydraulic conductivity, $\mathrm{T}=$ transmissivity, $\mathrm{Q}=$ volumetric flow rate, $\mathrm{H}=$ thickness of interval, $\left(h_{0}-h\right) p=$ change in head from static condition, $t=$ time since onset of injection, $\mathrm{R}=$ borehole radius and $\mathrm{S}=$ storativity.

A basic assumption for this equation is that the flow is strictly horizontal into the well for both cases. In order to solve the Cooper-Jacob equation an assumption is required about the relationship between the transmissivity, and the storage coefficient, in the aquifer. One assumption is that the storage coefficient and the transmissivity vary so that each aquifer layer has the same diffusivity (Young, 1992) The advantage of the Cooper-Jacob equation is that only one measurement of drawdown is needed to iteratively solve for a transmissivity while the disadvantage of the Cooper-Jacob equation is that one must assume a value of the effective well radius, the storage coefficient, and negligible skin effects (Young, 1992). The advantage of the Cooper-Jacob straight-line equation is that no assumptions are required about the values of the storage coefficient, the effective radius, and negligible skin effects while the disadvantage of the Cooper-Jacob straight-line equation is that one needs continuous measurements of the drawdown which can be overcome by using a pressure transducer coupled to an electronic data logger (Young, 1992).

Morin and others (1993) did use these types of calculations to find the hydraulic conductivity for different elevations in wells 44 and 45 with an uncertainty of \pm 0.4 orders of magnitude. Large uncertainty is on account of the very small drawdowns measured in these wells: $(3 \mathrm{~cm}(0.01 \mathrm{ft})$ recorded in well 44 while pumping at $91 \mathrm{~L} / \mathrm{min}(24 \mathrm{gal} / \mathrm{min})$. Pumping well 45 at $24 \mathrm{gal} / \mathrm{min}$ resulted in a $0.08 \mathrm{~m}(0.25 \mathrm{ft})$ drawdown, and well 46 pumped at $106 \mathrm{~L} / \mathrm{min}$ ( $28 \mathrm{gal} / \mathrm{min}$ ) produced less than $3 \mathrm{~cm}(0.01 \mathrm{ft}$ ) of head change (Morin, 


\section{APPENDIX A}

Cross-section ICPP 
et al., 1993). For well 44 they found that the hydraulic conductivities of seven individual layers that span approximately two orders of magnitude can be summed to a cumulative transmissivity of about $890,000 \mathrm{ft}^{2} /$ day. In well 45 they found hydraulic conductivities that ranged over roughly 1.5 orders of magnitude which sum to a cumulative transmissivity of $35,000 \mathrm{ft}^{2} /$ day. Other calculations such as these on the previously mentioned wells were not carried out by them due to the large degree of uncertainty involved.

Transmissivity of Quaternary basalt in the SRP determined from aquifer tests commonly exceeds $100,000 \mathrm{ft}^{2} / \mathrm{d}$ and in places 1 million $\mathrm{ft}^{2} / \mathrm{d}$ (Whitehead, 1992). Irrigation wells open to less than $31 \mathrm{~m}(100 \mathrm{ft})$ of aquifer yield as much as $26,495 \mathrm{~L} / \mathrm{min}$ $(7,000 \mathrm{gal} / \mathrm{min})$ with only a few meters of drawdown. So these transmissivities estimates are at least close to previous figures found for the SRP.

\section{Relationship of Pumping Well to Fluid Movement}

The nearby pump CPP-2 at the ICPP has an effect on wells USGS 44 and 46 (Bennecke and Wood, 1992, Morin et al., 1993 this study). Preliminary studies defining the velocity and direction of flows in wells at the INEL have been carried out in the past. Morris and others in 1964 did a number of tests on over 20 wells at various places in the INEL area. He used a tracejector sonde to detect the flows which were measured in the wells with velocities ranging up to $9 \mathrm{~m} / \mathrm{min}$ (30 feet/minute). The overall flow direction found in the study by Morris and others (1964) is down the borehole. Barraclough and others (1965) also did work on the fluid movement in wells with a tracejector sonde. This work was done in the ICPP area on wells numbers $42,43,48,49,51,52$, and 59. Direction of flow was more variable than that measured by Morris and others (1964) with velocities ranging also up to $9 \mathrm{~m} / \mathrm{min}(30 \mathrm{ft} / \mathrm{min})$. Flow reversals were also noted and attributed to nearby pumping wells with the reversals occurring over relatively short periods of time, in some instances less than an hour. So past flow reversals have been noted, their presence indicates a connection to the pumping well itself. In the present study detailed records were kept of 
when the pumping well CPP-2 turned on and off during flowmeter work. With this information it was proved that the pump did have an effect on the fluid movement in the well when it turned on.

Discussion of relationships of identified permeable zones to the CPP-1 and CPP-2 wells can be understood by referring to the cross-section (Appendix A). The upper production zone in the E-H flow groups in CPP-1 and CPP-2 (identified by screened intervals and producing zones indicated or drillers' logs) and the contact of the E-H flow groups with the underlying I flow group in CPP-1 and CPP-2 are both at higher elevations than comparable features in wells 44,45 , and 46 (Barrash, et al., 1994). The lower production zone in CPP-1 and CPP-2 occurs in the I flow group (Anderson, 1991) at an elevation higher than the base of wells 44,45 , and 46 (Barrash, et al., 1994). But changes in flow rates when the pumping starts indicates that there is a connection. To explain some of these conditions Barrash, and others (1994) have suggested that the upper hydrostratigraphic unit in wells 44,45 , and 46 may be continuous with the upper screened producing zones in the E-H flow groups in CPP-1 and CPP-2, and that a higher permeability unit may exist below the bottoms of wells 44,45 , and 46 that is hydraulically connected to the lower screened producing zones in the I flow group in CPP-1 and CPP-2 (James, 1920, Morin, et al., 1993, and Barrash, et al., 1993). Tentative correlation of the thick flow (flow 12 of Lanphere, et al., 1994 in well 123) in the I group with a thick flow in well 48 and with the lower region of wells 44, 45, and 46 led Barrash and others (1994) to speculate that a higher permeability unit may occur up to 25 to $35 \mathrm{ft}$ below wells 44,45 , and 46 based on projection of the base of the thick flow from wells 48 and 123 (Barrash, et al., 1994).

Upon examination of a cross-section (Appendix A) made from the study of borehole TV logs at the ICPP it is apparent that the upper completed portions of the pumping well CPP-2 is drawing from the E-H lava flows. The lower completed intervals in the pumping well would tend to draw from the top of the I group. Based on past work done on well 48 
and TV-log observations (from wells 42,48 , and 123) that a series of basalt flows exists below the I flow group; it would seem to validate Barrash and others (1994) idea of a permeable unit below most of the wells examined at ICPP. It is still not clear in this author's mind which direction the natural flow of fluid would be in the boreholes studied if the pumping wells CPP-1 and CPP-2 were shut off long enough for the groundwater regime to equilibrated to natural conditions, but it is apparent that the pumping wells do change the direction of flow and usually increase the velocity of flowing fluid in the boreholes. The fact that this change occurs so quickly indicates that the aquifer at this level acts more like a semi-confined aquifer compared to an unconfined aquifer. Basalt flow stratigraphy from TV logs indicates that the aquifer can most likely be visualized as a series of semipermeable layers with permeable layers in-between them. It seems to this author that the pumping well induces flow in the basalt rocks in particular areas where the basalt is made up of many thin basalt flow-units or thin piles of basalt lava flows rather than very thick basalt lava flows. This is shown in the cross-section (Appendix A) where the upper completed portions of CPP-2 are stratigraphically over an interval containing a large number of thin basalt flows, while the lower completed portions of the well are located stratigraphically within with the thick "I" group. Notice that it is only when this lower group of basalt flows is encountered that it shows up as being permeable in well 48 . Notice also that although several basalt lava flows occur in the upper flow groups (E-H) of wells 59,48 , and 44 , permeable intervals only occur in intervals of very thin basalt lava flows. This then is an indication to this author that a genetic connection exists between basalt flows that are permeable versus basalt flows that are not. The genetic connection being that pahohoe basalts that are farther away from the vent which are thicker may only have a permeable area at their top in the columnar zone rather than pahoehoe basalt flows closer to the vent that have flow-units and are thin which will be more permeable then those farther away and thicker. 


\section{CHAPTER 10. OTHER GEOPHYSICAL LOGGING OF BOREHOLES IN BASALT}

\section{Purpose And Objectives}

So far the only geophysical well logging tools discussed have been the borehole TV camera, caliper, the impeller flowmeter, trace injector sonde, and heat-pulse flowmeter. Other types of borehole geophysical tools are available to gather information about the subsurface. The purpose of these tools is to gain a better quantitative understanding of the rock in a borehole. The objective is to obtain and analyze other borehole geophysical logs available on the boreholes in this study to better define the basalt sequences. This data is from the U. S. Geological Survey (mostly listed in Bartholomay, 1990) and from logs made by Boise State University. Although these logs are not the sole purpose of this study they were helpful in delineating features in the basalt that otherwise would have not been identified.

\section{Borehole Geophysical Results On Basalts}

\section{Temperature Logs}

Temperature gradients have been well studied in the past and as a rule of thumb temperatures increase the deeper into the Earth. This is the simplest case, but variations can occur. Changes can occur to this simple case when lithology changes are associated with significant changes in the thermal conductivity of the rocks. Thermal conductivity for the stratified basalt and sediment section, is around 1.4 to $1.6 \mathrm{~W} / \mathrm{m}$ degree Kelvin (Wood and Bennecke, 1994). Brott and others (1981) gained geothermal data from 248 holes in southeastern Idaho. They found three heat flow regimes identified as "above", "in", and 
"below" the aquifer system. The above regime they found to be generally conductive and is controlled by the difference between the mean annual surface temperature and the local aquifer temperature, which may produce a negative geothermal gradient over large areas. Within the top tens of meters of the aquifer the heat flow regime is convective and the temperatures are approximately isothermal due to the mixing of circulating fluid in the aquifer they found. But below the aquifer they noted a more conductive heat flow regime with constant geothermal gradients. The SRP aquifer generally has temperatures ranging from $8^{\circ}$ to $9^{\circ} \mathrm{C}$ in the recharge zones to $14^{\circ}$ to $15^{\circ} \mathrm{C}$ in the discharge zone with the temperatures in the central part of the aquifer varying from $10^{\circ}$ to $20^{\circ} \mathrm{C}$.

A common feature of wells in the basalt section is isothermal intervals caused by water flowing vertically in a well, having entered at one permeable zone, and exiting at another permeable zone of lower head. Another feature in some wells at the INEL is a geothermal gradient that decreases downward (negative gradient) occurring where a major zone of cooler groundwater flow lies beneath the interval penetrated by the well (Wood and Bennecke, 1994) and (Appendix B). In other wells logged in the vicinity at the ICPP and those logged by Morin and others (1993) the temperature profiles show increasing temperature downward in the lower parts of the wells (generally below the permeable zone at the top of the "I" group of flows using stratigraphy of Anderson (1991)) (Wood and Bennecke, 1994). To understand this it is helpful once again to look at the work done by Brott and others (1981). Using their ideas one could generate a sequence of events following the geothermal history of water moving through the SRP. It would start off with water entering the aquifer at the recharge areas. Because the recharge water, which originates mainly from snow melt at high elevations, is at a lower temperature than the mean annual surface temperature of the recharge areas, a negative shallow temperature gradients and low aquifer temperatures would result. As the groundwater becomes heated in the aquifer, the temperature of the water increases and exceeds the mean annual surface 
temperature resulting in a temperature profile with a minimum inflection that may appear as an isothermal zone. Also fluid movement in this particular interval will also generate an isothermal temperature curve (Brott, et al., 1981). At deeper depths the groundwater is heated mainly from conduction and thus the stagnant well-bore fluid takes on a normal geothermal gradient increasing in temperature with depth.

\section{Gamma Logs}

Natural Gamma logs have been used previously to identify basalt flow groups and are used as the basis for correlating (Anderson and Lewis 1989, and Hegmann and Wood 1994). An analysis of eastern Snake River plain basalts of Pleistocene age demonstrated that flows vary from $0.26 \%$ to $2.71 \% \mathrm{~K}_{2} \mathrm{O}$ (Kuntz, et al., 1992), and this is thought to be responsible for variations in natural gamma response (Anderson and Bartholomay, 1996). Gamma emissions are believed to be uniform in related flows of similar age and source at INEL (Anderson and Lewis, 1989). Gamma logs were used by this author for correlation of individual basalt lava flows and particularly for identification of sedimentary interbeds. The gamma-ray intensity of Snake River Basalt logged in wells 6 inches in diameter is generally less than 0.005 milliroentgen per hour $(\mathrm{mr} / \mathrm{hr})$ compared to the intensity of eolian silt (loess) which ranges from about 0.0075 to about $0.0125 \mathrm{mr} / \mathrm{hr}$ (Jones, 1961). The borehole TV logs also are compared directly with the gamma log in trying to identify a sedimentary interbed since a large gamma count does not necessarily indicate a sedimentary interbed.

\section{Neutron Logs}

Calibrated neutron logs can be used to evaluate the water content or relative porosity value for small-diameter boreholes. A detailed basalt lava flow stratigraphy has been worked out for a number of the wells by using the borehole TV logs. When comparing this stratigraphy with the corresponding neutron log of a particular well some interesting results 
can be interpreted (see Appendix C). The top, middle, and bottom of a basalt flow can be identified by a particular neutron water content or relative porosity value. These relative porosity values display a repeating signature that repeats in basic form for different lava flows. The pattern can be seen as a very large neutron relative porosity value starting 0.3 to $0.6 \mathrm{~m} \mathrm{(1} \mathrm{to} 2 \mathrm{ft}$ ) from the top of the basalt lava flow which gradually decreases to about the center of the basalt lava flow where it stays at a fairly constant value until the top of the lower vesicular zone is reached were it continues to increase spiking to a large neutron relative porosity value at the top of the next basalt lava flow (for an example of this see Appendix C - USGS borehole 45 the basalt lava flow from $152 \mathrm{~m}$ to $159 \mathrm{~m}$ ( $500 \mathrm{ft}$ to 523 $\mathrm{ft})$ ). The cause of this log character can be assumed to be related to the basalt rock itself. The upper vesicular zone is made up of many vesicles compared to the center zone and its number of vesicles or vesicularity decreases toward the center of the basalt lava flow. This could account for the gradually decreasing neutron porosity signature starting at the top of the lava flow. The lower vesicular zone has fewer overall vesicles (compared to the upper vesicular zone). The number of vesicles increases towards the bottom of this zone. The observation that the neutron relative porosity values increase downward through this lower vesicular zone indicates water bearing porosity of vesicles saturated with water.

Another possibility for the changes in the neutron logs could be the result of the many fractures present in the basalt rock. Using the same stratigraphy (Appendix C) it can be seen that intervals with many fractures or enlarged boreholes show a large neutron value (although an enlarged borehole may show as a high porosity on account of the water-filled enlargement if it is not a compensated tool). Commonly fractures are present a few meters below the upper part of a lava flow due to the columnar nature of some flows. These columnar zones are usually represented in a well as enlarged diameters or "cave" like features seen in borehole TV camera logs. It is very common to have a large number of fractures present in the upper vesicular zone compared to the central zone and lower 
vesicular zone. Hegmann and Wood (1994) also noticed this fact that the flow tops seemed to have a large neutron value while the rest of the lava flow had a relatively lower neutron value.

\section{Density Logs}

Density logs have also been examined along with the detailed stratigraphy worked out for some of the wells at the INEL (Appendix C). Like the neutron logs a signature in the density logs can be found for individual basalt lava flows. The tops of the basalt lava flows have a relatively low density value while the central part of the basalt lava flows have a higher density value. The density values are the lowest a few feet below the top of the basalt lava flow and increase gradually until the top of the center zone where it jumps to a higher density value and then stays fairly constant or gradually decreases in density to the bottom of the flow. The lower vesicular zone like in the neutron log does not seem to have any effect on the density log despite it vesicular appearance in outcrop, cores, and TV logs. The apparent signature repeats itself for every new basalt lava flow. This was also noted by Hegmann and Wood (1994) in their study of wells at the RWMC. Knutson and others (1990) also noted changes in density along different parts of a basalt lava flow from measurements done on plug samples from cores. They found that the vesicular element bulk densities are less than $2.60 \mathrm{~g} / \mathrm{cm}^{3}$ (generally $2.40 \mathrm{~g} / \mathrm{cm}^{3}$ ) while the nonvesicular element bulk densities are greater than $2.60 \mathrm{~g} / \mathrm{cm}^{3}$ (generally $2.70 \mathrm{~g} / \mathrm{cm}^{3}$ ) (Knutson, et al., 1990). Golder and associates (1991) on well 123 found dry densities for the upper vesicular zone to be $2.29 \mathrm{~g} / \mathrm{cm}^{3}$ and the central zone to be $2.54 \mathrm{~g} / \mathrm{cm}^{3}$. All of these results point to a denser central part versus the vesicular portions. Fractures and vesicles are usually absent in this central part of a flow as described in outcrop, cores, and TV logs. This lack of vesicularity would explain the increase in density in the central part of a basalt lava flow. 
Acoustic Televiewer Logs

Acoustic televiewer logs are very helpful in identifying fractures found in boreholes at the INEL. Morin and others (1993) logged wells USGS 44, 45, and 46 at the ICPP with the acoustic televiewer. They found that dip angles vary over a wide range from steeply dipping features that extend vertically for 10-15 feet to subhorizontal depositional contacts. They also found the strike azimuths of dipping fractures and plotted them as a function of elevation (Figure 45) which showed no obvious pattern of fracture distribution versus depth. A complementary histogram of strike azimuths was also generated which demonstrated wide variation in directions of strike, but also defined a primary mode for the fracture population with a median orientation of North $30^{\circ}$ East, or the same back azimuth of $210^{0}$ (Figure 45 ).
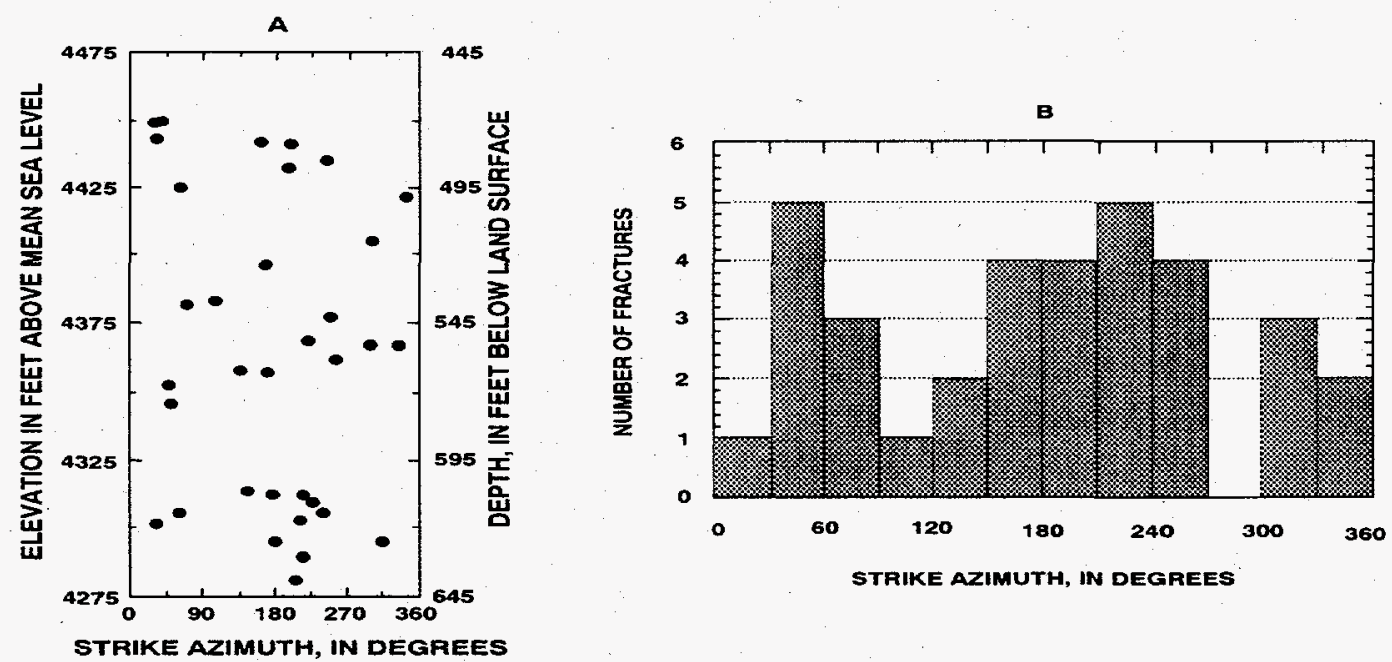

Figure 45. Figure showing the relations of (a) fracture strike azimuth to depth, and (b) fracture frequency to strike azimuth for discrete fractures that were not associated with rubbley, brecciated or wellbore enlargement areas. Fractures were identified from acoustic televiewer logs for wells 44, 45, and 46 (After Morin, et al., 1993). 


\section{CHAPTER 11. CONCLUSIONS}

Important conclusions that can be drawn from the foregoing information include the following.

1. Basalt flow cooling unit contacts are close fitting and planar lacking undulations of more than a meter sometimes with a parting or crack not longer than a few meters along the outcrop wall. The lower vesicular zone rests upon the upper vesicular zone of the underlying flow allowing identification of the different flow zones and thus the different basalt lava flows.

2. A model for a typical SRP basalt lava flows can be generated based on its vesicle and fracture distribution. This proposed model was generated because the current nomenclature could not adequately define the details found in this study.

3. Based on this model the upper part of a basalt lava is characterized by a high degree of vesicularity which grades downward to few vesicles in the central part of the lava flow. The fractures characteristic of the upper vesicular zone are in the form of pseudocolumnar fractures and tend to be vertical.

4. The central part of a basalt lava flow exhibits a lack of vesicles and has relatively long curvilinear fractures as well as vertical and horizontal fractures.

5. Pipe vesicles and vesicle plumes indicate the bottom part of a basalt lava flow. The bottom of the basalt lava flows (lower vesicular zone) have an inverse vesicular arrangement meaning vesicle abundance increases downward to the base as compared with the top of the lava flow (upper vesicular zone).

6. Columnar zones may be present in the SRP basalt lava flows. They are generally found at the top of the lava flows, and more commonly found in thick lava flows rather than 
in thin ones.

7. More abundant joints are found in areas of the basalt flow containing columns.

8. Spacing for smaller aperture joints are predominately closer when compared to larger aperture joints.

9. Basalt lava flows are slab pahoehoe in nature and the abundance of flow-units indicate a medial to distal facies for the basalts studied.

10. Vesicle patterns and fractures observed in outcrops studied are consistent with observations of the borehole TV logs and cores.

11. Impeller flowmeter work on 3 wells at the ICPP identified permeable locations within the wells. A nearby (732 $\mathrm{m}(2400 \mathrm{ft}))$ pumping $(11734 \mathrm{~L} / \mathrm{min}(3100 \mathrm{gpm}))$ well CPP-2 changed the direction and velocity of fluid movement in these wells when it was turned on and off. It took less than 10-15 seconds for this change to take place.

12. Intervals accepting and yielding flows in boreholes were examined by borehole geophysical work. These intervals are interpreted as the most permeable parts of the section. The most permeable intervals are the upper vesicular zone, columnar zone, central zone, and flow contacts in that particular order of importance.

13. Thin basalt lava flows and flow-units are most likely to be avenues for fluid movement versus thicker basalt lava flows based upon flowmeter logs.

14. Neutron/Density signatures can be used with the proposed basalt lava flow model to identify the different zones in a basalt lava flow.

15. Throughout the vicinity of ICPP intrawell flows occur between the fracture zone in the E-H groups and fractures in the upper 6 to $15 \mathrm{~m}$ (20 to $50 \mathrm{ft}$ ) of the I group. The lower part of the I group appears to be of low permeability (well 45 does not show large intrawell flows). However, in well 48 intrawell flow was detected by previous workers between the fracture in the lower $15 \mathrm{~m}(50 \mathrm{ft})$ of the I group and the upper $21 \mathrm{~m}(70 \mathrm{ft})$ of the underlaying unit. 


\section{BIBLIOGRAPHY}

Ackerman, D. J., 1991, Transmissivity of the Snake River Plain Aquifer at the Idaho National Engineering Laboratory, Idaho: U. S. Geological Survey Water Resources Investigations Report 91-4058, pp. 1-35.

Anderson, S. R., and Lewis, B. D., 1989, Stratigraphy of the unsaturated zone at the RadioActive Waste Management Complex, Idaho National Engineering Laboratory, Idaho: U. S. Geological Survey Water Resources Investigations Report 89-4065, pp. $1-54$.

Anderson, S. R., 1991, Stratigraphy of the unsaturated zone and uppermost part of the Snake River Plain Aquifer at the Idaho Chemical Processing Plant and Test Reactors Area, Idaho National Engineering Laboratory, Idaho: U. S. Geological Survey Water Resources Investigations Report 91-4010, pp. 1-39.

Anderson, S. R., and Bartholomay, R. C., in press, 1996, Use of natural-gamma-ray logs and cores for determining stratigraphic relationships of basalt and sediment at the Radioactive Waste Management Complex, Idaho National Engineering Laboratory, Idaho: Journal of the Idaho Academy of Science.

Augustithis, S. S., 1978, Atlas of the textural patterns of basalts and their genetic significance: Elsevier Scientific Publishing Company, New York, pp. 1-313.

Aydin, A. A., and DeGraff, J. M., 1988, Evolution of polygonal fracture patterns in lava flows: Science, vol. 239, pp. 471-476.

Barraclough, J. T., Teasdale, W. E., Robertson, R. G., and Jensen, R. G., 1965, Hydrology of the National REactor Testing Station Idaho: U. S. Geological Survey, WaterResources Division, Open-File Report, pp. 1-25. 
Barrash, W., Morin, R. H., Wood, S. H., Anderson, R. G., Jensen, R. G., and Bennecke, W. M., 1993, Geophysical logging evidence for stratigraphic controls on hydrology in the Snake River Plain aquifer at the Idaho National Engineering Laboratory (INEL), southeastern Idaho, EOS, vol. 74, pp. 283-284.

Barrash, W., Morin, R. H., Wood, S. H., and Bennecke, W. M., 1994, Hydrostratigraphic interpretation of the upper portion of the Snake River Plain Aquifer near the Idaho Chemical Processing Plant at the INEL: in Proceedings, 1994 Symposium on Engineering Geology and Geotechnical Engineering, (March 23-25, 1994, Boise): P. K. Link editor, pp. 181-194.

Bartholomay, R. C., 1990, Digitized geophysical logs for selected wells on or near the Idaho National Engineering Laboratory, Idaho: U. S. Geological Survey, Open-File Report 90-366, pp. 1-347.

Beard, N. C., 1959, Quantitative study of columnar jointing: Bulletin of the Geological Society of America, vol. 70, pp. 379-382.

Bennecke, W. M., and Wood, S. H., 1992, Impeller flow-meter logging of vertical cross flow between basalt aquifers through wells at the Idaho National Engineering Laboratory, eastern Snake River Plain, Idaho: a progress report: Borehole geophysics research program, Department of Geosciences, Boise State University, pp. 1-23.

Boggs, J. M., Young, S. C., Benton, D. J., and Chung, Y. C., 1990, Hydrogeologic characterization of the MADE site: EPRI Interim Report EN-6915, Palo Alto, CA.

Brott, C. A., Blackwell, D. D., and Ziagos, J. P., 1981, Thermal and tectonic implications of heat flow in the eastern Snake River Plain, Idaho: Journal of Geophysical Research, vol. 86, pp. $11709-11734$.

Call, R. D., Savely, J. P., and Nicholas, E. E., 1976, Estimation of joint set characteristics from surface mapping data: 17 th Symposium on Rock Mechanics, Snowbird Utah, August 25-27, 1976. Preprint Proceedings published by University of Utah, pp. 1-132.

Cas, R. A. F., and Wright, J. V., 1988, Volcanic Successions: Unwin Hyman Ltd, UK, pp. 59-78. 
Cooper, H. H., and Jacob, C. E., 1946, A generalized graphical method for evaluating formation constants and summarizing well-field history: Transactions of the America Geophysical Union, no. 217, pp. 626-534.

Deutsch, M., and West, S. W., 1952, Geology of site 14 and vicinity, National Reactor Testing Station, Idaho: U. S. Geological Survey, Water-Resources Division, IDO22019-USGS. pp. 1-40.

Dickinson, W. R., and Vigrass, L. W., 1965, Geology of the Suplee-Izee area, Crook, Grant and Harney Counties, Oregon: Oregon Department of Geological Mineral Resources Bulletin, vol. 46, pp. 69-94.

Faust, G. T., 1975, A review and interpretation of the geologic setting of the Watchung Basalt Flows, New Jersey: Geological Survey Professional Paper 864-A, pp. 1-40.

Faust, G. T., 1978, Joint systems in the Watchung Basalt Flows, New Jersey: Geological Survey Professional Paper 864-B, pp. 1-43.

Fink, J. H., and Fletcher, R. C., 1978, Ropy pahoehoe: surface folding of a viscous fluid: Journal of Volcanology and Geothermal Research, vol. 4, pp. 151-170.

Goddard, E. N., Trask, P. D., De Ford, R. K., Rove, O. N., Singewald, J. T., and Overbeck, R. M., 1992, Rock-Color Chart: Geological Society of America, Co.

Golder Associates Inc., 1991, Geohydraulic and petrographic analyses of samples from well \#121 and well \#123: Golder Associates Inc., Ref. C86-131159 Task Order 6, pp. 8 .

Golder Associates Inc., 1990, Final well completion report for wells 121, 122, and 123 at the Idaho Chemical Processing Plant: Golder Associates Inc., Ref. C86-131159, Task 6, pp. 1-35.

Greeley, R., 1971, Observations of actively forming lava tubes and associated structures, Hawaii: Modern Geology, vol. 2, pp. 207-223.

Greeley, R., 1982, The Snake River Plain, Idaho: Representative of a new category of volcanism: Journal of Geophysical Research, vol. 87, no. B4, pp. 2705-2712. 
Guest, J. E., Underwood, J. R., and Greeley, R., 1980, Role of lava tubes in flows from the Observatory Vent, 1971 eruption on Mount Etna: Geological Magazine, vol. 117, pp. 601-606.

Hegmann, M. J., and Wood, S. H., 1994, Hydrostratigraphy of the Snake River Plain Aquifer beneath the Radioactive Waste Management Complex at the Idaho National Engineering Laboratory: a preliminary report: in Proceedings, 1994 Symposium on Engineering Geology and Geotechnical Engineering, (March 23-25, 1994, Boise): P. K. Link editor, pp. 195-206.

Hess, A. E., 1986, Identifying hydraulically conductive fractures with a slow-velocity borehole flowmeter: Canadian Geotechnic Journal, vol. 23, pp. 69-78.

James, A. V. G., 1920, Factors producing columnar structure in lavas and its occurrence near Melbourne, Australia: Journal of Geology, vol. 28, pp. 458-469.

Johnson, G. S., Olsen, J. H., and Ralston, D. R., 1994, Hydrologic testing in wells near the Idaho Chemical Processing Plant at the Idaho National Engineering Laboratory: in Proceedings, 1994 Symposium on Engineering Geology and Geotechnical Engineering, (March 23-25, 1994, Boise): P. K. Link editor, pp. 253-265.

Jones, P. H., 1961, Hydrology of waste disposal National Reactor Testing station Idaho an interim report: U. S. Geological Survey IDO-22042-USGS, pp. 1-82.

Jones, R. W., 1969, Comparison of Columbia River Basalts and Snake River Plains Basalts: in Proceedings Of The Second Columbia River Basalt Symposium, Eastern Washington State College, Washington, Gilmour, E. H., and Stradling, D., editors, pp. 209-221.

Keys, W. S., and MacCary, L. M., Techniques of water-resources investigations of the United States Geological Survey; application of borehole geophysics to waterresources investigations: U. S. Geological Survey, 4 th printing, pp. 1-126.

Knutson, C. F., McCormick, K. A., Smith, R. P., Hackett, W. R., O'Brien, J. P., and Crocker, J. C., 1990, FY 89 report RWMC vadose zone basalt characterization: EG\&G Idaho, Inc. EGG-WM-8949, pp. 1-126. 
Kulander, B. R., Dean, S. L., and Ward, B. J., 1990, Fractured core analysis: Interpretation, logging, and use of natural and induced fractures in core: AAPG Methods in Exploration Series, no. 8. pp. 1-88.

Kuntz, M. A., Covington, H. R., and Schorr, L. J., 1992, An overview of basaltic volcanism of the eastern Snake River Plain, Idaho: Geological Society of America memoir 179, pp. 227-267.

Lanphere, M. A., Champion, D. E., and Kuntz, M. A., 1994, Petrography, age, and paleomagnetism of basalt lava flows in coreholes Well 80, NRF 89-04, NRF 89-05, and ICPP 123, Idaho National Engineering Laboratory: U. S. Geological Survey Water Resources Division, Open File Report 93-327, pp. 2-40.

LeRoy, L. W., LeRoy, D. O., and J. W., 1977, Subsurface Geology: 4 th edition, Colorado School of Mines, Golden Colorado, pp. 1-589.

Long, P. E., and Davidson, N. J., 1981, Lithology of the Grande Ronde Basalt with emphasis on the Umtanum and McCoy canyon flows: in Myers, C. W., and Price, S. M., eds., Subsurface geology of the Cold Creek syncline: RHO-BWI-ST-14, Rockwell Hanford Operations, Richland, Washington, July 1981, p. 1-240.

Long, P. E., and Wood, B. J., 1986, Structures, textures, and cooling histories of Columbia River basalt flows: Geological Society of America Bulletin, vol. 97, pp. 1144-1155.

Macdonald, G. A., 1967, Forms and structures of extrusive basaltic rocks: In the Poldervaart Treatise on rocks of basaltic composition, H. H., Hess and A. Poldervaart (eds.), vol. 1, Interscience, New York, pp. 1-61.

McMillan, K., Cross, R. W., and Long, P. E., 1987, Two-stage vesiculation in the Cohassett flow of the Grande Ronde Basalt, south-central Washington: Geology, vol. 15, pp. $809-812$.

Meints, J. P., 1986, Statistical characterization of fractures in the Museum and Rocky Coulee flows of the Grande Ronde formation, Columbia River Basalts; Masters thesis, Washington State University, pp. 1-124. 
Moltz, F. J., Morin, R. H., Hess, A. E., Melville, J. G., Guven, O., 1989, The impeller meter for measuring aquifer permeability variations: evaluation and comparison with other tests: Water Resources Research, vol. 25, pp. 1677-1683.

Morin, R. H., Hess, A. E., and Paillet, F. L., 1988, Determining the distribution of hydraulic conductivity in a fractured limestone aquifer by simultaneous injection and geophysical logging: Ground Water, vol. 26, no. 5, pp. 587-595.

Morin, R. H., Barrash, W., Paillet, F. A., and Taylor, T. A., 1993, Geophysical logging studies in the Snake River Plain aquifer at the Idaho National Engineering Laboratory - wells 44, 45, and 46: U. S. Geological Survey Water Resources Investigations Report 92-4184, pp. 1-44.

Morris, D. A., Barraclough, J. T., Chase, G. H., Teasdale, W. E., and Jensen, R. G., 1964, Hydrology of subsurface waste disposal National Reactor Testing Station, Idaho: Annual Progress Report, 1963: U. S. Geological Survey, Water-Resources Division, pp. $40-46$.

Nace, R. L., Deutsch, M., and Voegeli, P. T., 1956, Geography, geology, and water resources of the National Reactor Testing Station, Idaho: U. S. Geological Survey, Water-Resources Division, IDO-22033-USGS, pp. 1-223.

Nichols, R. T., 1936, Flow-units in basalt: Journal of Geology, vol. 44, pp. 617-630.

Peckham, A. E., 1959, Investigation of underground waste disposal, chemical processing plant area, National Reactor Testing Station, Idaho: U. S. Geological Survey, WaterResources Division, IDO-22039-USGS, pp. 1-35.

Peterson, D. W., and Tilling, R. I., 1980, Transition of basaltic lava from pahoehoe to aa, Kilauea Volcano, Hawaii: field observations and key factors: Journal of Volcanology and Geothermal Research, vol. 7, pp. 271-293.

Pittman, J. R., Jensen, R. G., and Fischer, P. R., 1988, Hydrologic conditions at the Idaho National Engineering Laboratory, 1982 to 1985: U. S. Geological Survey Water Resources Division, Open File Report 89-4008, pp. 2-73. 
Pollard, D. D., and Aydin, A. A., 1988, Progress in understanding jointing over the past century: Geological Society of America Bulletin, vol. 100, pp. 1181-1204.

Reed, M. F., 1994, Mineralogy and depositional sources of sedimentary interbeds beneath the Idaho National Engineering Laboratory: Eastern Snake River Plain, Idaho: in Proceedings, 1994 Symposium on Engineering Geology and Geotechnical Engineering, (March 23-25, 1994, Boise): P. K. Link editor, pp. 153-164.

Rehfeldt, K. R., Hufschmied, P., Gelhar L. W., and Schaefer, M. E., 1989, Measuring Hydraulic conductivity with the borehole flowmeter: EPRI Topical Report EN-6511, Palo Alto, CA.

Roberts, J. C., 1961, Feather-fracture, and the mechanics of rock-jointing: American Journal of Science, vol. 259, pp. 481-492.

Robertson, J. B., 1974, Digital modeling of radioactive and chemical waste transport in the Snake River Plain Aquifer at the National Reactor Testing Station, Idaho: U. S. Geological Survey Open File Report IDO-22054, pp. 1-124.

Sahagian, D. L., 1985, Bubble migration and coalescence during the solidification of basaltic lava flows: Journal of Geology, vol. 93, pp. 205-211.

Sahagian, D. L., Anderson, A. T., and Ward, B., 1989, Bubble coalescence in basalt flows: comparison of a numerical model with natural examples: Bulletin of Volcanology, vol. 52 , pp. $49-56$.

Spry, A., 1962, The origin of columnar jointing, particularly in basalt flows: Geological Society of Australia Journal, vol. 8, no. 2, pp. 191-216.

Stearns, H. T., and Macdonald, G. A., 1946, Geology and ground-water resources of the island of Hawaii: U. S. Geological Survey, Bulletin 9, pp. 1-357.

Tomkeieff, S. I., 1940, The basalt lavas of the Giants's Causeway district of northern Ireland: Bulletin of Volcanology, ser. 11, vol. 6, pp. 89-146.

Walker, G. P. L., 1970, Compound and simple lava flows and flood basalts: Bulletin of Volcanology, vol. 35, pp. 579-590. 
Walker, G. P. L., 1973, Lengths of lava flows: Philosophical Transactions of the Royal Society of London, A. 274, pp. 107-118.

Walker, G. P. L., 1989, Spongy pahoehoe in Hawaii: a study of vesicle-distribution patterns in basalt and their significance: Bulletin of Volcanology, vol. 51, pp. 199-209.

Waters, A. C., Donnelly-Nolan, J. M., and Rogers, B. W., 1990, Selected caves and lavatube systems in and near Lava Beds National Monument, California: U. S. Geological Survey, Bulletin 1673, pp. 1-102.

Whitehead, R. L., 1986, Geohydrologic framework of the Snake River Plain, Idaho and eastern Oregon: U. S. Geological Survey Hydrologic Investigations Atlas HA-681, 3 sheets.Pelton, J. R., 1990, Characterization of sources of interference with primary shallow reflections: some ideas for future projects, Technical Report BSU CGISS 9001,3 p. 1-32.

Whitehead, R. L., 1992, Geohydrologic Framework of the Snake River Plain Regional Aquifer System, Idaho and Eastern Oregon: U. S. Geological Survey Professional Paper 1408-B, pp. 1-32.

Whitehead, R. L., and Covington, H. R., 1987, Thousand Springs area near Hagerman, Idaho: in Bues, S. S. (ed.), Centennial Field Guide, Geological Society of America, vol. 2, pp. 131-134.

Wood, S. H., and Bennecke, W. M., 1994, Vertical variation in groundwater chemistry inferred from fluid specific-conductance well logging of the Snake River Plain Basalt Aquifer, Idaho National Engineering Laboratory, southeastern Idaho: in Proceedings, 1994 Symposium on Engineering Geology and Geotechnical Engineering (March 2325, 1994, Boise): P. K. Link editor. pp. 267-283.

Young, S. C., 1992, A newly developed borehole flowmeter technology for heterogeneous aquifers: Tennessee Valley Authority Engineering Laboratory report, pp. 1-25. 
APPENDIX A

Cross-section ICPP 


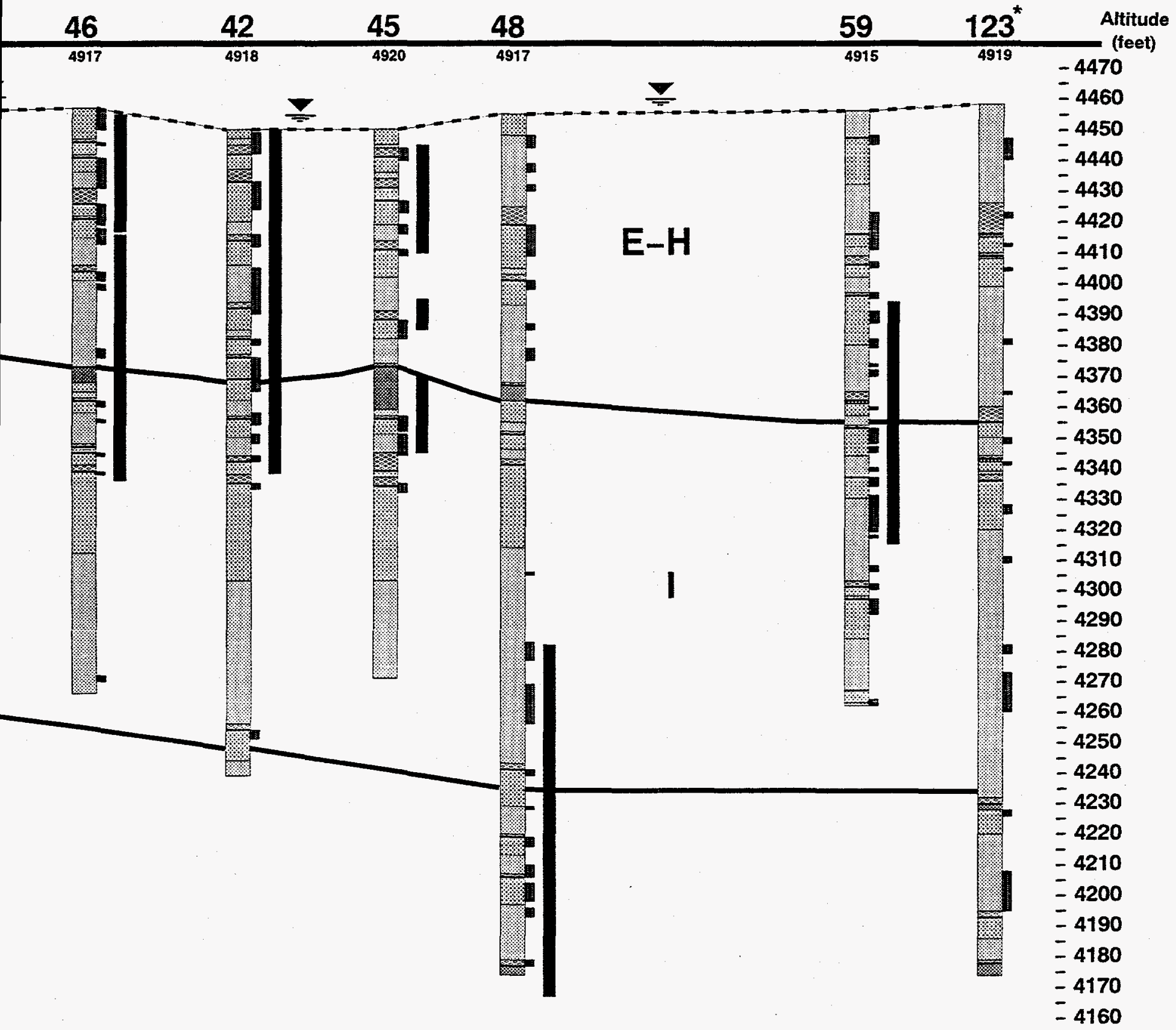

turated basalt aquifer at the ICPP. Identification and placement ehole TV logs of selected wells. The terms in the key are taken from ractured/Enlarged intervals are places in the borehole seen ures present or intervals of enlarged borehole diameters. The Fluid Flow ent in the borehole identified by the impeller flowmeter or by previous to them are boreholes not investigated for fluid movement. The letter Anderson (1991) and the solid lines drawn are directly from his work. in natural-gamma radiation across the contacts of the stratigraphic own for the different basalt zones which are based on TV logs. 


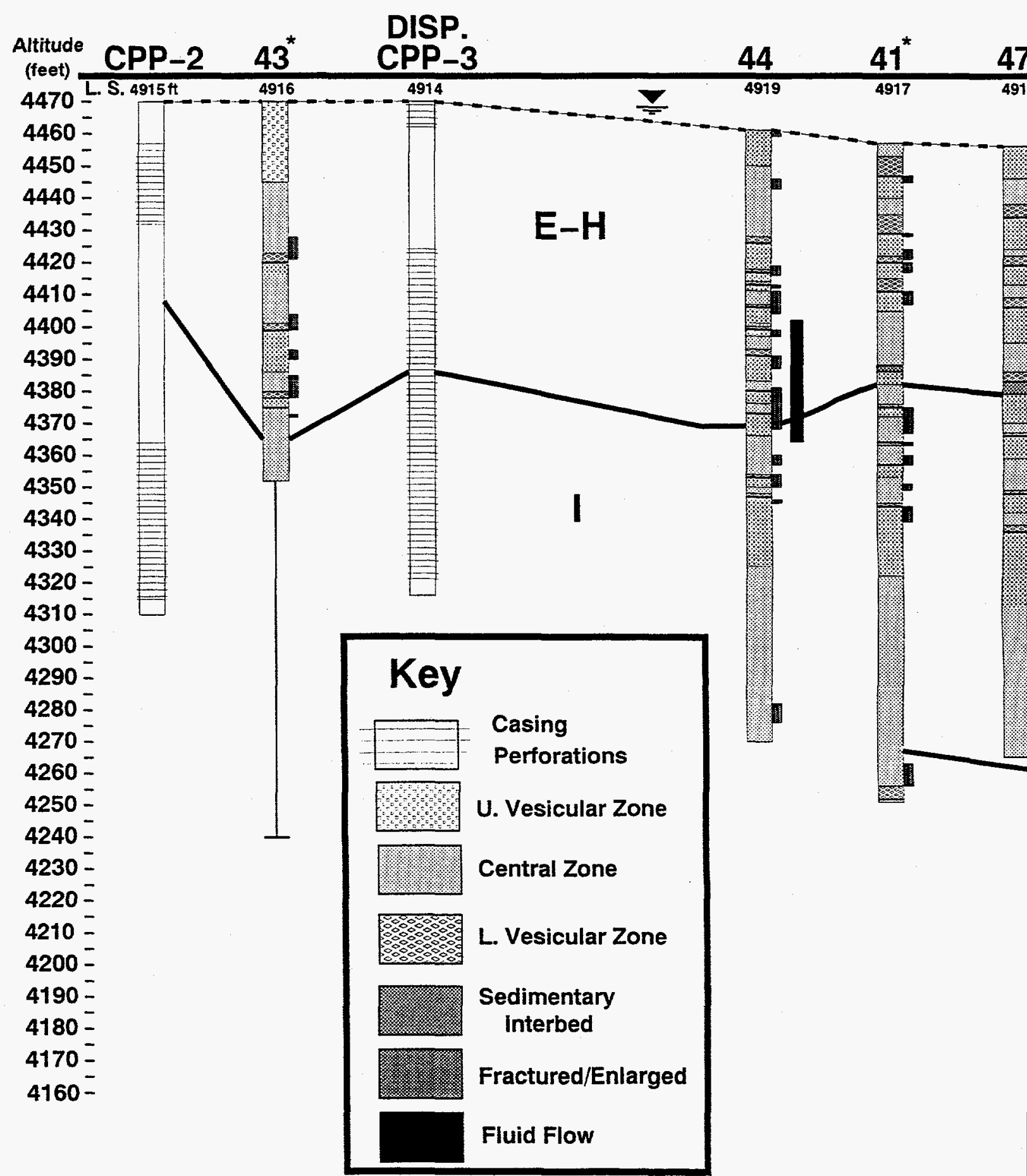

A-46. Figure showing a cross-section of of the basalt lava flow features are based the nomenclature developed in chapter 4. on the TV logs that have a large number 0 portions shown are the locations of fluid $m$ work by others. The boreholes with the "* designations $\mathrm{E}-\mathrm{H}$ and I units are the work He based these correlations on distinct ch units and thus are different from the conta 
APPENDIX B

Temperature Logs 


\section{Temperature Logs}

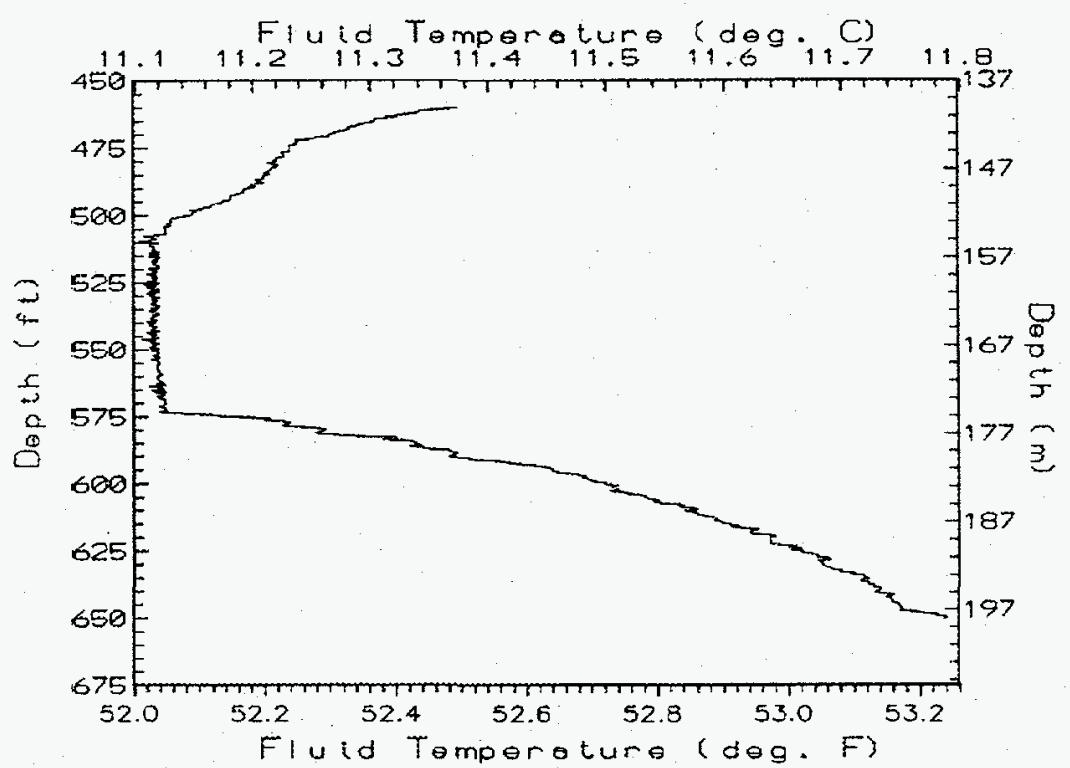

B-47. Figure showing a temperature $\log$ from borehole 44 . Isothermal areas are usually where fluid is moving in the borehole.

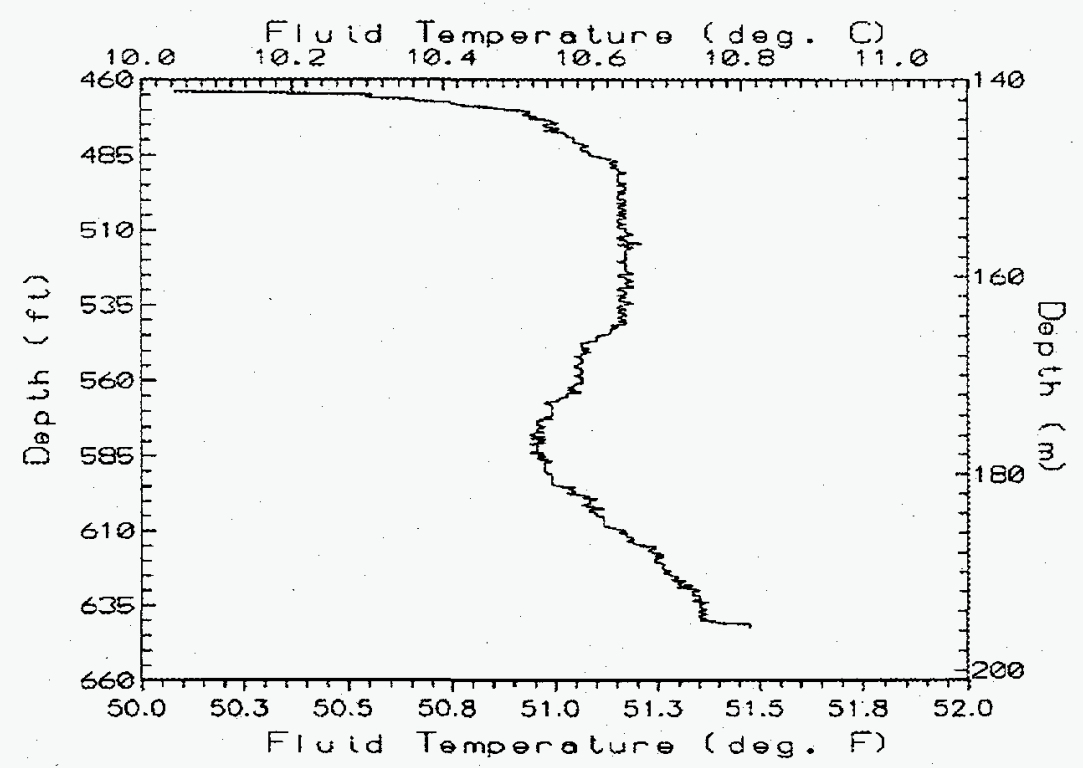

B-48. Figure showing a temperature log from borehole 45 . Isothermal areas are usually where fluid is moving in the borehole. 


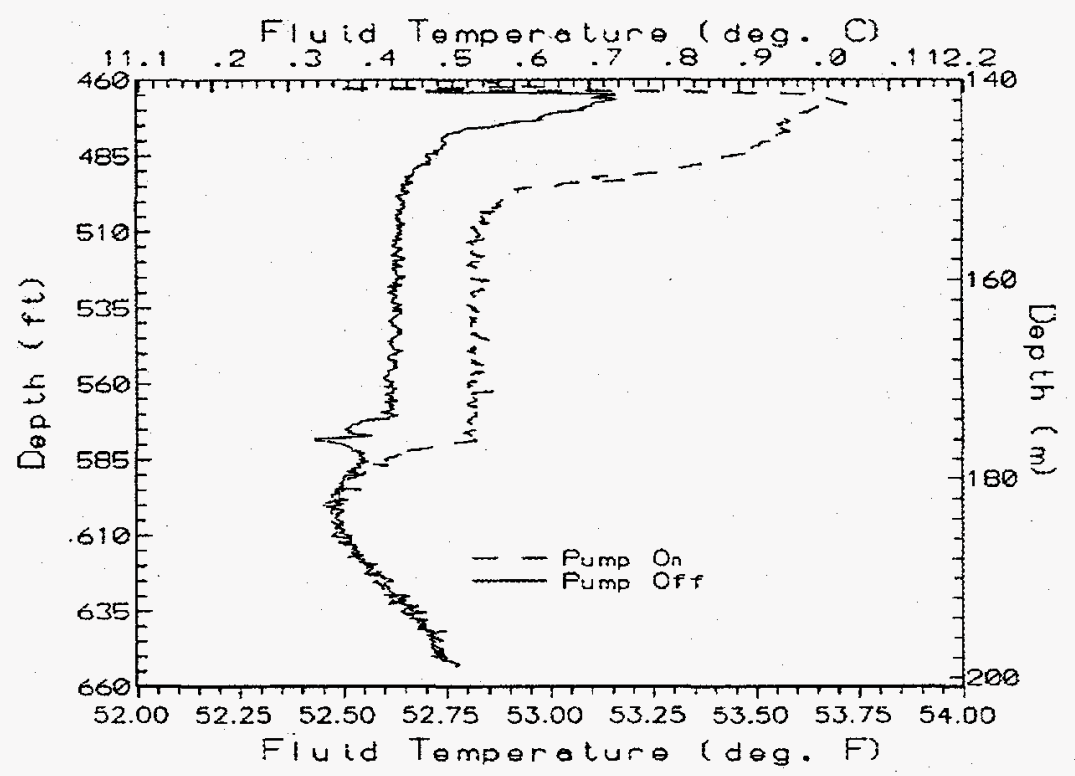

B-49. Figure showing temperature logs from borehole 46 . Isothermal areas are usually where fluid is moving in the borehole. Two separate temperature runs are shown with one run during the time when the nearby pump (CPP-2) is off (the solid line) while the other was run during the time when the pump was on (the dotted line). Notice that the temperature increase and changes its general shape when the pump turns on. 
APPENDIX C

Geophysical Logs 


\section{Geophysical Logs}

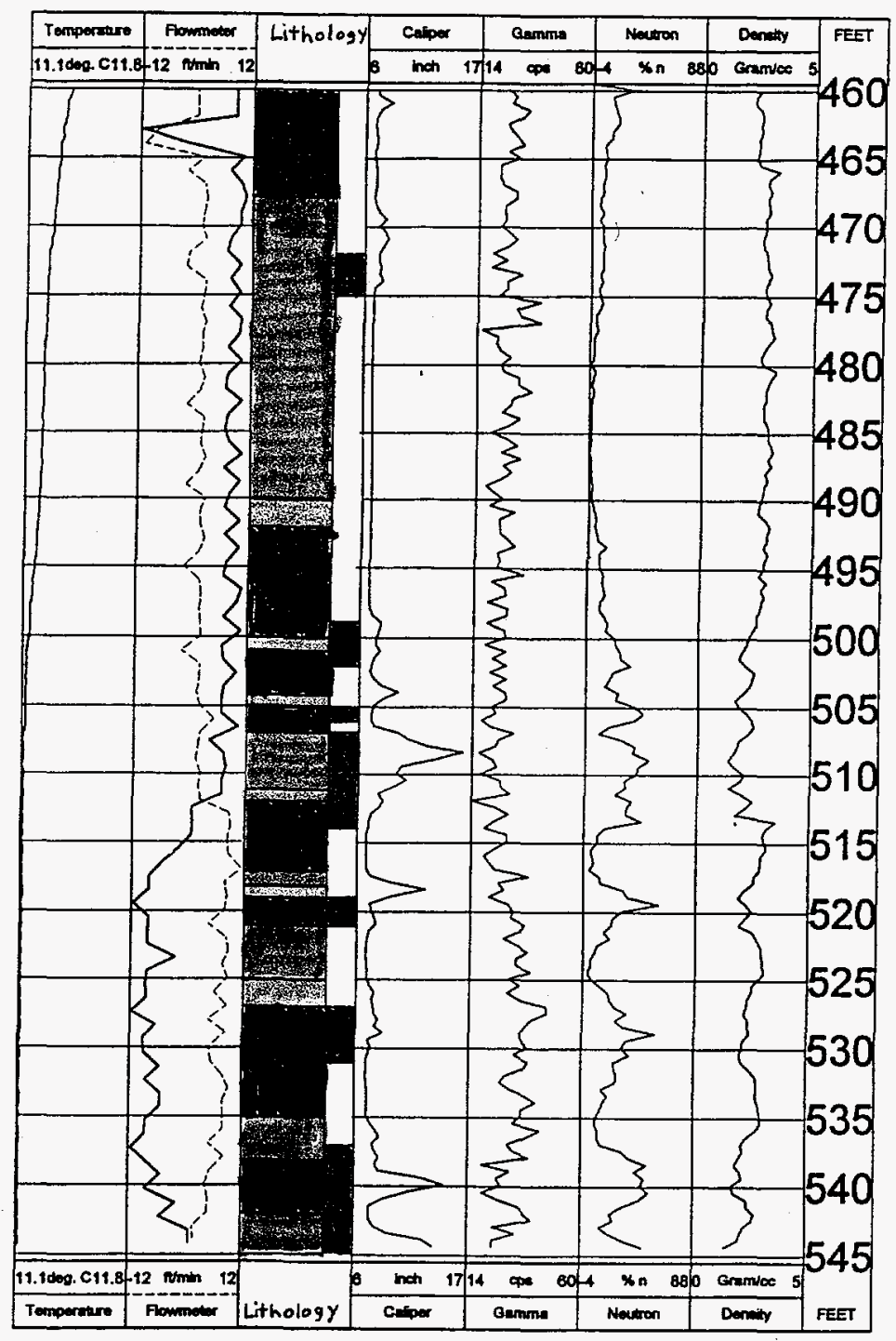

C-50. Figure showing six geophysical logs from borehole 44. The flowmeter plot has two separate flowmeter runs with the solid line being a run when the pumping well (CPP2) was turned on vs. the dotted line showing the flowmeter run that was taken when the pump was off. The lithology was generated from the borehole TV logs with the individual colors equal to different basalt lava flow features defined in chapter 4 . The colors red $=$ upper vesicular zone, yellow = central zone, blue = lower vesicular zone, gray = sedimentary interbed, and green $=$ fractured portions of the borehole wall or borehole enlargements. The following figures C-51 and 52 are the same. 


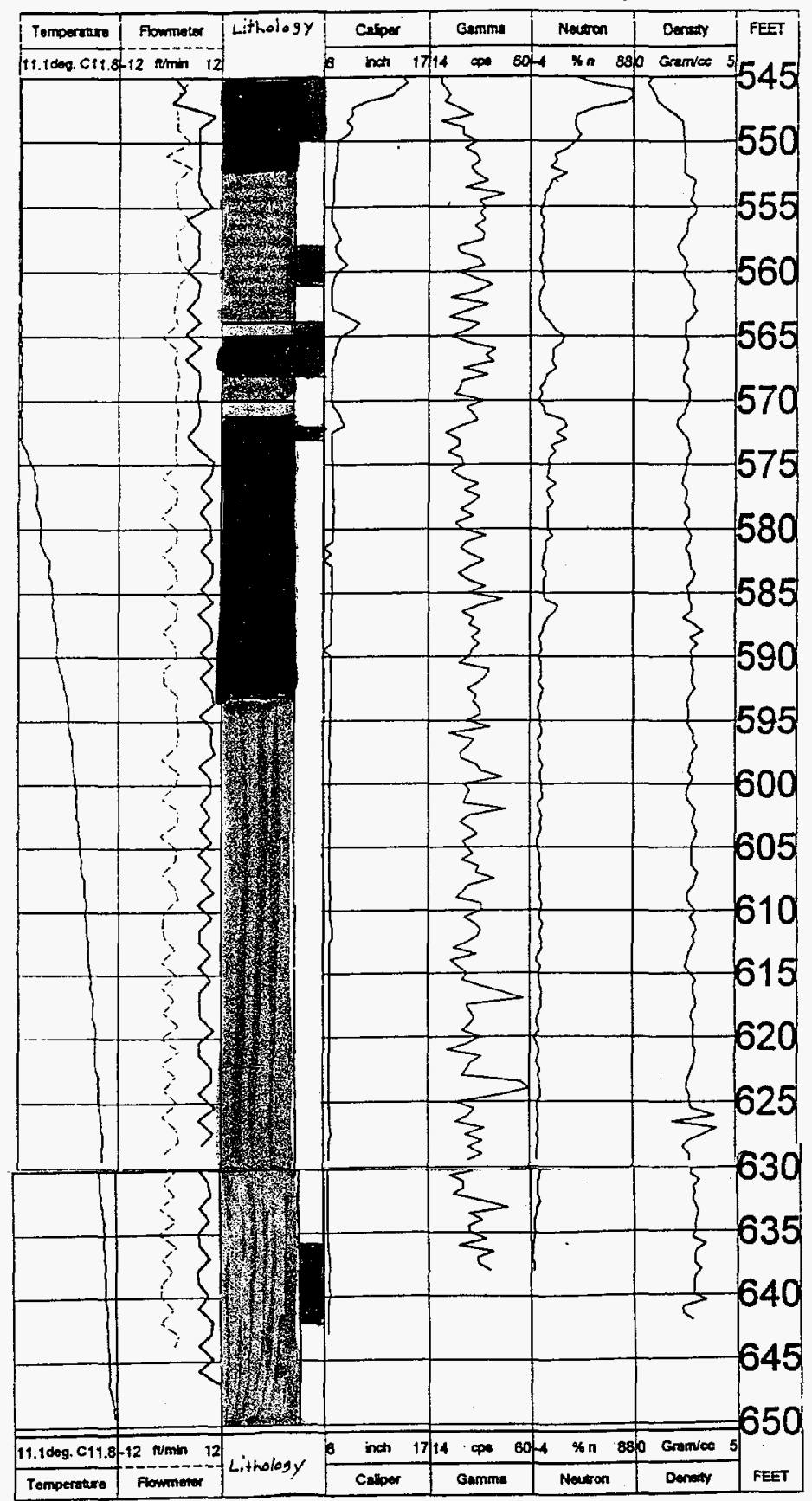

C-51.

C-52. Figure showing six geophysical logs from borehole 44. Depths from 545 to $650 \mathrm{ft}$. 


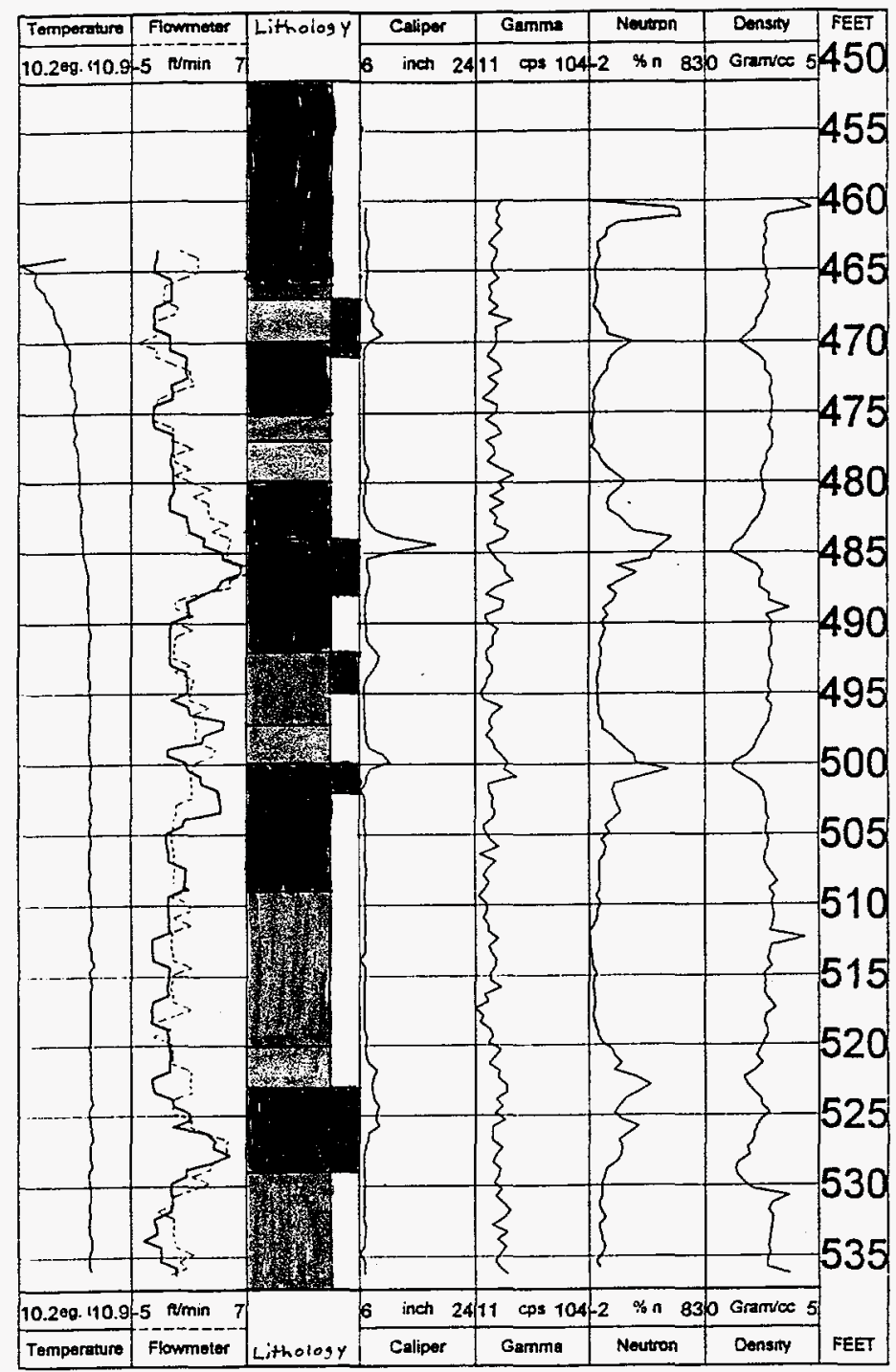

C-53. Figure showing six geophysical logs from borehole 45 . The flowmeter plot has two separate flowmeter runs with the solid line being a run when the pumping well (CPP2) was turned off vs. the dotted line showing the flowmeter run that was taken when the pump was on. The lithology was generated from the borehole TV logs with the individual colors equal to different basalt lava flow features defined in chapter 4 . The colors red $=$ upper vesicular zone, yellow = central zone, blue = lower vesicular zone, gray = sedimentary interbed, and green $=$ fractured portions of the borehole wall or borehole enlargements. Figures C-54 and C-55 are the same. 


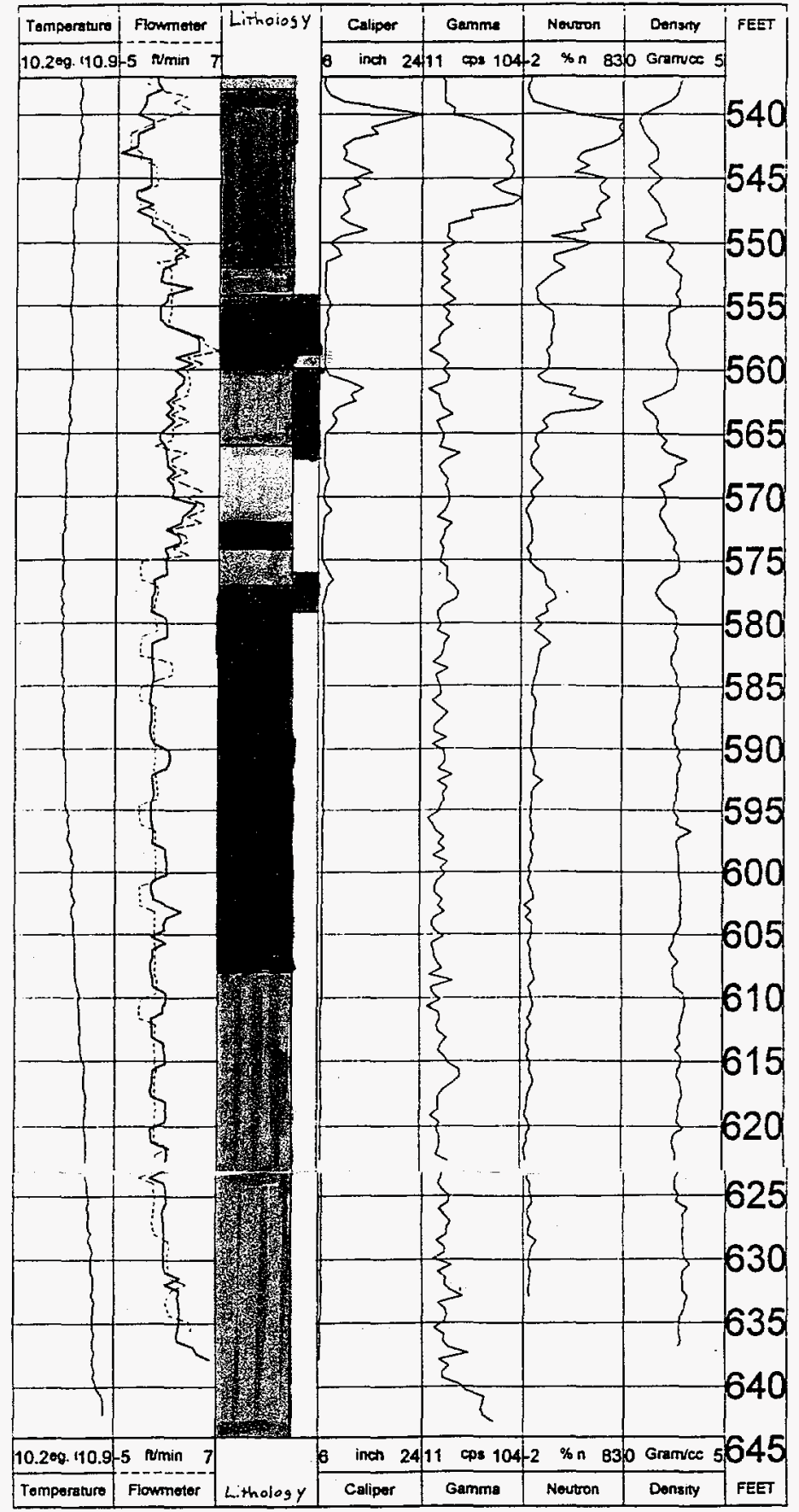

C-54

C-55. Figure showing six geophysical logs from borehole 45. Depths from 625 to $645 \mathrm{ft}$. 


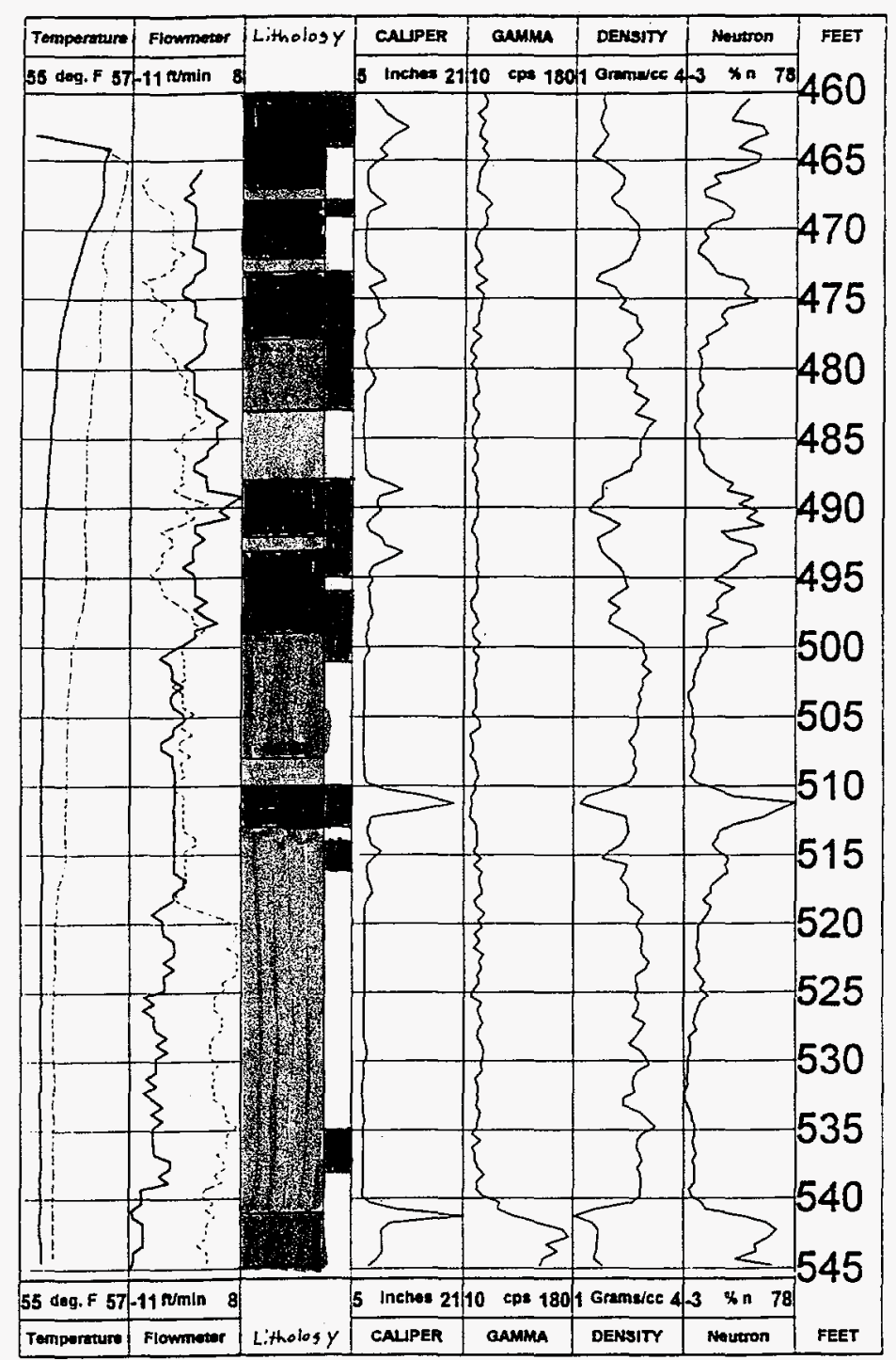

C-56. Figure showing six geophysical logs from borehole 46 . The flowmeter plot has two separate flowmeter runs with the solid line being a run when the pumping well (CPP2) was turned off vs. the dotted line showing the flowmeter run that was taken when the pump was on. Two separate temperature runs are also shown with the dotted line indicating a time when the pump was on vs. the solid line indicating that the pump was off. The lithology was generated from the borehole TV logs with the individual colors equal to different basalt lava flow features defined in chapter 4 . The colors red = upper vesicular zone, yellow $=$ central zone, blue $=$ lower vesicular zone, gray $=$ sedimentary interbed, and green $=$ fractured portions of the borehole wall or borehole enlargements. Figures C-57 and C-58 are the same. 


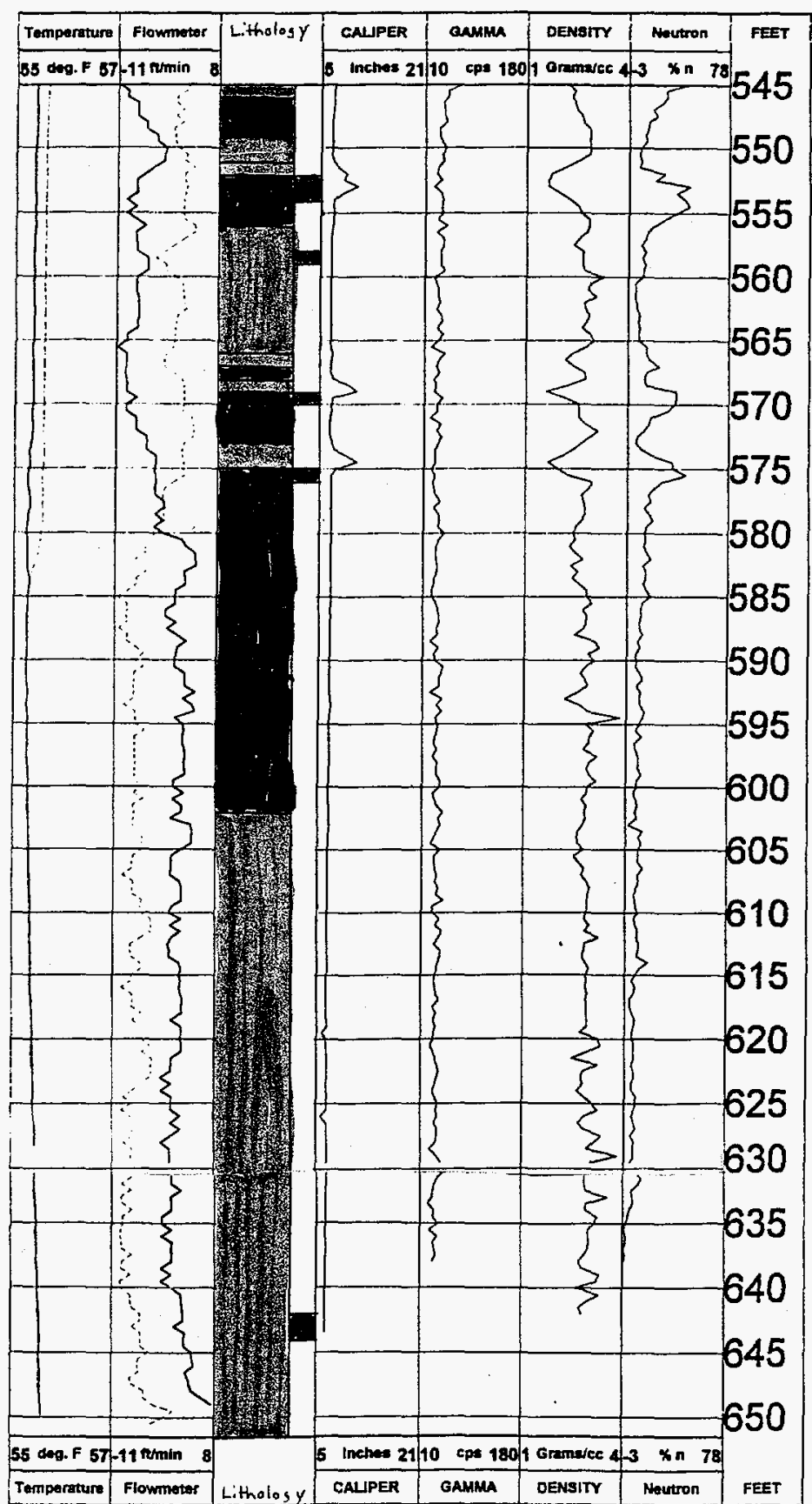

C-57. $650 \mathrm{ft}$.

C-58. Figure showing six geophysical logs from borehole 46 . Depths from 545 to 